\title{
Why and How Organizational Members Encourage Their Peer Coworkers to Voluntarily Exit the Organization: An Investigation of Peer-Influence Exit Tactics
}

\author{
Michael Sollitto \\ West Virginia University
}

Follow this and additional works at: https://researchrepository.wvu.edu/etd

\section{Recommended Citation}

Sollitto, Michael, "Why and How Organizational Members Encourage Their Peer Coworkers to Voluntarily Exit the Organization: An Investigation of Peer-Influence Exit Tactics" (2014). Graduate Theses, Dissertations, and Problem Reports. 115.

https://researchrepository.wvu.edu/etd/115

This Dissertation is protected by copyright and/or related rights. It has been brought to you by the The Research Repository @ WVU with permission from the rights-holder(s). You are free to use this Dissertation in any way that is permitted by the copyright and related rights legislation that applies to your use. For other uses you must obtain permission from the rights-holder(s) directly, unless additional rights are indicated by a Creative Commons license in the record and/ or on the work itself. This Dissertation has been accepted for inclusion in WVU Graduate Theses, Dissertations, and Problem Reports collection by an authorized administrator of The Research Repository @ WVU.

For more information, please contact researchrepository@mail.wvu.edu. 
Why and How Organizational Members Encourage Their Peer Coworkers to Voluntarily Exit the Organization: An Investigation of Peer-Influence Exit Tactics

\title{
Michael Sollitto
}

Dissertation submitted to the Eberly College of Arts and Sciences at West Virginia University in partial fulfillment of the requirements for the degree of

\author{
Doctor of Philosophy \\ in \\ Communication Studies \\ Rebecca M. Chory, Ph.D., Chair \\ Johny T. Garner, Ph.D. \\ Alan K. Goodboy, Ph.D. \\ Christine E. Rittenour, Ph.D. \\ Keith Weber, Ed.D. \\ Department of Communication Studies
}

Morgantown, West Virginia

2014

Keywords: Organizational exit, peer coworker relationships, peer-influence exit tactics, motives, agreeableness, competitiveness, self-esteem, perceived similarity, work performance, liking, organizational climate, organizational culture, organizational justice

Copyright 2014 Michael Sollitto 


\begin{abstract}
Why and How Organizational Members Encourage Their Peer Coworkers to Voluntarily Exit the Organization: An Investigation of Peer-Influence Exit Tactics
\end{abstract}

\title{
Michael Sollitto
}

Previous scholars have found that organizational members use various tactics to encourage their peer coworkers to voluntarily exit their organizations. These tactics are known as peer-influence exit tactics. What has been missing from the literature is clarity about the factors that influence organizational members' use of peer-influence exit tactics. This dissertation explored the construct of peer-influenced exit to develop greater clarity about the motives for encouraging peer coworkers to leave, the characteristics of the peer-influence exit tactic source and receiver, and the organizational influences on peer-influenced exit. Study 1 used an open-ended survey design to explore the motives, process, and means through which peer-influenced exit occurs and the success of using peer-influence exit tactics. Results indicated that organizational members use eight peer-influence exit tactics and have four overarching motives for using them. Organizational members also reported that they consciously planned their tactics and the tactics were used with some success. Study 2 used an experimental design to explore how certain tactic source and receiver characteristics and organizational characteristics affect the use of peerinfluence exit tactics. Results of an exploratory factor analysis revealed that organizational members use affirmation, unprofessional, depersonalization, and professional peer-influence exit tactics. Results of the experiment indicated that organizational members use affirmation, unprofessional, depersonalization tactics more frequently with low performing peer coworkers than with high performing peer coworkers. No differences emerged regarding the use of peerinfluence exit tactics based on the cohesiveness of the organizational culture. The results also revealed relationships between competitiveness, agreeableness, and self-esteem of the source and peer-influence exit tactics. Study 3 incorporated a correlational design in which working adults were surveyed about their personal experiences with peer-influenced exit. Results revealed that personal gain, altruistic, organizational enhancement, and climate improvement motives predicted the use of peer-influence exit tactics, as did the competitiveness, agreeableness, and self-esteem of the source, perceived similarity, work performance, liking, and organizational influence of the target, and the organizational climate, supervisor complicity, and coworker regard. The results provide greater insight into the antecedents and outcomes of organizational exit that are valuable for both organizational communication scholars and organizational practitioners. 


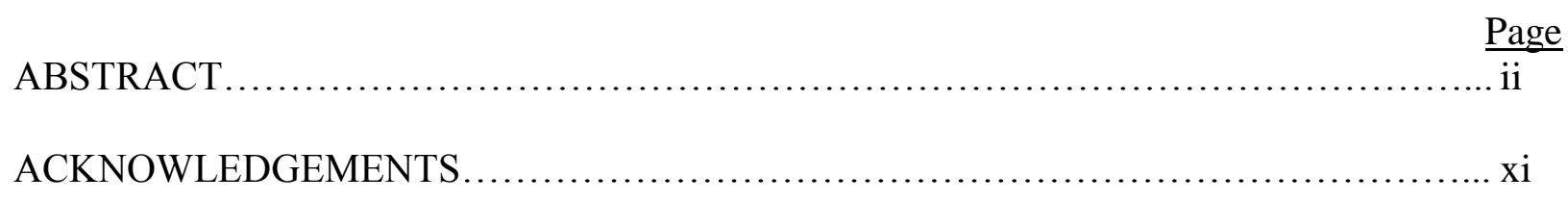

CHAPTER 1: INTRODUCTION............................................. 1

Turnover................................................................. 1

Effects of Turnover.................................................... 4

Negative Effects............................................... 4

Positive Effects...................................................

Reasons for Voluntary Exit........................................... 8

The Voluntary Exit Process................................................ 13

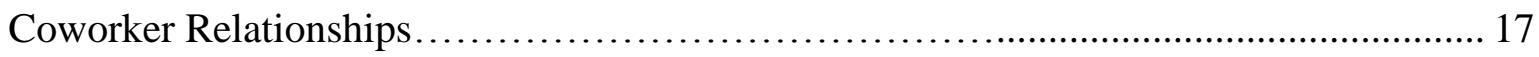

Positive Coworker Relationships.......................................... 18

Peer Relationship Types......................................... 18

Friendships.................................................. 19

Workplace Romance.............................................. 21

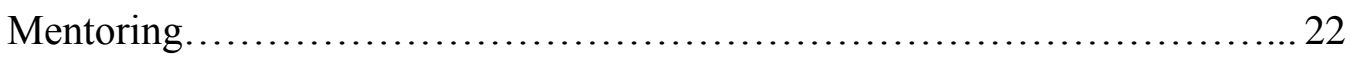

Negative Effects of Positive Coworker Relationships............................. 22

Friendships.................................................... 23

Workplace Romance............................................ 24

Mentoring....................................................... 25

Problematic Peer Coworkers............................................... 26

Difficult Coworkers...............................................26

Troublesome Others.............................................. 27 
Bullies. 28

Network Isolates............................................. 28

Positive Coworker Communication............................................... 30

Social Support............................................... 30

High Quality Information Exchange.................................. 31

Problematic Coworker Communication..................................... 32

Employee Emotional Abuse........................................ 33

Abusive Supervision................................................. 33

Supervisor $[$ Non] Support........................................ 33

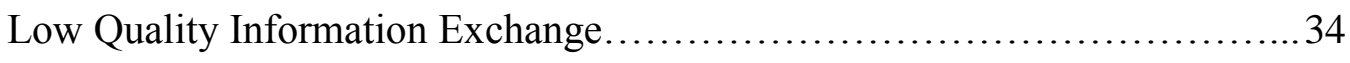

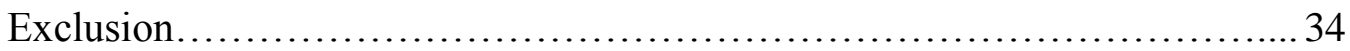

Distancing Behaviors........................................... 35

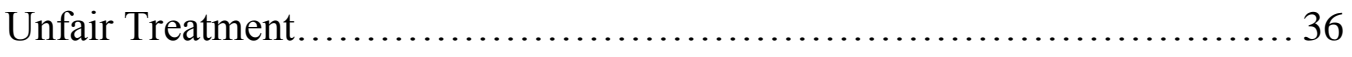

Concertive Control................................................. 37

Antecedents and Effects of Problematic Coworker Communication......................37

Peer Coworker Relationships and Organizational Exit............................ 39

Peer-Influence Exit.............................................40

Strategies for Encouraging Voluntary Exit........................... 40

Predictors of Peer-Influence Exit Tactic Use............................ 42

Statement of the Problem................................................ 45

Rationale, Hypotheses, and Research Questions............................47

Peer-Influence Exit Tactics...................................... 47

Peer-Influence Exit Tactics' Sources' Motives.......................... 48 
Peer-Influence Exit Tactics' Sources' Characteristics...................... 51

Peer-Influence Exit Tactics' Targets' Characteristics.......................54

Organizational Characteristics.................................... 59

Planning of Peer-Influence Exit Tactics.............................66

Effectiveness of Peer-Influence Exit Tactics.......................... 67

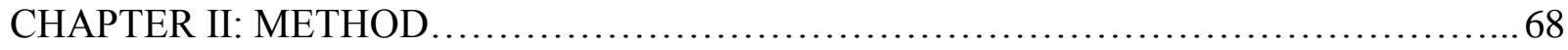

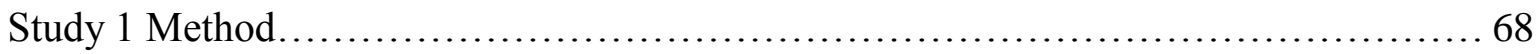

Participants and Procedures...............................................6 68

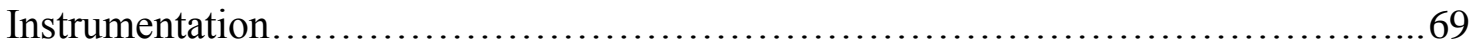

Data Analysis........................................................ 70

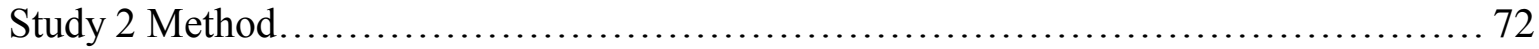

Participants and Procedures............................................... 72

Experimental Design and Manipulation.................................... 74

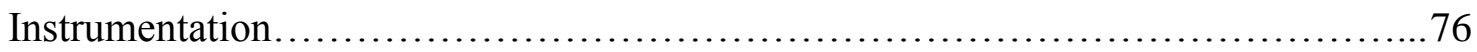

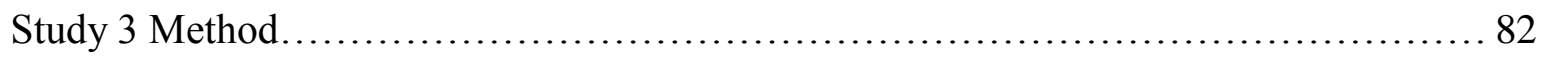

Participants and Procedures.............................................. 82

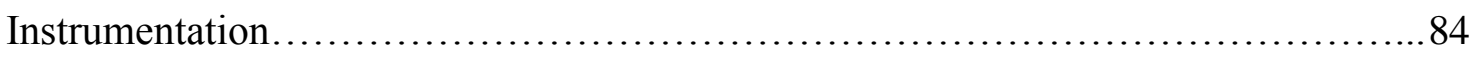

CHAPTER III: RESULTS ................................................... 95

Study 1 Results........................................................ 95

Research Question 1: Peer-Influence Exit Tactics............................... 95

Research Question 2: Motives for Encouraging a Peer Coworker to Exit.............. 104

Research Question 13: Planning of Peer-Influence Exit Tactics.................... 114

Research Question 14: Effectiveness of Peer-Influence Exit Tactics............... 117 


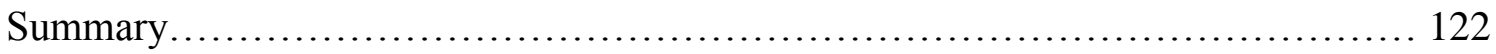

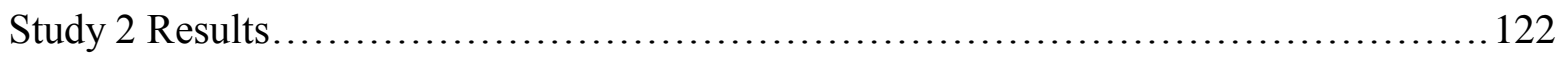

Source Characteristics...................................................... 122

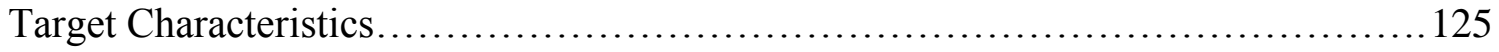

Organizational Characteristics............................................... 126

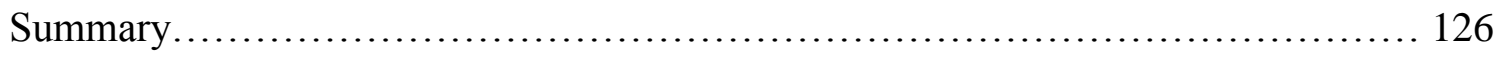

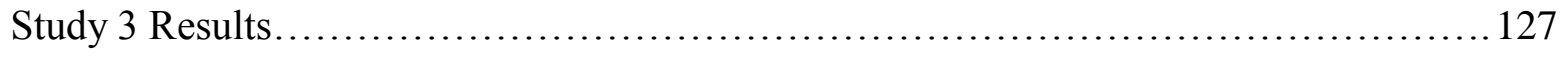

Source Characteristics.................................................... 131

Target Characteristics...................................................... 135

Organizational Characteristics................................................. 139

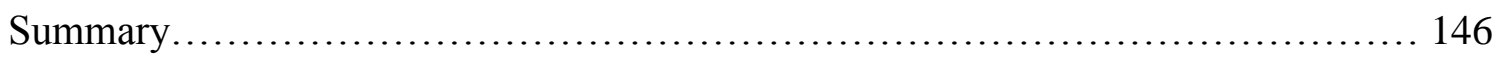

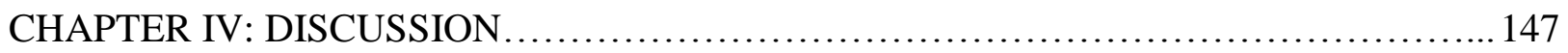

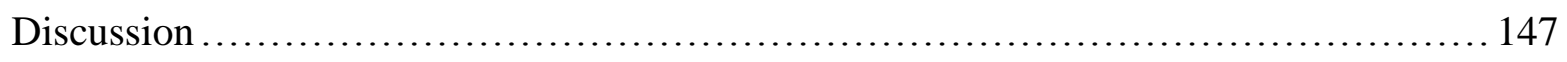

Peer-Influence Exit Tactics................................................... 147

Motives for Encouraging Voluntary Exit......................................... 155

Relationship Between Peer-Influence Exit Tactics and Motives....................... 160

Source Characteristics....................................................... 164

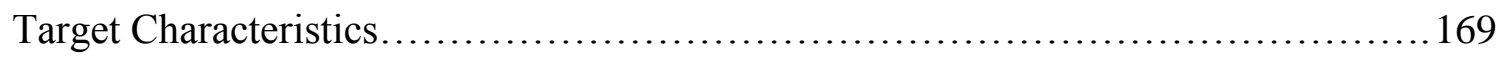

Organizational Characteristics............................................... 174

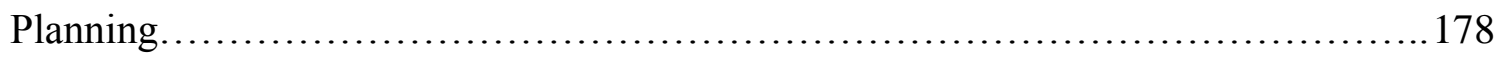

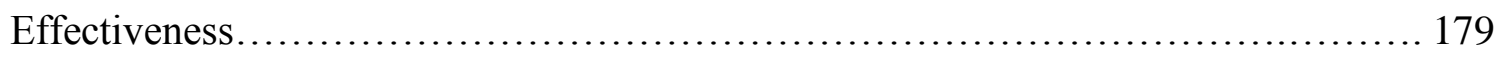

Limitations and Directions for Future Research................................ 180

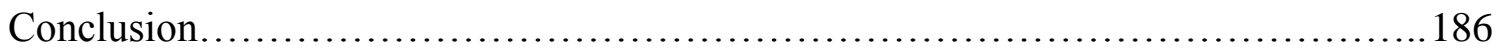


Appendix A: Cox's (1999) Strategies Used to Encourage Voluntary Exit................232

Appendix B: Sollitto, Chory, and Weber's (2013) Peer-Influence Exit Tactics.......... 234

Appendix C: Open-Ended Items........................................... 235

Appendix D: Job Satisfaction Scale........................................ 236

Appendix E: Study 1 Questionnaire..........................................237

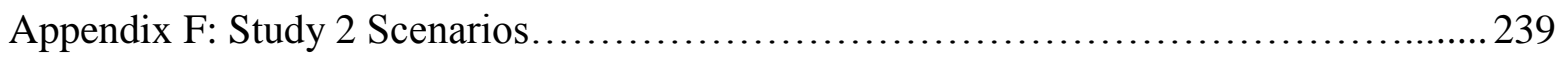

Appendix G: Desire to See a Peer Exit Scale Items............................... 241

Appendix H: Competitiveness Scale Items................................. 242

Appendix I: Agreeableness Scale Items....................................... 243

Appendix J: Rosenberg Self-Esteem Measure Items ............................. 244

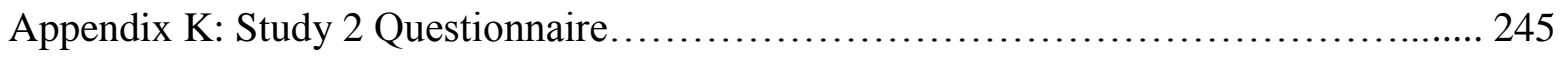

Appendix L: Coworker Similarity Scale Items............................... 251

Appendix M: Work Performance (In-Role Behaviors Scale) Items................. 252

Appendix N: Liking/Social Attractiveness Scale Items........................... 253

Appendix O: Organizational Influence Scale Items..............................254

Appendix P: Organizational Justice Scale Items................................255

Appendix Q: Organizational Culture (Teamwork) Scale Items...................... 256

Appendix R: Organizational Climate Scale Items.............................. 257

Appendix S: Supervisor Complicity Items.....................................259

Appendix T: Coworker Regard Items....................................... 260

Appendix U: Study 3 Questionnaire.......................................... 261 
Appendix V: Summary of Hypotheses and Research Questions..................... 270 


\section{List of Tables}

Table 1: Exploratory Factor Analysis Factor Loadings for Desire for Peer to Exit Measure... 77

Table 2: Exploratory Factor Analysis Factor Loadings for Peer-Influence Exit Measure......80

Table 3: Exploratory Factor Analysis Factor Loadings for Supervisor Complicity Measure...90

Table 4: Exploratory Factor Analysis Factor Loadings for Motives Measure.

Table 5: Peer-Influence Exit Tactics: Behaviors and Communication Used to Encourage Peer

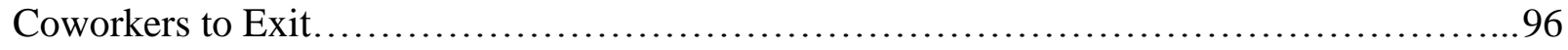

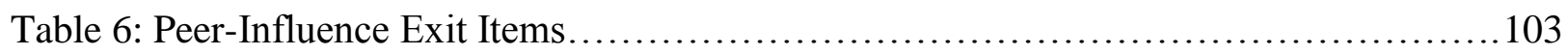

Table 7: Motives for Encouraging Peer Coworkers to Exit.............................. 106

Table 8: Motives for Influencing a Peer Coworker to Voluntarily Exit Items.................113

Table 9: Thought Process for Encouraging Peer Coworkers to Exit...................... 115

Table 10: Effect of Peer-Influence Exit Tactics on Receiver............................ 117

Table 11: Peer Coworker Exit Behavior After Receiving Peer-Influence Exit Tactics......... 121

Table 12: Reasons Peer Coworkers Voluntarily Exited Organization...................... 121

Table 13: Descriptive Statistics and Correlation Matrix for Study 2 Variables................ 124

Table 14: Effect of Peer Work Performance on the Use of Peer-Influence Exit Tactics........ 125

Table 15: Effect of Perceived Teamwork on the Use of Peer-Influence Exit Tactics.......... 126

Table 16: Correlation for Study 3 Variables....................................... 128

Table 17: Motives for Influencing Peer Coworkers to Exit as Predictors of the Use of PeerInfluence Exit Tactics........................................................ 131

Table 18: Source Characteristics as Predictors of the Source's Use of Peer-Influence Exit Tactics 133

Table 19: Source Characteristics as Predictors of the Motives for Influencing Peer Coworkers to

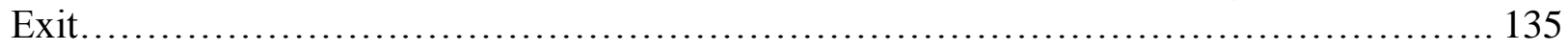


Table 20: Target Characteristics as Predictors of the Source's Use of Peer-Influence Exit Tactics .137

Table 21: Target Characteristics as Predictors of Motives for Encouraging a Peer Coworker to Exit......

Table 22: Organizational Characteristics as Predictors of the Source's Use of Peer-Influence Exit Tactics.................................................................... 142

Table 23: Organizational Characteristics as Predictors of Motives for Encouraging a Peer Coworker to Exit............................................................ 144

Table 24: Logistic Regression Analysis Results for Peer-Influence Exit Tactics Predicting Voluntary Exit Decisions..................................................... 146 


\section{ACKNOWLEDGMENTS}

This acknowledgement section represents the conclusion to a long and strenuous career as a student. I began my formal education in 1992 at Lone Oak Elementary School, and I am happy to say that with the completion of my dissertation, I have ended my formal education in 2014 at West Virginia University. In my 22 years as a student, I have been fortunate to have many great influences that have served me well as I have progressed toward the completion of my dissertation.

The process of writing a dissertation should never really be described by anyone as fun, because it is certainly a stressful and tedious process, but I am proud to say that I have now finished my dissertation, and am ready to move on to new endeavors in my life and career. However, I know that I never would have completed my education or my doctoral dissertation without the guidance and support from those closest to me during my lengthy journey.

First, my immediate family deserve praise for their support and encouragement throughout my academic career. My mother, Kara Sollitto, deserves special consideration for her continual outpouring of support and validation as I progressed through school. While she never liked the prospect of me moving away to West Virginia University to pursue my Ph.D., she understood that it was the decision that was best for me, and that it was the path that I should follow. My father, Jerry Sollitto, also deserves mention, as well. Though he passed away in 2008 after a long fight with bladder cancer, he continued to serve as an inspiration for me as I completed my degree. I shudder to think about where I would be without the influence of my mother and father because they were always there for me, supporting me in the activities with which I was involved, whether it was driving me to baseball practices and games during my baseball career, or ensuring that I had everything that I needed to survive while I was away at 
college. My brother, Philip Sollitto, was also a good influence on me, as well, because he was always a pretty bright guy, so I wanted to be intelligent, too.

Second, there are so many influences that I had before I arrived at West Virginia University that I believe deserve credit. Michael Ceglinski and Jim Mizell were great motivators for me while I played baseball at Lone Oak High School, and I still believe that many lessons that I learned on the baseball diamond helped provide me with the strength and inspiration needed to be a successful scholar. Steve Cox, Francie Smith, Mickey Miller, Dave Gesler, John Spinda, Mike Bokeno, and Tina Coffelt all helped provide me a great education as an Organizational Communication major and graduate student at Murray State University. Each one of them helped me find my niche as a student and were instrumental in my decision to pursue a Ph. D.

Third, I had the pleasure of working with a great advisor at WVU, Dr. Rebecca Chory. I admire Dr. Chory's ability to guide both Hailey Gillen and I toward completing our dissertations within one day of one another. Dr. Chory showed remarkable patience with me as we worked together to formulate and conduct my dissertation studies, and for that I am grateful. I know that I am a better scholar for having Dr. Chory as my advisor. In addition to working with Dr. Chory, I was also fortunate to work with Alan Goodboy, Keith Weber, Christy Rittenour, and Johny Garner as my dissertation committee members. I would like to thank them for the contributions they made to improve the quality of my dissertation. In addition to my advisor and committee members, I would also like to thank Dr. Martin and Dr. Myers for their help in the many manuscripts I wrote with them.

Fourth, I would like to thank my closest colleagues who helped me navigate the stressful terrain at WVU. I will always appreciate the support, encouragement, debate, and insight that I 
received from my colleagues at WVU. Great people such as CJ Claus, Colleen Malachowski, Zac Johnson, Sara Labelle, Kelly Odenweller, Hailey Gillen, Zac Goldman, Greg Cranmer, Alex Lancaster, Shannon Carton, Hannah Ball, Jordan Atkinson, and Ashley Seal. We all had a bunch of good times together, and it was a pleasure to be associated with them for so long at WVU. As I conclude, I am excited about my immediate future at Texas A\&M Corpus Christi, and I hope to make the Department of Communication Studies at WVU proud as I continue the legacy of WVU graduates. 


\section{CHAPTER I: INTRODUCTION}

\section{Turnover}

In organizational life there are few things that absolutely everyone will experience during his/her organizational tenure. Everyone can say with certainty that he/she will enter organizations and will eventually leave organizations in one form or another (Kramer, 2010). Turnover is a fact of organizational life with important consequences for organizations, employees, and society. Turnover is defined by Mobley $(1982$, p. 10) as "the cessation of membership in an organization by an individual who received monetary compensation from the organization." Furthermore, turnover is considered to be a permanent transition beyond the confines of the organization (Macy \& Mirvis, 1983). By defining turnover as permanent, it helps distinguish it from other forms of movement in the organization, such as temporary layoffs, transfers, and promotions (McEvoy \& Cascio, 1985).

Generally, there are two forms of organizational exit: involuntary exit and voluntary exit. Involuntary organizational exit occurs when employees are terminated by their employers against their will. For example, involuntary exit occurs when employees are fired, laid off, or forced to retire (Kramer, 2010; McEvoy \& Cascio, 1985). Conversely, voluntary organizational exit occurs when employees perceive that they have a choice about their departure (Kramer, 2010) and leave the organization. For example, voluntary exit occurs when employees leave their organizations for new opportunities or to improve their career (Kramer \& Miller, 2014).

As the United States labor market has stabilized in recent years, total turnover has decreased from 15\% in 2010 to 13\% in 2011 (Bureau of Labor Statistics, 2012). In 2011, 9\% of departing employees were leaving voluntarily and 4\% were leaving involuntarily (Bureau of Labor Statistics, 2012). However, turnover is still considered a problem for organizations and 
their employees (Giang, 2013), as 3\% of employees are currently leaving organizations every month (Bureau of Labor Statistics, 2013). Individuals seemingly exit jobs as frequently as they begin them, thus creating a need to understand the reasons why people leave their organizations (Jablin, 1987).

Leaving organizations is such a certainty of organizational life that it has spurred one of the most comprehensive literatures in organizational scholarship (Griffeth, Hom, \& Gaertner, 2000). Scholars from diverse disciplines such as Industrial/Organizational Psychology, Management, and Sociology have devoted substantial attention to organizational turnover since the early 1900s (Griffeth et al., 2000). Indeed, Cotton and Tuttle (1986) argued that few areas of organizational scholarship had received as much attention as employee turnover, as literally hundreds of reviews, empirical studies, and meta-analyses on the topic had been produced in the prior several decades. Scholars exploring turnover have typically explored its antecedents and causes (e.g., Griffith et al., 2000; Staw, 1984), the positive and negative consequences of turnover for both the individual and the organization (Meyer, Stanley, Herscovitch, \& Topolnystsky, 2002; Mobley, 1982), and methods on how organizations can reduce their turnover rates by retaining their valuable employees (Griffith \& Hom, 2001).

Whereas turnover has been the subject of thousands of articles in various disciplines (Griffeth et al., 2000), organizational communication scholars have focused relatively little attention on turnover or organizational exit (Jablin, 2001). According to Jablin (1987), research on organizational exit has lagged behind research conducted on other organizational communication processes for two primary reasons. First, organizational communication scholars have mostly been interested in demonstrating relationships between communication behaviors and employee adjustment variables such as assimilation, job satisfaction, and organizational 
commitment, at the expense of other dependent variables. The focus on assimilation, satisfaction, and commitment is likely due to the desire of scholars working from a managerial perspective to show key organizational decision makers how their behaviors and communication with subordinates can affect their subordinates' organizational adjustment (Mobley, 1982; Redding \& Tompkins, 1988). Second, communication behaviors associated with organizational exit are often difficult to identify because they may both cause exit decisions and be manifestations of other problems. For example, the communication behaviors that occur prior to organizational exit might be heavily influenced by dissatisfaction with the organization, workplace relationships, or any number of problems related to the organization (Jablin, 1987). Thus, as Kramer (2010) argued, organizational communication scholars have fewer knowledge claims available to them about the role of communication in voluntary organizational exit than scholars from other disciplines (e.g., Management, Industrial/Organizational Psychology) have about the role of organizational factors in voluntary turnover.

In addition to filling the void about organizational exit in the organizational communication literature, organizations can benefit from this research. Being aware of the many communicative tactics that drive organizational exit can assist organizations in implementing strategies to improve their effectiveness by retaining valuable employees. Managers can apply knowledge gained from this dissertation to their hiring practices. For example, knowing the profile of organizational members who are more likely to push their peer coworkers out of the organization could help organizations save time, money, and energy that would be expended conducting job searches to replace departed employees. They could save these valuable organizational resources by counseling organizational members who score highly on personality 
tests that predict the use of peer-influence exit tactics, and advising them against such tactics for the sake of the organization.

Departing organizational members can also benefit from this research by realizing the reasons why their peer coworkers would want them to voluntarily exit. They can use knowledge gained from this dissertation to evaluate their behaviors to uncover why they might be targeted by their peer coworkers. By identifying the qualities or characteristics that make them susceptible to peer-influence exit tactics, organizational members can address their limitations and improve upon them to enjoy more fulfilling organizational experiences. This dissertation will help build knowledge claims about organizational exit within the organizational communication discipline and provide insight to organizations about the tactics that organizational members use to encourage their peer coworkers to voluntarily exit, which could help organizations prevent these tactics from occurring, and help them retain valuable employees.

\section{Effects of Turnover}

A major reason that scholars have focused on turnover is due to its effect on the organization, the remaining members of the organization, and the departing members of the organization (Jablin, 2001). The effects of turnover may be either negative or positive. The negative effects tend to harm organizations while the positive effects tend to benefit organizations.

Negative effects. The potential negative consequences of turnover to the organization include costs associated with recruiting and training new employees, disruption of organizational performance, disruption of social and communication patterns, decline in employee morale, undifferentiated control strategies (i.e., management responding to turnover with inappropriate, 
ineffective, or counter-productive responses), and strategic opportunity costs (i.e., organizations canceling creative ventures or alliances that would have been beneficial for the organization; Mobley, 1982).

DeConinck and Bachmann (2011) stated that employee turnover adversely affects organizations by creating costs to recruit and train employees and by potentially disrupting the performance of remaining employees. The costs associated with recruiting and training new employees is staggering and varies based upon the quality of the departing employee and his/her replacement (Mobley, 1982). Disruption of organizational performance involves the potential loss of efficiency while the departing employee contemplates leaving the organization, the cost of having a vacant position while a search for a replacement employee is occurring, and the possibility of remaining employees having to compensate for the lack of production from the departing employee and subsequently having their own performance suffer (Mobley, 1982). As a result, the pressure experienced by employees performing multiple roles could eventually lead to decreased job satisfaction and a higher likelihood of exiting the organization (Jones, Chonko, Rangarajan, \& Roberts, 2007).

Disruption of social and communication patterns may occur when the departing employee is particularly valued within the social collective of the organization and the remaining employees have a difficult time coping with his/her departure (Jablin, 2001; Mobley, 1982). The remaining organizational members may be unsure how they are going to replace both a valued friend and dependable worker, and subsequently have to make sense of the changes to their social network (Kramer, 1989, 1993, 2011; Kramer, Callister, \& Turban, 1995).

Likewise, the morale of the remaining organizational members can decline with the departure of valued employees. Remaining employees may be upset about the departure of their 
colleagues, leading them to experience a decline in their attitudes toward the workplace (Mobley, 1982). The uncertainty that employees experience after their coworkers leave could, in some cases, lead them to think about leaving the organization themselves (Johnson, Bernhagen, Miller, \& Allen, 1996), especially if there are other opportunities available (Farrell \& Rusbult, 1981; Hamel, 2009).

Undifferentiated control strategies involve organizations making arbitrary rules or implementing inappropriate organizational procedures to curtail employee exit (Mobley, 1982). Strategies such as increased human resources training for managers or blanketed pay raises for all employees may actually hurt organizational performance if such policies are not carefully considered (Griffith \& Hom, 2001). Strategic opportunity costs involve the organization being unable to negotiate successful business ventures or their long-range planning being hindered (Mobley, 1982). For example, an organization may have plans to unveil a new product at a specific time, but might have to delay or cancel the unveiling due to members of the workforce voluntarily leaving the organization.

Other negative outcomes of organizational exit include remaining members experiencing uncertainty about how the organization will replace valuable members (Jablin, 2001), or experiencing remorse about remaining in the organization if employees exited due to large-scale layoffs (Johnson et al., 1996). Remaining members of the organization could also experience changes in their network position/location because key information or social support sources departed the organization, which could influence their decisions to leave the organization as well (Feeley, Moon, Kozey, \& Slow, 2010; Susskind, 2007). Additionally, organizational members may be personally disrupted by experiencing a loss in benefits, friendships, and weakening family ties due to the stress of turnover (DeConink \& Bachmann, 2011). 
Positive effects. Scholars have reasoned that turnover or organizational exit can also have positive effects on the organization. Mobley (1982) stated that the potential positive effects include displacement of poor performers, innovation, flexibility, adaptability, decrease in other withdrawal behaviors, and reduction of conflict.

Organizations stand to benefit when weak performers depart because it allows the organization to fill the vacancy with a potentially more motivated and skilled employee (Mobley, 1982). Researchers have discovered that when poor performers are less satisfied with the organization, they are more likely to express their desire to exit the organization (Futrell \& Parasuraman, 1984). Furthermore, McEvoy and Cascio’s (1987) meta-analysis revealed that high-performing employees were less likely to exit the organization.

The organization may also experience positive outcomes when turnover results in greater innovation, flexibility, and adaptability. Mobley (1982) explained that turnover provides the opportunity for organizations to hire new employees with new ideas, knowledge, approaches, and work styles. Employees looking to advance in the organization may also find it advantageous for turnover to occur because it provides them with increased opportunities for career development and promotions.

Turnover can also decrease the likelihood of employee withdrawal or antisocial behavior. Researchers have argued that employees who would like to leave their organizations, but lack the opportunity to leave due to deficient alternatives or family situations, may engage in resistance tactics such as absenteeism, apathy, sabotage, latent or displaced dissent, and doing poor quality work (Kassing, Piemonte, Coman, \& Mitchell, 2012; Mobley, 1982). Thus, having dissatisfied employees who would like to exit the organization, but are unable to leave due to external constraints, can be a disadvantage for the organization. Organizations can benefit from the 
removal of dissatisfied or resistant employees rather than incur the negative repercussions of unprofessional behavior in the workplace.

Reduction of conflict is another positive consequence of turnover. Some organizational members may be incapable of working through their fundamental differences in values or beliefs and subsequently destroy the climate of the organization. Removing employees who are poor at managing conflict can potentially enhance the functioning of the organization and improve efficiency (Mobley, 1982). Clearly, employee turnover affects the livelihood of organizations and their employees (McEvoy \& Cascio, 1985).

\section{Reasons for Voluntary Exit}

Several key themes have emerged that explain why individuals choose to depart their organizations. Lee, Mitchell, Wise, and Fireman (1996) provided a framework suggesting that employees leave organizations due to planned exit, shock resulting in quitting, shock resulting in searching for jobs before quitting, and gradual disenchantment.

Planned exit refers to departure from an organization that employees know of beforehand. A distinguishing characteristic of planned exit is that a date is known in advance of the departure. Lee and colleagues (1996) asserted that events associated with planned exit are often non-work events such as pregnancy, graduation, spouse's retirement or transfer, or health considerations. Because planned exit involves knowing the specific date or time period of departure, employees can create scripts and develop plans to follow as they disengage from their workplaces (Davis \& Myers, 2012). Employees being able to follow scripts, frame the reasons for departure, and shape the stories told about their departure may have an easier to transition into their new occupations and/or new life situations (Jablin, 2001). For example, employees 
who control the narrative surrounding their departure may be able to save face and frame their exit in more positive terms than employees whose coworkers shape their departure stories.

Although Kramer (2010) argued that retirement was a separate reason for exiting the organization, it shares characteristics with planned departure. Retirement occurs when employees know that they will be leaving the organization due to working a specified amount of time. Retirement could be motivated by shocks or gradual disengagement (to be discussed), but other events, such as the organization's financial viability, could also influence decisions to retire (Kramer, 2010). The transition into retirement includes a number of communication activities associated with decreasing engagement with the workplace, such as increased interaction with spouses, family members, and contacts unaffiliated with the workplace, reduced contact with coworkers, and preparation for activities once retirement begins (Avery \& Jablin, 1988). Additionally, once retirement begins, individuals frequently feel the loss of their close connections in the organization, and begin to dissociate from the workplace, necessitating adjustment for the retirees, their family members, and remaining members of the organization (Avery \& Jablin, 1988; Jablin, 2001; Smith \& Dougherty, 2012).

A second reason for voluntary exit identified by Lee et al. (1996) was shock resulting in quitting, which involves employees being so emotionally taken aback by an organizational event that they suddenly and unexpectedly leave the organization. The likelihood of employees exiting the organization due to shock increases with perceived violations of ethics, mergers between organizations and competitors, being passed over for promotions, and experiencing sexual harassment. Furthermore, working hard to produce good work and follow organizational rules only to see another colleague receive promotion opportunities or privileged positions could produce feelings of hopelessness and/or resentment strong enough to motivate an employee to 
simply quit (Kramer, 2010; Lee et al., 1996). The abrupt departure due to shock creates limited opportunities for the departing employees to consult with family members or peer coworkers in an attempt to help them calm down or seek emotional support (Kramer, 2010). Subsequently, the immediate departure creates a situation in which an employee may provide a brief explanation for departing, limiting the opportunities for remaining employees to make sense of the departure (Jablin, 2001).

Shock resulting in a job search before quitting occurs when a dissatisfied employee actively searches for other jobs before exiting the organization (Lee et al., 1996). Shocked employees may be caught off guard by the actions of their organizations or by the organizational members with whom they associate, but they take the time to test the job market and look for other employment opportunities before they leave the organization. The shock experienced by employees might adversely affect their satisfaction toward the organization (Allen, 1996), thus making them more likely to consider other alternatives. Kramer (2010) asserted that communication after experiencing a shock might be secretive and limited only to close friends in the organization to avoid having to explain the reasons for departure and losing connections in the organization's social network. Only when new jobs are found and accepted, is it likely that shocked employees will overtly reveal that they are leaving the organization. Furthermore, the departing employees may frame their exit as a chance to pursue new opportunities or to have a change of scenery as opposed to appearing to be disgruntled and leaving on poor terms (Kramer, 2010).

Gradual disenchantment is characterized by growing dissatisfaction over an extended period of time (Lee et al., 1996). Inadequacy of information (Sias, 2005), lack of social support (Feeley et al., 2010), low quality relationships (Allen, 1996; Scott et al., 1999), employee 
emotional abuse (Lutgen-Sandvik, 2003), the perceived inability to express contradictory opinions (Kassing et al., 2012), and abusive supervision (Tepper, 2000) could over time lead employees to exit their organizations. It is reasonable to assume that employees who become disenchanted are likely to have overt interactions with their colleagues about their dissatisfaction (Kassing, 1998), but they may try to keep their dissatisfaction from authority figures to avoid negative repercussions (e.g., reduced raises or being fired; Kramer, 2010). Other factors such as organizational injustice (Martin, 1979; Tepper, 2000), emotional exhaustion, lack of communication symmetry (Richardson, Alexander, \& Castleberry, 2008), lack of organizational identification (Apker, Propp, \& Ford, 2009), dissatisfaction with pay and job (Cotton \& Tuttle, 1986; Mobley, 1982), and lack of embeddedness in the social network (Mitchell, Holtom, Lee, Sablynski, \& Erez, 2001) also imply gradual disenchantment and subsequent exit. Jablin (2001) asserted that gradual disenchantment eventually reaches a threshold. Once employees experience certain amounts of disappointment, frustration, and dissatisfaction in their jobs, they seriously consider exiting. The disenchanted employee probably makes a formal announcement regarding his/her departure once a new job or opportunity has been secured (Kramer, 2010).

Although Kramer (2010) reasoned that career changes or being recruited for other jobs are distinct reasons for organizational exit, they could result from gradual disenchantment. Career changes is a motive for voluntary exit that involves individuals changing the type of work that they perform (Kramer, 2010). Employees who change careers may do so to pursue their hopes and aspirations (Tan \& Kramer, 2012) or because they have become dissatisfied with their current careers (Ebaugh, 1988). Tan and Kramer (2012) found that employees wishing to change their careers engaged in a variety of communication tactics dealing specifically with family members, such as silencing naysayers and confirming the call to change occupations. 
When employees silenced naysayers about their decision to leave their occupations they avoided open discussion about their plans to leave until after they had settled into their new organizational roles. By confirming the call, employees supported their decision to change occupations by arguing that they were changing their careers because they were called by a higher power to do something else with their lives, and then seeking affirmation from family members about their change.

Individuals who are recruited for other jobs could potentially be disenchanted, thus increasing the likelihood of departure, but the individuals might also have no intention to leave the current organization until they receive an offer to join a new organization. Kramer (2010) stated that employees with highly specialized occupations or employees who occupy top levels in the organizational hierarchy are more likely to be recruited away from the organization. For example, Elmore (2009) found that among employees in the highly specialized industry of journalism, women reported being recruited away from their organizations with the possibility of continuing to be a journalist, while spending more time away from the organization and with family.

Aside from the reasons for exiting presented by Lee and colleagues (1996) and Kramer (2010), there appears to be another prominent reason that employees voluntarily exit their organizations. General uncertainty or lack of information about work roles or requirements is a major contributor to an employee's decision to exit (Allen, 1996; Griffeth \& Hom, 2001; Jablin, 1987; Susskind, 2007). Quality information exchange is an essential feature of organizational health and the adjustment of employees (Morrison, 2002). Subsequently, for employees to remain in an organization and be comfortable in their jobs, they need information about the organization, specific information about their jobs, the social network, the culture of the 
organization, the politics of the organization, and feedback (Morrison, 1995). Certainty about leadership and peer coworker relationships positively affects employee outcomes such as organizational identification and satisfaction (Kramer, Meisenbach, \& Hansen, 2013). Researchers have also discovered that when information quality is low, employees are less adjusted and more likely to leave their organization (Scott et al., 1999). Loss of information sources due to organizational downsizing may also affect employees' desire to leave the organization, as the uncertainty created by both the downsizing and the departure of coworkers may influence feelings of remorse about remaining (Susskind, Miller, \& Johnson, 1998). Additionally, when employees experience role ambiguity-- lack of information necessary to adequately perform their job-- they tend to express greater desire to depart from the organization (Donnelly \& Ivancevich, 1975; Kahn, Wolfe, Quinn, Snoek, \& Rosenthal, 1964). Rizzo, House, and Litzman (1970) discovered that role ambiguity predicted employees' propensity to leave and suggested that when employees are deprived of needed information, they begin to seriously consider exiting the organization.

\section{The Voluntary Exit Process}

While there are many reasons why organizational members voluntarily exit their organizations, scholars have argued that exit occurs as part of a larger process (Jablin, 2001). When organizational communication scholars do study employee turnover, they tend to consider it as part of the organizational assimilation process (Jablin, 2001). Jablin and Krone (1987) defined organizational assimilation as the process through which individuals enter, become integrated into, and eventually leave the organization. Despite arguments that organizational assimilation occurs less linearly than originally conceptualized (see Bullis, 1993), Jablin (1982) 
asserted that organizational assimilation consists of four distinct phases: anticipatory socialization, entry, metamorphosis, and exit (Jablin, 1982).

In the anticipatory socialization phase, prospective employees begin to formulate expectations and perceptions about the nature of work within a particular organization or industry (Jablin, 2001). Information sources in the anticipatory socialization phase include peers, media, family, and prior work experiences (Jablin, 1985; 2001; Kramer, 2010). The formation of expectations tends to exert considerable impact on the adjustment that employees make to the organization once they officially begin their tenure (Wanous, 1992). For example, when employees receive realistic job previews from recruiters, they tend to be more productive and less likely to voluntarily exit (Phillips, 1998).

In the entry phase, individuals officially begin their role in the organization and are exposed to the organization's culture, norms, and expectations (Jablin, 1982). Organizational members also begin to alter their roles and make sense of their membership in the organization (Myers \& Scott, 2010). Uncertainty tends to be high during the entry phase, requiring employees to seek information through various tactics (Kramer, 2004; Miller, 1996; Miller \& Jablin, 1991).

In the metamorphosis phase, employees experience a cognitive change in which they no longer consider themselves newcomers (Jablin, 1982). Employees believe that they truly belong in the organization, become fully-functioning and participating members of the organization (Gailliard, Myers, \& Seibold, 2010), and begin to formulate accurate assessments of the organizational culture, climate, and the relationships that comprise the organization (Jablin, 1987). Despite feeling a sense of arrival and being a fully-functioning member, organizational members may experience uncertainty about newcomers (Gallagher \& Sias, 2009), job 
promotions (Kramer \& Noland, 1999), transferring to new locations (Kramer, 1989), and organizational change initiatives (Susskind, 2007).

Finally, the exit phase involves three distinct stages: preannouncement, announcement/actual exit, and postexit (Jablin, 2001). Preannouncement includes the cues, signals, or shocks that precede departure from the organization. It is in the preannouncement stage of organizational exit that employees make sense of organizational events and conclude that they want to leave the organization. Being shocked enough to quit, gradual disenchantment, and being recruited away (Lee et al., 1996) likely occur in the preannouncement stage.

Jablin (2001) noted that employees intending to leave the organization are exposed to a variety of messages that lead them to question the attractiveness of the organization and their place within it. It is reasonable to assume that the messages peer coworkers use with each other could create some dissonance about the organization that could lead to detachment from the organization (Cox, 1999). In a study of employees who made voluntary career changes from more prestigious careers to less prestigious careers, Tan and Kramer (2012) found that departing members communicated to gather information, seek feedback, garner social support, silence naysayers, and confirm their call to less prestigious careers. Clearly, communication is a vital part of the preannouncement phase of organizational exit as employees begin to make decisions and seek support from their social network before they publicly disclose their plans to leave (Jablin, 2001; Tan \& Kramer, 2012).

Announcement/actual exit involves public disclosure of the intention to leave. The announcement of exit allows organizational members to provide reasoning for the departure and to focus on the problems of their organizations (Jablin, 2001). Tan and Kramer (2012) found that employees contemplated three major issues during the announcement phase of 
organizational exit. First, employees considered the timing of the announcement about job changes and utilized covert or overt strategies to generate greater acceptance of their decision to leave. Second, employees framed the message to members of their social network to generate support for their decision to leave. Third, employees strategized the delivery of the messages about their impending departure to find the most effective method for communicating why they want to make changes in their careers.

Postexit occurs when the absence of the departing employee is felt by those remaining in the organization and is marked by uncertainty for both the leaver and the remaining organizational members (Jablin, 2001). Departing members feel uncertainty about their new endeavors, while the remaining members experience uncertainty about how well newcomers will fit into the organization and the impact they will have (Gallagher \& Sias, 2009). A major communicative component of the postexit phase is reframing to manage one's identity (Tan \& Kramer, 2012). For instance, employees attempt to change the way others perceive their new job or career choice by aligning the new job or career with more socially desirable ones or by communicating the importance of work in the new field or organization. Jablin (2001) reasoned that postexit likely ends when the social network of the departing member ceases inquiring about changes in job status and reasons for leaving.

Investigating organizational exit from an assimilation perspective has allowed scholars to examine the effects of events throughout an individual's organizational tenure on decisions to leave the organization. Organizational communication scholars have looked at voluntary exit has part of prolonged experience. Organizational exit is conceptualized as a process, rather than a distinct event, that involves mutual withdrawal between organizations and their members (Jablin, 2001). A mutual withdrawal occurs when individuals decrease or end their relationship 
with the organization, while the organization decreases its involvement or association with the individual. Despite the frequency with which organizational exit occurs and the numerous organizational and individual variables that influence it, less is known about the organizational exit portion of organizational assimilation than about the anticipatory socialization, entry, or metamorphosis phases (Jablin, 1987). The development of peer coworker relationships can be a major influence on each of the phases of organizational assimilation.

\section{Coworker Relationships}

Peer coworker relationships in the organizational context refer to the connections between coworkers whose positions occupy the same level of the organizational hierarchy and who have no formal authority over each other (Sias, 2009b). They tend to represent the most abundant type of organizational relationship because there tends to be only a small number of supervisors, but a proliferation of people on the same hierarchical level. As such, organizational members often expend more energy communicating with their peer coworkers than they do any other organizational member (Sias et al., 2002). Peer coworker relationships are also considered nonvoluntary relationships because employees are unable to choose with whom they work (Hess, 2000). The influence of peer coworker relationships in the organizational context is difficult to overstate, as the quality of these relationships often exerts more influence on organizational outcomes than the quality of supervisor-subordinate relationships (Chiaburu \& Harrison, 2008). Also peer coworker relationships provide employees necessary information, mentoring, opportunities for feedback, social support, opportunities to exert power and influence on one another (Sias, 2009b), and are important for successful integration into the organization (Gailliard et al., 2010; Myers, Park, \& Seibold, 2011). 
Developing high quality peer coworker relationships tends to yield many positive outcomes related to organizational assimilation and adjustment (Myers et al., 2011). For example, Kramer (1996) found that higher proportions of high quality relationships predicted greater job satisfaction and greater role innovation. Supportive peer coworker relationships also tended to predict the certainty that employees have about their jobs, which may then lead to higher levels of organizational identification and job satisfaction (Kramer, Meisenbach, \& Hansen, 2013). Hart, Miller, and Johnson (2003) reported that support from coworkers influenced organizational commitment. Peer coworker relationships are also essential for familiarizing newcomers with the cultural norms of the organization (Louis, Posner, \& Powell, 1983) and they serve as sources of social support during organizational entry (Kramer, 1994; Zorn \& Gregory, 2005). Peer coworkers are also instrumental in dealing with stressful and traumatic experiences (Myers, 2005; Scott \& Myers, 2005; Tracy, Myers, \& Scott, 2006), acquiring information about other people, politics, and the specific terminology used by organizational members (Hart, 2012), and making sense of coworkers' differential treatment from supervisors (Sias, 1996; Sias \& Jablin, 1995).

\section{Positive Coworker Relationships}

Peer relationship types. According to Kram and Isabella (1985), there are three types of peer coworker relationships: information peers, collegial peers, and special peers. The information peer is considered to be an acquaintance with whom communication is characterized by discussion of the workplace and low levels of self-disclosure, social support, and trust. The collegial peer is a combination of a coworker and friend with whom the content of communication focuses on a blend of organizational information and personal interests, and is characterized by moderate amounts of self-disclosure, social support, and trust. The special peer 
is considered to be a best friend that develops in the organizational setting. Communication between special peers is mostly about personal interests, with high amounts of self-disclosure, social support, and trust.

Information peer relationships tend to be the most common type of organizational peer coworker relationship (Fritz, 1997). Organizational members with information peers tend to receive lower quality information (Sias, 2005), perceive less solidarity, (Myers \& Johnson, 2004), express less communication openness (Myers, Knox, Pawlowski, \& Ropog, 1999), perceive less connection and familiarity between themselves and other employees, report less job competency (Sollitto, Johnson, \& Myers, 2013), and use fewer affinity-seeking strategies (Gordon \& Hartman, 2009) than employees with collegial or special peer relationships. Additionally, organizational members with larger proportions of information peer relationships tend to report lower levels of task knowledge about their work roles (Kramer, 1994), lower levels of adjustment to their new organizations (Kramer, 1996), and perceive lower levels of cohesion in their organizations (Odden \& Sias, 1997) than employees with higher proportions of collegial or special peer relationships.

Friendship. While the formation of superficial relationships, like information peer relationships, tends to predict less adjustment to the organization than developing special and collegial peer relationships, information peer relationships can develop into more enriching and closer relationships over time (Sias \& Cahill, 1998). In fact, employees' percentages of information peers decreased as their organizational tenure increased (Kramer, 1994). As peer coworker relationships evolve, they become increasingly personal and intimate (Sias \& Cahill, 1998). These personal and intimate relationships become more than simple role relationships, they become friendships. 
Workplace friendships can be defined based upon their voluntary and personalistic nature. Workplace friendships are voluntary because employees can choose the coworkers with whom they develop closer bonds. They are also personalistic in that friends communicate with one another based on their similarities and shared interests rather than based upon their organizational roles. Furthermore, Sias and Cahill (1998) reported that a combination of workplace contextual factors and individual factors influence the development of peer coworker relationships into more rewarding friendships. The likelihood that coworkers transition to friends is driven by a number of factors, including sharing tasks, similarity of attitudes, and personality (Sias \& Cahill, 1998; Sias, Pederson, Gallagher, \& Kopaneva, 2012; Sias, Smith, \& Avdeyeva, 2003).

Specifically, Sias and Cahill (1998) identified three transitions that gradually increased the intimacy and closeness of peer coworker relationships. The first transition involved acquaintances developing into friends. Sharing the same physical space, sharing tasks, and spending time together outside of work facilitated the first transition. The second transition involved friends developing into close friends. Discussion of problems both inside and outside of the workplace, increased socializing outside of the workplace, and spending time with each other's families facilitated the second transition. In the second transition the communication became more open and candid. The third transition involved close friends developing into "almost" best friends. Increased communication outside of work, shared life events, and discussion of problems both inside and outside of the workplace contributed to this closer bond between peer coworkers. In a subsequent study, Sias et al. (2003) found that women were more likely than men to report increases in communication intimacy and the discussion of life events during the transitions into higher quality relationships. 
Once peer coworkers have reached a desirable and satisfying state in their relationships it becomes necessary to maintain them. Sias et al. (2012) found that politeness is integral in maintaining relationships. In workplace friendships that were perceived as escalating to levels of intimacy that were uncomfortable for one of the friends, employees rated relational maintenance tactics of indirect conversational refocus and openness/direct conversational refocus as more polite than avoidance tactics. Indirect conversational refocus tactics involved deliberately and tactfully moving conversations from more intimate topics toward workplace topics. Openness/direct conversational refocus tactics involved explicitly stating that the conversation should move from more intimate topics to less intimate ones. Avoidance tactics involved simply eluding interactions with coworkers.

Workplace romance. The presence of workplace romances can also affect peer coworker relationships and friendships in the organization (Sias, 2009b). Workplace romances are defined as emotional, physiological, and consensual relationships in which two members of the organization share mutual sexual attraction (Sias, 2009b). According to Horan and Chory (2013), employees appear to be becoming more accepting of workplace romances. Workplace romances can have positive impacts on the employees involved in them and on the larger work environment. Employees tend to report increases in their production and motivation when involved in workplace romances (Dillard \& Broetzman, 1989; Sias, 2009). For example, Dillard (1987) discovered that employees engaging in workplace romances for love showed an increase in their productivity in comparison to employees engaging in workplace romances for job or ego motives. Moreover, Pierce, Byrne, and Aquinis (1996) found that employees participating in workplace romances reported higher levels of job satisfaction as a result of their romance. Gillen and Chory (2014) found that workplace romances could yield positive benefits for the 
organizational members involved in the workplace romance and the organization. For example, individuals who reported engaging in workplace romances stated that their performance improved in the organization and that they were excited to go to work each day.

Mentoring. Other relationships between peer coworkers that have received attention from researchers for their positive effects are mentoring relationships. Having peer coworkers serve as mentors offers an alternative to traditional forms of mentoring provided by experienced supervisors, as peer coworkers offer unique forms of assistance to one another, have more frequent contact with each other, and are often more accessible than supervisors (Kram \& Isabella, 1985). Mentoring relationships with peer coworkers can often be more effective than formal mentoring relationships (Raabe \& Beehr, 2003). Peer coworkers are capable of providing different types of career support to one another such as skill development, coaching, emotional support, feedback, new perspectives on work, challenges for their work, affirmation, and assistance in building and maintaining social networks (Allen \& Finklestein, 2003).

The support provided by peer coworkers increases over time and leads to higher levels of knowledge creation and sharing behaviors in the organization (Bryant, 2005). Indeed, seeking support to cope with organizational stressors and to gain helpful advice about career development are key functions of the peer coworker relationship (Sias, 2009b). Peer coworkers serving as mentors can positively affect employees' attitudes about the organization and their job effectiveness (Chiaburu \& Harrison, 2008).

\section{Negative Effects of Positive Coworker Relationships}

There can also be many negative effects that occur in coworker relationships. Backstabbing and derogation are effects that could adversely affect coworker relationships. Malone and Hayes (2012) found that peer coworkers use a variety of active and passive 
strategies to stab each other in the back. Active strategies included talking behind the back of the peer coworker, lying, stealing credit, and blaming or falsely accusing. Passive strategies included breaking promises and withholding information. Moreover, employees who reported being overbenefited in their peer coworker relationships were more likely to belittle or derogate their partners than employees who were underbenefited or equitably treated (Westerman, 2013).

Friendship. Bridge and Baxter (1992) argued that maintaining friendships in the organization could be a stressful experience because it involves managing a variety of dialectical tensions stemming from the blended nature of the relationship. Employees with high quality relationships have to make sense of their peer coworkers as individuals with whom they share information outside of the organization and as individuals upon whom they depend inside the organization. Subsequently, if the dialectical tensions between peer coworkers are poorly managed, the relationship may deteriorate (Sias, Heath, Perry, Silva \& Fix, 2004).

Peer coworker relationships may also deteriorate due to problem personalities, distracting life events, promotions, and betrayals (Sias et al., 2004). Deterioration of peer coworker relationships due to problem personalities occurs when one person in the relationship can no longer tolerate the personality or behavior of his/her peer coworker. Distracting life events involve one person in the relationship being unable to overcome events that occur outside of the workplace, which negatively affects the person's job performance. Conflicting expectations occurs when coworkers have disparate expectations about how they should interact with another. Promotions can lead to deterioration of peer coworker relationships when one person advances to a new position and becomes a supervisor of his/her peer coworker. The subsequent promotion can make it awkward for the two friends and create situations in which one needs to keep 
organizational information private from the other. Betrayals are violations of trust in the dyad that can break down the relationship (Sias et al., 2004).

Additionally, Sias and Perry (2004) observed that individuals use three strategies to disengage from their peer coworker relationships: cost-escalation, depersonalization, and stateof-the-relationship talk. Cost-escalation occurs when individuals engage in intentional negative behavior, such as speaking in a condescending tone or criticizing their peer coworker. Depersonalization occurs when individuals decrease the amount and quality of communication they have with their peer coworker, and state-of-the-relationship talks occur when individuals have direct conversations about the deterioration of the relationship with a peer coworker. The consequences of peer coworker relationship deterioration include emotional stress, turnover, decreased job performance, and lessons learned about relationships (Sias et al., 2004). Thus, peer coworker relationships involve careful negotiation of their positive and negative aspects.

Workplace romance. Most of the research conducted regarding workplace romances indicate that they can be divisive and lead to negative outcomes for individuals and the organization (Sias, 2009b). Dillard, Hale, and Segrin (1994) reported that when employees perceived that their coworkers were involved in workplace romances due to job motives, it had an adverse effect on the organizational climate and work performance. Likewise, Malachowski, Chory, and Claus (2012) found that employees' perceptions of their peer coworkers engaging in workplace romance for job motives was associated with beliefs that their peer coworkers would receive unfair organizational advantages due to the romance.

Problems seem to arise when organizational members discover that their peer coworkers are engaging in workplace romances with authority figures. For example, Horan and Chory (2009) found that employees reported less trust in, less interpersonal solidarity with, and less 
honest and accurate disclosures with peer coworkers who were dating supervisors than with peer coworkers who were dating organizational members on the same hierarchical level. Deception with a peer coworker was also more likely to occur when employees perceived that their peer coworkers were dating authority figures versus peers (Horan \& Chory, 2011; Malachowski et al., 2012). Individuals who engage in workplace romances with organizational superiors are also viewed as less caring and trustworthy than individuals who engage in workplace romances with employees on the same hierarchical level (Malachowski et al., 2012; Horan \& Chory, 2011; 2013).

Mentoring. As with peer coworker and romantic relationships, mentoring relationships can also yield negative outcomes. Scandura (1998) noted that mentoring relationships have the potential for destructiveness due to jealousy, mistrust, dislike, anger, or hostility that might arise between mentors and protégés. Scandura presented a typology of destructive mentoring relationships which included negative relations, sabotage, difficulty, and spoiling. Negative relationships occur when the power differential between mentors and protégés is consciously reinforced and physical or verbal abuse arises. Sabotage relationships emerge when either the mentor or protégé insists upon taking revenge or ignores one another to facilitate a response. Difficult relationships arise when the mentor and protégé have benevolent intentions toward one another, but conflict or fundamental disagreements prevent constructive communication and support. Spoiling relationships emerge when there are benevolent intentions between the mentor and protégé, but one or more events have made the relationship less rewarding than it could have been. 


\section{Problematic Peer Coworkers}

Just as there are productive types of organizational relationships, there are other types of relationships that can seriously derail organizational productivity (Fritz \& Omdahl, 2006) and civility (Fritz, 2012). Individuals with whom relationships are considered negative or disadvantageous in the workplace have been labeled difficult coworkers (Duck, Foley, \& Kirkpatrick, 2006), troublesome others (Fritz, 2002), disliked coworkers (Hess, Omdahl, \& Fritz, 2006), and bullies (Lutgen-Sandvik, 2006). While the terms used to describe disadvantageous work relationships vary, they all represent undesirable aspects of nonvoluntary work relationships (Hess, 2000) and the chaos that can ensue because of them (Fritz, 1997; Omdahl \& Fritz, 2006).

Difficult coworkers. Duck et al. (2006) described difficult coworkers as employees who are socially constructed by their peer coworkers as disagreeable people to work with because they impose undesired social identities on receivers, showcase infringing personalities, and create role constraints between self and work. There are three types of incompatibility that might lead peer coworkers to perceive an employee as difficult: person-person incompatibility, rolerole incompatibility, and person-role incompatibility. Person-person incompatibility involves personal dislike between two employees, which can greatly hinder production. Role-role incompatibility occurs when the context of work influences a person being perceived and socially constructed as difficult. For example, the nature of tasks and position take a toll on employees leading them to become difficult to work with and to form constructive relationships with. Person-role incompatibility involves conflict between the person and the work role (s)he assumes in the sense that a person's values and interests are incongruent with the work role performed. Problems such as hostile behavior or poor performance emerge when organizational 
members are unable to reconcile complexities of the organizational structure and culture (Duck et al., 2006).

Troublesome others. Another type of problematic coworker is the troublesome other. Relationships with troublesome others exceed occasional conflict and include active disdain between the parties (Fritz, 2002). Fritz $(2002,2006)$ identified eight types of troublesome peer coworkers: independent other, soap opera star, bully, adolescent, self-protector, mild annoyance, rebellious playboy/playgirl, and abrasive, incompetent harasser. The independent other is characterized as troublesome because he/she exhibits a tendency to reject the positional power of a coworker. The soap opera star tends to focus an excessive amount of time on his/her personal problems and on those of coworkers. The bully tends to be controlling and determined to have work done his/her own way, regardless of how anyone else feels. The adolescent is a troublesome other who is fearful that someone else will take his/her job and is often unprofessional and immature. The self-protector advances his/her own interests. The mild annoyance is a characterized as slightly irritating to coworkers. The rebellious playboy/playgirl makes a habit of making uncomfortable sexual advances to other employees, while disregarding authority figures. The abrasive, incompetent harasser exhibits behaviors that are unprofessional, distracting, and dogmatic.

The effects of relationships involving difficult coworkers or troublesome others are decidedly negative as the number of problematic peer coworkers that an employee reports having is predictive of emotional burnout (i.e., exhaustion, depersonalization, and reduced personal accomplishment), anxiety, depression, and negative thoughts (Omdahl \& Fritz, 2006). Additionally, Fritz and Omdahl (2006) found that the proportion of negative peer coworkers 
reported by employees negatively affected employees' job satisfaction and organizational commitment and increased their cynicism about the workplace.

Bullies. In addition to the problems caused in organizations by difficult coworkers and troublesome others, bullies represent a major threat to organizations (Lutgen-Sandvik, Namie, \& Namie, 2009) and the positive emotional experiences of employees (Lutgen-Sandvik, Riforgiate, \& Fletcher, 2011). Bullies do this, in part, by creating stress and lower job satisfaction for coworkers (Lutgen-Sandvik, Tracy, \& Alberts, 2007). Bullying often takes place in supervisorsubordinate relationships (Lutgen-Sandvik, 2003), but peer coworkers are the sources of bullying behaviors, as well (Kinney, 2012). Lutgen-Sandvik and colleagues (2009) asserted that bullying represents a repeated act involving mistreatment in the form of verbal abuse, offensive conduct, and behaviors that hinder production and harm the health of employees. Humiliation, withholding information, threatening behavior, pressure to refrain from claiming something that is rightfully his/hers, being ignored, and hints to quit one's job are bullying behaviors received by employees (Lutgen-Sandvik et al., 2007). Bullying may create a strong desire for individuals to leave the organization as a show of resistance and to avoid the constant humiliation, aggression, and scorn (Lutgen-Sandvik, 2006).

Network isolates. Organizations are comprised of webs of interactions, relationships, and information exchange (Stohl, 1995). Network isolates are organizational members who have relatively few connections in the organization's social network (Monge \& Eisenberg, 1987). It can be undesirable to be on the fringes of the organization's social network because needed links to information and key resources are unavailable (Susskind et al., 1998). Indeed, employees are at risk for becoming isolated from their organization's social network when they have fewer 
contacts to rely upon for information and engage in few information-seeking behaviors (Sias, Kramer, \& Jenkins, 1997).

Organizational members who are on the periphery of their organizations' social networks and have weak interpersonal connections are more likely to leave the organization (Feeley, 2000; Feeley \& Barnett, 1997; Feeley, Hwang \& Barnett, 2008). Specifically, Feeley and Barnett (1997) explored the impact of a person's social network on his/her likelihood to leave the organization. Three distinct models were explored: the structurally equivalent model, the social influence model, and the erosion model. The structurally equivalent model theorized that employees would behave similarly in their likelihood to voluntarily leave the organization, the social influence model posited that employees with a greater number of direct communication links with leavers would be more likely to leave, and the erosion model predicted that individuals located on the edges of the social network would be more likely to leave or become disconnected from the social network. All three models predicted organizational exit, with the erosion model accounting for the most variance. The results lend support to the notion that employees with fewer connections in the organization are more likely to leave, probably because they have less access to information, which in turn, could lower organizational identification.

In a study intended to replicate and extend the conclusions of Feeley and Barnett (1997), Feeley (2000) discovered that closeness of relationships within the social network was related to organizational commitment and that closeness, betweenness (frequency that a position falls between pairs of other positions in the network), and degree (number of connections) in the social network were negatively related to organizational exit. Additionally, through the use of meta-analysis, Feeley et al. (2010) found that social support and network centrality were positively related, whereas network centrality and turnover were negatively related. 
Furthermore, social support and turnover were negatively related. Feeley and colleagues (2010) suggested that building supportive bonds in the organization is helpful for maintaining membership in the organization. Being part of friendship networks (networks of high quality relationships) tends to be a stronger negative predictor of turnover than being part of peer networks (networks of acquaintances; Feeley et al., 2008).

Overall, the results of network studies reveal that individuals on the periphery of their organizations' social networks are at a disadvantage in terms of receiving needed social support, information, and resources. In sum, exposure to difficult coworkers, troublesome others, disliked coworkers, bullies, or being less connected to the social network of the organization greatly increases the likelihood of engaging in voluntary organizational exit (Jablin, 2001; Stohl, 1995).

\section{Positive Coworker Communication}

Social support. Peer coworkers engage in a variety of helpful and positive activities that aid in each other's adjustment (Kramer, 1994, 1996; Powell et al., 1983) and assimilation (Zorn \& Gregory, 2005). One of these positive activities is the expression of social support (Miller, 2012; Sias, 2009). Burleson and MacGeorge (2002) asserted that social support is the verbal and nonverbal messages produced for the purpose of assisting others perceived as needing help or assistance. Organizations can be stressful environments, which necessitates the communication of social support so employees can cope (Cahill \& Sias, 1997; Ray, 1987). Kram and Isabella (1985) argued that peer coworkers are excellent sources of social support due to the experiences and tasks that they accomplish together.

Social support is helpful even before entering the organization. Holmstrom, Russell, and Clare (2013) observed that helpful and supportive messages received by job applicants during a 
job search were useful for their self-esteem. Once employees begin their tenures in the organization, the support that they receive from their peer coworkers helps reduce their uncertainty about the organization (Kramer, 1996), and increases their organizational commitment (Hart et al., 2003), satisfaction (Ducharme \& Martin, 2000; Kramer et al., 2013; Morrison, 2008), and advancement (Kram \& Isabella, 1985). The social support provided by peers can also positively affect organizational identification (Fay \& Kline, 2012; Wiesenfeld, Raghuram, \& Garud, 2001), create memorable experiences for employees as they assimilate into the organization (Barge \& Schlueter, 2004), and lead to positive affect toward the nature of work and the organization (Lutgen-Sandvik et al., 2011). Furthermore, when the organization is more supportive of its employees, they can then engage in more supportive behaviors with one another (Eisenberger, Armeli, Rexwinkel, Lynch, \& Rhoades, 2001; Odden \& Sias, 1997).

It seems that when organizational members have supportive peer coworker relationships they are more likely to experience positive organizational outcomes. For example, when employees receive inclusion messages--communication that allowed them to establish and maintain satisfactory relationships in the organization, collegial talk--communication focused on solidarity, friendliness, and cooperation, and social support--assistance provided to employees to restore confidence, help, and cope with organizational stressors, they were more identified with their organizations (Fay \& Kline, 2012).

High quality information exchange. In addition to the act of providing social support, peer coworkers provide information about the organization (Sias, 2009b). Whereas supervisors often give useful information about the basic structure of the organization and the integral nature of one's roles (Jablin, 1979, 1980; Miller \& Jablin, 1991), peer coworkers are often the best sources for gathering more detailed organizational information (Comer, 1991; Hart, 2012). 
Miller and Jablin (1991) asserted that new employees actively seek to reduce their uncertainty through seven distinct tactics: direct questions, indirect questions, third-party questions, disguising conversations, surveillance, testing, and observing. These tactics change over time, as individuals assimilate into the organization (Jablin, 1984; Kramer, 1994). Seeking information from peer coworkers, as opposed to supervisors, may be less threatening to the image that employees desire to maintain (Miller, 1996). Thus, employees consider the social costs (Miller, 1996; Tidwell \& Sias, 2005), usefulness of information (Morrison, 1995), and comfort with ambiguity (Teboul, 1995) before actively seeking information. Organizational members do tend to receive timelier and more accurate information when they have a larger proportion of collegial versus informational peer coworkers in the organization (Sias, 2005). Employees also tend to be more satisfied with their coworker relationships when they receive information from their peer coworkers (Allen, 1996; Scott et al., 1999). Overall, the exchange of quality information between peer coworkers has decidedly positive outcomes for the organization and the individual (Sias, 2009b).

\section{Problematic Coworker Communication}

Just as there are employee communication activities that assist in assimilation and adjustment, there are communication activities that adversely affect these processes. Much of the research on negative organizational communication has focused on the supervisorsubordinate relationship. For instance, when employees are the recipients of such antisocial behavior from their supervisors as emotional abuse (Lutgen-Sandvik, 2003), abusive supervision (Tepper, 2000), or deprivation of information (Johnson et al., 1996), they tend to be more likely to leave their organizations. 
Employee emotional abuse. Employee emotional abuse (EEA) involves being terrorized through repeated, targeted, and destructive communication by more powerful members of the organization. Lutgen-Sandvik (2003) asserted that EEA progresses through six stages, beginning with an incident in which emotional abuse from an authority figure is triggered. In the second stage, the authority figure constructs the dominant discourse of the emotional abuse and shapes the story about the events for both the recipient of the abuse and others in the organization. In the third stage, the authority figure becomes more antagonistic and destructive toward the abused employee. Next, authority figures from multiple levels of the organizational hierarchy combine their accounts and work to discredit the employee's claims of abuse. The fifth stage is characterized by the authority figures working to slander the abused employee's reputation and work. Finally, the abused employee departs from the organization. Thus, when authority figures are hostile toward employees, employees exit because they can no longer withstand the emotional abuse they have received (Lutgen-Sandvik, 2003).

Abusive supervision. Similarly, abusive supervision can lead to turnover. Tepper (2000) defined abusive supervision as constant belittling of subordinates through sustained hostile verbal or nonverbal behaviors. Tepper (2000) found that organizational members who were victims of abusive supervision perceived lower levels of organizational justice, and experienced lower levels of satisfaction and commitment, and higher levels of work -family conflict. Such employees find the prospect of leaving their organizations more appealing than remaining (Tepper, 2000).

Supervisor [non-]support. The support provided by managers during workforce reductions also plays a role in turnover. Johnson and colleagues (1996) discovered that employees were more likely to leave their organizations when they perceived a lack of support 
from their authority figures. Because of the tumultuous experience of surviving workforce reductions, employees rely upon the comfort that their managers can give them. When the support is lacking, employees express their desire to leave the organization (Johnson et al., 1996).

Low quality information exchange. The quality of information that organizational members receive from their coworkers also impacts employees' affective responses about the organization. Specifically, receiving late, unclear, or outdated information can serve as a breaking point and lead employees to consider exiting the organization (Jablin, 2001). Jablin (1987) argued that the quality of communication between coworkers leads to affective organizational responses, such as commitment and satisfaction. These affective responses then influence employees' likelihood of leaving the organization. In a test of Jablin's (1987) assertions, Allen (1996) found that when employees received higher quality information in terms of timeliness, accuracy, usefulness, and clarity they were less likely to exit.

Exclusion. Another negative communication act that is often perpetrated by peer coworkers is exclusion. Exclusion is defined as communication that rejects employees' relational, task, or identity goals in the organization. The exclusion process involves nonexistent interaction and superficial or infrequent communication. Sias (2009a) suggested that targets of exclusion and isolation from organizations' social networks are susceptible to decreased work productivity and increased psychological harm. Organizational members exclude their coworkers to prevent them from achieving higher organizational status or success because they possess qualities that are different from the employees enacting the exclusion, and/or because they hold a position that is desirable to the excluders (Sias, 2012). Organizational members may also exclude their coworkers due to personality characteristics. 
Organizational features lead to exclusion, as well. Proximity, tasks/positions, lack of action from supervisors about detecting or stopping the exclusion, and organizational climate all may influence exclusion. Organizational members who are physically removed from their coworkers may find it difficult to stay updated on the task and social information needed to function in the organization, thus proximity plays a role in exclusion. The tasks or positions that organizational members occupy also influence exclusion because employees at the lower levels of the organizational hierarchy might have fewer close connections in the organization due to the lack of competent communication skills (Reinking \& Bell, 1991). Supervisors' unwillingness or inability to prevent exclusion may also work to encourage or reinforce it (Cox \& Kramer, 1995; Lutgen-Sandvik, 2003). Organizations that encourage or breed competition or individualism may create a climate of defensiveness, leading employees to exclude their coworkers for material or financial gain (Sias, 2012). The act of exclusion may be a primary means through which employees encourage their peer coworkers to voluntarily exit the organization (Cox, 1999).

Distancing behaviors. Hess (2006) asserted that employees utilize the distancing strategies of avoidance, disengagement, and cognitive dissociation to limit the amount of time they spend with coworkers they consider to be problematic. Avoidance strategies involve evading difficult others by limiting the duration of conversations, saying little of substance during the conversation, or involving other employees in the interaction. Disengagement strategies are characterized by preventing conversations from reaching a more intimate level, less use of affirming communication behaviors, and an impersonal focus on the other person. Cognitive dissociation involves changing one's mindset about troublesome others or creating negative judgments about them to create a sense of detachment between employees and troublesome coworkers. 
Unfair treatment. According to Colquitt (2001), organizational justice refers to the perceptions that organizational members report about their treatment in the organization and the fairness of decisions made by authority figures. There are three dimensions of organizational justice: distributive, procedural, and interactional justice. Distributive justice refers to the perceived fairness of organizational outcomes received by an organizational member. Organizational outcomes could include pay, promotions, and raises. Procedural justice is an organizational member's perception of the fairness of the processes used for determining organizational outcomes and includes the consistency of standards utilized for arriving at the outcomes. Interactional justice involves perceptions of the fairness and quality of interpersonal treatment employees receive when decisions are made and outcomes are implemented (Colquitt et al., 2001).

Cropanzano, Li, and Benson (2011) found that when coworkers perceived just treatment amongst themselves they were more likely to work better as a unit, and in turn, experienced greater work productivity. Clearly, when organizational justice is perceived, employees experience a host of positive organizational and individual outcomes. In contrast, feelings of unfairness could lend themselves to disgruntled employees who wish to see others leave the organization (Cohen-Charash \& Mueller, 2007).

Perceptions of fairness and equitable treatment in the organization are communicative based upon how employees interact and socially construct them (Sias \& Jablin, 1995). Sias and Jablin (1995) found that fairness was one of the main reasons organizational members discussed events of differential treatment involving fellow employees. Organizational members make decisions, evaluate, and arrive at shared meaning with each other about differential treatment based upon group or organizational norms/rules and moral standards. Furthermore, Cohen- 
Charash and Mueller (2007) found that envious employees who perceived unfair working conditions were more likely to engage in harming behaviors, such as sabotaging or misleading others.

Concertive control. Another potentially powerful influence that peer coworkers have on one another is concertive control. Concertive control involves groups of peer coworkers governing themselves and ensuring the standards, norms, and values of the organization are understood and acted upon by one another (Barker, 1993; Thompkins \& Cheney, 1985). It may involve coworkers disciplining and punishing each other (Barker \& Cheney, 1994). Peer coworkers influence one another to maintain organizational functioning and meet organizational goals through competition, peer pressure, undermining efforts, empowerment, or collaboration (Barker, 1993; Barker \& Thompkins, 1994; Larson \& Thompkins, 2005; Papa, Auwal, \& Singhal, 1997; Thompkins \& Cheney, 1985).

\section{Antecedents and Effects of Problematic Coworker Communication}

Due to the adverse nature of negative communication acts, it is important to understand the organizational and individual antecedents to them. Baron (2004) asserted that aggressive acts or negative communication in the organization could be influenced by social, situational, and personal factors. Social factors involve the words and behaviors of fellow employees, including frustration, direct provocation, displaced aggression, triggers of displaced aggression, and exposure to aggressive social models in the work group. Situational factors involve structural or environmental features, such as temperature, crowding, and noise. Personal factors involve personality or communication characteristics, such as type A behavior patterns, perceptions of evil intent in coworkers, and feelings of superiority. 
Additional personal factors influencing antisocial organizational communication include trait verbal aggressiveness, indirect interpersonal aggressiveness, and Machiavellianism (Avtgis \& Chory, 2010). For example, verbally aggressive employees are less likely to express their contradictory opinions about the organization's procedures and policies in a constructive manner (Kassing \& Avtgis, 1999). Employees characterized by their tendency to use indirect interpersonal aggressiveness engage in malicious and destructive behaviors, such as spreading rumors and betraying the confidences of others (Beatty, Valencic, Rudd, \& Dobos, 1999). Organizational members with Machiavellian tendencies exhibit both interpersonal and organizational deviance (Bennett \& Robinson, 2000), identify less with their job (Mudrack, 1989), are more dishonest (Ashton, Lee, \& Son, 2000), and tend to disregard organizational values or the values of their coworkers (Yurtsever, 2003). Machiavellian employees also express high need for achievement, desire status, and engage in counterproductive work behaviors (Dahling, Whitaker, \& Levy, 2009). They engage in fewer organizational citizenship behaviors and greater levels of impression management (Becker \& O’Hair, 2007), as well.

The effects of negative communication in the workplace can be quite profound (LutgenSandvik \& Sypher, 2009). When employees are the recipients of exclusion messages, they tend to experience lower organizational identification and commitment (Fay \& Kline, 2012). Sias (2009a) argued that when employees are excluded and treated as outcasts they likely feel lonelier and have higher stress and anxiety levels. In a similar vein, employees who perceive themselves to have been stabbed in the back tend to experience a variety of negative emotions such as shock, indignity, anger, frustration, and embarrassment (Malone \& Hayes, 2012). Being an outcast or maintaining fewer connections in the organization is related to turnover (Feeley \& Barnett, 1997). Likewise, targets of bullies may feel helpless and eventually exit the organization 
(Lutgen-Sandvik, 2006). Thus, it is evident that supportive peer coworker relationships improve one's organizational experiences, whereas negative peer coworker relationships make it difficult to achieve desired individual or organizational outcomes. The quality of peer coworker relationships that organizational members have in the organization could contribute to organizational exit.

\section{Peer Coworker Relationships and Organizational Exit}

Voluntary exit is a distinctly communicative event (Jablin, 2001), however, researchers have traditionally looked at non-communication factors as antecedents to voluntary organizational exit. These factors include the external economy, type of industry, organizational size, pay, job content, and individual characteristics of employees (Mobley, 1982). When communication factors are considered, they tend to be those that occur in the supervisorsubordinate relationship (e.g., abusive supervision, bullying, or lack of information). Limited research has been conducted on the role played by peer coworkers' communication in voluntary organizational exit (Cox, 1999).

Given that peer coworker relationships are complex, influential, and highly prevalent in organizational life, greater attention should be devoted to their role in encouraging voluntary organizational exit. It is evident that troublesome work relationships, exclusion, and concertive control may influence an individual's desire to leave the organization, but a greater focus needs to be placed on understanding how peer coworkers may use these and similar behaviors to impact their peers' voluntary organizational exit. Greater attention is warranted due to the effect that peer coworker communication has on organizational functioning and the organizational members involved. 


\section{Peer-Influence Exit}

One way that peer coworkers influence organizational exit is through peer-influence exit tactics, which are defined as the messages and behaviors employees intentionally use to influence their peer coworkers to leave the organization (Sollitto, Weber, \& Chory, 2013). In a study specifically focused on how employees encourage voluntary organizational exit from their peer coworkers, Cox (1999) reasoned that employees grow weary and frustrated with their peer coworkers, but lack the organizational authority to end their work relationships. Thus, employees seemingly attempt to affect the peer coworker's cost/benefit ratio of remaining in the organization by increasing the personal costs and decreasing the benefits associated with organizational membership. Organizational peers do this by making it difficult for their coworkers to function in the workplace, in part, by inundating them with messages and behavioral strategies designed to influence them to leave.

\section{Strategies for Encouraging Voluntary Exit}

Cox (1999) found that employees use a variety of supportive and destructive messagebased and behavior-based strategies to encourage their peer coworkers to leave the organization (see Appendix A). The most commonly reported message that employees used with their peer coworkers was disparaging or negatively criticizing their peers for the purpose of pointing out inadequacies, illuminating that their peer coworkers may be performing poorly in their jobs, and to show how they are a bad fit for their work roles. Other strategies included encouraging peers to consider, seek, or find a new job/career alternative; disparaging or negatively criticizing the peer's job, company, or management; commending/praising other jobs, organizations, or career alternatives; encouraging self-evaluation; informing them of job/career alternatives; warning of negative consequences or outcomes; reviewing beliefs about work and life; telling/encouraging 
peers to exit/resign; commending/praising the choice of voluntary exit/resignation;

commending/praising the peer's positive qualities; and issuing exit ultimatums. Many of these strategies are antisocial and aggressive forms of communication (e.g., disparaging the peer), while others are prosocial and supportive messages (e.g., informing the peer of job/career alternatives).

The behaviors employees reported intentionally utilizing to encourage exit appeared to be mostly antisocial in Cox's (1999) study. The most commonly reported behavior was communication avoidance or decrease with peer, suggesting that employees deliberately exclude their coworkers and restrict information flow to them in an effort to nudge them out of the organization. Other negative behaviors included communication engagement or increase with workgroup members or supervisors for the purpose of spreading gossip and backstabbing others, ceasing or decreasing help/support, acting hostile/unfriendly, and performing malicious acts to sabotage/harm the peer. Many of the behaviors reported suggest that employees almost go out of their way to impact a peer coworker's decision to exit the organization. Other behaviors are seemingly more prosocial and supportive, such as providing job transition assistance in the form of helping with resumes, and interacting more frequently with peer coworkers to provide constructive feedback and to listen to complaints.

The results of Cox's (1999) study provided an initial account of the messages and behaviors employees intentionally use to influence peer coworkers to leave the organization and provided a glimpse into the latent goals that employees have when influencing their peer coworkers to exit. It subsequently served as a foundation for scholarship intended to increase understanding of the phenomenon of organizational members pushing their peer coworkers out of the organization (Sollitto, Weber, \& Chory, 2013). 
Heeding the suggestion of Cox (1999) to assess the characteristics of employees who encourage their peer coworkers to leave and the frequency with which it is accomplished, Sollitto et al. (2013) developed a measure to assess the frequency of peer-influence exit tactic use and its individual and organizational predictors. The results of their study indicated that employees draw upon prosocial and antisocial tactics to influence their peer coworkers to leave the organization (see Appendix B). Prosocial tactics are messages or behaviors that support the influenced coworker and offer him/her help and assistance toward finding future employment outside of the current organization. Antisocial tactics are malicious messages or behaviors that are meant to damage the influenced coworker so that he/she will eventually leave the organization.

Sollitto, Chory, and Weber (2014) found that among the receivers of peer-influence exit tactics, the proportion of targets who voluntarily exited the organization was greater than the proportion who involuntarily exited. These results suggest that the use of peer-influence exit tactics successfully motivated receivers to leave the organization. The recipients of the peerinfluence exit tactics may have reasoned that it was better for them to voluntarily exit the organization rather than incur the embarrassment or damage to their career by being fired from the organization.

\section{Predictors of Peer-Influence Exit Tactic Use}

Peer coworker relationships may be fraught with competition, drama, jealousy, envy, or violations of trust, and backstabbing (Malone \& Hayes, 2012; Sias, 2006, 2009a). Organizational, personality/communication traits, and interpersonal factors may play a role in the messages and behaviors that organizational members use to influence their peer coworkers to voluntarily exit the organization. Personality traits that could conceivably influence the use of 
peer-influence exit tactics are competitiveness, agreeableness, and self-esteem. These personality traits have frequently been explored as antecedents of both productive (Barrick \& Mount, 1991) and deviant workplace behaviors (Colbert, Mount, Harter, Witt, \& Barrick, 2004). Peer-influence exit tactics could be considered either productive or deviant workplace behaviors, depending on the form that they take. While exploring additional personality traits could provide insight about peer-influence exit tactics, it is reasonable to believe that competitiveness, agreeableness, and self-esteem will be related to the use of peer-influence exit tactics. Organizational factors such as the desire to secure promotions or higher standing in organizations might inspire employees to resort to tactics designed to make the lives of their peer coworkers miserable (Malone \& Hayes, 2012) or to push their coworkers out of the organization. Likewise, the inability to get along with each other or to develop healthy, working relationships may influence pushing coworkers to leave the organization. It is also possible that employees simply want what is best for their peer coworkers and influence them to leave the organization so they will be happy and more satisfied with their personal and professional lives (Cox, 1999). An organizational member may perceive that a valued peer coworker is struggling with the stress of working in an organization that fails to appreciate his/her talents or contributions and as a result suggests that he/she think about leaving the organization as a way to receive the recognition he/she deserves and the happiness sought (Sollitto et al., 2013).

Employees may receive subtle hints or orders from their supervisors to encourage poor performers or troublesome employees to leave the organization. Cox and Kramer (1995) found that managers sometimes drop hints to their subordinates to exit the organization to avoid the complexities involved with firing individuals, or they may solicit help from subordinates in persuading problem employees to exit. Additionally, supervisors might rely upon information 
received from subordinates about poor performers and seek advice from them before they make a decision about firing a poor performer. However, Sollitto et al. (2013) found no relationship between employees' reported leader-member exchange with their supervisors or their integration into the culture of the organization with their communication of peer-influence exit tactics.

Personality/communication traits also influence the use of peer-influence exit tactics. Sollitto et al. (2013) found that the source's Machiavellianism was positively related to his/her use of prosocial and antisocial tactics, suggesting that even when employees use supportive, prosocial messages to influence exit, they may still have an underlying, manipulative reason for doing so. In a subsequent study, Sollitto and Martin (2013) reported that employees who were more verbally aggressive and indirectly aggressive were more likely to use antisocial peerinfluence exit tactics.

Interpersonal factors, such as relationship type and feelings of workplace jealousy and envy, are also associated with the use of peer-influence exit tactics. Sollitto and Martin (2013) found that employees with information peer relationships reported more frequent use of antisocial peer-influence exit tactics than employees with collegial peer relationships. Employees with special and collegial peer relationships reported more use of prosocial tactics than employees with information peer relationships.

Regarding workplace jealousy and envy, Sollitto et al. (2014) found that when employees were more jealous of their peer coworkers, they were more likely to use prosocial and antisocial peer-influence exit tactics. It appears that the quality of relationship that employees report having and their communication characteristics play a role in the tactics they use to encourage their peer coworkers to exit the organization. Overall, these results have provided a glimpse into 
the organizational, personality/communication traits, and interpersonal factors that may drive the communication of peer-influence exit tactics.

\section{Statement of the Problem}

Organizational communication scholars have recently begun to better understand organizational exit through studying phenomena such as how organizational members frame their departure during exit interviews (Gordon, 2011), how they gradually disengage from their coworkers, roles, and organizations (Davis \& Myers, 2012), and how they adjust to retirement (Smith \& Dougherty, 2012). However, few of these studies have explicitly explored the communication that takes place between organizational members and their peer coworkers during organizational exit. In addition to research on peer-influenced exit having implications for organizational communication scholars, this research also has implications for organizations.

A variety of individuals affiliated with the organization can benefit from knowledge about peer-influence exit. First, because the use of peer-influence exit tactics could harm the organization (e.g., by pushing out valued employees) and/or its employees (e.g., by obstructing employees' abilities to perform tasks, by causing emotional distress), information about this topic would help organizational decision-makers to prevent or remedy such outcomes. Realizing the reasons why and the tactics that are used can help managers retain their valued organizational members and discipline other members who act in ways that are incongruent with the organization's goals, missions, or values. Second, employees may use the knowledge gained from this study to reassess their work performance, relationships with key decision makers, and ability to conform to organizational standards, as these may impact the receipt of peer-influence exit tactics. They could then adjust their behavior accordingly. 
Given that peer coworker relationships represent an important presence in both the personal and professional lives of organizational members (Sias \& Cahill, 1998; Sias et al., 2012), it would be reasonable to believe that organizational members openly discuss their exit intentions with one another. Likewise, it is reasonable to assume that organizational members also persuade their peer coworkers to voluntarily depart from the organization for a variety of reasons. Initial work on the role that organizational members play in affecting the voluntary exit of their peer coworkers conducted by Cox and Kramer (1995) revealed that supervisors advise certain subordinates to influence problematic workers to quit their jobs to avoid being punished or terminated. In addition, Cox (1999) developed a list of behavior-based and message-based strategies that organizational members use to encourage their peer coworkers to leave. This research served as the basis for the work conducted by Sollitto and colleagues (Sollitto et al., 2014; Sollitto \& Martin, 2013; Sollitto et al., 2013). They focused on developing a profile of the organizational member who uses peer-influence exit tactics.

Although the initial research has been helpful in learning about organizational exit in greater detail, more questions remain about the construct of peer-influenced exit. Researchers must consider the motives that organizational members report for engaging in peer-influence exit tactics. Such understanding can help researchers determine if peer-influence exit tactics are more likely to occur due to the source's or receiver's characteristics. Also, examining how organizational influences relate to the use of peer-influence exit tactics can provide detail about the contextual features of the organization and how they play a role in such behavior. Each organization has its own distinct culture and climate, as such, it is those distinct features of organizations that likely influence the use of peer-influence exit tactics. Therefore, the purpose of this dissertation is to develop greater understanding of peer-influence exit by exploring the 
factors that affect it, including sources' motives and traits, the targeted peer coworker's characteristics, and the features of the organization in which the source and target work.

Three studies were conducted to continue exploration of the construct of peer-influenced exit. The first study involved collecting qualitative data to elicit information about why and how organizational members encourage their peer coworkers to voluntarily exit. Data from that study also served as a foundation for creating a new measure of peer-influence exit tactics and a measure to assess the motives for engaging in peer-influence exit tactics. The second study used an experimental design in which participants were presented with scenarios depicting variations on an organizational characteristic and target characteristic. Participants were asked to report the peer-influence exit tactics they would use with the coworkers in the scenarios, as well as other information. The third study incorporated a cross-sectional design in which working adults were surveyed and their responses used to examine the relationships among peer-influence exit tactics and source characteristics, receiver characteristics, and organizational influences.

\section{Rationale, Hypotheses, and Research Questions}

\section{Peer-Influence Exit Tactics}

Organizational members use a variety of strategies and tactics to encourage their peer coworkers to voluntarily exit the organization. Cox (1999) found that organizational members use both message-based and behavior-based messages to influence their peer coworkers to leave. Additional research by Sollitto et al. (2013) suggested that organizational members use prosocial and antisocial tactics with their peer coworkers. These efforts have provided an initial framework for exploring the form that peer influence exit takes, but it is unclear if those are the only ways that organizational members encourage their peer coworkers to voluntarily exit. To 
learn more about the types of messages and/or behaviors organizational members use, the following research question was proposed:

RQ1: What types of messages and/or behaviors do organizational members use to encourage a peer coworker to voluntarily leave the organization?

\section{Peer-Influence Exit Tactics' Sources’ Motives}

Cox (1999) reasoned that organizational members seek to achieve their latent goals by encouraging their peer coworkers to voluntarily exit. His assertion was based on his research findings about how organizational members push incompetent coworkers out of the organization so that they avoid being fired. Therefore, one thing that may motivate organizational members to use peer-influence exit tactics is the desire to improve the efficiency, productivity, or performance of the organization. The existence of problematic performers could severely stifle the competitiveness of the organization. Organizational members might encourage their peer coworkers to exit the organization because they want to see the organization succeed and think that eliminating problematic performers will make that happen. Specifically, organizational members might desire to see increased efficiency with which the organization produces goods, exchanges information, or provides service to their customers. By ridding themselves of problematic peer coworkers, they may believe the organization would be in a better position to thrive.

Organizational members might also engage in peer-influence exit tactics to improve their personal standing in the organization by achieving more powerful positions. Individuals often enter their organizations with hopes and dreams of advancing up the organizational hierarchy, rising to positions of power, and earning a respectable wage for the work that they perform (Granrose \& Portwood, 1987). Targeted peer coworkers could be seen as an obstacle to the 
achievement of organizational members' professional goals, thus making them susceptible to peer-influence exit tactics by individuals who are hungry for recognition, promotions, and privileged positions. Members might also seek improved relationships with their supervisors, as that could guarantee them preferred assignments, greater autonomy, and more perks (Graen \& Uhl-Bien, 1995). Developing relationships with other knowledgeable and powerful people in the organization's social network is also a key consideration for organizational members (Shumate \& Contractor, 2014) who hope to use these relationships to obtain positions that would allow them to make decisions and distribute orders (Ibarra \& Andrews, 1993). It seems reasonable that some organizational rewards and benefits become easier to achieve when certain individuals no longer stand in the way.

Similarly, seeing other members rise to prominence, develop quality relations with supervisors, or hold privileged positions within the organization could spark jealousy (Vecchio, 2000). Feelings of jealousy are positively related to the use of peer-influence exit tactics (Sollitto et al., 2014). The appeal of power and prestige in the organization can also influence the way in which individuals attempt to gain power (Aquino, Tripp, \& Bies, 2005). The aspiration for promotions, authority, and powerful connections could potentially lead organizational members to achieve their goals through underhanded or socially inappropriate methods, such as by influencing others to depart from the organization.

Organizational members might also desire to see a beleaguered colleague find a more rewarding career or occupation. Seeing that their peer coworkers are perpetually unhappy, unproductive, or frustrated might create an opportunity for organizational members to encourage them to find more fulfilling job opportunities. Cox (1999) found that some organizational members provided assistance and support to their peer coworkers as a strategy to influence their 
voluntary exit. Those organizational members may have simply wanted their peer coworkers to be happy with their careers and to find organizations that they believed would allow them to fulfill their professional goals and to find personal satisfaction.

Organizational members may also be motivated to encourage their peer coworkers to exit because they desire a more supportive and collegial organizational climate. Certain individuals possess characteristics or behave in ways that disrupt the climate of the organization (Fritz, 2002). Individuals who create a toxic environment could actually decrease the productivity and satisfaction of organizational members (Fritz \& Omdahl, 2006). Therefore, organizational members may use peer-influence exit tactics to rid the organization of the destructive presence of disruptive peer coworkers.

Overall, there may be a variety of motives that organizational members have for encouraging their peer coworkers to voluntarily exit, but researchers have yet to develop a comprehensive understanding of what those motives are and how they relate to the likelihood of using peer-influence exit tactics. In an effort to gain increased clarity about the motives that serve as a foundation for organizational members influencing their peer coworkers to leave the organization, the following research questions were proposed:

RQ2: What motives do organizational members have for influencing a peer coworker to voluntarily leave the organization?

RQ3: What is the relationship between organizational members' motives for influencing a peer coworker to voluntarily leave the organization and the use peer-influence exit tactics? 


\section{Peer-Influence Exit Tactics' Sources' Characteristics}

Personality traits such as competitiveness, agreeableness, and self-esteem could influence the use of peer-influence exit tactics. Individual characteristics of organizational members can have a major effect on their performance, level of organizational adjustment, and the relationships they form with their coworkers (Gardner, Reithel, Cogliser, Walumba, \& Foley, 2013; George, 1992; Jones, 1986). Thus, they are also likely to influence the enactment of peerinfluence exit tactics.

Competitiveness refers to a personality characteristic representing the intense desire to compete and defeat others through any personal or professional cost in order to enhance feelings of self-worth (Ryckman, Hammer, Kaczor, \& Gold, 1990). Competitive individuals are greatly concerned with defeating others, regardless of the context (Mowen, 2004). Competitiveness tends to be a positive predictor of employee performance (Karatepe, Uludag, Menevis, Hadzimehmedagic, \& Baddar, 2006), self-set goals in the organization (Brown, Cron, \& Slocum, 1998), and job dedication (Fletcher et al., 2008).

Organizational members who are competitive constantly want to improve themselves and see life events as games in which there are clear winners and losers (Mowen, 2004).

Consequently, competitive organizational members would be likely to use peer-influence exit tactics because they are concerned with winning more privileged positions, assignments, and rewards in the organization at the expense of their peer coworkers. Competitiveness likely influences the use of peer-influence exit tactics utilized because competitive organizational members want to achieve their goals regardless of the costs associated with their behavior (Mowen, 2004). Thus, they are expected to use any tactic necessary to encourage their peer coworkers to voluntarily exit, as long as it causes the peers to exit. To understand more about 
the relationship between competitiveness and the use of peer-influence exit tactics, the following hypothesis was proposed:

H1: The source's competitiveness will be related to the use of peer-influence exit tactics. Agreeableness refers to being likable and cooperative (John \& Srivastava, 1999; McCrae \& Costa, 1999). Organizational members who report high levels of agreeableness tend to prefer cohesive and supportive organizations (Judge \& Cable, 1997) as opposed to organizations that are rigid and competitive (Gardner et al., 2013). They also report higher levels of job performance than less agreeable organizational members (Witt, Burke, Barrick, \& Mount, 2002). Agreeableness tends to negatively relate to verbal aggressiveness (Tremblay \& Ewart, 2005), which is positively associated with the use of antisocial peer-influence exit tactics (Sollitto \& Martin, 2013). Due to their amicable nature, agreeable organizational members might be content working with problematic peer coworkers, and refrain from actively encouraging them to exit the organization. On the other hand, agreeable organizational members might desire a work environment that is more conducive to high-quality relationships. However, when agreeable organizational members decide that they want to see a peer coworker exit the organization, they likely rely on more supportive or prosocial tactics rather than antisocial tactics because they tend to value the relationships that they have with their coworkers. The following hypothesis was proposed to address the relationship between agreeableness and peer-influence exit tactics:

H2: The source's agreeableness will be related to the use of peer-influence exit tactics. Self-esteem is defined as the perception that individuals hold of themselves being capable, worthy, and significant (Rosenberg, 1965). Self-esteem tends to be positively related to a variety of organizational outcomes, such as job satisfaction, motivation, performance, and citizenship behavior (Judge \& Bono, 2001; Pierce \& Gardner, 2004). Robins, Hendin, and 
Trzesniewski (2001) found that self-esteem was also positively associated with workgroup effectiveness and the ability to stay on task.

The relationship between self-esteem and peer-influence exit tactics is unclear. Organizational members who report high levels of self-esteem likely feel confident in their abilities and their standing in the organization, and as a result, may encourage a peer-coworker who is disruptive or performing poorly to leave. This might occur because they are adamant in their beliefs about how the organization should operate. Individuals with low self-esteem might be insecure about their positions in the organization, thus making them more likely to use peerinfluence exit tactics to push out their competition. Furthermore, organizational members who report high levels of self-esteem might be unconcerned with the behaviors of their peer coworkers because they are confident in their own ability to perform well, regardless of the behavior of their peer coworkers. Self-esteem may also affect the use of peer-influence exit tactics in that organizational members with high self-esteem could use more prosocial or supportive tactics because they are concerned about the welfare of their colleagues and perform behaviors to ensure their well-being (Bowling, Eschleman, Wang, Kirkendall, \& Alarcon, 2010). Conversely, people with high self-esteem may use antisocial tactics because they are comfortable with themselves and may have little concern about the repercussions of their behavior. To explore these possibilities between self-esteem and peer-influence exit tactics, the following research question was proposed:

RQ4: What is the relationship between the source's self-esteem and the use of peerinfluence exit tactics?

Researchers have also yet to explore the relationship between sources' personality traits and their motives for using peer-influence exit tactics. However, it seems likely that personality 
traits affect the motives organizational members have for encouraging their peer coworkers to voluntarily exit. Agreeable organizational members may want their peer coworkers to leave the organization because they simply want them to find more fulfilling work opportunities or to improve the quality of the organization. Competitive organizational members may encourage their peer coworkers to leave because they see them as obstacles to the goals they want to achieve. Thus, removing the obstacle provides them a better opportunity to succeed and achieve their goals. The following research question addresses the relationship between organizational members' motives for enacting peer influence exit tactics and their personality traits:

RQ5: What is the relationship between the source's personality traits (i.e., competitiveness, agreeableness, and self-esteem) and the source's motives for influencing a peer coworker to voluntarily leave the organization?

\section{Peer-Influence Exit Tactics' Targets' Characteristics}

(Dis) similarity is a salient reason why individuals become the target of destructive behavior in their organizations (Harvey et al., 2006; Sias, 2012). Sias (2012) argued that targets of exclusion are often organizational members who are perceived to be dissimilar from the source and who are unable to speak the preferred or proprietary language of the organization. This dissimilarity can become particularly important in organizational cultures in which conformity among members and adherence to strict rules are valued (Barker \& Cheney, 1994). Furthermore, Fritz (2002) found that peer coworkers tend to be disliked and labeled as troublesome because they possess different styles of communicating, working, conducting business, and treating people. Individuals who are dissimilar from others in the organization are particularly vulnerable to attacks on their character and their performance (Kassing \& Waldron, 
2014). Thus, coworkers who simply look, act, and work differently than other organizational members might be targeted for receiving peer-influence exit tactics.

Given that Sias (2012) stated that dissimilarity is one reason that the antisocial act of exclusion occurs, it seems possible that when the targets of peer-influence exit tactics are perceived as different or dissimilar from the source, the source will utilize more aggressive or antisocial forms of peer-influence exit tactics. Likewise, organizational members will likely feel more empathy for peer coworkers who are similar to them (Richardson et al., 2008) and would be more likely to refrain from using antisocial tactics with them. Instead, those feelings of empathy might lead to the use of more socially appropriate tactics with similar coworkers. Subsequently, the source's similarity to the target should be related to both the use of peerinfluence exit tactics. Thus, the following hypothesis was proposed:

H3: The source's perceived similarity with the target of peer-influence exit tactics will be related to the use of peer-influence exit tactics.

Work performance is another reason why employees might be the recipient of peerinfluence exit tactics. Fritz (2002) found that peer coworkers are often disliked because they are perceived to be incompetent, perform work incorrectly, and lie about their accomplishments. Organizational members can often behave in uncivil or destructive ways with people that they determine to be poor performers or who are generally disliked (Fritz, 2012; Kassing \& Waldron, 2014). Furthermore, given the emphasis on production and efficiency in contemporary organizations (Sias et al., 2012), the inability to perform work according to organizational standards might make certain organizational members particularly susceptible to receiving peerinfluence exit tactics. 
On the other hand, organizational members might refrain from utilizing peer-influence exit tactics because they genuinely want to help their coworkers become better workers (Allen \& Finklestein, 2003). They also may know that the targeted coworkers will eventually be fired due to their inability to adequately perform their work (Cox \& Kramer, 1995). Coworkers might bide their time until authority figures notice the lack of competence and terminate the peer without them becoming personally involved. Because the association between target performance and the use of peer-influence exit tactics is unclear, the following research question was proposed:

RQ6: What is the relationship between the source's perception of the work performance of the peer-influence exit target and the use of peer-influence exit tactics?

Liking/social attraction is a strong predictor of relationship initiation and subsequent friendship development (Sias \& Cahill, 1998). It may also be related to the use of peer-influence exit tactics. Typically, when organizational members like their coworkers they care about their well-being and want them to succeed (Sias, 2009). In general, liking is expected to be negatively related to the use of peer influence exit tactics because organizational members should have no desire to encourage people they like to voluntarily exit.

However, when liked coworkers are dissatisfied, peers likely engage in peer-influence exit tactics to persuade unhappy employees to find employment elsewhere in order to be happier. Due to their positive affect for the employee, coworkers are likely to use prosocial peer influence exit tactics to encourage them to exit. Consistent with this logic, Sollitto and Martin (2013) found that when organizational members reported that the targets of their peer-influence exit tactics were special or collegial peers, they used prosocial tactics to encourage them to leave the organization. Sollitto and Martin reasoned this occurred because the source of the peer-influence 
exit tactics liked his/her peer coworker and wanted him/her to succeed in a different organization in which he/she would be happier. Conversely, Sollitto and Martin discovered that when organizational members reported that the targets of their peer-influence exit tactics were information peers, they used antisocial tactics. This result suggested that when organizational members liked their peer coworkers less, they were less considerate in the things they did to encourage them to leave. To develop a better understanding of the association between liking/social attraction and the use of peer-influence exit tactics, the following hypothesis was proposed:

H4: The source's liking of the peer-influence exit target will be related to the use of peer influence exit tactics.

The target's organizational influence may be another reason why he/she receives peerinfluence exit tactics. Salin (2003) argued that employees who are perceived to possess considerable influence in the organization could also be targets of hostile and aggressive behavior. Similarly, organizational members who are perceived to be the recipients of undeserved preferential treatment could find themselves ostracized from the workgroup and treated as social pariahs (Sias \& Jablin, 1995). To that end, organizational members may target coworkers whom they perceive to have influential relationships with authority figures in the organization. By removing a coworker with considerable clout and influence, attainment of personal organizational goals may be more likely to occur (Salin, 2003). Because the desire for power is a likely motive of peer influence exit tactic use, employees may encourage influential employees to leave the organization because they pose a threat to the achievement of the source's personal and professional goals. 
It is also possible that the organizational influence of the target could influence the type of peer-influence exit tactics used by the source. Organizational members who see that their peer coworkers have considerable influence in the organization might behave in hostile or antisocial ways toward them to persuade them to leave because they believe the influence of their peer coworker is undeserved. In contrast, individuals who engage in destructive organizational behavior tend to be politically skilled (Kassing \& Waldron, 2014; Salin, 2003). Thus, it would be reasonable to believe that politically skilled organizational members who want their peer coworkers to leave would use prosocial peer-influence exit tactics because they realize that repercussions for any overtly negative behavior could occur. To account for these possibilities, the following hypothesis was proposed.

H5: The source's perceptions of the target's organizational influence will be related to the use of peer-influence exit tactics.

The relationship between peer-influence exit target characteristics and sources' motives for encouraging their peer coworkers to leave the organization is unclear. The characteristics of the receiver, such as degree of similarity with the source, performance, social attractiveness, and organizational influence, could all be associated with the reasons why organizational members want to push them out of the organization. For example, when the target possesses characteristics that are dissimilar from the source, the source may be motivated to use peerinfluence exit tactics because he/she wants the organization to succeed, and the dissimilarity of the target decreases the opportunity for that success to occur. Also, when the targets are disliked or possess considerable influence, organizational members might be motivated to encourage them to leave because they want a more harmonious working environment or because they want 
fewer obstacles to achieving their pursuit of power and prestige. To account for these possibilities, the following research question was proposed:

RQ7: What is the relationship between the source's perceptions of the target's similarity, work performance, liking, and organizational influence and the source's motives for influencing a peer coworker to voluntarily leave the organization?

\section{Organizational Characteristics}

Organizational cultures represent patterns of behavior, interaction, and values held by organizational members (Glaser, Zamanou, \& Hacker, 1987). They are a set of artifacts, values, and assumptions that are constructed by organizational members and subsequently guide their behavior (Keyton, 2011). Because organizational culture affects the behavior and communication of organizational members (Keyton, 2014), it is likely that it impacts the use of peer-influence exit tactics. Supporting the link between organizational culture and peer-influenced exit, Sias (2012) argued that the social context is a significant contributor to exclusion, which could lead to turnover (Kassing \& Waldron, 2014).

An important component of organizational culture is teamwork, the ability for organizational members to work together as a cohesive unit, engage in open and honest communication, and cooperate with one another (Glaser et al., 1987). Organizational members report more congruency between their personal standards and organizational standards when their organizational cultures are more conducive to interpersonal rapport (Gardner et al., 2013).

The link between teamwork and the use of peer-influence exit tactics is unclear because it seems that higher levels of teamwork could influence greater use of discipline or punishment of peer coworkers who fail to uphold organizational values (Barker \& Cheney, 1994). Therefore, stronger teamwork could increase the likelihood of organizational members encouraging those 
who fail to conform to voluntarily exit. Conversely, higher levels of teamwork could lead organizational members to be content and work with one another to achieve the best results for the organization, thus making the use of peer-influence exit tactics less likely. To better understand the link between teamwork and the use of peer-influence exit tactics, the following research question was proposed:

RQ8: What is the relationship between the source's perceptions of organizational teamwork and the use of peer-influence exit tactics?

Organizational climate refers to organizational members' perceptions of communication or the work environment (Jablin, 1980). Climate differs from organizational culture in that organizational climate represents a description of what occurs for organizational members, whereas organizational culture represents the reasons why events and patterns of behavior exist (Patterson et al., 2005). But like organizational culture, climate greatly influences the behavior of organizational members (Zummuto, Gifford, \& Goodman, 2000), and therefore, likely impacts peer-influenced exit.

The relationship between organizational climate and the use of peer-influence exit tactics is important to consider. Perceptions of organizational climate predict a variety of communication outcomes, such as the quality of peer coworker relationships (Odden \& Sias, 1997), level of certainty about organizational events (Clampitt \& Williams, 2005), and the expression of organizational dissent (Kassing, 2008). Furthermore, organizational climates that are unsupportive or hostile may lead to exclusion (Sias, 2012), backstabbing (Malone \& Hayes, 2012), low levels of organizational commitment (Fletcher, Major, \& Davis, 2008), and eventual departure from the organization (Buttner, Lowe, \& Billings-Harris, 2010). 
The perceptions of autonomy, welfare of organizational members, formalization of procedures, effort of organizational members, and pressure to produce represent key dimensions of organizational climate that affect the performance and behavior of organizational members (Patterson et al., 2005). Autonomy refers to the perception that organizational members have opportunities to make their own decisions. Welfare refers to the perception of how caring the organization is to its members. Formalization is the perception of how important it is for organizational members to follow strict rules and procedures. Effort is the perception of the level of exertion organizational members expend in their work roles. Pressure to produce is the degree to which organizational standards are demanding. Researchers have yet to consider the effect of organizational climate on the use of peer-influence exit tactics. However, it is conceivable that organizational members' perceptions of organizational climate will be related to the use of peer-influence exit tactics. To develop a better understanding of how organizational climate influences the use of peer-influence exit tactics, the following research question was proposed:

RQ9: What is the relationship between the source's perceptions of organizational climate and the use of peer-influence exit tactics?

Organizational justice could also influence the use of peer-influence exit tactics. Organizational justice refers to the perceptions that organizational members possess regarding their treatment in the organization and the fairness of decisions made by authority figures (Colquitt et al., 2001). Perceptions of organizational justice influence the affective and behavioral responses of organizational members, and are expected to relate to peer-influenced exit. In their meta-analysis, Colquitt and colleagues (2001) found that employees who perceived their organizations as just and fair tended to report more job satisfaction, commitment, and 
higher work performance. Chory and Hubbell (2008) discovered that when organizational members perceived fair and equitable treatment they were less likely to engage in antisocial communication and behaviors such as indirect interpersonal aggressiveness, hostility, obstructionism, and deception.

Additionally, when organizational members treat their coworkers fairly, they work better as a unit and report greater levels of production (Cropanzano, et al., 2011). However, when organizational members perceive low levels of organizational justice it has adverse effects on the organization, such as organizational members sabotaging and misleading their coworkers (Cohen-Charash \& Mueller, 2007; Malachowski et al., 2012). Given that injustice could lead to antisocial behavior in the organization (Cohen-Charash \& Mueller, 2007), it seems reasonable that perceptions of organizational justice could affect the use of peer-influence exit tactics.

According to Equity Theory, individuals behave in ways that allow them to create more balance in their relationships with their organizations and coworkers (Adams, 1965; Walster, Berscheid, \& Walster, 1973). Employees might respond to perceptions of injustice or being underbenefitted in their relationships with aggression because they believe that the aggression will allow them to even the balance with their coworkers. The research by Cohen-Charash and Mueller (2007) suggests a link between perceptions of unfairness and antisocial behavior in the workplace congruent with Cox's (1999) findings about the strategies employees use to encourage voluntary exit. For example, behaviors found in Cox's study (1999), such as restricting information, disparaging others, and behaving in hostile and unfriendly ways toward peer coworkers, may be a response to perceptions of injustice in their organizations or with their peer coworker, and an attempt to achieve greater balance. Thus, it seems evident that perceptions of organizational justice would be associated with the use of peer-influence exit tactics. To develop 
a better understanding of how the perception of organizational justice is associated with the use of peer-influence exit tactics, the following hypothesis was proposed:

H6: The source's perceptions of organizational justice will be related to the use of peerinfluence exit tactics.

Job satisfaction is an affective component of the organizational environment that could be associated with the use of peer-influence exit tactics. Hackman and Oldman (1975) defined job satisfaction as the degree to which organizational members are happy with their jobs. As one of the most explored constructs in organizational literature (e.g., Iaffaldano \& Muchinsky, 1985), job satisfaction has been related to numerous organizational constructs such as the relational maintenance behaviors of peer coworkers (Madlock \& Booth-Butterfield, 2012), coworker relationship quality (Allen, 1996; Sias, 2005), information quality (Scott et al., 1999), and the level of certainty about peer coworkers and leaders (Kramer et al., 2013). Given that satisfaction tends to be positively related to organizational outcomes such as identification (Kramer et al., 2013) and negatively related to propensity to leave (Scott et al., 1999) one would expect that satisfied organizational members would be content with their work relationships and experiences. However, the relationship between satisfaction and the use of peer-influence exit tactics is unclear. To develop a better understanding of how the source's job satisfaction is associated with the use of peer-influence exit tactics, the following research question was proposed:

RQ10: What is the relationship between the source's job satisfaction and the use of peerinfluence exit tactics?

Coworker regard is reflected in Luhtanen and Crocker's (1992) definition of public collective self-esteem, which they defined as an individual's judgments of how other people 
evaluate him/her. In the organizational context, this reflects an organizational member's perceptions regarding his/her coworkers' judgments and evaluations of him/her (Butler \& Constantine, 2005). While relatively few studies have been conducted regarding public collective self-esteem in the organizational context, it has been related to low levels of burnout (Butler \& Constantine, 2005). Furthermore, Crocker and Luhtanen (1990) found that individuals with higher collective self-esteem tended to make biased assessments of their social groups when their collective identities were threatened. This could mean that organizational members may use peer-influence exit tactics with peer coworkers who threaten their membership with certain social segments in the organization. If organizational members feel threatened or harshly evaluated by their peer coworkers, they could react with attempts to encourage them to exit the organization. To assess the relationship between coworker regard and the use of peer-influence exit tactics, the following research question was proposed:

RQ11: What is the relationship between the source's perceptions of coworker regard and the use of peer-influence exit tactics?

Supervisor complicity is another characteristic of the organizational environment that may affect the likelihood of using peer-influence exit tactics. Cox and Kramer (1995) found that supervisors sometimes approach their subordinates about poor-performing employees, and instruct them to encourage the poor-performing organizational members to voluntarily exit. Supervisors use this tactic to avoid the legal hassle and drama associated with terminating employees (Cox \& Kramer, 1995). Supervisors might also wish to avoid uncomfortable interactions with poor-performing organizational members, and thus, conspire with their subordinates to affect the departure of these employees. 
Organizational members may also desire to improve or maintain the relationships they have with their supervisors, and engage in peer-influence exit tactics as a way to ensure that the status of their relationships improve or remain unchanged. Thus, supervisor complicity should be related to the use of peer-influence exit tactics. To better understand the relationship between supervisor complicity and the use of peer-influence exit tactics, the following hypothesis was proposed:

H7: The source's perceptions of supervisor complicity will be related to the use of peerinfluence exit tactics.

Additionally, the characteristics of the organization, such as culture, climate, organizational justice, and supervisor complicity could influence the motives organizational members have for encouraging their peers to voluntarily exit. Organizational characteristics tend to be important predictors of communication behaviors (Keyton, 2014; Zummuto et al., 2000), and thus, may impact the goals that organizational members want to achieve by pushing their peers coworkers to exit. For example, if the organizational culture is characterized by low levels of teamwork or if the organizational climate is hostile, organizational members may be motivated to use peer-influence exit tactics because in those types of environments it is acceptable to achieve goals through any means necessary. If organizational members perceive low levels of justice, they may be motivated to use peer-influence exit tactics to create more balance in their relationships with the organization, and they can do that by encouraging their peer coworkers to leave. Moreover, supervisor complicity could affect organizational members' motives in that they want to impress their supervisors and help them achieve greater levels of organizational success. To gain greater clarity about how organizational characteristics affect the motives for using peer-influence exit tactics, the following research question was proposed: 
RQ12: What is the relationship between the source's perceptions of his/her organization's characteristics (i.e., organizational culture, climate, justice, job satisfaction, coworker regard, and supervisor complicity) and the source's motives for influencing a peer coworker to voluntarily leave the organization?

\section{Planning of Peer-Influence Exit Tactics}

Although studies have shown that organizational members use peer-influence exit tactics, more information needs to be gathered about the intentionality of their use. According to Goals, Plans, Actions Theory, individuals seek to achieve their goals by planning their behavior, and then enacting their planned behavior (Dillard, 1990). Berger (1997) argued that when people have the desire to see an event transpire in interpersonal interactions, they develop goals for the event, and then begin planning the process through which that event will reach fruition. These goals provide meaning to human action and serve as the foundation for human behavior (Dillard, Segrin, \& Harden, 1989). Dillard (1990) argued that whenever individuals engage in the action of persuading others, it is purposeful action that requires agency and awareness. Consistent with this logic, organizational members who desire to see a peer coworker voluntarily exit will likely plan their actions to achieve their desired goal. In other words, it can be expected that, as in other persuasive situations, individuals plan their use of peer-influence exit tactics.

Plans can vary based on the situation encountered, activated goals, and previously engrained plans (Dillard, 2008). According to Berger and diBattista (1993), plans are hierarchically arranged from less to more complex and more important goals should lead to greater planning. After planning their approach, individuals put their plans into action to achieve their desired results (Dillard, 1990). The goals and the rewards associated with the situation are likely to determine whether direct confrontation is appropriate or necessary (Henningsen, Valde, 
\& Debow, 2013). Though it is reasonable to conclude that peer-influence exit tactics are intentionally used, more research needs to be conducted to investigate this claim. Therefore, the following research question was proposed:

RQ13: To what extent do sources consciously plan their use of peer-influence exit tactics?

\section{Effectiveness of Peer-Influence Exit Tactics}

Peer-influence exit tactics are designed to persuade peer coworkers to voluntarily leave the organization. Sollitto et al. (2014) found that a greater proportion of peer-influence exit tactic targets voluntarily exited the organization than involuntarily exited. However, no data were obtained to determine if the targets exited as a result of receiving peer-influence exit tactics or if they exited due to other reasons. Researchers have yet to fully grasp how successful the tactics truly are in achieving their desired outcome. Questions remain about whether peer- influence exit tactics cause voluntary exit or if perhaps employees rationalize leaving their organizations by attributing their departures to receiving peer-influence exit tactics. Specifically, it is unknown to what extent organizational members voluntarily leave the organization after being the recipient of peer-influence exit tactics. Thus, the following research question was proposed:

RQ14: How effective are peer-influence exit tactics in encouraging peer coworkers to voluntarily leave the organization? 


\section{CHAPTER II: METHOD}

\section{Study 1 Method}

\section{Participants and Procedures}

Data for Study 1 was collected via an online questionnaire. Individuals over the age of 18 and employed full-time (worked more than 35 hours a week) were recruited for the study through four methods. First, undergraduate students enrolled in courses at a large Mid-Atlantic university were asked to recruit friends, parents, and/or relatives to participate. Students were provided paper flyers containing information about the study and the email address of the lead author. Individuals recruited for the study were instructed to email the researcher to receive an internet link to the online questionnaire housed on www.surveymonkey.com. Upon receipt of the email, the researcher thanked the individual for agreeing to participate in the study and sent him/her a link to the online questionnaire. Second, participants were recruited by the researcher, who solicited participation from his interpersonal contacts through emails and a Facebook posting containing the internet link to the questionnaire. The researcher also asked the individuals he contacted to pass along the link to anyone they thought would be interested in participating in the study. Third, an explanation of the study and the link to the online questionnaire were posted on the university's intranet system. Interested individuals who met the inclusion criteria participated by clicking the link, which took them directly to the questionnaire. Fourth, an explanation of the study and the link to the online questionnaire were posted on Amazon's Mechanical Turk (www.mtruck.com; Amazon Mechanical Turk, 2014). Amazon’s Mechanical Turk is an open online marketplace consisting of over 100,000 individuals from a variety of countries who perform tasks for requesters in exchange for monetary rewards (Buhrmester, Kwang, \& Gosling, 2011). Interested individuals who met the inclusion criteria 
participated by clicking the link which took them to the questionnaire. Upon completing the questionnaire, individuals were paid $\$ 0.35$ for their work.

Participants included 205 full-time working adults drawn from a variety of organizations. The sample was composed of 107 men (52\%), 86 women (42\%), and 12 unidentified (6\%). Participants ranged in age from 19 to $67(M=32.38, S D=9.67)$ years. Ethnicity of participants included Caucasian/White $(n=74,36 \%)$, Asian American/Asian $(n=88,43 \%)$, Native American $(n=12,6 \%)$, African American/Black $(n=9,4 \%)$, Hispanic/Latino $(n=5,2 \%)$, and 17 unidentified (8\%). Job fields represented in the sample included managerial and professional $(n=87,42 \%)$, technical, sales, and administrative support $(n=65,32 \%)$, service occupations $(n$ $=22,11 \%)$, precisions production, craft, and repair $(n=10,5 \%)$, operators, fabricators, laborers $(n=6,3 \%)$, and 15 unidentified job fields (7\%). Length of employment ranged from 1 to 384 months $(M=58.12, S D=67.44)$ and the mean number of hours worked per week was $42.60(S D$ $=10.45)$.

\section{Instrumentation}

Participants were asked to respond to several open-ended questions pertaining to communication and behaviors toward targeted coworkers, peer-influence exit tactics, motives, characteristics of the target, tactic success, planning involved in encouraging peer coworkers to leave the organization, and demographic information. Appendix C contains the open-ended items for Study 1. Prior to completing the open-ended questions, participants were presented with the following instructions:

"Think of your past work experiences, jobs, organizations you've worked for. From among all those experiences, think of a peer coworker (someone at your same job level, not a superior or subordinate) you want(ed) to leave the organization, quit, transfer, etc. In other words, think of a peer you work(ed) with whom you wish(ed) would leave your organization." Please write the first name of this peer coworker here 
The open-ended data were used to discover the motives organizational members have for encouraging their peer coworkers to voluntarily exit, the tactics they use to affect it, the intentionality of the messages and/or behaviors, and the effectiveness/success of the messages and/or behaviors. The data were also used to develop measures regarding the motives for using peer-influence exit tactics and the specific peer-influence exit tactics used to encourage peer coworkers to voluntarily exit. The entire questionnaire for Study 1 appears in Appendix E.

\section{Data Analysis}

Using a grounded theory approach, data analysis proceeded through two stages. As suggested by Strauss and Corbin (1998), a constant comparative method of data analysis was used to develop a thorough understanding and firm grasp of the categories represented in the qualitative data. First, the data were analyzed to create inductively derived typologies regarding the motives, tactics, and plans that organizational members report for encouraging their coworkers to voluntarily exit. The unit of analysis included each response by participants that indicated unique themes. The researcher open-coded initial responses and developed a code book for the variables of motives for wanting a peer to exit, peer-influence exit tactics, intentionality of use of the tactics, and success/effectiveness of tactics. The themes were derived from common statements and examples expressed by participants. Once a series of statements or responses from participants was determined to share conceptual overlap with other statements, they were grouped together and given a label. Labels were altered if a more encompassing term could be used to describe the emergent themes. Second, the researcher and an undergraduate student research assistant unfamiliar with the purpose of the research each independently coded $20 \%$ of the data using the previously created codebook. Any discrepancies in coding were discussed between the researcher and the assistant, and resolved through mutual agreement. 
Intercoder reliability using Scott's pi was computed for each variable. Scott's pi was .89 for motives, .81 for tactics, .91 for intentionality, and .90 for success/effectiveness of tactics. The researcher then coded the remainder of the data into the previously identified categories.

Many of the research questions and hypotheses were analyzed through more than one statistical procedure, given the different studies and forms of data. Research questions 1, 2, 13, and 14 were answered in Study 1. To answer research question one, which asked what types of messages and/or behaviors do organizational members use to encourage a peer coworker to voluntarily leave the organization, data were analyzed from two items on the questionnaire. One question asked "once you realized you wanted [Peer name] to leave the organization, describe how you (have) behaved toward and/or communicated with [Peer name].” The other question asked "do/did you do or say anything to [Peer name] try to get [Peer name] to leave the organization? Describe what you do/did to encourage [Peer name] to leave the organization." Two questions were used to assess the types of messages and behaviors that organizational members used to provide richer detail about how organizational members generally behaved with their peer coworkers they wanted to exit and then specifically how they behaved in an effort to encourage them to voluntarily exit.

To answer research question two, which asked what motives do organizational members have for influencing a peer coworker to voluntarily leave the organization, data were analyzed from three items on the questionnaire. One item instructed participants to "describe [Peer name]." The second item instructed participants to "explain why you wanted(ed) [Peer name] to leave the organization." The third item inquired "why do/did you do or say those things to encourage [Peer name] to leave the organization?" Three questions were used to assess the motives that organizational members had for influencing their peer coworkers to voluntarily exit. 
Each question was asked to provide greater insight into all possible reasons why organizational members would want to encourage their peer coworkers to voluntarily exit the organization.

Following the procedures recommended by DeVellis (2003) and used by scholars in previous scale creation (e.g., Stafford \& Canary, 1991), the responses to the items referenced above were sorted and redundant items discarded. Then using previous research as a guide (e.g., Cox, 1999; Sollitto et al., 2013; 2014), the remaining responses were utilized to create Likert scale items to quantitatively assess motives and peer-influence exit tactics in Studies 2 and/or 3.

To answer research question 13 , which asked "to what extent do sources consciously plan their use of peer-influence exit tactics," responses to the item that asked participants to "describe the thought process behind encouraging [Peer name] to leave" were analyzed. To answer research question 14, which asked "how successful are peer-influence exit tactics in encouraging peer coworkers to voluntarily leave the organization," responses to the item that asked participants to "explain the effect your behavior and/or communication has had on [Peer name]'s decision to leave the organization" was analyzed. Research question 14 was also analyzed using a binomial distribution to determine if the proportion of peer-influence exit tactic targets still employed in the organization and the proportion of targets who exited differed. A binomial distribution was also to determine if the proportion who voluntarily exited and the proportion who involuntarily exited differ. A chi-square test was used to determine if the reasons organizational members exited the organization were evenly distributed among the categories.

\section{Study 2 Method}

\section{Participants and Procedures}

Data for Study 2 was collected via an online questionnaire. Individuals over the age of 18 and employed full-time (worked more than 35 hours a week) in the United States were recruited 
for the study through four methods. First, undergraduate students enrolled in courses at a large Mid-Atlantic university were asked to recruit friends, parents, and/or others to participate. Students were provided paper flyers containing information about the study and the email address of the lead researcher. Individuals recruited for the study were instructed to email the researcher to receive an internet link to the online questionnaire housed on www.surveymonkey.com. Upon receipt of the email, the researcher thanked the individual for agreeing to participate in the study and sent him/her a link to the online questionnaire. Second, participants were recruited by the researcher, who solicited participation from his interpersonal contacts through emails and a Facebook posting containing the internet link to the questionnaire. The researcher also asked the individuals he contacted to pass along the link to anyone they thought would be interested in participating in the study. Third, an explanation of the study and the link to the online questionnaire were posted on the university's intranet system. Interested individuals who met the inclusion criteria participated by clicking the link, which took them directly to the questionnaire. Fourth, an explanation of the study and the link to the online questionnaire were posted on Amazon's Mechanical Turk (Amazon Mechanical Turk, 2014). Amazon's Mechanical Turk is an open online marketplace consisting of over 100,000 individuals from a variety of countries who perform tasks for requesters in exchange for monetary rewards (Buhrmester, Kwang, \& Gosling, 2011). Interested individuals who met the inclusion criteria participated by clicking the link which took them to the questionnaire. Upon completing the questionnaire, individuals were paid $\$ 0.35$ for their work.

Participants included 253 adults working full-time in the United States in a variety of organizations. The sample was composed of 133 men (53\%), 114 women (45\%), and 6 individuals who failed to identify their sex $(2 \%)$. Participants ranged in age from 18 to $70(M=$ 
32.57, $S D=11.06)$ years. Ethnicity of participants included Caucasian/White $(n=171,68 \%)$, Asian American/Asian $(n=38,15 \%)$, African American/Black $(n=17,7 \%)$, Native American $(n=10,4 \%)$, Hispanic/Latino $(n=9,3.5 \%)$, and 8 individuals who failed to identify their ethnicity (2.5\%). Occupational fields represented in the sample included managerial and professional ( $n=87,34 \%)$, technical, sales, and administrative support $(n=83,33 \%)$, service occupations $(n=55,22 \%)$, precision production, craft, and repair $(n=11,4 \%)$, operators, fabricators, laborers $(n=10,4 \%)$, and 7 unidentified job fields $(3 \%)$. Length of employment ranged from 1 to 32 years $(M=5.16, S D=5.36)$ and the mean number of hours worked per week ranged from 35 to $96,(M=43.67, S D=7.62)$.

\section{Experimental Design and Manipulation}

The study used a 2 (receiver characteristic: high performance vs. low performance) x 2 (organizational characteristic: high teamwork vs. low teamwork) x 2 (receiver sex: male vs. female) experimental design with separate scenarios for each of the eight conditions (See Appendix F). Participants were randomly assigned to one condition when they accessed the questionnaire on www.surveymonkey.com. According to Cohen (1988), using conventional standards of .05 for statistical significance and .80 for observed power, and conducting tests of main effects in factorial designs (with the sample size adjustment calculated with formula 8.4.4 on p. 396), approximately 17 participants were needed in each condition to detect a moderate effect size of .25. The 253 participants were distributed among the eight conditions as follows: high performer/high teamwork/male receiver $(n=30)$, high performer/high teamwork/female receiver $(n=35)$, low performer/low teamwork/male receiver $(n=29)$, low performer/low teamwork/female receiver $(n=29)$, high performer/low teamwork/male receiver $(n=30)$, high 
performer/low teamwork/female receiver $(n=30)$, low performer/high teamwork/male receiver $(n=34)$, and low performer/high teamwork/female receiver $(n=36)$.

The scenarios read: "Imagine you have a coworker named [Male or Female target name] who is at the same job level you are $-[$ he/she $]$ is not your superior or subordinate. Please respond to the following items regarding your feelings and behavior toward [Male or Female target name]."

Work performance was operationalized using items from the In-Role Behaviors Scale (Williams \& Anderson, 1991). In the high work performance scenarios the targeted coworker was depicted as fulfilling his/her responsibilities, performing essential tasks, paying attention to his/her job obligations, and generally being a good worker. In the low work performance scenarios, the targeted coworker was depicted as failing to fulfill his/her responsibilities, failing to perform essential tasks, neglecting his/her job obligations, and generally being a poor worker.

Teamwork was operationalized using items from the Organizational Culture Scale (Glaser et al., 1987). In the high teamwork scenarios the organization was depicted as a place in which organizational members were concerned about each other, resolved disagreements cooperatively, were honest and considerate, and functioned as a team. In the low teamwork scenarios the organization was depicted as a place in which organizational members were unconcerned about each other, did not cooperate to resolve disagreements, were dishonest and inconsiderate, and did not function as a team.

Receiver sex was operationalized using names commonly recognized as referring to men or women. The name Tom was used to depict a male peer coworker and the name Mary was used to depict a female peer coworker. 
After reading the scenarios, participants completed measures assessing their desire to see the coworker in the scenario leave the organization (manipulation check), perceptions of peer performance and organizational teamwork (manipulation checks), and their likelihood of using the various peer-influence exit tactics. Participants also completed measures assessing their competitiveness, agreeableness, self-esteem, and their demographic characteristics.

\section{Instrumentation}

Desire to see a peer exit was measured with a 5-item measure, developed specifically for this study, which assesses the extent to which organizational members wanted the coworker described in the scenarios to leave the organization. Responses were solicited using a five-point Likert scale ranging from strongly disagree (1) to strongly agree (5). Higher scores indicated greater desire for organizational members to see the given peer coworker leave the organization (See Appendix G).

An exploratory factor analysis (EFA) with principal axis extraction and promax rotation was performed on the measure to assess its dimensionality. Four criteria were used for determining the number of factors retained. Each factor needed to have a minimum eigenvalue of 1.0, account for at least $5 \%$ of the variance, yield a primary factor loading of .50 with no secondary factor loadings above .30 , and no factor could have factor loadings that cross loaded. A one factor solution accounting for $91.60 \%$ of the variance (eigenvalue $=4.58$ ) and consisting of all five original items was produced. Cronbach alpha reliability coefficient of $.98(M=2.94$, $S D=1.37$ ). Each item loaded at .90 and above on the single factor. Table 1 contains the items and factor loadings for the measure. 
Table 1

Exploratory Factor Analysis Factor Loadings for Desire for Peer to Exit Measure

\begin{tabular}{|l|c|}
\hline Items & Factor 1 \\
\hline 1. I want [Peer name] to quit. & $\mathbf{9 3}$ \\
\hline 2. I would be happy if [Peer name] quit his/her job. & $\mathbf{9 6}$ \\
\hline 3. I would desire for [Peer name] to find a job at another organization. & $\mathbf{9 0}$ \\
\hline 4. I wish [Peer name] would leave. & $\mathbf{9 7}$ \\
\hline 5. I hope [Peer name] would leave the organization. & $\mathbf{9 7}$ \\
\hline
\end{tabular}

Note. Principal axis factoring with promax rotation.

The Desire for Peer to Exit measure was used as a manipulation check to ensure that the scenarios depicted a peer coworker who participants actually wanted to leave the organization. It was expected that participants would have a greater desire for the peer coworker to voluntarily exit when they were exposed to the low performance/low teamwork condition than when they were exposed to the high performance/high teamwork condition. Results of an independent samples $t$-test confirmed this assumption, $t(120)=16.07, p<.001$. Individuals who were exposed to the low performance/low teamwork condition expressed greater desire for their peer coworkers to leave $(M=3.93, S D=.79)$ than individuals who were exposed to the high performance/high teamwork condition $(M=1.55, S D=.84)$.

Work performance of the coworker depicted in the scenario was measured with one item (“[Male or Female target name] is a good worker"). The item was based on the In-Role Behaviors Scale (Williams \& Anderson, 1991) that assesses the quality of work performed by organizational members. This measure was used as a manipulation check to ensure that participants perceived the work performance of the coworker in the low performance conditions to be lower than the work performance of the peer coworker depicted in the high performance 
conditions. Results of an independent samples $t$-test confirmed that the manipulation worked as anticipated, $t(217.78)=-10.22, p<.001$. Individuals who were exposed to a scenario depicting a low performance worker reported that the employee depicted in the scenario was a lower performer $(M=2.93, S D=1.29)$ than individuals who were exposed to a scenario depicting a high performer $(M=3.91, S D=1.03)$.

Teamwork was measured with one item ("This organization is one in which people are friendly and cooperative with one another") based on the teamwork subscale of the Organizational Culture Survey (Glaser et al., 1987). This subscale assesses organizational members' perceptions of coordination with and concern for colleagues. It was expected that participants would perceive the teamwork of the organization in the low teamwork conditions to be lower than the teamwork of the organization in the high teamwork conditions. Results of an independent samples $t$-test confirmed that the manipulation worked as anticipated, $t(246)=-$ $19.50, p<.001$. Individuals who were exposed to a scenario depicting low teamwork reported that the organization depicted in the scenario consisted of lower teamwork $(M=1.80, S D=.88)$ than individuals who were exposed to a scenario depicting high teamwork $(M=4.09, S D=.97)$.

Peer-influence exit tactics were assessed with a measure that assesses the frequency with which individuals use various tactics to encourage their peer coworkers to voluntarily exit the organization. Items for this measure were based upon both previous research (Cox, 1999; Sollitto et al., 2013; Sollitto et al., 2014) and the responses from open-ended questions in Study 1. Responses were solicited using a five-point Likert scale ranging from strongly disagree (1) to strongly agree (5).

An exploratory factor analysis with principal axis extraction and promax rotation was performed on the measure to assess its dimensionality. Four criteria were used for determining 
the number of factors retained. Each factor needed to have a minimum eigenvalue of 1.0, account for at least $5 \%$ of the variance, yield a primary factor loading of .50 with no secondary factor loadings above .30 , and no factor could have factor loadings that cross loaded. Results of the EFA produced a four factor solution with 42 total items.

The first factor, labeled affirmation tactics, tapped into organizational members' attempts to encourage their peer coworkers to exit by being friendly, helpful, and constructive. It accounted for $44.91 \%$ of the variance (eigenvalue $=18.86$ ) and consisted of 15 items with a Cronbach alpha reliability coefficient of .96 . Scores on this factor ranged from 1 to $5(M=2.33$, $S D=.99)$

The second factor, labeled unprofessional tactics, which tapped into organizational members' attempts to encourage their peer coworkers to exit by being aggressive, hostile, and destructive, accounted for $13.00 \%$ of the variance (eigenvalue $=5.46$ ). It consisted of 15 items and had a Cronbach alpha reliability coefficient of .97 . Scores ranged from 1.00 to $5.00(M=$ $1.67, S D=.84)$.

The third factor, labeled depersonalization tactics, tapped into organizational members' attempts to encourage their peer coworkers to exit by withdrawing or limiting the amount of communication they had with them. This factor accounted for $6.57 \%$ of the variance (eigenvalue $=2.76$ ), consisted of 7 items, and had a Cronbach alpha reliability coefficient of .95 . Scores ranged from 1.00 to $5.00(M=2.14, S D=1.05)$.

The fourth factor, labeled professional tactics, which tapped into organizational members' attempts to encourage their peer coworkers to exit by being civil and polite, accounted for $5.00 \%$ of the variance (eigenvalue $=1.92$ ). It consisted of 5 items with a Cronbach alpha 
reliability coefficient of .92 . Scores ranged from 1.00 to $5.00(M=3.88, S D=.97)$. Table 2

contains the items and factor loadings for this measure.

Table 2

Exploratory Factor Analysis Factor Loadings for Peer-Influence Exit Measure

\begin{tabular}{|c|c|c|c|c|}
\hline Items & & & ctor & \\
\hline & 1 & 2 & 3 & 4 \\
\hline $\begin{array}{l}\text { 1. Commend or praise other jobs, organizations, or career } \\
\text { alternatives }\end{array}$ & .74 & -.11 & .01 & -.11 \\
\hline 2. Inform him/her of job or career alternatives & .81 & .02 & -.02 & -.06 \\
\hline 3. Encourage him/her to review his/her personal beliefs about work & .59 & .09 & .04 & .04 \\
\hline 4. Commend the advantages of choosing to leave the organization & .70 & .16 & .07 & -.10 \\
\hline $\begin{array}{l}\text { 5. Commend the positive qualities that he/she may offer another } \\
\text { organization }\end{array}$ & .87 & -.07 & -.01 & .03 \\
\hline 6. Provide him/her assistance for transitioning into another job & .82 & -.08 & -.01 & -.01 \\
\hline a/her about other job openings & .82 & -.06 & .20 & .05 \\
\hline 8. Tell hi & .84 & -.06 & .16 & .04 \\
\hline 9. Help him/her & .84 & -.08 & .05 & .06 \\
\hline $\begin{array}{l}\text { 10. Recommend that he/she attend an interview at another } \\
\text { organization }\end{array}$ & .93 & -.12 & .08 & -.05 \\
\hline 11. Tell him/her not to worry because other jobs will be available & .81 & .07 & -.09 & -.01 \\
\hline $\begin{array}{l}\text { 12. Inform him/her of the benefit packages offered by other } \\
\text { organizations }\end{array}$ & .89 & .01 & -.03 & -.01 \\
\hline $\begin{array}{l}\text { 13. Suggest that another organization would better utilize his/her } \\
\text { skill set }\end{array}$ & .83 & -.06 & .05 & -.02 \\
\hline $\begin{array}{l}\text { 14. Say that the organization was failing to use his/her talents like } \\
\text { they should }\end{array}$ & .67 & .29 & -.20 & .12 \\
\hline $\begin{array}{l}\text { 15. Tell him/her that he/she deserved to work for another } \\
\text { organization }\end{array}$ & .79 & .22 & -.26 & .12 \\
\hline 16. Prevent his/her ideas from being heard & .17 & .70 & -.02 & -.06 \\
\hline 17. Inten & .01 & .76 & .07 & -.07 \\
\hline 18. Impede a & .03 & .83 & .00 & -.03 \\
\hline 19. Act hostile or unfriendly with him/her & .01 & .73 & .17 & .03 \\
\hline 20. Neglect him/her as much as possible & -.02 & .60 & .29 & -.08 \\
\hline 21. Belittle him/her when we speak with one another & -.04 & .95 & -.08 & .02 \\
\hline 22. Be unfriendly with him/her & -.07 & .86 & .07 & -.10 \\
\hline 23. Communicate with him/her in a & -.11 & .96 & .03 & .08 \\
\hline 24. Act angry in conversations with him/her & -.18 & .95 & .07 & .08 \\
\hline 25. Have him/her take on more responsibility than & .06 & .70 & -.02 & -.02 \\
\hline 26. Treat him/her poorly & -.07 & .91 & -.03 & -.01 \\
\hline 27. Convince him/her to resign from $\mathrm{h}$ & .28 & .57 & .04 & -.08 \\
\hline
\end{tabular}




\begin{tabular}{|l|c|c|c|c|}
\hline 28. Tell him/her to quit his/her job & .17 & $\mathbf{. 6 8}$ & .01 & -.03 \\
\hline 29. Spread rumors about him/her to everyone in the organization & .09 & $\mathbf{. 7 7}$ & -.20 & -.02 \\
\hline 30. Speak about his/her wrongdoing with everyone & .15 & $\mathbf{. 6 4}$ & .01 & .01 \\
\hline 31. Avoid discussing work with him/her & .01 & .14 & $\mathbf{. 7 1}$ & .05 \\
\hline 32. Keep his/her role in work projects as isolated as possible & .15 & .08 & $\mathbf{. 6 8}$ & -.05 \\
\hline $\begin{array}{l}\text { 33. Keep to myself instead of engaging in conversations with } \\
\text { him/her }\end{array}$ & & & & \\
\hline 34. Stop talking to him/her & .02 & .07 & $\mathbf{. 8 4}$ & .06 \\
\hline 35. Stay away from him/her as much as possible & -.11 & .39 & $\mathbf{. 5 6}$ & -.05 \\
\hline 36. Keep conversations to a minimum with him/her & -.08 & .10 & $\mathbf{. 7 9}$ & -.06 \\
\hline 37. Reduce the number of conversations I have with him/her & .01 & -.07 & $\mathbf{. 9 6}$ & .06 \\
\hline 38. Maintain professionalism when speaking with him/her & .00 & -.09 & $\mathbf{. 9 9}$ & .03 \\
\hline 39. Be polite in my discussions with him/her & .08 & -.08 & .12 & $\mathbf{. 7 5}$ \\
\hline 40. Treat him/her in a professional way & .03 & .05 & -.03 & $\mathbf{. 9 4}$ \\
\hline 41. Be civil with him/her & -.05 & .05 & -.03 & $\mathbf{. 9 0}$ \\
\hline 42. Avoid showing negative emotions to him/her & -.10 & -.02 & .06 & $\mathbf{. 9 2}$ \\
\hline
\end{tabular}

Note. Principal axis factoring with promax rotation.

Competitiveness was measured with Mowen’s (2004) Competitiveness Scale, a 4-item

measure that assesses individuals' tendency to enjoy competition and their desire to be better

than others. Responses were solicited using a five-point Likert scale ranging from strongly

disagree (1) to strongly agree (5). Previous Cronbach alpha reliability coefficients ranged from

.89 to .92 (Fang \& Mowen, 2009; Mowen, 2004). Higher scores indicated greater levels of competitiveness (See Appendix H).

A confirmatory factor analysis was performed on the measure to ensure its dimensionality. Results of the CFA suggested the model provided a good fit to the data, $\chi^{2}(2)=$ $3.57, p=.17 ; \mathrm{CFI}=.99, \mathrm{NFI}=.99, \mathrm{RFI}=.96, \mathrm{RMSEA}=.06$. The Cronbach alpha reliability coefficient in this study was .88 . Scores ranged from 1.00 to $5.00(M=3.10, S D=.96)$.

Agreeableness was measured with the agreeableness subscale of the Big Five inventory (John, Donahue, \& Kentle, 1991). This 9-item scale assesses the individual's tendency to be considerate and cooperative with others. Responses were solicited using a five-point Likert scale ranging from strongly disagree (1) to strongly agree (5). Previous Cronbach alpha reliability 
coefficients ranged from .66 to .88 (Benet-Martinez \& John, 1998; Fossati, Borroni, Marchione, \& Maffei, 2011; Soto, John, Gosling, \& Potter, 2010). Higher scores indicated greater levels of agreeableness (See Appendix I).

A confirmatory factor analysis was performed on the measure to ensure its dimensionality. Results of the CFA suggested the model provided a poor fit to the data, $\chi^{2}(27)=$ $175.02, p=.00 ; \mathrm{CFI}=.78, \mathrm{NFI}=.75, \mathrm{RFI}=.56, \mathrm{RMSEA}=.15$. However, the Cronbach alpha reliability coefficient in this study was acceptable at .79 . Scores ranged from 1.00 to $5.00(M=$ $3.75, S D=.66)$

Self-esteem was measured with the Rosenberg Self-Esteem Scale (Rosenberg, 1965), a 10-item measure that assesses individuals' feelings of being significant and meaningful. Responses were solicited using a five-point Likert scale ranging from strongly disagree (1) to strongly agree (5). Previous Cronbach alpha reliability coefficients ranged from .80 to .87 (Lebel, 2010; Robins, Hendin, \& Trzesniewski, 2001; Wadman, Durkin, \& Conti-Ramsden, 2008). Higher scores indicated greater levels of self-esteem (See Appendix J).

A confirmatory factor analysis was performed on the measure to ensure its dimensionality. Results of the CFA suggested the model provided a poor fit to the data, $\chi^{2}(35)=$ $239.38, p=.00 ; \mathrm{CFI}=.86, \mathrm{NFI}=.84, \mathrm{RFI}=.75, \mathrm{RMSEA}=.15$. However, the Cronbach alpha reliability coefficient was acceptable at .91 . Scores ranged from 1.00 to $5.00(M=3.76, S D=$ .81). The questionnaire used in Study 2 appears in Appendix K.

\section{Study 3 Method}

\section{Participants and Procedures}

Data for Study 3 was collected via an online questionnaire. Individuals over the age of 18 and employed full-time (worked more than 35 hours a week) in the United States were recruited 
for the study through four methods. First, undergraduate students enrolled in courses at a large Mid-Atlantic university were asked to recruit friends, parents, and/or others to participate. Students were provided paper flyers containing information about the study and the email address of the lead researcher. Individuals recruited for the study were instructed to email the researcher to receive an internet link to the online questionnaire housed on www.surveymonkey.com. Upon receipt of the email, the researcher thanked the individual for agreeing to participate in the study and sent him/her a link to the online questionnaire. Second, participants were recruited by the researcher, who solicited participation from his interpersonal contacts through emails and a Facebook posting containing the internet link to the questionnaire. The researcher also asked the individuals he contacted to pass along the link to anyone they thought would be interested in participating in the study. Third, an explanation of the study and the link to the online questionnaire were posted on the university's intranet system. Interested individuals who met the inclusion criteria participated by clicking the link, which took them directly to the questionnaire. Fourth, an explanation of the study and the link to the online questionnaire were posted on Amazon's Mechanical Turk (www.mtruck.com; Amazon Mechanical Turk, 2014). Amazon's Mechanical Turk is an open online marketplace consisting of over 100,000 individuals from a variety of countries who perform tasks for requesters in exchange for monetary rewards (Buhrmester, Kwang, \& Gosling, 2011). Interested individuals who met the inclusion criteria participated by clicking the link which took them to the questionnaire. Upon completing the questionnaire, individuals were paid $\$ 0.35$ for their work. Participants included 252 adults working full-time in a variety of organizations in the United States. The sample was composed of 122 men (48\%), 105 women (42\%), and 25 unidentified $(10 \%)$. Participants ranged in age from 19 to $65(M=33.89, S D=11.29)$ years. 
Ethnicity of participants included Caucasian/White $(n=130,51.5 \%)$, Asian American/Asian $(n$ $=50,20 \%)$, Native American $(n=19,7.5 \%)$, African American/Black $(n=18,7 \%)$, Hispanic/Latino ( $n=7,3 \%)$, and 28 unidentified (11\%). Occupational fields represented in the sample included managerial and professional $(n=85,34 \%)$, technical, sales, and administrative support ( $n=80,31 \%)$, service occupations $(n=44,17.5 \%)$, precision production, craft, and repair $(n=9,3.5 \%)$, operators, fabricators, laborers $(n=8,3 \%)$, and 26 unidentified job fields (10\%). Length of employment ranged from 1 to 30 years $(M=6.65, S D=6.18)$ and the mean number of hours worked per week ranged from 35 to $96(M=43.67, S D=7.62)$.

\section{Instrumentation}

Upon agreeing to participate in the study, participants were provided a prompt reading:

“Think of your past work experiences, jobs, organizations you've worked for. From among all those experiences, think of a peer coworker (someone at your same job level, not a superior or subordinate) you want(ed) to leave the organization, quit, transfer, etc. In other words, think of a peer you work(ed) with whom you wish(ed) would leave your organization. Please write the first name of this peer coworker here . Please answer the following questions."

Once participants read the prompt, they responded to items regarding peer-influenced exit, their own characteristics, the characteristics of their targeted peer coworkers, and the characteristics of their organizations.

Competitiveness was measured with Mowen's (2004) Competitiveness Scale, a 4-item measure that assesses individuals' tendency to enjoy competition and their desire to be better than others. Responses were solicited using a five-point Likert scale ranging from strongly disagree (1) to strongly agree (5). Previous Cronbach alpha reliability coefficients ranged from .89 to .92 (Fang \& Mowen, 2009; Mowen, 2004). Higher scores indicated greater levels of competitiveness. 
A confirmatory factor analysis was performed on the measure to ensure its dimensionality. Results of the CFA suggested the model provided a good fit to the data, $\chi^{2}(2)=$ $6.50, p=.04 ; \mathrm{CFI}=.99, \mathrm{NFI}=.98, \mathrm{RFI}=.92, \mathrm{RMSEA}=.09$. The Cronbach alpha reliability coefficient in this study was .85 . Scores ranged from 1.00 to $5.00(M=3.00, S D=1.00)$.

Agreeableness was measured with the agreeableness subscale of the Big Five inventory (John, Donahue, \& Kentle, 1991). This 9-item scale assesses the individual's tendency to be considerate and cooperative with others. Responses were solicited using a five-point Likert scale ranging from strongly disagree (1) to strongly agree (5). Previous Cronbach alpha reliability coefficients ranged from .66 to .88 (Benet-Martinez \& John, 1998; Fossati et al., 2011; Soto, John, Gosling, \& Potter, 2010). Higher scores indicated greater levels of agreeableness.

A confirmatory factor analysis was performed on the measure to ensure its dimensionality. Results of the CFA suggested the model provided a poor fit to the data, $\chi^{2}(27)=$ $280.36, p=.00 ; \mathrm{CFI}=.61, \mathrm{NFI}=.61, \mathrm{RFI}=.34, \mathrm{RMSEA}=.19$. The Cronbach alpha reliability coefficient in this study was .81 . Scores ranged from 1.00 to $5.00(M=3.62, S D=.68)$.

Self-esteem was measured with the Rosenberg Self-Esteem Scale (Rosenberg, 1965), a 10-item measure that assesses individuals' feelings of being significant and meaningful. Responses were solicited using a five-point Likert scale ranging from strongly disagree (1) to strongly agree (5). Previous Cronbach alpha reliability coefficients ranged from .80 to .87 (Lebel, 2010; Robins et al., 2001; Wadman et al., 2008). Higher scores indicated greater levels of self-esteem.

A confirmatory factor analysis was performed on the measure to ensure its dimensionality. Results of the CFA suggested the model provided a poor fit to the data $\chi^{2}(5)=$ 
$229.75, p=.00 ; \mathrm{CFI}=.60, \mathrm{NFI}=.58, \mathrm{RFI}=.34, \mathrm{RMSEA}=.22$. The Cronbach alpha reliability coefficient in this study was .85 . Scores ranged from 1.00 to $5.00(M=3.71, S D=.71)$.

Coworker (dis)similarity was measured with the perceived similarity subscale of the Friendship Development Scale (Sias et al., 2003), a 4-item scale that assesses the degree of commonality organizational members perceive with their coworkers. Responses were solicited using a five-point Likert scale ranging from strongly disagree (1) to strongly agree (5). Previous Cronbach alpha reliability coefficients ranged from .81 to .90 (Sias et al., 2012; Sias et al., 2003). Higher scored indicated greater similarity between organizational members and their peer coworkers (See Appendix L).

A confirmatory factor analysis was performed on the measure to ensure its dimensionality. Results of the CFA suggested the model provided a relatively adequate fit to the data, $\chi^{2}(2)=11.83, p=.00 ; \mathrm{CFI}=.99, \mathrm{NFI}=.99, \mathrm{RFI}=.93, \mathrm{RMSEA}=.14$. The Cronbach alpha reliability coefficient in this study was .92 . Scores ranged from 1.00 to $5.00(M=2.66, S D$ $=1.15)$.

Work performance of the targeted coworker was measured with the In-Role Behaviors Scale (Williams \& Anderson, 1991), a 7-item scale that assesses the quality of work performed by organizational members. Responses were solicited using a five-point Likert scale ranging from strongly disagree (1) to strongly agree (5). Williams and Anderson (1991) reported a Cronbach's alpha reliability coefficient of .91. Higher scores indicated greater levels of work proficiency (See Appendix M).

A confirmatory factor analysis was performed on the measure to ensure its dimensionality. Results of the CFA suggested the model provided a poor fit to the data $\chi^{2}(14)=$ 
$176.99, p=.00 ; \mathrm{CFI}=.84, \mathrm{NFI}=.83, \mathrm{RFI}=.65, \mathrm{RMSEA}=.22$. The Cronbach alpha reliability coefficient in this study was .85 . Scores ranged from 1.00 to $5.00(M=3.18, S D=.85)$.

Liking/social attractiveness of the targeted coworker was measured with the social attraction subscale of the Interpersonal Attraction Scale (McCroskey \& McCain, 1974), a 5-item scale that assesses how likable an individual is. Responses were solicited using a five-point Likert scale ranging from strongly disagree (1) to strongly agree (5). Previous Cronbach alpha reliability coefficients ranged from .75 to .80 (McCroskey \& McCain, 1974; Neulip et al., 2005; Walther et al., 2008). Higher scores indicated stronger liking (See Appendix N).

A confirmatory factor analysis was performed on the measure to ensure its dimensionality. Results of the CFA suggested the model provided a poor fit to the data $\chi^{2}(35)=$ $477.12, p=.00 ; \mathrm{CFI}=.60, \mathrm{NFI}=.58, \mathrm{RFI}=.34, \mathrm{RMSEA}=.22$. The Cronbach alpha reliability coefficient in this study was .79. Scores ranged from 1.00 to $5.00(M=2.85, S D=.95)$.

Organizational influence of the targeted coworker was measured with a modified version of the Leader-Member Exchange-7 (Graen, Novak, \& Sommerkamp, 1982), a 7-item scale that assesses the relationship quality between supervisors and subordinates. Items were reworded to reflect how organizational members perceive the quality of the relationship between targets and their supervisors. Responses were solicited using a five-point Likert scale ranging from strongly disagree (1) to strongly agree (5). Cronbach alpha reliability coefficients for the original version of the measure ranged from .80 to .92 (Bezuijen, van Dam, van den Berg, \& Thierry, 2010; Harris \& Kacmar, 2006; Mueller \& Lee, 2002). Higher scores indicated greater relationship quality between supervisors and targeted coworkers (See Appendix O).

A confirmatory factor analysis was performed on the measure to ensure its dimensionality. Results of the CFA suggested the model provided a poor fit to the data $\chi^{2}(14)=$ 
$103.34, p=.00 ; \mathrm{CFI}=.85, \mathrm{NFI}=.84, \mathrm{RFI}=.75, \mathrm{RMSEA}=.16$. The Cronbach alpha reliability coefficient in this study was .84 . Scores ranged from 1.00 to $5.00(M=3.24, S D=.74)$.

Organizational justice was measured with the Organizational Justice Scale (Moorman, 1991), an 18-item measure that assesses organizational members' perceptions of fairness across three dimensions: distributive justice, procedural justice, and interactional justice. Responses were solicited using a five-point Likert-type scale ranging from to a small extent (1) to to a large extent (5). Cronbach alpha reliability coefficients for the three dimensions ranged from .86 to 93 (Miller et al., 2012; Moorman, 1993). Higher scores indicated greater levels of perceived fairness in the organization (See Appendix P).

A confirmatory factor analysis was performed on the measure to ensure its dimensionality. Results of the CFA suggested the model provided an adequate fit to the data, $\chi^{2}$ $(132)=318.82, p=.00 ; \mathrm{CFI}=.93, \mathrm{NFI}=.90, \mathrm{RFI}=.86, \mathrm{RMSEA}=.07$. The Cronbach alpha reliability coefficients in this study were $.89(M=2.64, S D=.78)$ for distributive justice, $.91(M$ $=2.57, S D=.74)$ for procedural justice, and $.91(M=2.70, S D=.76)$ for interactional justice. Scores for each dimension ranged from 1.00 to 5.00 .

Organizational culture was measured with the teamwork subscale of the Organizational Culture Survey (Glaser et al., 1987), an 8-item measure that assesses organizational members' perceptions of coordination with and concern for their colleagues. Responses were solicited using a five-point Likert scale ranging from strongly disagree (1) to strongly agree (5). Previous Cronbach alpha reliability coefficients ranged from .93 to .94 (Schrodt, 2002; SikorskaSimmons, 2005). Higher scores indicated greater levels of teamwork (See Appendix Q). A confirmatory factor analysis was performed on the measure to ensure its dimensionality. Results of the CFA suggested the model provided a poor fit to the data $\chi^{2}(20)=$ 
122.33, $p=.00 ; \mathrm{CFI}=.90, \mathrm{NFI}=.88, \mathrm{RFI}=.79, \mathrm{RMSEA}=.14$. The Cronbach alpha reliability coefficient in this study was .91 . Scores ranged from 1.00 to $5.00(M=2.67, S D=.66)$.

Organizational climate was measured with the autonomy, welfare, formalization, effort, and pressure to produce subscales of the Organizational Climate Measure (Patterson et al., 2005). Autonomy is a 5-item subscale that assesses organizational members' ability to make their own decisions. Welfare is a 4-item subscale that assesses organizational members' perceptions about the organization's concern for them. Formalization is a 5-item subscale that assesses organizational members' perceptions of how strictly rules are followed in the organization. Effort is 5-item subscale that assesses organizational members' level of exertion in their job roles. Pressure to produce is a 5-item subscale that assesses organizational members' perceptions about the expectations placed upon them. Responses were solicited using a fivepoint Likert scale ranging from strongly disagree (1) to strongly agree (5). Previous Cronbach alpha reliability coefficients for the five dimensions ranged from .67 to .91 (Patterson et al., 2005). Higher scores indicated greater levels of each dimension (See Appendix R).

A confirmatory factor analysis was performed on the measure to ensure its dimensionality. Results of the CFA suggested the model provided a poor fit to the data $\chi^{2}$ (229) $=1013.45, p=.00 ; \mathrm{CFI}=.65, \mathrm{NFI}=.60, \mathrm{RFI}=.51, \mathrm{RMSEA}=.12$. The Cronbach alpha reliability coefficients in this study were $.65(M=3.07, S D=.58)$ for autonomy, $.71(M=2.93$, $S D=.65)$ for welfare, $.47(M=3.27, S D=.50)$ for formalization, $.58(M=.58, S D=.53)$ for effort, and $.55(M=3.04, S D=.54)$ for pressure to produce.

Supervisor complicity was measured with a 5-item scale developed for this study that assesses how involved supervisors are in the plans that organizational members have for encouraging peer coworkers to exit. Responses were solicited using a five-point Likert scale 
ranging from strongly disagree (1) to strongly agree (5). Higher scores indicated greater levels of complicity between supervisors and subordinates (See Appendix S).

An exploratory factor analysis (EFA) with principal axis extraction and promax rotation was performed on the measure to assess its dimensionality. Four criteria were used for determining the number of factors retained. Each factor needed to have a minimum eigenvalue of 1.0 , account for at least $5 \%$ of the variance, yield a primary factor loading of .50 with no secondary factor loadings above .30 , and no factor loadings could cross load. A one factor solution accounting for $66.60 \%$ of the variance (eigenvalue $=3.30$ ) was produced. The factor consisted of all five original items and had a Cronbach alpha reliability coefficient of .91 $(M=$ $2.68, S D=1.14)$. Each item loaded above .68 on the single factor. Table 3 contains the items and factor loadings for the measure.

Table 3

Exploratory Factor Analysis Factor Loadings for Supervisor Complicity Measure

\begin{tabular}{|l|c|}
\hline Items & Factor \\
\hline $\begin{array}{l}\text { 1. My supervisor and I talk(ed) about organizational members whom my supervisor } \\
\text { and I think should leave. }\end{array}$ & $\mathbf{. 8 5}$ \\
\hline $\begin{array}{l}\text { 2. My supervisor informs/informed me about organizational members whom my } \\
\text { supervisor and I think should leave. }\end{array}$ & $\mathbf{. 8 3}$ \\
\hline $\begin{array}{l}\text { 3. My supervisor is/was aware of certain organizational members whom I } \\
\text { think/thought should leave. }\end{array}$ & $\mathbf{. 6 8}$ \\
\hline 4. My supervisor asks/asked me to encourage certain members to leave. & $\mathbf{. 8 5}$ \\
\hline $\begin{array}{l}\text { 5. My supervisor instructs/instructed me to encourage certain organizational } \\
\text { members to leave. }\end{array}$ & $\mathbf{. 8 3}$ \\
\hline
\end{tabular}

Note. Principal axis factoring with promax rotation.

Job satisfaction was measured with the job satisfaction subscale of the Job Diagnostic Survey (Hackman \& Oldham, 1975), 3-item measure that assesses organizational members' level of happiness with their work. Responses were solicited using a five-point Likert scale ranging from strongly disagree (1) to strongly agree (5). Previous Cronbach alpha reliability coefficients 
ranged from .73 to .82 (Hackman \& Oldham, 1975; Kramer, 1996; Sias, 2005). Higher scores reflected greater levels of satisfaction (See Appendix D).

A confirmatory factor analysis was performed on the measure to ensure its dimensionality. Results of the CFA suggested the model provided a good fit to the data $\chi^{2}(1)=$ $1.92, p=.17 ; \mathrm{CFI}=.99, \mathrm{NFI}=.98, \mathrm{RFI}=.90, \mathrm{RMSEA}=.06$. The Cronbach alpha reliability coefficient in this study was .63. Scores ranged from 1 to $5(M=2.74, S D=.69)$.

Coworker regard was measured with an adapted version of the public collective selfesteem subscale (Luhtanen \& Crocker, 1992), a 4-item measure that assesses the degree to which individuals believe that they are negatively evaluated by members from outside of their social groups. Items were modified to reflect the degree to which organizational members believe they are negatively evaluated by their peer coworkers. Responses were solicited using a five-point Likert scale ranging from strongly disagree (1) to strongly agree (5). Previous Cronbach alpha reliability coefficients for the original scale ranged from .78 to .85 (Colquitt, 2001; Luhtanen \& Crocker, 1992). Higher scores reflected greater levels of regard experienced from peer coworkers (See Appendix T).

A confirmatory factor analysis was performed on the measure to ensure its dimensionality. Results of the CFA suggested the model provided a good fit to the data $\chi^{2}(1)=$ $.05, p=.83 ; \mathrm{CFI}=.99, \mathrm{NFI}=.98, \mathrm{RFI}=.98, \mathrm{RMSEA}=.05$. The Cronbach alpha reliability coefficient in this study was .69. Scores ranged from 1 to $5(M=3.79, S D=.77)$.

Motives for encouraging a peer to exit were measured with a scale developed for this study that assesses individuals' reasons for encouraging their peer coworkers to leave the organization. A pool of 20 items was developed based upon the responses to the open-ended questions in Study 1. Responses were solicited using a five-point Likert scale ranging from 
strongly disagree (1) to strongly agree (5). Higher scores indicated stronger endorsement of the reason for wanting a peer coworker to exit the organization.

An exploratory factor analysis with principal axis extraction and promax rotation was performed on the measure to assess its dimensionality. Four criteria were used for determining the number of factors retained. Each factor needed to have a minimum eigenvalue of 1.0, account for at least $5 \%$ of the variance, yield a primary factor loading of .50 with no secondary factor loadings above .30, and no factor loadings could cross load. Results of the EFA produced a four factor solution with 19 total items.

The first factor, labeled personal gain, represented organizational members' desire to see their peer coworkers exit so they, themselves, could have better opportunities. This factor accounted for $33.41 \%$ of the variance (eigenvalue $=6.35$ ) and consisted of 7 items. The Cronbach alpha reliability coefficient was $.90(M=1.98, S D=.79)$.

The second factor, labeled altruistic, represented organizational members' desire to see their peer coworkers exit so their peer coworkers could be happier and appreciated at another organization. This factor accounted for $15.06 \%$ of the variance (eigenvalue $=2.86$ ) and consisted of 4 items with a Cronbach alpha reliability coefficient of $.84(M=2.26, S D=.81)$.

The third factor, labeled organizational enhancement, represented organizational members' desire to see their peer coworkers exit so their organization could operate more smoothly. This factor accounted for $5.95 \%$ of the variance (eigenvalue $=1.13$ ) and consisted of 4 items with a Cronbach alpha reliability coefficient of $.85(M=2.53, S D=.84)$.

The fourth factor, labeled climate improvement, represented organizational members' desire for their peer coworkers to exit so the organization's climate would be more supportive. This factor accounted for $5.00 \%$ of the variance (eigenvalue $=1.00$ ) and consisted of 4 items 
with a Cronbach alpha reliability coefficient of $.83(M=2.60, S D=.87)$. Table 4 contains the items and factor loadings for the measure.

Table 4

Exploratory Factor Analysis Factor Loadings for Motives Measure

\begin{tabular}{|c|c|c|c|c|}
\hline Items & \multicolumn{4}{|c|}{ Factor } \\
\hline & 1 & 2 & 3 & 4 \\
\hline 1. Possesses(ed) undesirable physical features & .67 & .16 & .12 & -.09 \\
\hline 2. Maintains(ed) an unhealthy physical appearance & .61 & .16 & .09 & -.07 \\
\hline 3. Is/was competition for me & .77 & .10 & .00 & -.04 \\
\hline 4. Is/was favored by supervisors & .66 & -.05 & .07 & .16 \\
\hline 5. Is/was a threat to my growth in the company & .80 & -.06 & -.11 & .10 \\
\hline 6. Works(ed) in a position that I want(ed) & .88 & -.04 & -.06 & -.07 \\
\hline 7. Holds/held me back by being in the organization & .81 & -.12 & -.02 & .04 \\
\hline 8. Has/had talents that could be better utilized elsewhere & .18 & .51 & -.05 & .09 \\
\hline $\begin{array}{l}\text { 9. Will have/had a better family situation if he/she left the } \\
\text { organization }\end{array}$ & .18 & .67 & -.07 & -.04 \\
\hline 10. Will be/would be under less stress by leaving the organization & -.03 & .88 & .00 & -.02 \\
\hline $\begin{array}{l}\text { 11. Will/would enjoy his/her work more if he/she went to another } \\
\text { organization }\end{array}$ & -.10 & .91 & -.00 & .00 \\
\hline 12. Rarely offers(ed) any contribution to the organization & .11 & -.05 & .75 & .01 \\
\hline 13. Is/was a poor worker & -.00 & -.04 & .95 & -.12 \\
\hline 14. Rarely cooperates(ed) with other employees & -.03 & -.06 & .72 & .08 \\
\hline 15. Creates(ed) problems for the organization & -.11 & .11 & .52 & .22 \\
\hline 16. Is/was manipulative & .04 & .08 & -.05 & .77 \\
\hline 17. Is/was self-centered & .00 & -.12 & -.06 & .86 \\
\hline 18. Distracts(ed) people from their work & .01 & .13 & .19 & .52 \\
\hline 19. Gossips(ed) about others & .00 & -.10 & .09 & .67 \\
\hline
\end{tabular}

Note. Principal axis factoring with promax rotation.

Peer-influence exit tactics was assessed with a measure that assesses the frequency with which individuals use various tactics to encourage their peer coworkers to voluntarily exit the organization. This measure was developed based on prior research (Cox, 1999; Sollitto et al., 2013; Sollitto et al., 2014), open-ended responses obtained in Study 1, and quantitative results obtained in Study 2. Responses were solicited using a five-point Likert scale ranging from strongly disagree (1) to strongly agree (5). Higher scores on the measure indicated greater use of the tactics. 
Because an exploratory factor analysis was conducted on this measure in Study 2, a confirmatory factor analysis was performed on the measure here to ensure its dimensionality. Results of the CFA suggested the model provided a poor fit to the data, $\chi^{2}(816)=2624.97, p=$ $.00 ; \mathrm{CFI}=.80, \mathrm{NFI}=.74, \mathrm{RFI}=.71, \mathrm{RMSEA}=.09$. The Cronbach alpha reliability coefficients in this study were $.95(M=2.81, S D=.93)$ for affirmation tactics, $.96(M=2.25, S D=.94)$ for unprofessional tactics, $.93(M=3.07, S D=.11)$ for depersonalization tactics, and $.88(M=3.67$, $S D=.83)$ for professional tactics.

Effectiveness of peer-influence exit tactics was measured by asking participants to indicate whether their peer coworker still works in their organization by selecting "yes" or "no." If participants selected "no," they were prompted to select whether their peer coworkers exited "voluntarily" or "involuntarily." If the participants chose "voluntarily," they were asked to provide reasons why their peer coworkers exited voluntarily. The number of peer coworkers remaining in the organization was $191(76 \%)$ and the number of peer coworkers who departed the organization was $60(24 \%)$. Of the 60 targets who exited the organization, 44 (73\%) exited voluntarily and 16 (27\%) exited voluntarily. The questionnaire used in Study 3 appears in Appendix U. 


\section{CHAPTER III: RESULTS}

\section{Study 1 Results}

As previously described, the unit of analysis included phrases, sentences, or series of sentences that indicated unique themes. In most cases, there was more than one unit or descriptor in response to each question. Participants listed between one and eight units in response to each question. The total number of units coded during this process was 1,573: 801 for motives, 483 for peer-influence exit tactics, 160 for intentionality/planning of tactics, and 129 for success/effectiveness of tactics.

Many of the research questions and hypotheses were analyzed through more than one statistical procedure, given the different studies and forms of data. Research questions 1, 2, 14, and 15 were answered in Study 1.

\section{Research Question 1: Peer-Influence Exit Tactics}

The first research question inquired about the types of messages and/or behaviors organizational members use to encourage a peer coworker to voluntarily leave the organization. This purpose of the question was to discover what organizational members said or did to push a coworker out of the organization (i.e., to identify peer-influence exit tactics). Four hundred and eighty-three (483) units were identified from the data for peer-influence exit tactics. Results of a thematic analysis revealed that organizational members engaged in eight distinct behaviors to encourage their peer coworkers to voluntarily exit: communicate professionally $(n=172)$, minimize communication ( $n=102)$, affirm talents and provide advice $(n=71)$, communicate overt statements $(n=55)$, act unprofessionally $(n=29)$, provide information and advice about other alternatives $(n=23)$, consult third-party sources $(n=21)$, and isolate $(n=10)$. Table 5 contains a summary of this data. 
Table 5

Peer Influence Exit Tactics: Behaviors and Communication Used to Encourage Peer Coworkers to Exit

\begin{tabular}{|c|c|c|c|c|}
\hline Peer Influence Exit Tactic & Example & $\begin{array}{l}\text { Item } 3 \\
(\%)\end{array}$ & $\begin{array}{l}\text { Item } 4 \\
(\%)\end{array}$ & $\begin{array}{l}\text { Freq. } \\
(\%)\end{array}$ \\
\hline $\begin{array}{l}\text { Communicate professionally- } \\
\text { behaving in a friendly and ethical } \\
\text { manner with peer coworker } \\
\text { congruent with organizational or } \\
\text { professional norms }\end{array}$ & $\begin{array}{l}\text { "Despite my feelings, I tried } \\
\text { to cooperate with her to keep } \\
\text { the organization moving } \\
\text { forward." }\end{array}$ & $\begin{array}{l}91 \\
(34 \%)\end{array}$ & $\begin{array}{l}81 \\
(38 \%)\end{array}$ & $\begin{array}{l}172 \\
(36 \%)\end{array}$ \\
\hline $\begin{array}{l}\text { Minimize communication- keeping } \\
\text { to themselves, limiting the number } \\
\text { of communication encounters they } \\
\text { have with their peer coworker, or } \\
\text { ignoring them }\end{array}$ & $\begin{array}{l}\text { "I tried to stay away from her } \\
\text { as much as possible because I } \\
\text { didn't want to be caught up in } \\
\text { her drama anymore." }\end{array}$ & $\begin{array}{l}95 \\
(35 \%)\end{array}$ & $\begin{array}{l}7 \\
(3 \%)\end{array}$ & $\begin{array}{l}102 \\
(21 \%)\end{array}$ \\
\hline $\begin{array}{l}\text { Affirm talents and provide advice- } \\
\text { complimenting their peer } \\
\text { coworker's skills sets, suggesting } \\
\text { that other organizations would better } \\
\text { utilize them, and counseling him/her } \\
\text { about how to improve } \\
\text { himself/herself elsewhere }\end{array}$ & $\begin{array}{l}\text { "I said to her that she is very } \\
\text { talented, so she should go } \\
\text { elsewhere to receive a better } \\
\text { salary." }\end{array}$ & $\begin{array}{l}13 \\
(5 \%)\end{array}$ & $\begin{array}{l}58 \\
(27 \%)\end{array}$ & $\begin{array}{l}71 \\
(15 \%)\end{array}$ \\
\hline $\begin{array}{l}\text { Communicate overt statements- } \\
\text { communicating in a direct and } \\
\text { honest manner with their peer } \\
\text { coworker about his/her performance } \\
\text { and the reasons he/she should exit }\end{array}$ & $\begin{array}{l}\text { "I vocally expressed my } \\
\text { disapproval of his } \\
\text { performance in casual } \\
\text { conversations." }\end{array}$ & $\begin{array}{l}27 \\
(10 \%)\end{array}$ & $\begin{array}{l}28 \\
(13 \%)\end{array}$ & $\begin{array}{l}55 \\
(11 \%)\end{array}$ \\
\hline $\begin{array}{l}\text { Act unprofessionally- being } \\
\text { inhospitable, cold, or demeaning } \\
\text { toward their peer coworker }\end{array}$ & $\begin{array}{l}\text { "I became less receptive to } \\
\text { the things he would say." }\end{array}$ & $\begin{array}{l}22 \\
(8 \%)\end{array}$ & $\begin{array}{l}7 \\
(3 \%)\end{array}$ & $\begin{array}{l}29 \\
(6 \%)\end{array}$ \\
\hline $\begin{array}{l}\text { Provide information and } \\
\text { encouragement about other } \\
\text { alternatives- giving their peer } \\
\text { coworker information and reducing } \\
\text { uncertainty about specific jobs, } \\
\text { careers, and opportunities }\end{array}$ & $\begin{array}{l}\text { "I would mention job } \\
\text { openings at other } \\
\text { organizations." }\end{array}$ & $\begin{array}{l}8 \\
(3 \%)\end{array}$ & $\begin{array}{l}15 \\
(7 \%)\end{array}$ & $\begin{array}{l}23 \\
(5 \%)\end{array}$ \\
\hline $\begin{array}{l}\text { Consult third-party sources- having } \\
\text { discussions with direct supervisors, } \\
\text { human resources, or peer coworker's } \\
\text { family members about their peer } \\
\text { coworker }\end{array}$ & $\begin{array}{l}\text { "I approached my manager } \\
\text { about his poor work and } \\
\text { future with the organization." }\end{array}$ & $\begin{array}{l}6 \\
(2 \%)\end{array}$ & $\begin{array}{l}15 \\
(7 \%)\end{array}$ & $\begin{array}{l}21 \\
(4 \%)\end{array}$ \\
\hline $\begin{array}{l}\text { Isolate- excluding their peer } \\
\text { coworker from social activities or } \\
\text { work projects }\end{array}$ & $\begin{array}{l}\text { "I supported initiatives to } \\
\text { prevent him from working or } \\
\text { spending time with us." }\end{array}$ & $\begin{array}{l}9 \\
(3 \%)\end{array}$ & $\begin{array}{l}1 \\
(.04 \% \\
\end{array}$ & $\begin{array}{l}10 \\
(2 \%)\end{array}$ \\
\hline
\end{tabular}




\begin{tabular}{|l|l|l|l|l|}
\hline & & & & \\
\hline & 271 & 212 & 483 \\
& $(56 \%)$ & $(44 \%)$ & $(100 \%)$ \\
\hline
\end{tabular}

Note. Item 3 was "Once you realized you wanted [Peer name] to leave the organization, describe how you behaved and/or communicated with [Peer name]. Item 4 was "Do/did you do or say anything to [Peer name] to try to get [Peer name] to leave the organization? Describe what you do/did to encourage [Peer name] to leave the organization.

Communicate professionally, which was the most frequently used behavior by

participants, entailed organizational members behaving in a friendly and ethical fashion congruent with organizational or professional norms. This particular behavior represented an attempt to push a coworker out of the organization by being friendly, gentle, and warm during communication interactions about departing the organization. In many cases, the participants indicated that they genuinely liked their peer coworker, so they wanted to behave as ethically, professionally, and morally as possible. For example, one participant noted "I behaved politely because he was a good person."

Additionally, by communicating professionally, organizational members focused upon maintaining cordial and pleasant relations with their peer coworkers and were able to continue focusing on their own business and work roles without creating undue drama or conflict in their organizations. A participant emphasized that point by saying "I had my work to do, so I just treated him like a human being and remained professional through it all." Thus, communicating professionally allowed employees to remain on good terms with their peer coworkers.

Minimize communication, the second most frequently used behavior by participants, entailed organizational members encouraging their peer coworkers to leave by keeping to themselves, limiting the number of communication interactions with the peer, or ignoring the peer. This particular behavior represented an attempt to push a coworker out of the organization largely by refusing to acknowledge the other person's presence, keeping interactions to a minimum, or keeping interactions succinct with little elaboration about anything other than 
exiting the organization. Organizational members tended to avoid or decrease communication with people they disliked and wanted to evade or shun inside the organization. For example, one participant reported, "I couldn't stand him, so I just stopped talking to him."

Additionally, organizational members avoided or decreased their communication in an attempt to limit the number of awkward or uncomfortable encounters with their peer coworkers. As another participant noted, "I kept my distance because you couldn't have a conversation with him. He always had a better story. His life was way worse. He couldn't separate life and work." As such, avoiding or decreasing communication functioned as a way for organizational members to limit the number of interactions they had with coworkers they wanted to exit the organization. Affirm talents and provide advice was the third most frequently used behavior by participants and entailed organizational members complimenting the skill sets of their peer coworkers, suggesting other organizations that would better utilize them, and counseling them about how to improve themselves elsewhere. This particular behavior represented an attempt to encourage a coworker to leave the organization by recognizing his/her talents and offering helpful tips and ideas for how to improve his/her professional standing. Organizational members who utilized this behavior seemed to value the contributions of their peer coworkers, but were concerned that the organization was failing to acknowledge or fully appreciate their abilities. For example, "I thought that the organization just didn't measure up to his abilities, so I told him that he will get a job in a better place than this that has a very challenging environment where his talents can be credited."

Additionally, organizational members affirmed the talents and provided advice to peer coworkers who they believed had the potential to be good workers elsewhere by helping them understand just how talented they were. "I told her that she was very gifted and to try to go to 
some other good organization for a better salary and for better recognition of her talents." Thus, when organizational members encouraged their peer coworkers to voluntarily exit through affirming their talents or providing advice, they did so by recognizing their talents and skill sets. Organizational members also worked to help them receive the recognition they deserved by creating connections with other organizations for them.

Communicate overt statements, the fourth most frequently used behavior by participants, entailed organizational members communicating about the performance of their peer coworkers and reasons why they should depart the organization. This particular behavior represented an attempt to influence a coworker to voluntarily exit the organization by being frank and forthright regarding the standing of their peer coworker in the organization. Organizational members who utilized this behavior wanted to confront their peer coworkers without wasting much time conversing about tangential topics or events, especially when they felt wronged by the behavior of their peer coworkers. For example, "Once he took credit for the work I had done. I was not able to prove that and the managing director believed it. I had no evidence to prove it, but I warned him for that behavior."

Act unprofessionally was the fifth most frequently used behavior by participants and entailed organizational members behaving in inhospitable, cold, or demeaning ways toward their peer coworkers. This particular behavior represented an attempt to influence a coworker to voluntarily exit the organization by being unfriendly, unprofessional, and mean. Organizational members who utilized this behavior communicated in hostile and unethical ways toward their peer coworkers often because they simply disliked them. For example, "I really disliked him so I communicated as rudely as possible with him to discourage him from continuing here." 
Other organizational members commented that they acted unprofessionally with their peer coworkers as a way to encourage their departure because they were poor fits for the organization and it seemed like they were never going to fully acclimate its culture. "He never paid attention to what he needed to do on the job and for managing clients, so it was clear that he was never going to fit in, so I just treated him poorly whenever I could." Therefore, when organizational members encouraged their peer coworkers to voluntarily exit by acting unprofessionally toward them, they behaved in ways that could be considered unethical or demeaning toward their peer coworkers.

Provide information and encouragement about other alternatives, which entailed organizational members giving their peer coworkers information and reducing uncertainty about specific jobs, careers, and opportunities, was the sixth most frequently used behavior by participants. This particular behavior represented an attempt to influence a coworker to voluntarily exit the organization by dispensing wisdom, support, and insight that is useful for gaining employment at other organizations. Organizational members who utilized this behavior generally communicated in supportive ways that functioned to help their peer coworkers remain calm about the uncertainties of their organizational membership and to provide professional connections to other organizations. For example, one participant noted "I tried to be supportive of him and get him connections to more people and open the doors for better living in other areas."

Additionally, organizational members stated that they provided information and encouragement about other alternatives to their peer coworkers. They did this to help their peer coworkers fulfill their professional ambition by engaging in more enriching work with greater responsibilities. For example, one participated noted, "He was a bright guy who wanted to work 
in government, so I encouraged him to look into those opportunities to find a new beginning there." Overall, when organizational members encouraged their peer coworkers to voluntarily exit the organization by providing information and encouragement about other alternatives, they were supportive and willing to help their peer coworkers reduce their uncertainty and discover opportunities that would be fulfilling or useful for their careers.

Consult third-party sources, which entailed organizational members having discussions with direct supervisors, human resources, or the peer coworkers' family members about their peer coworkers, was the seventh most frequently used behavior by participants. Though this behavior involved indirectly influencing their peer coworkers to voluntarily exit the organization, the intention was still to influence exit. This particular behavior involved reporting violations of organizational policy, poor performance, or unprofessional behavior to organizational authority figures such as immediate supervisors and human resources personnel. They also reported violations to other coworkers, or by mentioning to family members that their peer coworker should pursue opportunities elsewhere. For example, one organizational member mentioned that while she had no direct conversations with her peer coworker about exiting the organization, she did consult with her supervisor about his performance. "I didn't say anything to him, but I just informed my manager about the case, said that he was a detriment to the organization, and suggested that it would be better if he went somewhere else."

Additionally, organizational members consulted with the family members of their peer when there was general concern about the well-being of the peer coworker. One participant stated he had noticed how much pressure was being placed on his peer coworker and consulted with the peer coworker's family about the situation. "I had spoken with his family about work and expressed my thoughts about his performance and that he should think about leaving or at 
least cutting his schedule." Overall, when organizational members encouraged their peer coworkers to voluntarily exit the organization by consulting third-party sources, they did so indirectly by having conversations with authority figures, other coworkers, and the family members of their peer coworkers.

Isolate, which entailed organizational members excluding their peer coworkers from social activities or work projects, was the eighth most frequently reported behavior. This particular behavior represented an attempt to influence a coworker to voluntarily exit the organization by implying that the peer understood that his/her presence was unwanted in the work environment and during informal social gatherings. Organizational members who utilized this behavior generally ostracized their peer coworkers and pushed them to the periphery of the social network so that they would understand their reduced professional and/or social status within the workgroup and the respondents would receive credit for the work they performed. For example, one participant noted that she isolated her peer coworker so that fellow organizational members would know that her peer coworker was selfish. "I tried to keep her work in the project as isolated as possible so that everyone knows what she is doing and to prevent her from taking the fruit of other's [sic] hard work."

Additionally, organizational members stated that they isolated their peer coworkers in an attempt to encourage them to leave by maliciously neglecting their peer coworkers' social or information needs. For example, "I would neglect her when she wants to talk with us whether it was about the workplace or just to shoot the breeze." Overall, when organizational members encouraged their peer coworkers to voluntarily exit the organization by isolating them, they did so to send a message that their behaviors were unwelcomed and they had no place in the work group or the social network. 
Once the data were analyzed to answer the research questions, six items drawn from actual responses and representative of each tactic that organizational members reported were written for use in a quantitative measure of peer-influence exit tactics. Table 6 contains the items that were developed to represent each tactic.

Table 6

Peer-Influence Exit Tactics Items

Communicate Professionally

Communicate in a friendly manner to him/her about his/her decision to leave

Maintain professionalism when speaking with him/her

Be polite in my discussions with him/her

Treat him/her in a professional way

Be civil with him/her

Avoid showing negative emotions to him/her

Minimize Communication

Keep to myself instead of engaging in conversations with him/her

Stop talking to him/her

Stay away from him/her as much as possible

Keep conversations to a minimum with him/her

Reduce the number of conversations I have with him/her

Refrain from answering his/her questions

\section{Affirm Talents and Provide Advice}

Compliment his/her ability

Offer advice about how to improve his/her performance in another organization

Suggest that another organization would better utilize his/her skill set

Say that the organization was failing to use his/her talents like they should

Tell him that he deserved to work for another organization

Detail the problems of the current organization to convince him to leave

\section{Overt Statements}

Confront him/her about leaving the organization

Warn him/her that he/she could be fired

Convince him/her to resign from his/her current position

Directly speak him/her about his/her behavior

Tell him/her that his/her behavior is unwelcomed in this organization

Tell him/her to quit his/her job 


\section{Act Unprofessionally}

Belittle him/her when we speak with one another

Be unfriendly with him/her

Communicate with him/her in a rude fashion

Act angry in conversations with him/her

Have him/her take on more responsibility than he/she can handle

Treat him/her poorly

Provide Information and Encouragement about other Alternatives

Provide information to him/her about other job openings

Tell him/her about other organizations that are hiring

Help him/her get a job at another organization

Recommend that he/she attend an interview at another organization

Tell him/her not to worry because other jobs will be available

Inform him/her of the benefit packages offered by other organizations

\section{Consult Third-Party Sources}

Discuss his/her behavior with other coworkers

Speak about his/her behavior with his/her immediate supervisor

Spread rumors about him/her to everyone in the organization

Speak about his/her wrongdoing with everyone

Inform manager about him/her

Report his/her behavior to Human Resources

\section{Isolate}

Ignore him/her as much as possible

Avoid discussing work with him/her

Keep his/her role in work project as isolated as possible

Disregard him/her when he/she needs my help

Neglect him/her has much as possible

Exclude him/her from group activities

\section{Research Question 2: Motives for Encouraging a Peer Coworker to Exit}

The second research question inquired about the motives organizational members have for encouraging a peer coworker to voluntarily leave the organization. Just over 800 units $(n=$ 801) were identified for motives. Results of a thematic analysis revealed that organizational members possess four distinct motives for encouraging their peer coworkers to voluntarily exit: Peer coworker is difficult to work with $(n=302)$, peer coworker is a detriment to the workplace 
$(n=295)$, respondent wants to improve work situation of peer coworker $(n=170)$, and respondent wants to improve his/her own standing $(n=34)$. Table 7 summarizes these results. 
Table 7

Motives for Encouraging Peer Coworkers to Exit

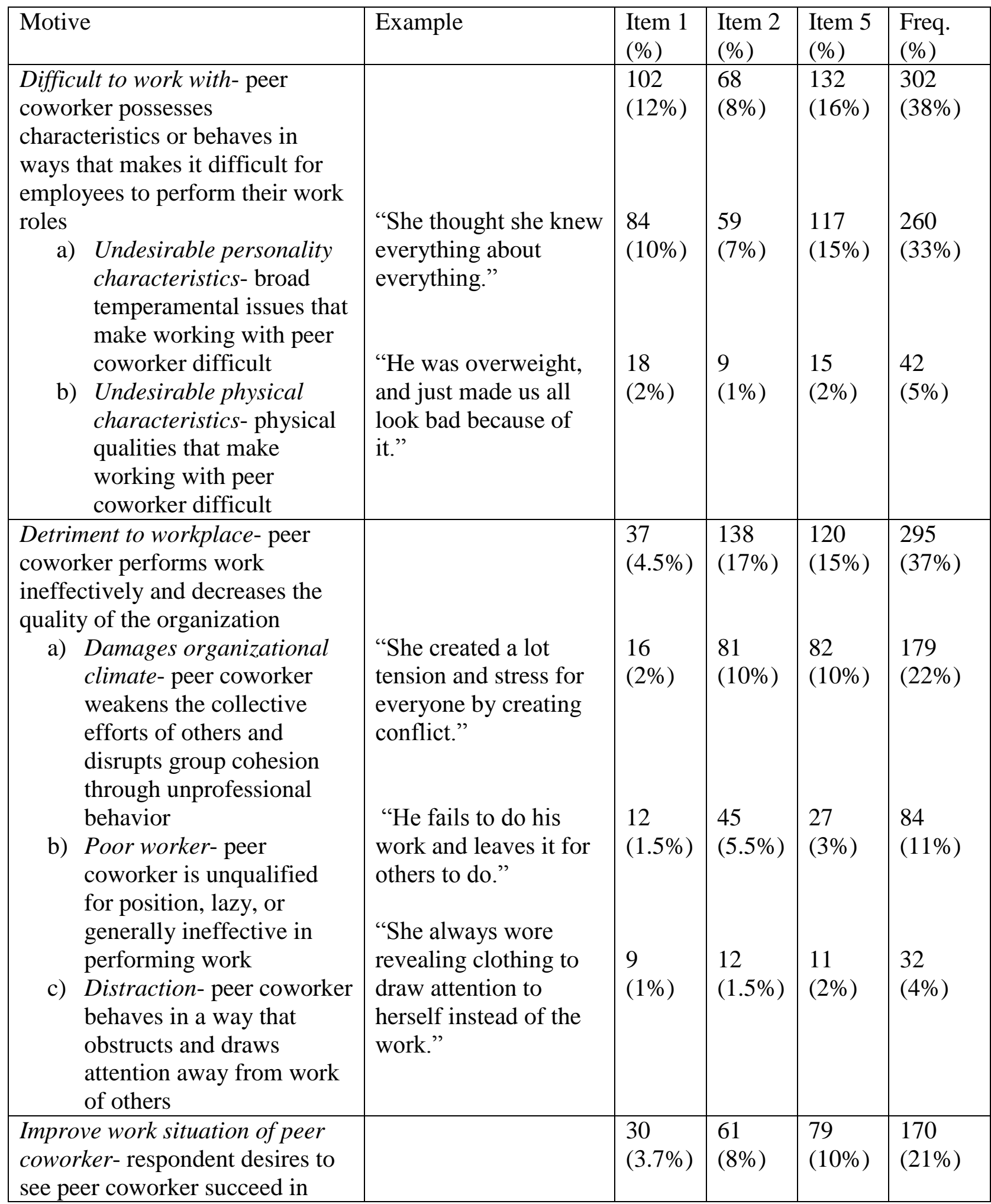




\begin{tabular}{|c|c|c|c|c|c|}
\hline $\begin{array}{l}\text { another organization } \\
\text { a) Talents or qualities } \\
\text { wasted by organization- } \\
\text { respondent desires to see } \\
\text { peer coworker with } \\
\text { characteristics, skills, or } \\
\text { talents, underutilized or } \\
\text { unrecognized by } \\
\text { organization leave to } \\
\text { better himself/herself } \\
\text { b) } \\
\text { Reduce stress- respondent } \\
\text { desires to see peer } \\
\text { coworker remove } \\
\text { himself/herself from the } \\
\text { pressure, strain, and } \\
\text { workload of the } \\
\text { organization } \\
\text { Family situation- } \\
\text { respondent desires to see } \\
\text { peer coworker spend } \\
\text { more time with his/her } \\
\text { family }\end{array}$ & $\begin{array}{l}\text { "His family lived in a } \\
\text { different place and he } \\
\text { really needed to get } \\
\text { back there with them." }\end{array}$ & $\begin{array}{l}1 \\
(0.1 \%)\end{array}$ & $\begin{array}{l}1 \\
(0.1 \%)\end{array}$ & $\begin{array}{l}2 \\
(0.2 \%)\end{array}$ & $\begin{array}{l}4 \\
(0.4 \%)\end{array}$ \\
\hline $\begin{array}{l}\text { Improve standing of self- } \\
\text { respondent will professionally } \\
\text { benefit from peer coworker's } \\
\text { departure } \\
\text { a) Competition- peer } \\
\text { coworker works similar } \\
\text { job, thus creating tension } \\
\text { between him/her and } \\
\text { respondent } \\
\text { b) Promotion opportunities- } \\
\text { peer coworker acts as an } \\
\text { obstacle to respondent } \\
\text { obtaining more } \\
\text { prestigious positions }\end{array}$ & $\begin{array}{l}\text { "He worked the same } \\
\text { job as me, so we } \\
\text { competed against one } \\
\text { another." } \\
\text { "I wanted the position } \\
\text { that she held." }\end{array}$ & $\begin{array}{l}5 \\
(0.6 \%) \\
4 \\
(0.5 \%)\end{array}$ & $\begin{array}{l}17 \\
(2 \%) \\
16 \\
(1.9 \%)\end{array}$ & $\begin{array}{l}12 \\
(2 \%) \\
11 \\
(1.8 \%)\end{array}$ & $\begin{array}{l}34 \\
(4 \%) \\
31 \\
(3.8 \%)\end{array}$ \\
\hline & & $\begin{array}{l}174 \\
(22 \%) \\
\end{array}$ & $\begin{array}{l}284 \\
(35 \%)\end{array}$ & $\begin{array}{l}343 \\
(43 \%) \\
\end{array}$ & $\begin{array}{l}801 \\
(100 \%) \\
\end{array}$ \\
\hline
\end{tabular}

Note. Item 1 was "Describe [Peer name]. Item 2 was "Explain why you want(ed) [Peer name] to leave the organization. Item 5 was "Why do/did you do or say those things to encourage [Peer name] to leave the organization?"

Peer coworker is difficult to work with entailed organizational members desiring their peer coworker to leave because he/she possesses characteristics or behaves in ways that makes it 
difficult for employees to perform their work roles. Two subcategories emerged from the data that provided further understanding for the motive and that represented particular reasons why peer coworkers were difficult to work with: undesirable personality characteristics $(n=260)$ and undesirable physical qualities $(n=42)$.

Undesirable personality characteristics represent the broad temperamental issues that make working with peer coworkers difficult. These qualities represented personality or communication traits that many organizational members considered to be difficult to overlook or objectionable in their particular workplaces. For example, one organizational member stated that she wanted her peer coworker to leave because the coworker was "bossy and was always right." For example, "she was perfectly adequate at her job, but infuriating to deal with on a personal level."

Undesirable physical qualities represent the salient and overt bodily features that make a person difficult to spend time with in the organization. These physical characteristics often focused on the targeted peer coworker's level of attractiveness, weight, height, or facial features. For example, one employee stated that he wished his peer coworker would leave because she "was pretty short and homely." Another organizational member commented that his coworker "was overweight and tough to look at." Thus, undesirable physical characteristics of peer coworkers represent reasons why organizational members find them difficult to work with. Peer coworker is a detriment to the workplace was the second most frequently reported motive for encouraging a peer coworker to voluntarily exit. This motive entailed organizational members wanting their peer coworker to leave because their peer coworker performs work ineffectively and decreases the quality of the organization. Three subcategories emerged that 
represented particular reasons why peer coworkers were detriments to the workplace: damages organizational climate $(n=179)$, poor worker $(n=84)$, and distraction $(n=32)$.

Damages organizational climate represents the notion that peer coworkers weaken the collective efforts of others and disrupt group cohesion through unprofessional behavior. Organizational members noted peer coworkers often liked to create conflict or refused to conform to the norms of the work group. For example, "he caused problems and created conflict between employees at work which goes against what we stand for." Another organizational member stated that her peer coworker fails to respect other coworkers and criticizes her. "Whenever he sees me he will come near to me and begin talking about my faults and being disrespectful to all of us." Overall, when peer coworkers damaged the organizational climate, organizational members were uncomfortable at work and found that their camaraderie with other coworkers was disrupted due to conflict or lack of respect.

Poor worker represents the notion that peer coworkers are generally unqualified for their positions, lazy, or ineffective in performing tasks. Poor workers were seen as detrimental to the functioning of the organization because they fail to accomplish tasks in a timely manner or rely upon other people to shoulder the workload. For example, "She doesn't take her job seriously and leaves all her work behind for us to do it." Additionally, one organizational member said that her peer coworker seems content allowing everyone else to assume responsibility while she plays on the computer. "Just because we (most of my colleagues) do the work, this particular person doesn't do anything except chatting on Facebook." Overall, when peer coworkers were poor workers, organizational members found themselves taking on added responsibility to compensate for their peers' ineffectiveness. Therefore, they encouraged poor performers to voluntarily exit. 
Distraction represents the notion that peer coworkers behave in a way that draws respondents' attention away from doing their own work. Organizational members who reported that their peer coworkers were a distraction mentioned that their coworkers seemed to lack focus on their work and often did things that limited the amount of work that the work group could do. For example, "he will be roaming around within the office and having chats with other people in the organization." Another participant noted that it was never easy to perform her required tasks at the office because her peer coworker was constantly seeking her attention with questions or other lines of conversation. "She was always interrupting me with a question that was often unrelated to the work or talking about something else. It was tough to work with her." Overall, when peer coworkers were distractions, organizational members found accomplishing their tasks or completing work to be more difficult.

Respondent wants to improve work situation of peer coworker was the third most frequently reported motive for encouraging a peer coworker to voluntarily exit. This motive entails organizational members wanting their peer coworker to leave due to their desire to see that peer coworker succeed in another organization. Three subcategories represented particular reasons why organizational members wanted their peer coworkers to improve their work situation: talents or qualities wasted by organization $(n=160)$, reduce stress $(n=6)$, and family situation $(n=4)$.

Talents or qualities wasted by organization represent the notion that organizational members want their peer coworkers to voluntarily exit the organization because their characteristics, skills, or talents are underutilized or unrecognized by the organization. For example, "he has lots of knowledge, but his current organization is not using it." Another participant noted that his peer coworker was one of the best employees, but key decision makers 
failed to acknowledge it. "He has accomplished more than most in his field. As long as he works here, the boss will own him and he will never be able to grow as an individual." Overall, when organizational members believed that the talents or skill sets of their peer coworkers were underutilized, they wanted their peer coworkers to find opportunities that would be more fulfilling and enriching to them.

Reduce stress represents the notion that organizational members want their peer coworkers to voluntarily exit the organization because they want to see them removed from the pressure, strain, and workload of the organization. For example, one participant stated, "I don't want to see him work this much harder." Additionally, another organizational member reported that he wanted to see his peer coworker avoid the pressure and struggles of working in a defensive and hostile climate. "He works hard and I don't want to see others insulting him and criticizing him for the work he does." Overall, when organizational members believed that work situations were detracting from the physical or mental health of their peer coworkers, they genuinely desired for their peers to remove themselves from the pressure of the workplace.

Family situation represents the notion that organizational members want their peer coworkers to voluntarily exit the organization because they believe that they should spend more time with their families. For example, "He was away from his family for a long time and in another country, so he used to miss them from time to time." Additionally, some organizational members believed that it would be best if their peer coworker stayed home to care for their families. "He was a family man with small children, so he should be with them more." Overall, when organizational members believed that the family situations of their peer coworkers were detracting from their organizational experience, they wanted to see them find an opportunity to balance their work with their family lives. 
Respondent wants to improve his/her own standing was the fourth most frequently reported motive for encouraging a peer coworker to voluntarily exit. This motive entails organizational members wanting their peer coworker to leave because that they will professionally benefit from their peer coworker's departure. Two subcategories represented particular reasons why organizational members believed that their peer coworkers were preventing them from reaching their own professional goals: competition $(n=31)$ and promotion opportunities $(n=3)$.

Competition represents the notion that organizational members want their peer coworkers to voluntarily exit because their peer coworker works a similar job, which creates tension between them. For example, one participant stated "We have similar talents and qualifications, but he is always competition for me." Another participant responded that his peer coworker seemed to get more attention from authority figures despite being similar in qualifications. "He always gets biased opportunities and the supervisor always asks for his opinion." Overall, when organizational members believed that their peer coworkers were competition for them, they were motivated to encourage them to voluntarily depart the organization.

Promotion opportunities represents the notion that organizational members want peer coworkers to voluntarily exit because they act as an obstacle to organizational members obtaining more prestigious positions in the organization. Organizational members reported that their peer coworkers occupied positions that they themselves wanted to hold. For example, "I would have wanted her to leave the organization due to the position that she held." Another organizational member reported that having his peer coworker in the organization was threatening to his professional aspirations. "He was a threat to my growth in that organization." Overall, when organizational members believed that their peer coworkers were obstacles to 
promotion opportunities or professional growth, they were motivated to encourage them to voluntarily depart the organization.

Once the data was analyzed to answer the research question, items drawn from actual responses and representative of each motive were written for use in a quantitative measure of the motives that organizational members have for encouraging their peer coworkers to voluntarily exit. Table 8 contains the items that were written for each tactic.

Table 8

Motives for Influencing a Peer Coworker to Voluntarily Exit Items

\section{Difficult to Work with}

Undesirable Physical Characteristics

Possesses(ed) undesirable physical features

Maintains(ed) an unhealthy physical appearance

\section{Undesirable Personality Characteristics}

Is/was manipulative

Is/was self-centered

\section{Detriment to Workplace}

Damages Organizational Climate

Rarely cooperates(ed) with other employees

Creates(ed) problems for the organization

\section{Poor Worker}

Rarely offers(ed) any contribution to the organization

Is/was a poor worker

\section{Distraction}

Distracts(ed) people from their work

Gossips(ed) about others

\section{Improve Work Situation of Peer Coworker}

Talents or Qualities Wasted by Organization

Has/had talents that could be better utilized elsewhere

Fails(ed) to receive proper salary for his/her contributions 


\section{Reduce Stress}

Will be/would be under less stress by leaving the organization

Will/would enjoy his/her work more if he/she went to another organization

\section{Family Situation}

Will have/had a better family situation if he/she left the organization

\section{Improve Standing of Self}

\section{Competition}

Is/was competition for me

Is/was favored by supervisors

\section{Promotion Opportunities}

Is/was a threat to my growth in the company

Works(ed) in a position that I want(ed)

Holds/held me back by being in the organization

\section{Research Question 13: Planning of Peer-Influence Exit Tactics}

Research question 13 inquired about the thought process behind organizational members encouraging their peer coworkers to voluntarily exit the organization. This purpose of the question was to discover how organizational members planned their behavior with a coworker they wanted to leave the organization. One hundred and sixty units for intentionality/planning of tactics were identified. Results of a thematic analysis revealed that organizational members experience three stages in the process of planning their behavior: Detect liked or disliked qualities about peer coworker $(n=75)$, devise behaviors $(n=60)$, and continue focusing on self $(n=25)$. Table 9 summarizes these results. 
Table 9

Thought Process for Encouraging Peer Coworkers to Exit

\begin{tabular}{|l|l|l|}
\hline Thought Process & Example & Frequency (\%) \\
\hline $\begin{array}{l}\text { Detect liked or disliked qualities about peer } \\
\text { coworker - respondent identifies } \\
\text { characteristics of peer coworker that are } \\
\text { underutilized or destructive to the } \\
\text { organization }\end{array}$ & $\begin{array}{l}\text { "Trust is important in this } \\
\text { line of work, and if you can't } \\
\text { trust someone, it affects your } \\
\text { work." }\end{array}$ & $75(47 \%)$ \\
\hline $\begin{array}{l}\text { Devise behaviors - respondent develops and } \\
\text { implements tactics to encourage the peer } \\
\text { coworker to exit }\end{array}$ & $\begin{array}{l}\text { "I am a chess player, and I } \\
\text { looked into his weaknesses, } \\
\text { and began to focus on } \\
\text { pushing him to leave." }\end{array}$ & $60(37 \%)$ \\
\hline $\begin{array}{l}\text { Continue focusing } \text { on self- respondent } \\
\text { maintains concentration on respondent's own } \\
\text { work and endeavors to distance } \\
\text { himself/herself from peer coworker }\end{array}$ & $\begin{array}{l}\text { "I kept working hard, but I } \\
\text { looked into opportunities } \\
\text { elsewhere." }\end{array}$ & $25(16 \%)$ \\
\hline \multicolumn{2}{|l|}{} & \\
\hline
\end{tabular}

Detect liked or disliked qualities about peer coworker represented the first thing that organizational members did when they realized they wanted a peer coworker to voluntarily exit the organization. This portion of the thought process involves organizational members realizing that their peer coworkers possess characteristics that are either desirable for other workplaces or undesirable and destructive for their current workplaces. Organizational members who reported detecting liked qualities about their peer coworker stated that they realized their peer coworkers were good performers in the organization, but were limited in their opportunities to progress or were noticeably unhappy with their organization. For example, "it was difficult to see him suffer everyday [sic] because he was in the best position he could hope to attain and would never successfully climb within that organization." Additionally, participants who reported detecting disliked qualities about their peer coworkers mentioned that they noticed their peer coworker was performing poorly in the organization and detracting from the success of other coworkers 
and the organization. "He was not fit for the current role which required good analytical skills. Therefore a suitable candidate was deprived of an opportunity to exhibit his skills." Overall, detecting certain qualities possessed by peer coworkers represented the initial phase in the process of encouraging peer coworkers to voluntarily exit.

Devise behaviors represented the second thing that organizational members did when they realized they wanted a peer coworker to voluntarily exit the organization. This portion of the thought process involves organizational members strategizing and/or enacting behaviors to encourage their peer coworkers to leave. Organizational members who reported devising behaviors stated that they plotted or performed behaviors that they believed would expedite their coworkers' departure from the organization. One participant noted that by encouraging her peer coworker to exit, she would no longer be subjected to her actions. For example, "I was thinking if I get him to leave, I would not have to listen to his b.s. anymore." Another participant stated that she actively encouraged her peer coworker to leave to avoid hindering the performance of the organization any longer. "I only wanted other employees to not be affected by his behavior which was hampering the quality of work; hence, I encouraged him to leave." Overall, the second phase of the process for encouraging peer coworkers to voluntarily exit involved developing strategies and/or enacting behaviors.

Continue focusing on self represented the third thing that organizational members did when they realized they wanted a peer coworker to voluntarily exit the organization. This portion of the thought process involves organizational members devoting their attention toward their own work after encouraging their peer coworker to leave. Organizational members mentioned that they concentrated on their specific work requirements and duties again. According to one participant, "I completed my job and enjoyed life." Another organizational 
member stated that he was comforted that his peer coworker had decided to exit the organization.

"I was very happy and relieved on learning about his departure from the organization." Overall, this phase represented returning to a sense of normalcy or tranquility in the workplace.

\section{Research Question 14: Effectiveness of Using Peer-Influence Exit Tactics}

Research question 14 inquired about the effectiveness of peer-influence exit tactics in encouraging a peer coworker to voluntarily exit the organization. This purpose of the question was to discover how effective organizational members were in accomplishing their goal of getting a peer to exit. Coders identified 129 units for success/effectiveness of tactics. Results of a thematic analysis revealed that the behaviors used by organizational members to encourage their peer coworkers to voluntarily leave the organization had four major effects on the receiver of the behaviors: expedited exit $(n=47)$, uncertain effect $(n=40)$, silver-lining effect $(n=34)$, and created remorse $(n=8)$. Table 10 summarizes these results.

Table 10

Effect of Peer-Influence Exit Tactics on Receiver

\begin{tabular}{|l|l|l|}
\hline Effect & Example & $\begin{array}{l}\text { Freq. } \\
(\%)\end{array}$ \\
\hline $\begin{array}{l}\text { Expedited Exit- peer coworker left } \\
\text { organization much quicker than } \\
\text { he/she ordinarily would have }\end{array}$ & $\begin{array}{l}\text { "After we spoke, he decided to move on to } \\
\text { another opportunity." }\end{array}$ & $\begin{array}{l}47 \\
(37 \%)\end{array}$ \\
\hline $\begin{array}{l}\text { Uncertain Effect- respondents were } \\
\text { unsure about how much influence } \\
\text { their actions had on peer coworkers }\end{array}$ & $\begin{array}{l}\text { "I don't know if she left as a direct result of my } \\
\text { behaviors, but she did leave, and we were } \\
\text { happy about it." }\end{array}$ & $\begin{array}{l}40 \\
(31 \%)\end{array}$ \\
\hline $\begin{array}{l}\text { Silver-Lining Effect- peer coworker } \\
\text { found better opportunities and } \\
\text { strengthened relationship with } \\
\text { respondent }\end{array}$ & $\begin{array}{l}\text { "He believed that what I told him was best for } \\
\text { his career, he thanked me for it, and eventually } \\
\text { left for a much better organization. We are } \\
\text { closer friends now because of it." }\end{array}$ & $\begin{array}{l}34 \\
(26 \%)\end{array}$ \\
\hline $\begin{array}{l}\text { Created Remorse- peer coworker } \\
\text { expressed shame and apologized for } \\
\text { causing problems in the } \\
\text { organization before exiting }\end{array}$ & $\begin{array}{l}\text { "She realized her behavior was harming the } \\
\text { organization, and she felt bad about it after she } \\
\text { left." }\end{array}$ & $\begin{array}{l}8 \\
(6 \%)\end{array}$ \\
\hline \multicolumn{2}{|l}{} & $\begin{array}{l}129 \\
(100 \%)\end{array}$ \\
\cline { 2 - 2 }
\end{tabular}


Expedited exit involves the recipient of peer-influence exit tactics leaving the organization much quicker than the respondent believed he or she ordinarily would have left. For example, one organizational member stated that the conversation that he had with his peer coworker was a turning point in that peer coworker's decision to accept another job opportunity. "He made up his mind to join another organization after we spoke."

Other organizational members mentioned that they believed the tactics they used empowered their peer coworkers to make career decisions for themselves. As one participant noted "I feel like I encouraged her to make decisions for herself." Overall, expedited exit reflected the notion that organizational members encouraged their peer coworkers to hasten their decision to voluntarily exit.

Uncertain effect represented the second most frequently reported effect of encouraging a peer coworker to voluntarily exit the organization. This effect involves organizational members being uncertain or unsure about the effect of their behaviors on their peer coworkers' decisions to voluntarily exit the organization. Organizational members mentioned that their peer coworkers often departed on their own volition with minimal influence from other people in the organization. As one participant said "I'm not sure I was the reason, but she was quite comfortable ignoring me and it didn't bother her to not be friends with all the staff."

Other organizational members mentioned that while they had conversations or behaved in a manner designed to encourage the departure of their peer coworker, ultimately, other circumstances more directly led to their exit. For example, one participant said "It is difficult to say that I directly influenced him, but my coworker did leave because of the manager." Another employee mentioned "My words probably had little effect because he had some family commitments." Overall, the uncertain effect represented how organizational members were 
unsure of the effect their behaviors had on encouraging their peer coworkers to voluntarily exit the organization.

Silver-lining effect represented the third most frequent effect of encouraging a peer coworker to leave reported by organizational members. This effect involves the recipient of peer-influence exit tactics leaving the organization for better opportunities, while also strengthening the relationship he/she developed with his/her former colleagues. Organizational members who reported that their behaviors created a silver-lining effect mentioned that they helped their peer coworkers find more fulfilling job or careers, which actually helped create stronger relational bonds. For example, one organizational member stated that her peer coworker greatly appreciated being encouraged to leave the organization and felt that her best interests were being taken into consideration by being influenced to leave. "I think she felt that I had her best interest at heart."

Other organizational members declared that their behaviors served to strengthen the relational bonds they had with their peer coworkers, which led to increased communication between them. As one participant noted "I congratulated her and wished her the best in her new career. We are in good relation still and we communicate more often." Another participant emphasized that his relationship with his peer coworker improved after encouraging him to exit. "We have a better friendship as a result of him leaving." Overall, the silver-lining effect was an outcome representing how the behaviors of organizational members resulted in better opportunities for their peer coworkers and reinforced the relationship between them.

Created remorse was the fourth most frequently reported effect of encouraging a peer coworker to voluntarily exit the organization. This effect involves the recipient of peer-influence exit tactics expressing shame and regret for causing problems in the organization prior to exiting. 
Organizational members who reported that their behaviors created remorse mentioned that the conversations they had with their peer coworkers or the behaviors enacted toward them created opportunities for their targeted peer coworkers to reflect on and realize their wrongdoing. For example, one participant stated that after realizing how destructive his peer coworker's actions were, he was remorseful. "He was ashamed at what he had done." Another participant said that her peer coworker "felt sorry." Overall, creating remorse was an effect representing how the behaviors of organizational members produced feelings of shame, guilt, and sheepishness for peer coworkers regarding ways that they had behaved in the organization prior to exiting.

Research question 14 was also assessed by examining the number of employees who had voluntarily left the organization and the reasons they did so. A binomial distribution analysis indicated that the proportions of organizational members who remained in the organization ( $n=$ $96,47 \%)$ and those who exited the organization $(n=109,52 \%)$ did not differ at a statistically significant level, $p=.53$. Thus, there were no differences in the number of organizational members who remained in the organization and the number of organizational members who exited.

Of the 109 targets who were reported to have left the organization, 81 (74\%) were reported to have exited voluntarily and $25(23 \%)$ were reported to have exited involuntarily. Results of a binomial distribution analysis indicated that the proportions differed at a statistically significant level, $p<.001$. A larger portion of the targets exited the organization voluntarily than exited it involuntarily. Three participants (3\%) failed to specify a reason for departing. Table 11 summarizes the frequencies. 
Table 11

Peer Coworker Exit Behavior after Receiving Peer-Influence Exit Tactics

\begin{tabular}{|c|c|}
\hline Exit Behavior & Frequency (\%) \\
\hline Exited & $109(52 \%$ of total $)$ \\
\hline Voluntarily & $81(40 \%$ of total $)$ \\
\hline Involuntarily & $25(12 \%$ of total $)$ \\
\hline Remained & $96(47 \%$ of total $)$ \\
\hline TOTAL & $205(100 \%)$ \\
\hline
\end{tabular}

Among the 81 targets who had voluntarily exited, respondents stated that $65(80 \%)$ had exited the organization for better opportunities, 28 (34\%) were reported to have simply quit (i.e., respondents did not provide further information), 13 (16\%) departed due to personal reasons, and $3(4 \%)$ retired (see Table 12). A single-sample chi-square analysis indicated that the proportions of reasons organizational members voluntarily left the organization differed at a statistically significant level, $\chi^{2}(3)=18.62, p<.001$. Table 12 summarizes these results. Table 12

Reasons Peer Coworkers Voluntarily Exited Organization

\begin{tabular}{|l|l|l|}
\hline Reason & Example & $\begin{array}{l}\text { Freq. } \\
(\%)\end{array}$ \\
\hline $\begin{array}{l}\text { Better Opportunity- peer coworker found } \\
\text { jobs or endeavors that were an } \\
\text { improvement over previous employment }\end{array}$ & $\begin{array}{l}\text { "He found a job that was more suitable to } \\
\text { him that paid much better." }\end{array}$ & $\begin{array}{l}65 \\
(60 \%)\end{array}$ \\
\hline $\begin{array}{l}\text { Quit- peer coworker exited without first } \\
\text { securing another opportunity }\end{array}$ & $\begin{array}{l}\text { "She quit without telling one or even } \\
\text { trying to find another place to work. I } \\
\text { think she just got tired of working." }\end{array}$ & $\begin{array}{l}28 \\
(26 \%)\end{array}$ \\
\hline $\begin{array}{l}\text { Personal Reasons- peer coworker } \\
\text { experienced health-related issues or had } \\
\text { family concerns }\end{array}$ & $\begin{array}{l}\text { "He wanted to spend more time with his } \\
\text { family and enjoy their company." }\end{array}$ & $\begin{array}{l}13 \\
(12 \%)\end{array}$ \\
\hline $\begin{array}{l}\text { Retired- peer coworker worked a } \\
\text { specified amount of time and exited the } \\
\text { organization }\end{array}$ & $\begin{array}{l}\text { "He was progressing in age, so he } \\
\text { retired." }\end{array}$ & $\begin{array}{l}3 \\
(3 \%)\end{array}$ \\
\hline \multicolumn{2}{|l}{} & $\begin{array}{l}109 \\
(100 \%)\end{array}$ \\
\hline
\end{tabular}




\section{Summary}

The results of the first study yielded information regarding the behaviors, motives, thought process behind, and effect of organizational members encouraging their peer coworkers to voluntarily leave the organization. Organizational members encourage their peer coworkers to voluntarily exit through the use of eight peer-influence exit tactics that vary from supportive and affirming tactics to hostile and unfriendly tactics. Organizational members also report four overarching motives for encouraging their peer coworkers to leave that represent their desire to improve the organization, rid themselves of people who are difficult to work with, to see their peer coworker improve him/herself by finding employment elsewhere, or their desire to improve their own standing by ridding themselves of peer coworkers who work similar jobs or have similar skill sets. The peer-influence exit process that organizational members engage in ranges from discovering something that they like or dislike about their peer coworkers to maintaining focus on their own endeavors. Finally, peer-influence exit tactics result in four different effects on peer coworkers: expedited exit, uncertain, silver lining, and created remorse.

\section{Study 2 Results}

Table 13 contains the descriptive statistics and a correlation matrix of all variables examined in the study.

\section{Source Characteristics}

Hypothesis one predicted that the competitiveness of the source would be related to the source's use of peer-influence exit tactics. Results of Pearson's correlations revealed partial support for this hypothesis as the source's competitiveness was positively related to the source's use of affirmation tactics, unprofessional tactics, and depersonalization tactics. There was no 
statistically significant relationship between the source's competitiveness and the source's use of professional tactics.

Hypothesis two predicted that the agreeableness of the source would be related to the source's use of peer-influence exit tactics. Results of Pearson's correlations revealed support for this hypothesis as the source's agreeableness was negatively related to the source's use of affirmation tactics, unprofessional tactics, and depersonalization tactics. The source's agreeableness was positively related to the source's use of professional tactics.

Research question four asked about the relationship between the self-esteem of the source and the source's use of peer-influence exit tactics. Results of Pearson's correlations revealed that the source's self-esteem was negatively related to the source's use of unprofessional tactics and positively related to the source's use of professional tactics. There was no statistically significant relationship between the source's self-esteem and the source's use of affirmation tactics or between the source's self-esteem and the source's use of depersonalization tactics. 
Table 13

Descriptive Statistics and Correlation Matrix for Study 2 Variables

\begin{tabular}{|c|c|c|c|c|c|c|c|c|c|c|c|}
\hline Variable & $M$ & $S D$ & 1 & 2 & 3 & 4 & 5 & 6 & 7 & 8 & 9 \\
\hline \multicolumn{12}{|l|}{ Source Characteristics } \\
\hline 1. Competitiveness & 3.09 & .96 & -- & & & & & & & & \\
\hline 2. Agreeableness & 3.76 & .66 & -.11 & -- & & & & & & & \\
\hline 3. Self-Esteem & 3.75 & .81 & -.10 & $.37^{* *}$ & -- & & & & & & \\
\hline \multicolumn{12}{|l|}{ Peer-Influence Exit Tactics } \\
\hline 4. Affirmation & 2.33 & .99 & $.19^{* *}$ & $-.20^{* *}$ & -.06 & -- & & & & & \\
\hline 5. Unprofessional & 1.66 & .84 & $.22^{* * *}$ & $-.54^{* * *}$ & $-.29^{* * * *}$ & $.56^{* * *}$ & -- & & & & \\
\hline 6. Depersonalization & 2.13 & 1.05 & $.18^{* *}$ & $-.35^{* * *}$ & -.06 & $.48^{* * *}$ & $.68^{* * *}$ & -- & & & \\
\hline 7. Professional & 3.87 & .97 & .06 & $.47^{* * *}$ & $.20^{* *}$ & -.12 & $-.43^{* * *}$ & $-.27^{* *}$ & - & & \\
\hline \multicolumn{12}{|l|}{ Target Characteristics } \\
\hline 8. Work Performance & 2.92 & 1.47 & .06 & .05 & -.07 & $-.27^{* * *}$ & $-.18^{* *}$ & $-.47^{* * *}$ & $.14^{*}$ & -- & \\
\hline 9. Teamwork & 3.20 & 1.38 & .06 & -.00 & .02 & -.10 & -.03 & $-.13^{*}$ & .08 & .14 & -- \\
\hline Desire for Peer to Exit & 2.94 & 1.37 & .10 & $-.16^{*}$ & -.06 & $.44^{* * *}$ & $.37^{* * *}$ & $.59^{* * *}$ & $-.24^{* * *}$ & $-.73^{* * *}$ & -.12 \\
\hline
\end{tabular}

Note. $* * * p<.001 . * * p<.01 . * p<.05$. 


\section{Target Characteristic}

Research question six asked about the relationship between the source's perception of the work performance of his/her peer coworker and the use of peer-influence exit tactics. Results of a multivariate analysis of variance (MANOVA) revealed a statistically significant main effect of peer work performance on the source's use of peer-influence exit tactics, Wilks' $\lambda=.73, F(4$, 190) $=17.36, p<.001$, partial $\eta^{2}=.27$. Univariate effects were statistically significant for affirmation tactics, $F(1,194)=9.81, p<.01$, partial $\eta^{2}=.05$; unprofessional tactics, $F(1,194)$ $=9.03, p<.01$, partial $\eta^{2}=.05$, and depersonalization tactics, $F(1,194)=59.33, p<.001$, partial $\eta^{2}=.24$. There was no statistically significant effect for professional tactics, $F(1,194)=$ $2.17, p=.13$, partial $\eta^{2}=.01$. Individuals reported that they would use affirmation, unprofessional, and depersonalization tactics to a greater extent with a low performer than with a high performer (see Table 14).

Table 14

Effect of Peer Work Performance on the Use of Peer-Influence Exit Tactics

\begin{tabular}{llll}
\hline & \multicolumn{2}{c}{ Work Performance } \\
High & Mean $(S D)$ & $\begin{array}{l}\text { Low } \\
\text { Mean }(S D)\end{array}$ & $F(d f)$ \\
\hline Peer-Influence Exit Tactics & $2.08(.65)$ & $2.51(.92)$ & $9.81^{*}(1,195)$ \\
Affirmation Tactics & $1.47(.78)$ & $1.83(.87)$ & $9.02^{*}(1,195)$ \\
Unprofessional Tactics & $1.61(.84)$ & $2.65(1.02)$ & $59.33^{* * *}(1,195)$ \\
Depersonalization Tactics & $3.98(1.02)$ & $3.77(.90)$ & $2.36(1,195)$ \\
Professional Tactics & & & \\
\hline Note. & &
\end{tabular}




\section{Organizational Characteristic}

Research question nine asked about the relationship between the source's perception of the teamwork of his/her peer coworker's organization and the use of peer-influence exit tactics. Results of a MANOVA revealed that there was no main effect of perception of teamwork on the use of peer-influence exit tactics, Wilks' $\lambda=.98, F(4,190)=.96, p=.43$, partial $\eta^{2}=.02($ see Table 15).

Table 15

Effect of Perceived Teamwork on the Use of Peer-Influence Exit Tactics

Teamwork

High Low

Mean $(S D) \quad$ Mean $(S D) \quad F(d f)$

Peer-Influence Exit Tactics

$\begin{array}{llll}\text { Affirmation Tactics } & 2.23(1.02) & 2.39(.94) & 1.26 \quad(1,195) \\ \text { Unprofessional Tactics } & 1.64(.87) & 1.67(.80) & 0.05 \quad(1,195) \\ \text { Depersonalization Tactics } & 2.07(1.04) & 2.25(1.10) & 1.45 \quad(1,195) \\ \text { Professional Tactics } & 3.91(.95) & 3.83(.99) & 0.35(1,195) \\ & & \\ \text { Note. }^{* * *} p<.001 .{ }^{* *} p<.01 .^{*} p<.05 & \end{array}$

\section{Summary}

The results suggested that the personality traits of organizational members and the work performance of a peer coworker affect the use of peer-influence exit tactics. Specifically, organizational members' competitiveness, agreeableness, and self-esteem were related to the use of various peer-influence exit tactics. There was a positive relationship between organizational 
members' competitiveness and their use of affirmation, unprofessional, and depersonalization tactics. Organizational members' agreeableness was positively related to the use of professional tactics, but negatively related to the use of affirmation, unprofessional, and depersonalization tactics. Organizational members' self-esteem was positively related to the use of professional tactics and negatively related to the use of unprofessional tactics. Furthermore, organizational members reported that they would be more likely to use affirmation, unprofessional, and depersonalization tactics with a poor work performer than with a strong work performer.

\section{Study 3 Results}

Table 16 contains a correlation matrix of all variables in the study. Research question three asked about the relationship between organizational members' motives for influencing a peer coworker to voluntarily leave the organization and their use of peer-influence exit tactics. Results of Pearson correlations indicated that the personal gain motive was positively related to organizational members' use of affirmation tactics, unprofessional tactics, and depersonalization tactics, and negatively related to the use of professional tactics. The altruistic motive was positively related to the use of affirmation tactics and unprofessional tactics, but there was no statistically significant relationship between the altruistic motive and the use of depersonalization tactics or professional tactics. The organizational improvement motive was positively related to the use of affirmation tactics, unprofessional tactics, depersonalization tactics, and professional tactics. The climate enhancement motive was positively related to the use of affirmation tactics, unprofessional tactics, depersonalization tactics, and professional tactics. 
Table 16

Correlation Matrix for Study 3 Variables

\begin{tabular}{|c|c|c|c|c|c|c|c|c|c|c|c|c|c|c|c|}
\hline Variable & 1 & 2 & 3 & 4 & 5 & 6 & 7 & 8 & 9 & 10 & 11 & 12 & 13 & 14 & 15 \\
\hline 1. Competitiveness & -- & & & & & & & & & & & & & & \\
\hline 2. Agreeableness & $-.18^{* *}$ & -- & & & & & & & & & & & & & \\
\hline 3. Self-esteem & $-.18^{* *}$ & $.52^{* * *}$ & -- & & & & & & & & & & & & \\
\hline 4. Affirmation & $.44^{* * * *}$ & $-.24^{* * *}$ & $-.23^{* * *}$ & -- & & & & & & & & & & & \\
\hline 5. Unprofessional & $.33^{* * * *}$ & $-.49^{* * * *}$ & $-.53^{* * *}$ & $.55^{* * * *}$ & -- & & & & & & & & & & \\
\hline 6. Depersonalization & -.03 & $-.20^{* *}$ & -.02 & .10 & $.45^{* * *}$ & -- & & & & & & & & & \\
\hline 7. Professional & -.09 & $.21^{* *}$ & $.32^{* * *}$ & .04 & $-.25^{* * *}$ & .10 & -- & & & & & & & & \\
\hline 8. Similarity & $.33^{* * * *}$ & $-.16^{* *}$ & $-.29^{* * *}$ & $.30^{* * * *}$ & $.27^{* * * *}$ & -.32 & -.07 & -- & & & & & & & \\
\hline 9. Work Performance & $.18^{* *}$ & .01 & -.11 & .04 & -.05 & $-.27^{* * *}$ & .06 & $.55^{* * *}$ & -- & & & & & & \\
\hline 10. Liking & .19 & -.01 & -.11 & $.17^{* *}$ & -.06 & $-.51^{* * *}$ & $-.13^{*}$ & $.57^{* * * *}$ & .42 & -- & & & & & \\
\hline 11. Org. Influence & $.31^{* * * *}$ & -.02 & -.09 & $.19^{* *}$ & .09 & -.12 & $.20^{* *}$ & $.55^{* * * *}$ & $.62^{* * *}$ & $.38^{* * *}$ & -- & & & & \\
\hline 12. Teamwork & $.30^{* * * *}$ & .09 & .03 & .06 & $.15^{*}$ & .02 & $.14^{*}$ & $.25^{* * *}$ & .10 & .13 & $.20^{* *}$ & -- & & & \\
\hline 13. Autonomy & $-.14^{*}$ & $.19^{* *}$ & .11 & $-.25^{* * *}$ & -.10 & .10 & .00 & .03 & .09 & .02 & .02 & $.25^{* * *}$ & -- & & \\
\hline 14. Welfare & .05 & $.15^{*}$ & .06 & -.08 & .01 & -.08 & $.16^{*}$ & $.19^{* *}$ & $.18^{* *}$ & .14 & $.17^{*}$ & $.55^{* * *}$ & $.33^{* * *}$ & -- & \\
\hline 15. Formalization & .01 & $.15^{*}$ & $.23^{* * *}$ & -.12 & $-.32^{* * *}$ & -.11 & .13 & $-.26^{* *}$ & .04 & $-.17^{*}$ & -.08 & $-.14^{*}$ & $-.19^{* *}$ & -.12 & -- \\
\hline 16. Effort & -.05 & $.17^{*}$ & $.23^{* * *}$ & -.13 & -.05 & .07 & $.18^{* *}$ & .06 & $.18^{* *}$ & -.05 & .12 & $.53^{* * *}$ & $.33^{* * *}$ & $.51^{* * *}$ & -.03 \\
\hline 17. Pressure Perform & -.08 & -.02 & $.25^{* * *}$ & .09 & -.12 & .05 & .05 & $-.19^{* *}$ & -.08 & -.08 & -.07 & $-.23^{* * *}$ & $-.26^{* * * *}$ & $-.19^{* *}$ & .10 \\
\hline 18. Distrib. Justice & $.21^{* *}$ & -.08 & -.07 & .10 & $.21^{* *}$ & -.04 & .10 & $.33^{* * *}$ & $.29^{* * *}$ & $.17^{*}$ & $.27^{* * *}$ & $.54^{* * * *}$ & $.22^{* * * *}$ & $.51^{* * *}$ & -.12 \\
\hline 19. Proced. Justice & $.20^{* *}$ & -.06 & -.06 & .11 & $.21^{* *}$ & .04 & .13 & $.36^{* * *}$ & $.25^{* * *}$ & $-.21^{* *}$ & $.33^{* * *}$ & $.68^{* * *}$ & $.18^{* * *}$ & $.60^{* * *}$ & $-.18^{* *}$ \\
\hline 20. Interact. Justice & $.20^{* *}$ & .08 & .10 & .06 & $.14^{* *}$ & .02 & $.19^{* *}$ & $.31^{* * *}$ & $.14^{*}$ & $.17^{*}$ & $.29^{* * *}$ & $.68^{* * *}$ & $.34^{* * * *}$ & $.62^{* * *}$ & -.12 \\
\hline 21. Sup. Complicity & $.42^{* * *}$ & $-.37^{* * * *}$ & $-.41^{* * *}$ & $.46^{* * * *}$ & $.63^{* * *}$ & $.17^{* *}$ & $-.19^{* *}$ & $.39^{* * *}$ & .07 & .08 & $.22^{* *}$ & $.23^{* * *}$ & -.05 & .08 & $-.29^{* * *}$ \\
\hline 22. Job Satisfaction & .12 & .11 & $21^{* *}$ & -.09 & -.08 & .02 & $.19^{*}$ & .04 & .08 & .10 & $.14^{*}$ & $.56^{* * *}$ & $.29^{* * *}$ & $.59^{* * *}$ & .04 \\
\hline 23. Coworker Regard & $-.19^{* *}$ & $.51^{* * * *}$ & $.72^{* * *}$ & $-.30^{* * *}$ & $-.63^{* * * *}$ & -.06 & $.36^{* * *}$ & -.41 & -.09 & $-.14^{*}$ & -.12 & -.00 & .10 & .01 & $.33^{* * *}$ \\
\hline 24. Personal Gain & $.38^{* * * *}$ & $-.43^{* * *}$ & $-.45^{* * *}$ & $.53^{* *}$ & $.77^{* * * *}$ & $.23^{* * *}$ & $-.21^{* * *}$ & $.40^{* * *}$ & .10 & .04 & $.23^{*}$ & $.18^{* *}$ & $-.18^{* *}$ & -.02 & $-.21^{* *}$ \\
\hline 25. Altruistic & $.42^{* * * *}$ & $-.21^{* *}$ & $-.28^{* * *}$ & $.57^{* * *}$ & $.49^{* *}$ & .04 & .01 & $.37^{* * * *}$ & .11 & .10 & $.19^{* *}$ & .10 & -.12 & -.02 & $-.19^{* *}$ \\
\hline 26. Org. Improve. & -.06 & $-.16^{*}$ & .03 & $.20^{* *}$ & $.27^{* * *}$ & $.46^{* * *}$ & $.20^{* * *}$ & $-.21^{* * *}$ & $-.46^{* * * *}$ & $-.36^{*}$ & $-.22^{* * *}$ & .04 & .10 & -.12 & $-.16^{*}$ \\
\hline 27. Clim. Enhance. & .02 & $-.13^{*}$ & .00 & $.17^{* *}$ & $.24^{* * * *}$ & $.52^{* * *}$ & $.19^{* *}$ & $-.26^{* * * *}$ & $-.31^{* * * *}$ & $-.42^{*}$ & -.10 & .02 & .06 & -.06 & -.07 \\
\hline
\end{tabular}




\begin{tabular}{|c|c|c|c|c|c|c|c|c|c|c|c|}
\hline Variable & 16 & 17 & 18 & 19 & 20 & 21 & 22 & 23 & 24 & 25 & 26 \\
\hline 16. Effort & -- & & & & & & & & & & \\
\hline 17. Pressure Perform & -.03 & -- & & & & & & & & & \\
\hline 18. Distrib. Justice & $.39^{* * *}$ & $-.23^{* * *}$ & -- & & & & & & & & \\
\hline 19. Proced. Justice & $.49^{* * *}$ & $-.19^{* *}$ & $.56^{* * *}$ & -- & & & & & & & \\
\hline 20. Interact. Justice & $.50^{* * * *}$ & $-.18^{* *}$ & $.59^{* * *}$ & $.71^{* * *}$ & -- & & & & & & \\
\hline 21. Sup. Complicity & -.05 & -.11 & $.35^{* * * *}$ & $.27^{* * *}$ & $.28^{* * * *}$ & -- & & & & & \\
\hline 22. Job Satisfaction & $.49^{* * *}$ & $-.24^{* * *}$ & $.42^{* * * *}$ & $.51^{* * *}$ & $.56^{* * *}$ & -.00 & -- & & & & \\
\hline 23. Coworker Regard & $.24^{* * *}$ & $.20^{* * *}$ & $-.19^{* *}$ & -.13 & .09 & $-.52^{* * * *}$ & $.18^{* *}$ & -- & & & \\
\hline 24. Personal Gain & -.09 & -.03 & $.24^{* * *}$ & $.22^{* *}$ & .13 & $.61^{* * *}$ & -.12 & $-.62^{* * *}$ & -- & & \\
\hline 25. Altruistic & -.11 & -.04 & $.16^{* *}$ & .11 & $.17^{* *}$ & $.46^{* * *}$ & -.10 & $-.32^{* * *}$ & $.56^{* * *}$ & -- & \\
\hline 26. Org. Improve. & -.10 & .07 & -.11 & .00 & .04 & $.15^{*}$ & -.06 & -.03 & $.24^{* * *}$ & $.22^{* * * *}$ & -- \\
\hline 27. Clim. Enhance. & -.02 & .10 & -.05 & .02 & .02 & .08 & .03 & -.07 & $.28^{* * *}$ & $.27^{* * * *}$ & $.55^{* * *}$ \\
\hline
\end{tabular}
Note. ${ }^{* * * *} p<.001{ }^{* *} p<.01 ;{ }^{*} p<.05$ 
To assess the ability of the motives to predict the use of peer-influence exit tactics, four multiple regressions were conducted, resulting in statistically significant models for each of the tactics. Results indicated that the motives accounted for $43 \%$ of the variance in the use of affirmation tactics, $F(4,215)=40.72, p<.001$. Personal gain and altruistic motives were statistically significant predictors of the use of affirmation tactics. Results indicated that the motives accounted for $61 \%$ of the variance in the use of unprofessional tactics, $F(4,214)=$ $83.95, p<.001$. Personal gain and organizational improvement were statistically significant predictors of unprofessional tactics. The motives accounted for $32 \%$ of the variance in depersonalization tactics, $F(4,218)=27.17, p<.001$. All four motives were statistically significant predictors of using depersonalization tactics. The motives accounted for $15 \%$ of the variance in the use of professional tactics, $F(4,223)=10.45, p<.001$. Personal gain and climate enhancement motives were statistically significant predictors of the use of professional tactics. Table 17 contains a summary of these results. 
Table 17

Motives for Influencing Peer Coworkers to Exit as Predictors of the Use of Peer-Influence Exit Tactics

\begin{tabular}{|c|c|c|c|c|}
\hline \multicolumn{2}{|r|}{$\begin{array}{l}\text { Affirmation } \\
r(\beta)\end{array}$} & $\begin{array}{c}\text { Unprofessional } \\
r(\beta)\end{array}$ & $\begin{array}{l}\text { Depersonalization } \\
r(\beta)\end{array}$ & \multirow{2}{*}{$\begin{array}{l}\text { Professional } \\
\qquad r(\beta) \\
-.21^{* * *}\left(.39^{* * *}\right)\end{array}$} \\
\hline $\begin{array}{l}\text { Personal } \\
\text { Gain }\end{array}$ & $.53^{* *}\left(.42^{* * *}\right)$ & $.77^{* * *}\left(.23^{* * *}\right)$ & $.23^{* * *}(-.07)$ & \\
\hline Altruistic & $.57^{* *}\left(-.18^{* *}\right)$ & $.49^{* *}\left(-.31^{* * *}\right)$ & $.04\left(-.26^{* *}\right)$ & $.01(.15)$ \\
\hline $\begin{array}{l}\text { Organizati } \\
\text { Improveme }\end{array}$ & nal $.20^{* *}(-.06)$ & $.27^{* * * *}\left(-.32^{* * * *}\right)$ & $.46^{* * *}(.11)$ & $.20^{* * * *}\left(.14^{* * * *}\right)$ \\
\hline $\begin{array}{l}\text { Climate } \\
\text { Enhancem }\end{array}$ & $\mathrm{nt} .17^{* *}(-.10)$ & $.24^{* * *}(-.09)$ & $.52^{* * *}\left(.34^{* * * *}\right)$ & $.19^{* *}(.21)$ \\
\hline$R^{2}$ & $.43^{* * * *}$ & $.61^{* * * *}$ & $.32^{* * * *}$ & $.15^{* * *}$ \\
\hline$F=$ & $40.72^{* * *}$ & $83.95^{\text {**** }}$ & $27.17^{\text {***** }}$ & $10.45^{* * * *}$ \\
\hline$d f=$ & 4,215 & 4,214 & 4,218 & 4,223 \\
\hline
\end{tabular}

Notes: $R^{2}$ refers to the variance accounted for by the model that includes all the predictor variables. $\beta$ refers to the standardized regression coefficient when all predictor variables are included in the model. ${ }^{* * *} p<.001,{ }^{* *} p<.01$. The Pearson correlations appear first and standardized regression coefficients appear in parentheses.

\section{Source Characteristics}

Hypothesis one predicted that the source's competitiveness would be related to the source's use of peer-influence exit tactics. Results of Pearson's correlations revealed partial support for this hypothesis as the source's competitiveness was positively related to the source's use of affirmation tactics and unprofessional tactics. There was no statistically significant relationship between the source's competitiveness and the source's use of depersonalization tactics or between the source's competitiveness and the source's use of professional tactics. 
Hypothesis two predicted that the agreeableness of the source would be related to the source's use of peer-influence exit tactics. Results of Pearson's correlations revealed support for this hypothesis as the source's agreeableness was negatively related to the source's use of affirmation tactics, unprofessional tactics, and depersonalization tactics. The source's agreeableness was positively related to the source's use of professional tactics.

Research question four asked about the relationship between the self-esteem of the source and the use of peer-influence exit tactics. Results of Pearson's correlations revealed that the source's self-esteem was negatively related to the source's use of affirmation tactics and unprofessional tactics. The source's self-esteem was positively related to the use of professional tactics. There was no statistically significant relationship between the source's self-esteem and the source's use of depersonalization tactics.

To assess the ability of the source characteristics to predict the use of peer-influence exit tactics, four multiple regressions were conducted, resulting in statistically significant models for each of the tactics. Results indicated that the source characteristics accounted for $24 \%$ variance in the use of affirmation tactics, $F(3,194)=21.24, p<.001$. Agreeableness and competitiveness were statistically significant predictors of affirmation tactics. Results indicated that the source characteristics accounted for $40 \%$ of the variance in the use of unprofessional tactics, $F(3,195)=45.58, p<.001$. Agreeableness, competitiveness, and self-esteem were statistically significant predictors of the use of unprofessional tactics. Results indicated that the source characteristics accounted for $4 \%$ of the variance in the use of depersonalization tactics, $F$ $(3,198)=3.59, p<.01$. Agreeableness was a statistically significant predictor of the use of depersonalization tactics. The source characteristics accounted for $9 \%$ of the variance in the use 
of professional tactics, $F(3,202)=7.30, p<.001$. Self-esteem was a statistically significant predictor of the use of professional tactics. Table 18 summarizes the results.

Table 18

Source Characteristics as Predictors of the Source's Use of Peer-Influence Exit Tactics

\begin{tabular}{|c|c|c|c|c|c|}
\hline & \multicolumn{2}{|c|}{$\begin{array}{c}\text { Affirmation } \\
r(\beta)\end{array}$} & $\begin{array}{c}\text { Unprofessional } \\
\qquad r(\beta)\end{array}$ & $\begin{array}{c}\text { Depersonalization } \\
r(\beta)\end{array}$ & $\begin{array}{l}\text { Professional } \\
\quad r(\beta)\end{array}$ \\
\hline Competitiveness & & $.44^{* * *}\left(.42^{* * * *}\right)$ & $.33^{* * *}\left(.23^{* * *}\right)$ & $-.03(-.07)$ & $-.09(-.03)$ \\
\hline Agreeableness & & $-.24^{* *}\left(-.18^{* *}\right)$ & $-.50^{* *}\left(-.31^{*}\right)$ & $-.20^{* * *}\left(-.26^{* *}\right)$ & $.21^{* * *}(.05)$ \\
\hline \multirow[t]{4}{*}{ Self-Esteem } & & $-.23(-.06)$ & $-.53^{* * *}\left(-.32^{*}\right)$ & $-.02(.11)$ & $.32^{* * *}\left(.28^{*}\right)$ \\
\hline & $R^{2}=$ & $.24^{* * *}$ & $.40^{* * * *}$ & $.04^{* * *}$ & $.09^{* * * *}$ \\
\hline & $F=$ & $21.24^{* * * *}$ & $45.58^{* * * *}$ & $3.59^{* * *}$ & $7.30^{* * * *}$ \\
\hline & $d f=$ & 3,194 & 3,195 & 3,198 & 3,202 \\
\hline
\end{tabular}

Notes: $R^{2}$ refers to the variance accounted for by the model that includes all the variables. $\beta$ refers to the standardized regression coefficient when all predictor variables are included in the model. $* * * p<.001, * * p<.01, * p<.05$. The Pearson correlations appear first and standardized regression coefficients appear in parentheses.

Research question five asked about the relationship between the source's personality characteristics and the source's motives for influencing a peer coworker to voluntarily leave the organization. Results of Pearson's correlations revealed that the source's competitiveness was positively related to the personal gain motive and the altruistic motive. There was no statistically significant relationship between the source's competitiveness and the organizational improvement or climate enhancement motives. The source's agreeableness was negatively related to the personal gain motive, the altruistic motive, the organizational improvement motive, and the climate enhancement motive. The source's self-esteem was negatively related to the personal gain motive and the altruistic motive. There was no statistically significant relationship 
between the source's self-esteem and the organizational improvement or climate enhancement motives.

To assess the ability of the source characteristics to predict the source's motives for influencing a peer coworker to voluntarily leave the organization, four multiple regressions were conducted, resulting in statistically significant models for three of the four motives. Results indicated that the source characteristics accounted for $32 \%$ of the variance in the personal gain motive, $F(3,204)=33.35, p<.001$. Agreeableness, competitiveness, and self-esteem were statistically significant predictors of the personal gain motive. The source characteristics accounted for $21 \%$ of the variance in the altruistic motive, $F(3,205)=18.84, p<.001$. Competitiveness and self-esteem were statistically significant predictors of the altruistic motive. Results indicated that the source characteristics accounted for $3 \%$ of the variance in the organizational improvement motive, $F(3,205)=2.94, p<.05$. Agreeableness was a statistically significant predictor of the organizational improvement motive. The model for the climate enhancement motive was not statistically significant, $F(2,205)=1.36, p=.26$. Table 19 summarizes these results. 
Table 19

Source Characteristics as Predictors of the Motives for Influencing Peer Coworkers to Exit

\begin{tabular}{|c|c|c|c|c|}
\hline & $\begin{array}{l}\text { onal Gain } \\
r(\beta)\end{array}$ & $\begin{array}{c}\text { Altruistic } \\
\qquad r(\beta)\end{array}$ & $\begin{array}{c}\text { Organizational } \\
\text { Improvement } \\
\qquad r(\beta)\end{array}$ & $\begin{array}{l}\text { Climate } \\
\text { Enhancement } \\
\quad r(\beta)\end{array}$ \\
\hline Competitiveness & $.38^{* * *}\left(.28^{* * *}\right)$ & $.42^{* * *}\left(.37^{* * *}\right)$ & $-.06\left(-.23^{*}\right)$ & $.02(.09)$ \\
\hline Agreeableness & $-.43^{* * *}\left(-.27^{* * *}\right)$ & $-.21^{* *}(-.04)$ & $-.16^{*}(.04)$ & $-.13^{*}(.00)$ \\
\hline Self-Esteem & $-.45^{* *}\left(-.25^{*}\right)$ & $-.28^{* * *}\left(-.20^{* * *}\right)$ & $.03(.15)$ & $.00\left(-.17^{* * *}\right)$ \\
\hline$R^{2}=$ & $.32^{* * * *}$ & $.21^{* * * *}$ & $.03^{*}$ & .01 \\
\hline$F=$ & $33.34^{* * * *}$ & $18.84^{* * * *}$ & $2.94^{*}$ & 1.36 \\
\hline$d f=$ & 3,204 & 3,205 & 3,205 & 3,205 \\
\hline
\end{tabular}

Notes: $R^{2}$ refers to the variance accounted for by the model that includes all the variables. $\beta$ refers to the standardized regression coefficient when all predictor variables are included in the model. $* * * p<.001, * * p<.01, * p<.05$. The Pearson correlations appear first and standardized regression coefficients appear in parentheses.

\section{Target Characteristics}

Hypothesis three predicted that the source's perceived similarity with the target of peerinfluence exit tactics would be related to the source's use of peer-influence exit tactics. Results of Pearson's correlations revealed partial support for this hypothesis as perceived coworker similarity was positively related to the source's use of affirmation tactics and unprofessional tactics and negatively associated with the source's use of depersonalization tactics. There was no statistically significant relationship between perceived coworker similarity and the source's use of professional tactics.

Research question six asked about the relationship between the source's perception of the work performance of the target of peer-influence exit tactics and the source's use of peer- 
influence exit tactics. Results of Pearson's correlations revealed that perceived work performance of a peer coworker was negatively related to the source's use of depersonalization tactics. There was no statistically significant relationship between perceived work performance of a peer coworker and the source's use of affirmation tactics, unprofessional tactics, or professional tactics.

Hypothesis four predicted that the source's liking of the peer-influence exit target would be related to the source's use of peer-influence exit tactics. Results of Pearson's correlations revealed partial support for this hypothesis as the source's liking of his/her peer coworker positively related to the source's use of affirmation tactics and negatively related to the source's use of depersonalization tactics and professional tactics. There was no statistically significant relationship between the source's liking of his/her peer coworker and the use of unprofessional tactics.

Hypothesis five predicted that the source's perception of the target's organizational influence would be related to the source's use of peer-influence exit tactics. Results of Pearson's correlations revealed that perceived organizational influence of a peer coworker was positively related to the source's use of affirmation tactics and professional tactics, and negatively related to the use of depersonalization tactics. There was no statistically significant relationship between perceived organizational influence and the source's use of unprofessional tactics.

To assess the ability of the target characteristics to predict the use of peer-influence exit tactics, four multiple regressions were conducted resulting in statistically significant models for each of the tactics. Results indicated that the target characteristics accounted for $11 \%$ of the variance in affirmation tactics, $F(4,222)=7.49, p<.001$. Coworker similarity, organizational influence, and work performance were statistically significant predictors of affirmation tactics. 
Results indicated that the target characteristics accounted for $16 \%$ of the variance in the use of unprofessional tactics, $F(4,220)=11.16, p<.001$. Coworker similarity, liking, and work performance were statistically significant predictors of the use of unprofessional tactics. Results indicated that the target characteristics accounted for $26 \%$ of the variance in the use of depersonalization tactics, $F(4,228)=21.41, p<.001$. Liking, organizational influence, and work performance were statistically significant predictors of the use of depersonalization tactics. Results indicated that the target characteristics accounted $11 \%$ of the variance in the use of professional tactics, $F(4,232)=7.97, p<.001$. Coworker similarity, social attractiveness, and organizational influence were statistically significant predictors of the use of professional tactics. Table 20 summarizes these results.

Table 20

Target Characteristics as Predictors of the Source's Use of Peer-Influence Exit Tactics

\begin{tabular}{|c|c|c|c|c|}
\hline & $\begin{array}{l}\text { Affirmation } \\
\qquad r(\beta)\end{array}$ & $\begin{array}{c}\text { Unprofessional } \\
\qquad r(\beta)\end{array}$ & $\begin{array}{l}\text { Depersonalization } \\
\qquad r(\beta)\end{array}$ & $\begin{array}{l}\text { Professional } \\
\qquad r(\beta)\end{array}$ \\
\hline Similarity & $.30^{* * *}\left(.32^{* * *}\right)$ & $.27^{* * *}\left(.52^{* * *}\right)$ & $-.32^{* * *}(-.07)$ & $-.07\left(.19^{* *}\right)$ \\
\hline Work Performance & $.04\left(-.28^{*}\right)$ & $-.05\left(-.28^{* * *}\right)$ & $-.27\left(-.17^{*}\right)$ & $.06(.02)$ \\
\hline Liking & $.04(-.06)$ & $.27^{* * *}\left(-.25^{* * * *}\right)$ & $-.51^{* * *}\left(-.47^{* * *}\right)$ & $-.13^{*}(-.19)$ \\
\hline Org. Influence & $.18^{* *}\left(.17^{*}\right)$ & $.07(.08)$ & $-.14\left(.21^{* *}\right)$ & $.21^{* * *}\left(.39^{* * *}\right.$ \\
\hline$R^{2}=$ & $.11^{* * *}$ & $.16^{* * *}$ & $.26^{* * *}$ & $.11^{* * *}$ \\
\hline$F=$ & $7.49^{* * *}$ & $11.16^{* * *}$ & $21.41^{* * * *}$ & $7.97^{* * * *}$ \\
\hline$d f=$ & 4,222 & 4,220 & 4,228 & 4,232 \\
\hline
\end{tabular}

Notes: $R^{2}$ refers to the variance accounted for by the model that includes all the variables. $\beta$ refers to the standardized regression coefficient when all predictor variables are included in the model. ***p<.001, **p<.01,* $p<.05$. The Pearson correlations appear first and standardized regression coefficients appear in parentheses. 
Research question seven asked about the relationship between the source's perception of the target's similarity, work performance, liking, and organizational influence and the source's motives for influencing a peer coworker to voluntarily leave the organization. Results of Pearson's correlations revealed that perceived coworker similarity was positively related to the personal gain motive and the altruistic motive and negatively related to the organizational improvement motive and the climate enhancement motive. Perceived work performance of a peer coworker was negatively related to the organizational improvement motive and the climate enhancement motive, but unrelated to the personal gain and altruistic motives. The source's liking of his/her peer coworker was negatively related to the organizational improvement motive and the climate enhancement motive, but unrelated to the personal gain and altruistic motives. Perceived organizational influence of a peer coworker was positively related to the personal gain motive and the altruistic motive, negatively related to the organizational improvement motive, and unrelated to the climate enhancement motive.

To assess the ability of the target characteristics to predict the motives for influencing a peer coworker to voluntarily leave the organization, four multiple regressions were conducted resulting in statistically significant models for each of the motives. Results indicated that target characteristics accounted for $22 \%$ of the variance in the personal gain motive, $F(4,230)=16.78$, $p<.001$. Coworker similarity, liking, and work performance were statistically significant predictors of the personal gain motive. Results indicated that target characteristics accounted for $15 \%$ of the variance in the altruistic motives, $F(4,232)=11.17, p<.001$. Coworker similarity was a statistically significant predictor of the altruistic motive. The target characteristics accounted for $26 \%$ of the variance in the organizational improvement motive, $F(4,232)=21.08$, $p<.001$. Liking and work performance were statistically significant predictors of the 
organizational improvement motive. The target characteristics accounted for $20 \%$ of the variance in the climate enhancement motive, $F(4,232)=15.44, p<.001$. Organizational influence, liking, and work performance were statistically significant predictors of the climate enhancement motive. Table 21 summarizes the results.

Table 21

Target Characteristics as Predictors of Motives for Encouraging a Peer Coworker to Exit

\begin{tabular}{|c|c|c|c|c|}
\hline & $\begin{array}{l}\text { Personal Gain } \\
r(\beta)\end{array}$ & $\begin{array}{l}\text { Altruistic } \\
r(\beta)\end{array}$ & $\begin{array}{c}\text { Organizational } \\
\text { Improvement } \\
\qquad r(\beta)\end{array}$ & $\begin{array}{l}\text { Climate } \\
\text { Enhancement } \\
\qquad \quad r(\beta)\end{array}$ \\
\hline Similarity & $.40^{* * *}\left(.58^{* * *}\right)$ & $.37^{* * *}\left(.47^{* * *}\right)$ & $-.21^{* * *}(.15)$ & $-.26^{* * *}(.00)$ \\
\hline Work Performance & $.10\left(-.18^{*}\right)$ & $.11(-.14)$ & $-.46^{* * *}\left(-.47^{* * *}\right)$ & $-.31^{* * *}\left(.31^{* * *}\right)$ \\
\hline Liking & $.04\left(-.24^{*}\right)$ & $.10(-.14)$ & $-.36^{*}\left(-.30^{*}\right)$ & $-.42^{*}\left(-.35^{*}\right)$ \\
\hline Org. Influence & $.23^{*}(.11)$ & $.19^{* *}(.08)$ & $-.22^{* * * *}(.10)$ & $-.10\left(.24^{* *}\right)$ \\
\hline$R^{2}=$ & $.22^{* * *}$ & $.15^{* * *}$ & $.26^{* * *}$ & $.20^{* * * *}$ \\
\hline$F=$ & $16.78^{* * *}$ & $11.17^{* * *}$ & $21.08^{* * * *}$ & $15.44^{* * *}$ \\
\hline$d f=$ & 4,230 & 4,232 & 4,232 & 4,232 \\
\hline
\end{tabular}

Notes: $R^{2}$ refers to the variance accounted for by the model that includes all the variables. $\beta$ refers to the standardized regression coefficient when all predictor variables are included in the model. ***p $<.001, * * p<.01, * p<.05$. The Pearson correlations appear first and standardized regression coefficients appear in parentheses.

\section{Organizational Characteristics}

Research question eight asked about the relationship between the source's perceptions of teamwork and the source's use of peer-influence exit tactics. Results of Pearson's correlations revealed that perceived teamwork was positively related to the source's use of unprofessional 
tactics and professional tactics. There was no statistically significant relationship between perceived teamwork and the source's use of affirmation tactics or depersonalization tactics.

Research question nine asked about the relationship between the source's perceptions of organizational climate and the source's use of peer-influence exit tactics. Results of Pearson's correlations revealed that perceived autonomy was negatively related to the source's use of affirmation tactics. Perceived welfare was positively related to the use of professional tactics. Perceived formalization was negatively associated with the use of unprofessional tactics. Perceived effort was positively related to the use of professional tactics. No other statistically significant relationships between the source's perceptions of organizational climate and the use of peer-influence exit tactics were observed.

Hypothesis six predicted that the source's perceptions of organizational justice would be related to the use of peer-influence exit tactics. Results of Pearson's correlations revealed that perceptions of distributive, procedural, and interactional justice were positively related to the source's use of unprofessional tactics. Perceptions of interactional justice were also positively related to the source's use of professional tactics. No other statistically significant relationships between perceptions of organizational justice and the use of peer-influence exit tactics were observed. Hypothesis six was partially supported.

Research question 10 asked about the relationship between the source's job satisfaction and the source's use of peer-influence exit tactics. Results of Pearson's correlations revealed that the source's job satisfaction was positively related to the use of professional tactics, but unrelated to the use of affirmation, unprofessional, and depersonalization tactics.

Research question 11 asked about the relationship between the source's perceptions of coworker regard and the source's use of peer-influence exit tactics. Results of Pearson's 
correlations revealed that perceptions of coworker regard were negatively related to the use of affirmation tactics, unprofessional tactics, and positively related to the use of professional tactics. There was no statistically significant relationship between the source's perceptions of coworker regard and the use of depersonalization tactics.

Hypothesis seven predicted that source's perceptions of supervisor complicity would be related to the use of peer-influence exit tactics. Results of Pearson's correlations revealed that perceptions of supervisor complicity were positively related to the source's use of affirmation tactics, unprofessional tactics, and depersonalization tactics. Supervisor complicity was negatively related to the use of professional tactics.

To assess the ability of the organizational characteristics to predict peer-influence exit tactics, four multiple regressions were conducted resulting in statistically significant models for three of the four tactics. Results indicated that organizational characteristics accounted for $24 \%$ of the variance in the use of affirmation tactics, $F(11,180)=6.20, p<.001$. Perceived autonomy, perceived pressure, and supervisor complicity were statistically significant predictors of affirmation tactics. Organizational characteristics accounted for 55\% of the variance in the use of unprofessional tactics, $F(11,180)=21.32, p<.001$. Perceptions of interactional justice, supervisor complicity, and coworker regard were statistically significant predictors of unprofessional tactics. Results indicated that organizational characteristics accounted for $17 \%$ of the variance in the use of professional tactics, $F(11,186)=4.34, p<.001$. Perceptions of distributive justice, supervisor complicity, and coworker regard were statistically significant predictors of professional tactics. The model for depersonalization tactics was not statistically significant. Table 22 summarizes the results. 
Table 22

Organizational Characteristics as Predictor's of the Source's Use of Peer-Influence Exit Tactics

\begin{tabular}{ccccc}
\hline & $\begin{array}{c}\text { Affirmation } \\
r(\beta)\end{array}$ & $\begin{array}{c}\text { Unprofessional } \\
r(\beta)\end{array}$ & $\begin{array}{c}\text { Depersonalization } \\
r(\beta)\end{array}$ & $\begin{array}{c}\text { Professional } \\
r(\beta)\end{array}$ \\
\hline Teamwork & $.06(.04)$ & $.15^{*}(.13)$ & $.02(.04)$ & $.14^{*}(.07)$
\end{tabular}

Organizational Climate

$\begin{array}{lllll}\text { Autonomy } & -.25^{* * *}\left(-.20^{* *}\right) & -.10(-.09) & .10(.16) & .00\left(-.17^{*}\right) \\ \text { Welfare } & -.08(-.12) & .01(-.11) & -.08\left(-.27^{* *}\right) & .16^{* *}(-.10) \\ \text { Formalization } & -.12(-.02) & -.32^{* * *}(-.04) & -.11(-.05) & -.13(-.02) \\ \text { Effort } & -.13(-.08) & -.05(.04) & .07(.12) & .18^{* *}(-.08) \\ \text { Pressure } & .09(.15) & -.12(-.02) & .05(.08) & .05(.08)\end{array}$

Organizational Justice

$\begin{array}{lllll}\text { Distributive } & .10(-.00) & .21^{* *}(-.08) & -.04(-.05) & .10\left(.25^{* *}\right) \\ \text { Procedural } & .11(.13) & .21^{* *}(.05) & .04(.09) & .13(.10) \\ \text { Interactional } & .06(.08) & .14^{*}(.16) & .02(-.02) & .20^{* *}(.04) \\ \text { pervisor Complicity } .46^{* * *}\left(.31^{* * *}\right) & .63^{* * *}\left(.31^{* * *}\right) & .17^{* *}(.08) & -.19^{* *}\left(.25^{* *}\right) \\ \text { Satisfaction } & -.09(-.02) & -.08(-.06) & .02(.10) & .19^{*}(-.02) \\ \quad R^{2}= & .23^{* * *} & -.63^{* * *}\left(-.50^{* * *}\right) & -.06(-.14) & .36^{* * *}\left(.25^{* *}\right) \\ \quad F= & 5.47^{* * *}(-.10) & .55^{* * *} & .03 & .18^{* * *} \\ \quad d f= & 12,178 & 19.29^{* * *} & 1.46 & 4.40^{* * *}\end{array}$

Notes: $R^{2}$ refers to the variance accounted for by the model that includes all the variables. $\beta$ refers to the standardized regression coefficient when all predictor variables are included in the model. ***p<.001, **p<.01,*p<.05. The Pearson correlations appear first and standardized regression coefficients appear in parentheses. 
Research question 12 asked about the relationship between the source's perceptions of his/her organization's characteristics and the source's motives for influencing a peer coworker to voluntarily leave the organization. Results of Pearson's correlations revealed that perceptions of teamwork, autonomy, formalization, procedural justice, distributive justice, and coworker regard were related to the personal gain motive. Perceptions of formalization, distributive justice, and coworker regard were related to the altruistic motive. Perceptions of formalization were negatively related to the organizational improvement motive. There were no statistically significant relationships between the organizational characteristics and the climate enhancement motive.

To assess the ability of the organizational characteristics to predict the motives for influencing a peer coworker to voluntarily leave the organization, four multiple regressions were conducted resulting in statistically significant models for each of the motives. Results indicated that organizational characteristics accounted for $55 \%$ of the variance in the personal gain motive, $F(11,185)=21.32, p<.001$. Perceived welfare, supervisor complicity, and coworker regard were statistically significant predictors of personal gain. Results indicated that organizational characteristics accounted for $25 \%$ of the variance in the altruistic motive, $F(11,187)=6.57, p<$ .001. Supervisor complicity was a statistically significant predictor of the altruistic motive. Organizational characteristics accounted for $8 \%$ of the variance in the organizational improvement motive, $F(11,185)=2.44, p<.01$. Perceived formalization was a statistically significant predictor of the organizational improvement motive. The model for the climate enhancement motive was not statistically significant. Table 23 summarizes the results. 
Table 23

Organizational Characteristics as Predictors of Motives for Encouraging a Peer Coworker to Exit

$\begin{array}{cccc}\text { Personal Gain } & \text { Altruistic } & \begin{array}{c}\text { Organizational } \\ \text { Improvement } \\ r(\beta)\end{array} & \begin{array}{c}\text { Climate } \\ \text { Enhancement } \\ r(\beta)\end{array} \\ .18^{* *}\left(.20^{* *}\right) & .10(.08) & .04(.10) & .02(.01)\end{array}$

Organizational Climate

$\begin{array}{lllll}\text { Autonomy } & -.18^{* *}(-.10) & -.12(-.10) & -.10(-.08) & .06(.11) \\ \text { Welfare } & -.02(-.16) & -.02(-.09) & -.12(-.11) & -.06(-.15) \\ \text { Formalization } & -.21^{* *}(.02) & -.19^{* *}(-.07) & -.16^{*}\left(-.24^{* *}\right) & -.07(-.03) \\ \text { Effort } & -.09(.02) & -.11(.09) & -.10(-.12) & -.02(-.06) \\ \text { Pressure } & -.03(.06) & -.04(.04) & .07(.08) & .10\left(.18^{*}\right)\end{array}$

Organizational Justice

$\begin{array}{lllll}\text { Distributive } & .24^{* * *}(.00) & .16^{* *}(-.01) & -.11(-.18) & -.05(-.12) \\ \text { Procedural } & .22^{* *}(.08) & .11(-.04) & .00(.01) & .02(.05) \\ \text { Interactional } & .13(.07) & .17^{* *}(.18) & .04(.11) & .02(.03) \\ \text { pervisor Complicity } .61^{* * *}\left(.34^{* * *}\right) & .46^{* * *}\left(.42^{* * *}\right) & .15^{*}(.11) & .08(.02) \\ \text { Satisfaction } & -.12(-.12) & -.10(-.02) & -.06(-.01) & .03(.18) \\ R^{2}= & .56^{* * *} & -.32^{* * *}(-.05) & -.03(-.08) & -.07(-.15) \\ \quad F= & 20.30^{* * *} & .55^{* * *} & .07^{* *} & .06 \\ \quad d f= & 12,182 & 19.29^{* * *} & 2.14^{* *} & .97\end{array}$

Notes: $R^{2}$ refers to the variance accounted for by the model that includes all the variables. $\beta$ refers to the standardized regression coefficient when all predictor variables are included in the model. $* p<.001, * * p<.01, * * * p<.05$. The Pearson correlations appear first and standardized regression coefficients appear in parentheses. 
Research question 14 asked how effective/successful peer-influence exit tactics were in encouraging peer coworkers to voluntarily exit the organization. A single-sample binomial distribution analysis indicated that the proportions of organizational members who remained in the organization, $n=191(76 \%)$, and those who exited the organization, $n=60(24 \%)$, were unequal, $p<.001$. Of the 60 targets who were reported to have left the organization, 44 (73\%) were reported to have exited voluntarily and 16 (27\%) were reported to have exited involuntarily. Results of a binomial distribution analysis indicated that the proportions were unequal, $p=.001$. A larger portion of the targets exited the organization voluntarily than exited it involuntarily.

To further assess the effect of the peer-influence exit tactics on peer coworkers' exit, a logistic regression was conducted. Results of the logistic regression, $\chi^{2}(4)=15.17, p<.01$; revealed that the use of two of the four peer-influence exit tactics predicted coworkers' remaining in or exiting the organization. Specifically, the use of unprofessional tactics $(\beta=-$ $.94)$, Wald $\chi^{2}(1)=11.17,(\exp \beta=.40), p<.001$; negatively predicted organizational members' exiting the organization, whereas the use of depersonalization tactics $(\beta=.50)$, Wald $\chi^{2}(1)=$ 7.87, $(\exp \beta=1.64), p<.01$; positively predicted organizational members' exiting. In summary, based upon the odds ratios, targets who received more unprofessional tactics were .40 times as likely to remain in the organization as targets who received fewer unprofessional tactics. In contrast, targets who received more depersonalization tactics were 1.64 times as likely to exit the organization as targets who received fewer depersonalization tactics. Table 24 summarizes these results. 
Table 24

Logistic Regression Analysis Results for Peer-Influence Exit Tactics Predicting Voluntary Exit Decisions

\begin{tabular}{lcccc}
\hline & $\beta$ & SE & Odds ratio & Wald statistic \\
\hline Affirmation Tactics & .34 & .22 & 1.40 & 2.36 \\
Unprofessional Tactics & -.94 & .28 & .40 & $11.17^{* * *}$ \\
Depersonalization Tactics & .50 & .18 & 1.64 & $7.87^{* *}$ \\
Professional Tactics & -.22 & .23 & .80 & .94 \\
\hline
\end{tabular}

Note. ${ }^{* * *} p<.001,{ }^{* *} p<.01$

\section{Summary}

The results suggested that the personality traits of organizational members, characteristics of the peer-influence exit target, and organizational characteristics play a role in both the use of peer-influence exit tactics and the motives that organizational members have for encouraging their peer coworkers to voluntarily exit. Specifically the competitiveness, agreeableness, and self-esteem of organizational members predicted the use of affirmation and unprofessional peerinfluence exit tactics and the personal gain and altruistic motives. Target characteristics of similarity, work performance, and organizational influence were predictors of affirmation tactics and each target characteristic predicted various motives. Organizational characteristics of perceived autonomy, supervisor complicity, and coworker regard predicted the use of affirmation and professional tactics and perceived welfare predicted the use of depersonalization tactics. Supervisor complicity and coworker regard both predicted the personal gain and altruistic motives. Finally, unprofessional tactics were used more frequently with peer coworkers who remained in the organization than with peer coworkers who departed the organization. 


\section{CHAPTER IV: DISCUSSION}

This purpose of this dissertation was to uncover greater detail about the antecedents and outcomes of peer-influence exit tactics. Earlier studies have indicated that peer-influence exit tactics are intentional messages and behaviors used to encourage the voluntarily organizational exit of peer coworkers (Sollitto et al., 2013), yet a need existed for revealing greater insight about why organizational members engage in such tactics and the outcomes of them. In this dissertation, the construct of peer-influence exit was explored through three different research methodologies: exploratory qualitative design with open-ended items, experimental design using scenarios, and survey design using questionnaires. Myers (2014) stated that organizational communication researchers and the discipline can benefit from exploring phenomena through the use of multiple methodologies, which is what this dissertation intended to do. Results produced through this design provided greater clarity regarding how organizational members encourage their peer coworkers to voluntarily exit the organization and their motives for doing so. Study 1 provided an initial understanding of peer-influence exit tactics, the reasons behind them, their planning, and their perceived effect on targeted peer coworkers. Study 2 provided an opportunity to uncover how various organizational situations and personality characteristics affected the use of peer-influence exit tactics. Study 3 provided insight about various source, target, and organizational characteristics and their relationships to the use and effectiveness of peer-influence exit tactics.

\section{Peer-Influence Exit Tactics}

The first major finding was about the messages and behaviors that organizational members use to encourage their peer coworkers to voluntarily exit the organization. Eight peer- 
influence exit tactics emerged through the thematic analysis. These results corroborate previous research and also provide new insight.

Communicate professionally was the most frequently cited tactic that organizational members utilized. This tactic appears to represent a behavior that organizational members use when they would like for their peer coworkers to voluntarily exit without creating drama, hostilities, or hurt feelings. Additionally, this tactic insinuates a desire for organizational members to continue acting with civility and warmth with their peer coworkers as a way to provide their peer coworkers with some distance to make a decision on their own and to help them maintain a desired professional image in the workplace, keep the organization functioning as well as possible, and avoid disrupting the communication climate of the organization.

Fritz (2012) asserted that organizational members who behave in civil ways with their peer coworkers despite experiencing conflicts or dislike for them, can still navigate the organizational terrain in ways that avoid disrupting the flow of the organization or the work of others. Furthermore, Anderson and Pearson (1999) forwarded that excessive conflict and incivility among organizational members can lead to increasingly tense work situations and excessive aggressive behaviors. Such tense work situations and aggressive behavior could potentially lead to loss of face and eventual departure from the organization for the targets of incivility. Perhaps by maintaining a friendly image and displaying warmth, organizational members can encourage their peer coworkers to voluntarily exit without experiencing severe repercussions if more aggressive tactics backfired on them or without experiencing a disruption to their professional successes. Thus, the communicate professionally tactic suggests a desire for organizational members to carefully nudge their peer coworkers out of the organization in an 
ethical manner that attempts to preserve the face of their peer coworkers and the effective functioning of the organization.

Minimize communication is a tactic that organizational members engage in by limiting their contact with their peer coworkers. By minimizing communication, organizational members attempt to push their peer coworkers to voluntarily exit by ignoring them and ensuring that any communication contact is kept to a minimum. It is conceivable that organizational members desire to minimize their communication with their peer coworkers because they dislike them and want to avoid contact with them.

According to Hess (2006), organizational members may distance themselves from disliked coworkers through the use of avoidance strategies, which involve organizational members limiting what they say to their peer coworkers, decreasing the length of communication interactions, and involving others in conversations with their disliked peers. Thus, it appears that organizational members engage in similar behaviors when they desire for their peer coworkers to exit the organization. Indeed, Cox (1999) discovered that communication avoidance with peer coworkers was one method that organizational members used to encourage voluntary exit. It seems that by avoiding disliked or targeted peer coworkers, organizational members can negatively affect the self-worth of the peer coworkers (Pierce, Gardner, Cummings, \& Dunham, 1989), which could lead them to pursue alternative career avenues or endeavors.

Affirm talents and provide advice is a peer-influence exit tactic in which organizational members compliment the abilities of their peer coworkers and provide them with insight about how they could improve their professional standing in another organization. This seems like a genuinely helpful tactic in which organizational members legitimately want their peer coworkers to make a career change and pursue professional opportunities more befitting their talents and 
accomplishments. Cox (1999) found that organizational members engage in a similar method of encouraging organizational exit by encouraging their peers to seek employment opportunities more aligned with their personal interests and personality. In an era in which organizations have difficulty keeping their most talented employees (Martin \& Schmidt, 2010) or making the most out of their creativity (Fairbank \& Williams, 2001), it is reasonable to assume that organizational members see that some of their peer coworkers are both talented and creative, but their organizations lack the resources or ingenuity to make proper use of them. Therefore, by complimenting them and offering words of wisdom, organizational members can persuade their talented peer coworkers to pursue opportunities that tap into their potential and lead to more professional success. Additionally, by using tactics such as affirming talents and providing advice, organizational members can nudge their coworkers out of the organization without hostilities or unprofessional acts. Such hostilities could create psychological problems for the targeted peer coworker or the organization (Cortina, Magley, Williams, \& Langhout, 2001).

Communicate overt statements is a peer-influence exit tactic in which organizational members ostensibly and directly tell their peer coworkers to leave. This tactic, which appears to be a combination of the strategies that Cox (1999) identified as "tell or encourage peers to leave immediately" and "issue exit ultimatum," involves organizational members encouraging their peer to voluntarily exit with little regard for their own face or the face of their peer coworkers. In other words, this tactic closely resembles what Brown and Levinson (1987) identified as a bald on record face threatening action in which organizational members directly tell their peer coworkers in a bold and efficient manner to leave.

Communicating overt statements suggests that organizational members have conceivably reached a point in their relationships with targeted peer coworkers in which the level of trust and 
disclosure is high, making it an acceptable tactic for encouraging voluntary exit. Conversely, it could mean that organizational members simply wanted to rid the organization of their peer coworkers and tried to accomplish that in as direct a manner as possible.

Act unprofessionally is a peer-influence exit tactic that represents inhospitable and demeaning behavior toward peer coworkers. Because acting unprofessionally defies the ethical and civil norms maintained by organizations, the use of this tactic suggests that organizational members may do anything in their power, even break from norms, to encourage their peer coworkers to exit. Organizational members who act unprofessionally are seemingly intent upon inflicting enough psychological harm on their peer coworkers to expedite their departure from the organization. Behaving in such unprofessional ways aligns with research demonstrating that malicious behavior can lead to decreased production and increased levels of turnover (Baron, 2004; Waldron \& Kassing, 2014).

Cox (1999) reasoned that acting in malicious or unprofessional ways with peer coworkers could be a way that organizational members seek to encourage their peer coworkers to alter how they view their exchanges with the organization, and subsequently influence them to exit. Thus, by remaining in the organization, they experience the spoils of having pushed their colleagues toward the breaking point of organizational exit. Another possibility is that the unprofessional behavior could be enacted in retaliation against peer coworkers for perceived transgressions against the source (Skarlicki \& Folger, 1997). It is possible that the use of unprofessional tactics could also force organizational members to alter their feelings toward the organization and voluntarily exit because they no longer feel satisfied, committed, or connected with their peer coworkers (Allen, 1996; Jablin, 1987). Thus, acting unprofessionally could have severe 
repercussions for the organization by making it a less comfortable place to work for everyone involved and by making it less productive.

Provide information and encouragement about other alternatives is a peer-influence exit tactic that represents a more positive and supportive tactic for encouraging voluntary exit. Organizational members who make use of this tactic seemingly want to help their peer coworkers improve themselves and experience greater organizational success elsewhere. Thus, they provide insight and support about other job opportunities and can have a positive effect on their peer coworkers' decisions to voluntarily exit. Providing information and encouragement about other alternatives could function as social support for individuals who are considering departing from their organizations.

Holmstrom et al. (2013) found that helpful messages directed at individuals who were searching for new jobs boosted their self-esteem and increased their level of job search activity. Thus, when organizational members provide assistance and support to their peer coworkers, it may function to increase their peers' morale and motivate them to put forth greater effort in their searches for new and better opportunities. In this way, perhaps receiving encouragement about job searches and using their colleagues to make connections with people in other organizations provides departing members extra incentive to find better organizations in which to work. Wanberg, Clomb, Song, and Sorenson (2005) corroborated this notion by finding that individuals typically make use of their social contacts when searching for new employment opportunities. Therefore, organizational members who provide information and support about job searches and future professional opportunities can impact the likelihood of their peer coworkers finding fulfilling new job alternatives. 
Consult third-party sources entails a less direct peer-influence exit tactic involving discussions with organizational members other than the targeted peer coworker. Organizational members who used this tactic seemed to enact it in two ways. First, they gossiped and spread rumors about their colleagues, such as what Cox (1999) described as sabotaging or harming peer coworkers. They consulted third parties by increasing communication with other work group members or supervisors. Second, organizational members followed organizational protocol and reported suspicious activity, poor performance, or unprofessional conduct to their immediate supervisors or human resources personnel.

Gossiping and spreading rumors about peer coworkers appears to be similar to what Malone and Hayes (2012) called backstabbing and Beatty et al. (1999) labeled as indirect interpersonal aggression. This means that organizational members could encourage their peer coworkers to voluntarily exit without ever having to directly confront them or to accept responsibility for their actions. Conversely, approaching authority figures regarding problematic peer coworkers aligns with the practical advice provided by Johnson and Indvik (2000) in that organizational members should deal with troublesome coworkers by following formal channels of communication and reporting behavior to authority figures. Therefore, consulting third-party sources is an indirect peer-influence exit tactic that encompasses two methods of influence.

Isolate is a peer-influence exit tactic characterized by organizational members neglecting and ignoring their peer coworkers. Organizational members who attempt to isolate their peer coworkers seemingly attempt to push their peer coworkers to the periphery of the organization, which is consistent with evidence suggesting that network isolates are more likely to exit the organization than organizational members more connected in their organization's social networks (Feeley et al., 2010). Isolate also provides evidence of Sias' (2012) claims about the 
effect of exclusion behaviors on organizational members. Additionally, organizational members seemingly realize that if they isolate or exclude their peer coworkers, their peer coworkers are less likely to hold influential positions in the organization or become obstacles to organizational members' professional growth (Sias, 2012).

After creating items for each of the peer-influence exit tactics identified in Study 1, the items were factor analyzed in Study 2, resulting in four peer-influence exit tactics. The first tactic that emerged via factor analysis was affirmation tactics. The affirmation tactics factor combined items from the "affirm talents and provide advice" and the "provide information and encouragement about other alternatives" tactics from Study 1. Based on the combination of those tactics from Study 1, it is apparent that organizational members attempt to be constructive, supportive, and helpful toward peer coworkers that they encourage to voluntarily exit.

The second tactic that emerged via factor analysis was unprofessional tactics. The unprofessional tactics factor combined items from the "act unprofessionally," "communicate overt statements," “consult third-party sources," and "isolate" tactics from Study 1. Based on the combination of those tactics from Study 1, it is apparent that organizational members engage in destructive and hostile acts to encourage their peer coworkers to voluntarily exit.

The third tactic that emerged via factor analysis was depersonalization tactics. The depersonalization tactics factor combined items from the "minimize communication" and "isolate" tactics from study one. Based on the combination of those tactics from Study 1, it is apparent that organizational members make an effort to avoid communicating or working directly with their peer coworkers. Furthermore, this dimension is congruent with the depersonalization strategy for disengaging from workplace friendships. Sias and Perry (2004) found that organizational members disengage from workplace friendships by avoiding close 
personal interaction and socializing outside of work, and they create clear distinctions between their work lives and personal lives. Thus, there is conceptual overlap between what Sias and Perry found and the peer-influence exit tactic that emerged in Study 2.

The fourth tactic that emerged via factor analysis was professional tactics. The professional tactics factor consisted of items from the "communicate professionally" tactic from Study 1. These items represent more of a passive attempt to encourage peer coworkers to leave. Peer coworkers who utilize professional tactics simply treat their peer coworkers with respect and maintain civility with them.

\section{Motives for Encouraging Voluntary Exit}

The second major finding was about the motives organizational members have for influencing their peer coworkers to voluntarily exit the organization. Four overarching motives emerged through the thematic analysis in Study 1. These results provide depth to the reasons why organizational members would or do engage in peer-influence exit tactics, thus filling a void in research about peer-influence exit.

The first motive that emerged was difficult to work with, in which organizational members want their peer coworkers to voluntarily exit because they display personality or physical characteristics or behaviors that make them intolerable as colleagues. This motive aligns with Sias' (2012) assertion that organizational members may exclude their peer coworkers due to their possession of various characteristics that make them different or incongruent with the typical image of organizational members. In this way, it appears that organizational members want their peer coworkers to leave because they are unable to handle the nuances that their peer coworkers bring to the workplace. It also seems to insinuate that some organizational members are obstinate in their views of what characteristics their peer coworkers should possess 
because unless those peer coworkers possess certain personality or physical characteristics, they will desire for them to exit the organization.

The second motive that emerged was detriment to workplace, in which organizational members want their peer coworkers to voluntarily exit because they interfere with the effective functioning of the organization and the cohesion of other organizational members. This motive reflects organizational members' desires for their fellow coworkers to uphold the vision and standards set forth by the organization through their performance. If the performance and behaviors of their peer coworkers falters, then organizational members seemingly want them to voluntarily exit. Thus, the detriment to workplace motive aligns with the notion of concertive control in which organizational members work together and create norms of behaviors that uphold the values and recommended practices of the organization without direct supervision from authority figures (Barker, 1999). In other words, organizational members work in concert with one another to complete tasks, and in doing so, create procedures, norms, and rituals regarding how they are to behave in the organization (Tompkins \& Cheney, 1985). Tompkins, Montoya, and Candrian (2009) noted that the foundation of concertive control consists of communication between organizational members and the combination of shared values, objects, and methods for making decisions. With this in mind, organizational members apparently realize when their peer coworkers become hindrances to that foundation, and wish to see them exit.

When organizational members manage and collaborate with one another, they often hold each other to a higher standard than do authority figures, which may lead to organizational members punishing or disciplining their peer coworkers for shoddy work or performance (Barker \& Cheney, 1994). In this way, organizational members may discipline their peer coworkers for 
disrupting the organization's effectiveness by encouraging them to leave the organization. By encouraging peer coworkers who are hindering the effectiveness of the organization to leave, organizational members can avoid having to overcompensate for these poor performers (Williams \& Karua, 1991). By doing so, they may actually improve the quality of the organization and help it avoid the costs of poor performance, which could be greater than actually incurring the cost of replacing the employee (Griffeth \& Hom, 2001).

The third motive that emerged was improve work situation of peer coworker, in which organizational members want to see their peer coworkers locate better professional opportunities for themselves. This motive reflects more of a humane and compassionate motive because it is grounded in the desire for organizational members to see their peer coworkers find organizations that would utilize their unique talents, limit the amount of stress experienced, or spend more time with their families. Cialdini, Schaller, Houlihan, Arps, Fultz, and Beaman (1987) discovered that when organizational members perceive sadness from their peer coworkers, they are more likely to help their peer coworkers. Perhaps organizational members sense that their peer coworkers are unhappy and desire to do what they can to alleviate the unhappiness. Indeed, the absence of positivity can have detrimental effects on job satisfaction, work happiness, and organizational commitment (Youssef \& Luthans, 2007). It is also plausible that organizational members realize that their peer coworkers are unhappy, and thus distracted from their work, which could lead to decreased performance and effectiveness by the organization (Mobley, 1982). In either case, the desire to bring about some sort of positive change for the peer coworkers appears to be the crux of the motive to improve the work situation of peer coworkers.

The fourth motive that emerged was improve standing of self, in which organizational members want to see their peer coworkers exit because they see their peer coworkers as 
obstacles to their own professional aspirations. This motive reflects a competitive, and perhaps selfish or Machiavellian spirit, suggesting that organizational members may conceivably do anything to succeed in the organization, even if it means influencing a peer coworker to exit. Rather than simply biding time and working hard, or perhaps in addition to doing these things to get noticed by authority figures, evidently, some organizational members encourage their peer coworkers to exit to reach goals that they have set for themselves. While a competitive spirit can lead to greater effort to learn specific skills necessary for performing work (Wang \& Netemeyer, 2002), it is conceivable that a competitive spirit could lend its self to deviant behaviors in the organization, such as criticizing coworkers or taking credit for their work (Jelinek \& Ahearne, 2010). Therefore, the desire for peer coworkers to voluntarily exit so organizational members can improve their own organizational standing seems conceivable, especially if the organization encourages competitive behavior between organizational members (Grojean, Resick, Dickson, \& Smith, 2004; Jelinek \& Ahearne, 2010).

After creating items for each of the motives for encouraging peer coworkers identified in Study 1, the items were factor analyzed in Study 3, resulting in four motives. The first motive that emerged via factor analysis was personal gain. The personal gain factor combined items from the "difficult to work with" and the "improve standing of self" motives from Study 1. Based on the combination of those motives from Study 1, it seems that organizational members wish to see their peer coworkers voluntarily exit because their peer coworkers have disliked physical features (that perhaps annoy or anger the source) and act as obstacles to promotions and other accolades presented by the organization. Perhaps ridding themselves of the peer coworkers who fail to fit the organization's mold for employees (Sias, 2012) and who work similar jobs are powerful reasons why organizational members want to encourage their peer coworkers to exit. 
The second motive that emerged via factor analysis was altruistic. The altruistic factor contained items from the "improve work situation of peer coworker" motive from Study 1. It seems that some organizational members do indeed wish to see their peer coworkers discover organizational opportunities that would be more conducive to their professional aspirations and physical and emotional welfare. The altruistic motive also reflects that organizational members are capable of holding positive feelings toward their colleagues (Lutgen-Sandvik et al., 2011) and being optimistic that they can gain employment with organizations that would employ them more effectively. Conceivably, organizational members who report the altruistic motive genuinely want their peer coworkers to have better organizational experiences than they are having in their current organizations.

The third motive that emerged via factor analysis was organizational enhancement. The organizational enhancement motive contained items from the "detriment to workplace" motive from Study 1. This motive seemingly reflects organizational members' identification with their organizations and their desire for their organizations to reach peak effectiveness by encouraging poor performers to voluntarily exit. Organizational identification can lead organizational members to defend their organizations and speak positively of them even when experiencing financial hardships (Williams \& Connaughton, 2011) or unethical business dealings (Ploeger \& Bisel, 2013). Thus, it seems conceivable that organizational members wish for their peer coworkers to leave because they are hindering organizational effectiveness. The organizational enhancement motive also reflects the need for organizational members to maintain concertive control over one another and continue striving to achieve the goals set forth by the organization (Barker, 1999). Perhaps the pride and/or identification that organizational members feel toward 
their organizations leads them to do engage in whatever tactics they can to preserve the prestige or effectiveness of the organization.

The fourth motive that emerged via factor analysis was climate improvement. The climate improvement motive contained items from "the difficult to work with" and the “detriment to workplace" motives. This motive reflects organizational members' desires to create or maintain a supportive climate in their organizations (see Mishra, Boynton, \& Mishra, 2014). Therefore, whenever organizational members have peer coworkers that disrupt the organizational climate, it can create conflict and decrease the satisfaction that they have with the organization (Jablin, 1980). Actions such as gossiping, spreading rumors, and distracting colleagues can seriously derail employee production (Baron, 2004), so it seems that organizational members want their peer coworkers to voluntarily exit whenever they consistently engage in such actions. If organizational members are to spend in excess of 40 hours a week in their organizations, it is reasonable to believe that they want as few distractions and hindrances to the organizational climate as possible.

\section{Relationship between Peer-Influence Exit Tactics and Motives}

The third major finding concerned the relationship between organizational members' motives and their use of peer-influence exit tactics. Each of the four peer-influence exit tactics was predicted by various motives. First, affirmation tactics were predicted by personal gain and altruistic motives. It seems as though people who desire for their peer coworkers to exit due to the personal gain motive engage in affirmation tactics to achieve their goal. This is similar to the assertion the Cox (1999) made that, even though organizational members use supportive and constructive methods for encouraging the voluntary exit of their peer coworkers, they are still engaging in tactics to satisfy their own goals and aspirations. Similarly, organizational members 
who desire peer exit for personal gain might also use the affirmation tactic because they want to maintain cordial relations with their peer coworkers despite wanting them to voluntarily exit. In this way, organizational members can rid themselves of obstacles to new personal success while also appearing to be friendly, constructive, and caring.

Additionally, the altruistic motive was positively related to affirmation tactics according to the correlation, but it was a negative predictor of affirmation tactics when entered into a regression with the other motives. This inconsistency could be due to multicollinearity or suppression in which there is an overlap of variance between predictors and criterion variables in a multiple regression (Beckstead, 2012). Based on these results, it appears that organizational members who have greater altruistic motives engage in fewer affirmation tactics. This could be interpreted to mean that organizational members who genuinely want their peer coworkers to voluntarily exit have reservations about complimenting or providing assurances to their peer coworkers. Perhaps they are reluctant to use affirmation tactics because they are unwilling or unable to engage in the process of helping their peer coworkers with job searches or find opportunities that would be best for them. Another possibility is that organizational members may be unwilling to face the potentially emotional conversation of encouraging their peer coworkers to leave, so they find other ways that they could encourage their peer coworkers to voluntarily exit.

Second, the use of unprofessional peer-influence exit tactics was predicted by the personal gain, altruistic, and organizational improvement motives. These results suggest that organizational members with the personal gain motive engage in more unprofessional tactics. It is conceivable that organizational members would do whatever they could to encourage their peer coworkers' voluntary exit, even if it means damaging their peer coworkers' reputation or 
professional standing. By engaging in unprofessional tactics, it could be a way for organizational members to reclaim power in their relationships with their peer coworkers (Cox, 1999) or to retaliate against their peer coworkers for perceived transgressions against them or the organization (Skarlicki \& Folger, 1997). It appears that engaging in unprofessional tactics similar to bullying (Waldron \& Kassing, 2014) or exclusion (Sias, 2012) is among the preferred tactics that organizational members use to accomplish their goals of achieving organizational success.

The results also suggest that organizational members with the altruistic motive engage in fewer unprofessional tactics, suggesting that organizational members who genuinely care about their peer coworkers refrain from causing them undue stress and trouble, despite wishing they would leave the organization. Organizational members may want to preserve the relationships that they have with their peer coworkers, so they refrain from using unprofessional tactics. Perhaps organizational members recognize that engaging in unprofessional tactics would damage their peer coworker relationships and possibly harm their organizational standing if they engaged in any unethical behavior.

Additionally, organizational members with the organizational improvement motive use fewer unprofessional tactics, which implies that employees who desire their organizations to improve refrain from causing any more damage or drama to their organization. While organizational members who feel high levels of organizational identification would conceivably want their peer coworkers to voluntarily exit, especially if they are detrimental to the effectiveness of the organization, they likely realize that behaving in unethical or unprofessional ways could have serious repercussions on the organization. For instance, using unprofessional 
tactics could lead to decreased production (Baron, 2004) or it could damage the values set forth by organizational leaders (Grojean et al., 2004).

Third, depersonalization tactics were predicted by the altruistic and climate enhancement motives. These results suggest that organizational members with the altruistic motive use fewer depersonalization tactics while organizational members with the climate enhancement motive engage in more depersonalization tactics. It appears that organizational members with the altruistic motive are reluctant to engage in any tactics that distance or isolate themselves from their peer coworkers. This might also mean that organizational members who genuinely care about their peer coworkers know that distancing themselves from and ignoring their peer coworkers is incongruent with how they believe other people should be treated in the organization. In other words, if organizational members feel the desire to help their peer coworkers find better professional endeavors, they realize that avoiding and shunning them is the wrong tactic to use to encourage them to leave.

Moreover, organizational members with the climate enhancement motive conceivably engage in depersonalization tactics because their peer coworkers are self-centered, manipulative, and distracting in the organization. Rather than dealing with people who are disruptive and troublesome, organizational members seemingly engage in depersonalization behaviors to avoid any dramatic confrontations and to send their peer coworkers the message that their distracting behavior is unwelcomed in the established organizational climate. Supportive organizational climates are important components of successful organizations (Patterson et al., 2005), thus anyone who disturbs such climates could be susceptible to isolation (Marshall, Michaels, \& Mulki, 2007) and exclusion (Sias, 2012), which are conceptually similar to depersonalization tactics. 
Fourth, the use of professional tactics was predicted by the personal gain and organizational improvement motives. Organizational members who want their peer coworkers to voluntarily exit so that they can benefit from the exit use professional tactics to achieve their goals. This is intriguing considering that selfishly wanting their peer coworkers to leave would conceivably lead to the use of hostile or destructive methods for encouraging exit because selfish or Machiavellian behavior tends to be associated with deviant organizational behavior such as dishonesty (Ashton et al., 2000) and the desire for power (Dahling et al., 2009). However, organizational members with the personal gain motive may possess enough communication and social competence to realize that unethical or unprofessional behavior could backfire and create undue conflict and drama. By behaving in professional ways, it can allow organizational members with the professional gain motive to maintain an ethical façade while concealing conniving desires and wishes.

Additionally, organizational members who want their peer coworkers to voluntarily exit for the purpose of improving the organization use professional tactics to achieve their goals. Apparently, organizational members who desire to see their organizations reach their goals and flourish remain cordial and friendly with their peer coworkers despite wishing they would exit. Perhaps to improve the organization, members take it upon themselves to be polite to those who are seemingly disrupting the effectiveness of the organization rather than reverting to tactics that could actually harm the quality of the organization.

\section{Source Characteristics}

The fourth major finding that emerged was the relationships between personality traits and the use of peer-influence exit tactics. Specifically, competitiveness, agreeableness, and selfesteem were each related to various peer-influence exit tactics. First, affirmation and 
unprofessional tactics were predicted by organizational members' competitiveness, which lends support to the notion that organizational members who view life as a game with clear winners and losers would use a range of tactics to encourage their peer coworkers to leave. The notion that competitive organizational members use affirmation tactics implies that their competitive spirit drives the manner in which they encourage voluntary exit because they would conceivably use any tactic that they have available to them to gain an advantage over their peer coworkers. Perhaps they realize that complimenting their peer coworkers and wishing them well in their professional endeavors is the best way for them to "win" and accomplish their goals. This reasoning aligns with Brown et al.'s (1998) finding that organizational members' trait competitiveness related to their attainment of self-set goals at work. Thus, playing nice and being friendly is a way that competitive organizational members push their peer coworkers to voluntarily exit.

Additionally, the discovery that competitive organizational members use more unprofessional tactics makes sense given their propensity to do whatever is in their power to accomplish goals or to defeat an adversary (Mowen, 2004). Apparently, competitive organizational members will behave unprofessionally if they see that they can professionally benefit from doing so. Perhaps the internal drive to succeed or win at all costs drives employees toward behaving in an unethical or unprofessional manner toward their peer coworkers to push them to exit.

Second, affirmation, unprofessional, and depersonalization tactics were each negatively predicted by organizational members' agreeableness. Organizational members who are relaxed, calm, and tranquil in their interactions (McCrae \& Costa, 1999) are less likely to offer encouragement and support to influence their peer coworkers to exit. Given that agreeable 
organizational members tend to engage in greater amounts of organizational citizenship behavior (Kamdar \& Dyne, 2007), they may still see potential for their peer coworkers to succeed in their current organizations and are reluctant to push them to leave, even through affirmation tactics. This might mean that agreeable organizational members are content with their work situations (Ployhart, Weekley, \& Baughman, 2006) and see no true value in using affirmation tactics to encourage voluntary exit. Agreeable organizational members may wish to see their peer coworkers remain and become productive members of their organizations.

Additionally, the discovery that agreeable organizational members use fewer unprofessional tactics and depersonalization tactics is plausible. Just as agreeable organizational members may be reluctant to use affirmation tactics, they may be reluctant to engage in tactics that consist of unethical or disconfirming behaviors. This may be because agreeable organizational members tend to do what they can to help the organization succeed through enacting behaviors beneficial to the organization and its members (Organ, 1994). It also corroborates previous research indicating that individuals high in agreeableness tend to be less physically and verbally aggressive (Ode, Robinson, \& Wilkowski, 2008; Tremblay \& Ewart, 2005) and engage in less deviant organizational behavior (Colbert, Mount, Harter, Witt, \& Barrick, 2004). Therefore, it seems to be against their nature to harm their peer coworkers or harm the organization through the use of unethical tactics.

Third, unprofessional and professional tactics were each predicted by organizational members' self-esteem. Organizational members who perceive themselves to be capable and worthy tend to use fewer unprofessional tactics, but more professional tactics. Taken together, organizational members with high self-esteem likely see no reason to create hardship for their peer coworkers by behaving indignantly toward them. This explanation is consistent with the 
finding of Robins et al. (2001) that high self-esteem organizational members tend to work well in groups with their coworkers. It also aligns with previous scholarship indicating that self-esteem is negatively related to verbal aggressiveness (Rancer, Kosberg, \& Silvestri, 1992).

Furthermore, high self-esteem organizational members might feel confident enough about their abilities to behave professionally and ethically to encourage their peer coworkers to voluntarily exit.

In addition to discovering the relationships between organizational members' personality characteristics and their use of peer-influence exit tactics, several key findings regarding their personality characteristics and their motives for encouraging peer coworkers to exit emerged. As with the peer-influence exit tactics, competitiveness, agreeableness, and self-esteem each predicted various motives.

First, the personal gain, altruistic, and organizational improvement motives were predicted by organizational members' competitiveness. It appears that competitive organizational members seek personal gain and want what is best for their peer coworkers, but hold little concern for their organizations' well-being. The positive relationship between competitiveness and the personal gain motive is reasonable to believe given competitive organizational members' penchant for perceiving life events as part of a game that they must win (Ryckman et al., 1990). As such, they seemingly want their peer coworkers to leave so they have an easier time "winning" and reaching their goals. It is possible that competitive organizational members can have altruistic motives, as well. This could mean that competitive organizational members project their competitiveness onto their peer coworkers and want them to find organizations in which they can flourish and become better employees. Holmes (1978) argued that projection occurs when individuals attribute their own personality characteristics onto other people. It 
could be that organizational members want to push their peer coworkers to exit the organization so their peers could maintain a competitive edge in their own lives and organizations.

Also, organizational members' competitiveness was a negative predictor of organizational improvement, suggesting that organizational members do not want their peer coworkers to exit because they care about the state of the organization. Instead, it appears that competitiveness lends itself to selfishness, so concern about the effective functioning of the organization is peripheral to the desire to see a peer coworker exit. Conceivably, competitive organizational members already see themselves as better than their peer coworkers, so they take less notice of how other organizational members limit the effectiveness of the organization.

Second, organizational members' agreeableness negatively predicted the personal gain motive. Apparently, agreeable organizational members are less concerned about pushing their coworkers to leave for their own selfish ambitions. This could mean that agreeable members' tendency to be satisfied or content with their jobs and organizations (Ployhart et al., 2006) and preference for supportive organizations (Judge \& Cable, 1997) leaves them less susceptible to selfish ambition. It also could insinuate, as Seibert and Kraimer (2001) noted, that agreeableness seems to be at odds with doing what is necessary to gain political advantages within organizations. Those political advantages could be to rid organizational members of their competition.

Third, organizational members' self-esteem negatively predicted the personal gain, altruistic, and climate enhancement motives. The negative relationship between self-esteem and personal gain could mean that when organizational members possess high levels of confidence and self-worth, they see relatively little competition between themselves and their peer 
coworkers. Perhaps high levels of confidence allow organizational members to see their peer coworkers as collaborators rather than competition (Duffy, Shaw, Scott, \& Tepper, 2006).

Furthermore, the negative relationship between self-esteem and the altruistic motive could mean that organizational members who are confident in themselves and their abilities have less selfish ambition and desire for their peer coworkers to voluntarily exit. Perhaps, as Sluss and Ashforth (2007) suggested, they have enough confidence in themselves that they can work and perform well without having to worry about the plight of their undervalued or underappreciated peer coworkers. The negative relationship between self-esteem and the climate enhancement motive suggests that organizational members feel strongly about their abilities and contributions to the organization and avoid focusing on how their peer coworkers detract from the organization's climate.

\section{Target Characteristics}

The fifth major finding that emerged concerned the influence of target characteristics on the use of peer-influence exit tactics and motives for encouraging peer coworkers to exit. Organizational members' perceptions of similarity with their peer coworker, their peer's work performance, liking of the peer, and the peer's organizational influence each predicted various peer-influence exit tactics and motives.

First, organizational members' perceptions of similarity with their peer coworker predicted the use of affirmation, unprofessional, and professional tactics. Perceptions of coworker similarity is associated with the use of affirmation tactics, perhaps because organizational members tend to develop close relationships with those that they perceive to have similar interests, backgrounds, and values (Sias, 2009; Sias \& Cahill, 1998). These close relationships often lead to sustained friendships (Sias et al., 2012) and exchange of supportive 
messages with one another (Fay \& Kline, 2012). Another possibility is that perceived similarity leads organizational members to treat their peer coworkers as they, themselves, would want to be treated. This might also explain the use of professional tactics, because it seems intuitive for organizational members to behave in ethical ways and assist their peer coworkers if there is perceived similarity. Thus, organizational members seem to use affirmation tactics with peer coworkers who they perceive as similar to them.

Conversely, it appears that perceptions of coworker similarity also predict the use of unprofessional tactics. This seems counterintuitive, but perhaps, some organizational members may engage in unprofessional actions with people that they perceive as similar to them because they believe that it is appropriate to engage in such actions. In this way, perhaps organizational members who use unprofessional tactics believe that they can use them because they, themselves, could withstand the unprofessional behavior. It is also possible that organizational members who use unprofessional tactics with coworkers whom they perceive as similar have histories of aggressive behavior (Greenberg \& Barling, 1999), that lead them to act in such ways.

Second, perceived work performance of peer coworkers negatively predicted affirmation, unprofessional, and depersonalization tactics. It seems that organizational members take offense to what they perceive as lazy or uninspired production in the organization, which explains why organizational members use fewer affirmation tactics to push out incompetent coworkers. Organizational members seem unlikely to provide insight about other jobs or opportunities to peer coworkers who are poor work performers. Work performance is something that organizational members are often prideful of in their organizations (Gunter \& Furnham, 1996), so it seems that organizational members who fail to uphold a high standard of performance are susceptible to the use of peer-influence exit tactics. The results of the scenarios in Study 2 bear 
this out, as well, as organizational members who were exposed to a scenario depicting a low performing peer coworker reported that they would use more unprofessional and depersonalization peer-influence exit tactics with that peer than organizational members who were exposed to a higher performing peer coworker.

Third, organizational members' liking of their peer coworkers negatively predicted the use of unprofessional and depersonalization tactics. It makes sense that when organizational members hold their peer coworkers in high regard they use fewer unprofessional and depersonalization tactics. Liking tends to influence the creation and maintenance of peer coworker relationships (Sias, 2009; Sias et al., 2012), and the use of unprofessional and depersonalization tactics could be detrimental to the relationship. Thus, it makes sense that as liking increases, the use of unprofessional and depersonalization tactics decreases. Myers and Johnson (2003) found similar results when they discovered that verbal aggressiveness and liking in interpersonal relationships were negatively related.

Fourth, organizational members' perceptions of their peer coworkers' organizational influence predicted the use of affirmation, depersonalization, and professional tactics. Through the use of affirmation tactics, organizational members can appear to care about their peer coworkers, and avoid disrupting their standing with authority figures. Similarly, because the peer's organizational influence is comprised of a close relationship with authority figures, organizational members may use depersonalization tactics with the peer to avoid being perceived as deviant or petty by the superior. By simply ignoring or shunning peer coworkers that are perceived to have considerable organizational influence, members can encourage their peer coworkers to voluntarily exit. By using professional tactics, organizational members can also maintain their professional image without harming their place in the organization's social 
networks. The use of depersonalization or professional tactics is likely advantageous because it also prevents organizational members from incurring the wrath of supervisors who may be overprotective of their prized employees.

In addition to discovering the relationships between target characteristics and peerinfluence exit tactics, several key findings emerged regarding target characteristics and organizational members' motives for encouraging peer coworkers to exit. As with the peerinfluence exit tactics, the target characteristics predicted a variety of motives.

First, the personal gain and altruistic motives were predicted by perceptions of coworker similarity. Employees desire peer coworkers who are similar to them to exit the organization perhaps because these peers possess similar skill sets and characteristics, thus providing competition for promotions, salary enhancements, and privileged positions. With that in mind, organizational members may want the peer coworkers who are similar to them to exit, so they can be the ones with unique skill sets and characteristics.

The positive relationship between perceptions of similarity and the altruistic motive is conceivable because people tend to act favorably toward people with whom they feel kinship or similarity (Sias et al., 2012), thus they may desire to see their peer coworkers find better professional opportunities.

Second, perceived work performance of peer coworkers negatively predicted the personal gain and organizational improvement motives and positively predicted the climate enhancement motive. It seems that when organizational members perceive their peer coworkers to be good performers they feel less strongly about gaining personal advantages, which could mean that they see their peer coworkers' performance as helpful to the performance of the organization. This is consistent with the finding that they are less motivated to see their peer coworkers exit in order 
to improve the organization. Again, exceptional work performance is beneficial to the organization, which in turn, could be beneficial to other organizational members' career success. However, perceptions of work performance seem to influence greater desire for peer coworkers to exit so the organizational climate can be enhanced. It is reasonable to believe that peer coworkers can be outstanding workers, but detriments to the workplace, if they feel that they can get away with being a jerk because they are a valued and competent employee, thus making them difficult to deal with for other members of the organization. Therefore, despite proficient work, certain peer coworkers may still disrupt the vibe of the organization (Dunlop \& Lee, 2004; Fritz, 2002).

Third, organizational members' liking of their peer coworkers negatively predicted the personal gain, organizational improvement, and climate enhancement motives. Thus it appears that when organizational members have high regard for their peer coworkers they are less likely to want their peers to leave due to selfish ambition or the desire to improve their organization or its climate. As many scholars have asserted, liking for coworkers can lead to more favorable perceptions of coworkers (Sias \& Cahill, 1998) and a more positive organizational climate (Farrell \& Finkelstein, 2011).

Fourth, organizational members' perceptions of their peer coworkers' organizational influence predicted the climate enhancement motive. Scholars have noted how favorable or differential treatment by authority figures toward certain organizational members can have negative effects on the organization (Sias \& Jablin, 1995). It appears that when organizational members perceive that their peer coworkers possess considerable organizational influence, it can adversely affect the organizational climate. For example, being invited to lunch with authority figures, or receiving prominent assignments or other organizational perks could create animosity 
between organizational members who fail to receive such amenities, and subsequently damage the organizational climate. Thus, organizational members desire to improve the climate of the organization when they perceive that their peer coworkers are too closely aligned with authority figures because those peer coworkers could potentially call attention to themselves and flaunt their close relationship with authority figures and the advantages that go along with it.

\section{Organizational Characteristics}

The sixth major finding that emerged concerned the influence of organizational characteristics on the use of peer-influence exit tactics and the motives for encouraging peer coworkers to exit. Organizational members' perceptions of organizational climate, organizational justice, supervisor complicity, and coworker regard each predicted various peerinfluence exit tactics and motives.

First, organizational members' perceptions of autonomy predicted the use of affirmation and professional tactics. The results suggest that whenever organizational members perceive autonomy in the way that they work and function in their organizations, they are less likely to use affirmation tactics. This result suggests that the autonomous nature of organizations creates fewer opportunities for organizational members to make assessments of their peer coworkers' work or it could be mean that organizational members actually spend less time interacting with their peer coworkers, thus creating fewer opportunities to develop a true sense of their peer coworkers' aspirations and the opportunities that would be better for them. Similarly, greater autonomy also resulted in the use of fewer professional tactics, which could be due to autonomy influencing less cordial interaction between peer coworkers or because autonomous employees have the opportunity to focus on their own work without needing to devote attention to their peers' performance. 
Second, organizational members' perceptions of distributive justice predicted the use of professional tactics. It appears that when organizational members receive what they believe to be fair outcomes in their organizational experiences, they use professional tactics to a greater extent, which aligns with the assertions of scholars who have found that perceptions of fairness are usually deterrents to antisocial behavior (e.g., Aquino, Lewis, \& Bradfield, 1999; Chory \& Hubbell, 2008). Another possibility is that the perceptions of fairness held by organizational members provides them the confidence that they could influence their peer coworkers to voluntarily exit without experiencing any adverse changes to their compensation or organizational rewards.

Third, supervisor complicity predicted the use of affirmation, unprofessional, and professional tactics, which lends support to the discovery of Cox and Kramer (1995) that supervisors instructed their employees to encourage underperforming peer coworkers to voluntarily exit. The positive association between supervisor complicity and affirmation tactics suggests that organizational members receive the blessing of their supervisors to encourage their peer coworkers to exit, and then proceed to provide suggestions and feedback regarding new professional endeavors. It is also plausible that organizational members utilize affirmation tactics as a way to push their peer coworkers to exit without causing them harm or creating a scenario in which the targeted peer coworkers could claim that there was wrongdoing or unethical behavior on the part of the organization.

Conversely, the association between supervisor complicity and unprofessional tactics provides reason to believe that organizational members engage in hostile or unfriendly ways of encouraging their peer coworkers to exit because they have immunity from organizational sanctions due to their relationship or some sort of agreement with their supervisor. 
Corroborating with supervisors could seemingly give organizational members the authority to engage in a variety of devious acts without facing much opposition from targeted peer coworkers or other members of the organization. The association between supervisor complicity and professional tactics suggests yet another possibility that organizational members behave in ethical or constructive ways with their peer coworkers because they do represent the interests and wishes of their supervisors.

Fourth, organizational members' perceptions of coworker regard predicted unprofessional and professional tactics. Given that coworker regard represents how organizational members believe that their peer coworkers view them, it is plausible to believe that higher perceived regard results in using fewer unprofessional tactics. Organizational members seem to refrain from negative actions toward their peer coworkers when they believe they are held in high esteem by those peer coworkers. Likewise, it appears that organizational members use professional tactics when they perceive that they are regarded highly by their fellow peer coworkers. This could mean that feeling valued and highly regarded by one's colleagues leads to greater civility and ethical behavior. Fritz (2012) asserted that organizational members have responsibilities to treat their peer coworkers with civility, especially when they, themselves, are treated with civility and fairness. Thus, highly regarded coworkers seemingly behave professionally with their peer coworkers because they receive ethical and civil treatment from their peer coworkers.

In addition to discovering the associations between organizational characteristics and peer-influence exit tactics, findings regarding the relationship between organizational characteristics and organizational members' motives for encouraging peer coworkers to exit also 
emerged. Perceptions of organizational culture, organizational climate, supervisor complicity, and coworker regard each predicted at least one motive.

First, perceptions of teamwork, a dimension of organizational culture, was a positive predictor of the personal gain motive. According to Glaser et al. (1987), teamwork represents the norm of collaboration and cohesion amongst organizational members. Thus, the positive association between teamwork and personal gain seems counterintuitive. However, it is possible that some organizational members desire to rebel against the cohesive norms of their organization and desire the coveted positions that their peer coworkers may hold. Perhaps an overemphasis on teamwork could lead to deviant or rebellious acts (Appelbaum, Laconi, \& Matousek, 2007). Vardi and Wiener (1996) suggested that misbehaving or deviating from cultural norms of an organization could be stimulated by the pursuit of personal goals and ambitions. Using this as a guide, it is plausible that greater teamwork could increase the personal gain motive.

Second, perceptions of formalization was a negative predictor of the organizational improvement motive. Formalization entails enforcement of workplace policies and procedures (Patterson et al., 2005). Perhaps when organizational members work in an organization governed by strict adherence to rules, there is less room for poor performance. It is possible that peer coworkers who are poor performers would be quickly punished or terminated through formal channels, thus creating less of a desire for organizational members to improve the organization through encouraging peer coworkers to voluntarily exit.

Third, perceptions of pressure to produce predicted the climate enhancement motive. Demanding organizational standards create the desire for organizational members to make their situations better by eliminating peer coworkers who are detrimental to the climate. Perhaps there 
are peer coworkers who actually make others look bad with their proficient work, so organizational members may want to push out their peer coworkers who create more pressure and higher standards in the organization because it results in less prestige for them and more pressure to sustain high levels of production. It is also possible that peer coworkers can create negative organizational environments (Fritz \& Omdahl, 2006), which could mean that organizational members desire a break from their troublesome peer coworkers (Fritz, 2002), and want to see them leave.

Fourth, supervisor complicity predicted both the personal gain and altruistic motives. Perhaps the agreements that organizational members have with their supervisors regarding the departure of their peer coworkers gives organizational members the belief that they can reap professional benefits from such an agreement. On the other hand, perhaps the agreement with supervisors that organizational members have instills in them a sense of empathy for their peer coworkers, and they wish to see them depart to experience better organizational outcomes. Another possibility is that organizational members who desire personal gain may approach their supervisors seeking approval to encourage certain peer coworkers who are acting as obstacles to success to exit.

Fifth, when organizational members believe that they are held in high esteem by their peer coworkers, they are less motivated by personal gain to encourage their peer coworkers to leave. It may be that when organizational members are held in high regard by their peer coworkers, they have little reason to compete with these peers who already view them as accomplished employees.

\section{Planning}

The seventh major finding that emerged was the revelation about the amount of planning that organizational members engage in regarding their use of peer-influence exit tactics. 
Creating goals and making plans to implement strategies to achieve those goals are an integral part of communication (Berger, 1997; Dillard, 1990). In this case, it appears that organizational members detect some quality or characteristic of their peer coworkers, whether it is good or bad, that they realize is troublesome to both organizational members and the targeted peer coworkers. After they realize that their peer coworkers possess those characteristics, they begin to create plans to use peer-influence exit tactics. Then they enact the plans.

Dillard (1990) argued that whenever individuals engage in the action of persuading others, it is purposeful and strategic. Thus, organizational members seem to be consciously aware of their actions and the goal that they are attempting to achieve. Once organizational members influence their peer coworkers to leave, they begin to focus their attention back on themselves. In other words, it appears that, once organizational members feel that they have accomplished their goal, they place their concentration on their own work situation.

\section{Effectiveness}

The effect of peer-influence exit tactics was assessed by asking organizational members to detail how they believed they affected their peer coworkers and by assessing the number of peer coworkers who departed the organization. The use of peer-influence exit tactics had four effects on the targets: expedited exit, uncertain effect, silver-lining, and created remorse. Organizational members believed that the use of their peer-influence exit tactics hastened the departure of their peer coworkers. Depending on the type of tactic used by organizational members, it is possible that the targets reached a point in which believed that they could no longer function in their organizations either because they were being treated poorly or because they trusted that the sources of the peer-influence exit tactics genuinely had their best interests in mind. 
Another effect was more ambiguous for those involved with peer-influence exit tactics. Organizational members would encourage their peer coworkers to leave, but were unsure exactly how much influence or how effective they were. The silver-lining effect represents how organizational members believed that their peer coworkers were in a better professional and/or life situation as the result of peer-influence exit tactics. Perhaps the discussions or support provided about new professional endeavors provided targets with the confidence needed to voluntarily exit and find organizations that were better for them. Organizational members also indicated that they created remorse in their peer coworkers by helping them realize that they had squandered several opportunities in the organization or that they were actually detriments to the workplace. In this case, targets expressed their apologies for causing organizational disturbances once they received peer-influence exit tactics.

Additionally, the results of Study 1 indicated that, while there was no statistically significant difference in the number of peer coworkers who remained and the number of peer coworkers who departed, most of the peer coworkers who departed, did so voluntarily. Peer coworkers who voluntarily exited did so for four primary reasons: better opportunity, quit, personal reasons, and retiring. It seems that the peer-influence exit tactics used by organizational members assisted their peer coworkers in making decisions about their futures and what they should do with their lives. The results of Study 3 indicated that more peer coworkers remained in the organization than departed from it, but of those who departed, most did so voluntarily.

\section{Limitations and Directions for Future Research}

As with any study, there were limitations to the studies comprising this dissertation. A potential limitation of Study 1 is the number of Asian Americans/Asians that participated in the study. While their viewpoints were helpful in learning more about peer-influence exit, they 
consisted of $43 \%$ of the sample, which is incongruent with both the United States population data and U.S. labor force data. According to the U. S. Census Bureau (2014), Asian Americans/Asians represent $5 \%$ of the population, and $5 \%$ of the U. S. workforce (Bureau of Labor Statistics, 2013), thus the incongruence between the Study 1 sample and the U. S. population could confound the results. The number of Asian Americans/Asians who participated in that study was likely influenced through data collection through Amazon's Mechanical Turk as more Asians tend to participate in Mturk than people of any other ethnicity (Ipeirotis, 2010). Another limitation from both Studies 2 and 3 involved the measures that were utilized. Following the recommendations of Levine (2005) and Miller et al. (2011) each measure was subjected to a confirmatory factor analysis, however measures assessing agreeableness, selfesteem, work performance, liking, organizational influence, teamwork, and organizational climate failed to reach recommended criteria for confirming the measurement model. Each measurement model fit was assessed using normal theory weighted least squares chi-square, the comparative fit index (CFI), the normed fit index (NFI), the relative fit index (RFI), and the root mean square error of approximation (RMSEA). Values of .95 are deemed appropriate for the CFI, NFI, and RFI, while values of .06 or below for the RMSEA are considered appropriate (Hu \& Bentler, 1999).

However, because established measures were used to assess each source, target, and organizational characteristic, the decision was made to use the measures as the creators had intended rather than alter the factor structures. The internal reliabilities for each of the measures, except for the formalization, effort, and pressure to produce dimensions of organizational climate, were all acceptable with a range of .79 to .92. While the content validity of each measure could be called into question, it appeared that each measure associated with the peer- 
influence exit tactics and motives as expected. Perhaps scholars should reexamine the measures that were utilized in this dissertation and revise the measures so that they perform better in assessing what they are intended to assess.

A third limitation related to scale development and creation concerned the Peer-Influence Exit Tactic Measure. Following the recommendations of DeVillis (2003), a construct was identified and items were inductively recreated from open-ended responses produced in Study 1. An exploratory factor analysis revealing four factors was conducted in Study 2 and that a prior factor structure was tested with a confirmatory factor analysis in Study 3. However, the fit statistics were shy of Hu and Bentler's (1999) recommended criteria. Although statistical analyses were conducted with the measure discovered from Study 2, the internal reliabilities ranged from .88 to .96 and the results were congruent with hypothesized relationships, which is provides initial evidence of construct validity. Future studies should continue exploring peerinfluence exit tactics in hopes of creating a more precise measure.

A fourth limitation was the use of self-report data to explore peer-influence exit tactics. This is a limitation because participants can only report on the behaviors that they are consciously aware of enacting. The reliance on self-report data may also create problems with social desirability in which people are reluctant to report about the negative or less desirable aspects of their workplace behavior. Specifically, participants' reluctance to report about the negative aspects of their peer-influence exit tactics could artificially inflate the presence of more constructive peer-influence exit tactics, such as affirmation tactics, which could lead to the conclusion that peer-influence exit tactics have a more positive effect on departing organizational members than they actually do. The self-report data also could limit the ability to generalize these results beyond the sample collected because relationships between peer-influence exit 
tactics and other variables were only explored from the source's perspective of peer-influence exit tactics. The reliance on self-report data could be overcome by conducting observations of actual workplace behavior in which researchers gain access to organizations to assess interactions among peer coworkers and the effect of those interactions on subsequent organizational outcomes such as production or voluntary organizational exit. Researchers could also triangulate observations with interviews and surveys to gain clearer understanding of peerinfluence exit tactics from multiple vantage points.

In addition to creating better measures to explore organizational communication phenomena, there are many directions for future research regarding peer-influence exit tactics. First, now that a knowledge base has been established regarding the source of peer-influence exit tactics, there is a need to capture the perspectives of peer-influence exit targets. By gaining insight from the targets of peer-influence exit tactics, scholars can gain a more complete picture of the effects of peer-influence exit tactics on organizational members and their organizations. Perhaps by studying responses to peer-influence exit tactics by the targets, scholars can pinpoint whether it is the combination of various tactics or the repeated enactment of specific tactics that are more effective in encouraging voluntary organizational exit. Jablin (1987) argued that organizational members reach a threshold of negative experiences or dissatisfaction with the organization before they depart. Perhaps there is a threshold of how long they can sustain peerinfluence exit tactics before they voluntarily exit. Additionally, Lee and colleagues (1996) reasoned that organizational members voluntarily depart their organizations due to being recruited away, gradual disenchantment, or shock. Voluntarily exiting due to behaviors from peer coworkers could conceivably be added as a reason why organizational members leave their organizations. 
Second, peer-influence exit tactics seem to be an inherently face threatening action for both the source and the target of the tactics because the tactics can be used to criticize the work performance, identity, and pride of coworkers. Individuals want to be perceived as competent and trustworthy employees in their organizations (Locke, 2004), so being attacked, criticized, or even politely nudged to voluntarily exit could be threatening to organizational members' face. It also could be threatening to the face of the source of the tactics, especially if the source respects his/her peer coworkers and believes the tactics may be an imposition on them. Brown and Levinson (1987) argued that although individuals desire for their face to be maintained during social interactions, some actions or requests can damage the face of the source and the target. In this way, organizational members who encourage their peer coworkers to leave could risk their face in such encounters by being perceived as a nuisance for being overly concerned with the experiences of their peer coworkers, while the targets could also lose face with regard to the tactics that are used to encourage exit. Scholars should assess the perspective of both the source and the targets to uncover how the concern for or rejection of each other's face impacts the use of peer-influence exit tactics. It is possible that face concerns are a key contributor to the type of tactic used by organizational members. Such an exploration could ground the use of peerinfluence exit tactics in Politeness Theory (Brown \& Levinson, 1987) to provide a more complete theoretical explanation for the selection of peer-influence exit tactics.

Third, other antecedents to the use of peer-influence exit tactics and the motives for encouraging peer coworkers to exit could be usefully explored. For example, the identification or pride that organizational members have for their organizations could seemingly play a role in their desire to see their peer coworkers voluntarily exit. Perhaps that identification leads organizational members to do everything in their power to uphold the mission statement or 
values of the organization, even if it means pushing a peer coworker toward making major career decisions.

Fourth, researchers need to develop better understanding of which tactics are used first and which tend to be the most effective. It is apparent that organizational members use peerinfluence exit tactics due to their own personality characteristics, their perceptions of their peer coworkers, and organizational characteristics, but scholars need to discover whether peerinfluence exit tactics persist over time, if they occur only one time, or if organizational members judge the effectiveness of their initial tactics, and then resort to other tactics to encourage their peer coworkers to voluntarily exit. Such understanding could help scholars detangle the conceptual overlap between peer-influence exit tactics, bullying, exclusion, deviant workplace behaviors, and aggression in organizations. Although conceptually similar, it appears that these behaviors can be differentiated from peer-influence exit tactics due to the intent. The intent to encourage peer coworkers to voluntarily exit appears to be the driving force behind the use of peer-influence exit tactics given the motives expressed by organizational members and the process through which they plan their efforts. Because organizational members appear to detect undesirable qualities in their peer coworkers, strategize about the behaviors that could be used to encourage their peer coworkers to exit, and eventually enact these tactics, it is reasonable to believe the organizational members engage in tactics specifically to encourage their peer coworkers to voluntarily exit. On the other hand, the intent behind other antisocial work behaviors could be simply for organizational members to vent frustrations or to cause problems for the organization and for their colleagues (Baron, 2004). 


\section{Conclusion}

Overall, four peer-influence exit tactics and four motives for encouraging peer coworkers to voluntarily exit the organization were discovered in this dissertation. These findings have both theoretical and practical implications. A theoretical implication is that a new phenomenon has been discovered that contributes to the expanding research about Jablin's (1982) organizational assimilation model, particularly to the organization exit stage. Dating back to Jablin's (1987) theoretical model of voluntary organizational exit, organizational communication scholars have struggled to make substantive claims about the organizational exit process (Kramer, 2010).

Although the influence that peer coworkers can have in the organizational assimilation process has been studied (Myers et al., 2011), only rarely have organizational communication scholars been able to clearly articulate the actual communication that occurs between organizational members about the decision to exit. Tan and Kramer (2012) discovered that many organizational members rationalize their decisions to their coworkers when they want to exit, while Davis and Myers (2012) revealed that organizational members often reminisce and discuss future goals with their peer coworkers. Although this is known, the actual content of communication regarding voluntary exit has been missing.

Jablin (1987) posited that organizational members' desire to voluntarily exit are influenced by their communication experiences and their affect toward the organization. Specifically, he argued that coworker communication could affect satisfaction or commitment to the organization. Using Jablin's (1987) model as a guide, peer-influence exit tactics could influence the affective responses to organizational events experienced by organizational members, which could then lead them to voluntarily exit. Additionally, Jablin (2001) forwarded 
that organizational members progress through a process of organizational exit in which they quietly decide to voluntarily exit, announce their decision to exit, and then slowly reduce their connection to their former organization. It is reasonable to believe that receiving peer-influence exit tactics precipitates the preannouncement stage of the organizational exit process.

A practical implication of this study's results is that both organizational members and authority figures could conceivably make use of peer-influence exit tactics, as Cox and Kramer (1995) found, to encourage underperforming or detrimental employees to exit the organization. As Cox and Kramer asserted, authority figures who notice that they have underperforming employees could collaborate with trusted organizational members about tactics that could be used to encourage those underperforming employees to voluntarily exit. The authority figure could seemingly be spared the uncomfortable experience of having to fire employees, avoid legal problems from the firing, and find better performing employees to replace the underperforming ones.

By using affirmation or professional tactics, organizational members could help their peer coworkers make their own decisions about exiting and potentially improve the functioning of the organization. On the other hand, organizations should realize that there are times in which organizational members engage in peer-influence exit tactics for selfish and antisocial reasons. Understanding when organizational members are mistreating their colleagues and why that mistreatment is occurring could help organizational management make more effective decisions to improve the functioning of their organizations. For example, if organizational members are ignoring, belittling, gossiping about, or undermining their peer coworkers' work, it could be to accomplish underlying goals of personal success or to undercut their peer coworkers. Organizations should be vigilant of such behavior because it could potentially result in more 
hostile organizational climates and could lead to the departure of productive organizational citizens.

This research can also be used to provide practical advice to authority figures, recipients, and sources of peer-influence exit tactics. First, organizational authority figures should realize the detriment that can be caused by a workforce that is free to use peer-influence exit tactics. By realizing that organizational members who are high in competitiveness, but low in both agreeableness and self-esteem, are more likely to engage in unprofessional peer-influence exit tactics, managers may attempt to mitigate these behaviors by screening prospective employees for these personality characteristics. The results of the tests could then be used to inform hiring decisions.

Managers can also discuss with both newcomers and veteran members the four tactics that organizational members use to encourage the voluntary exit of their peer coworkers, and discourage their use. Another thing that managers could do is educate their workforce about the repercussions that the use of peer-influence exit tactics can have on the organization's bottom line and the employees' livelihood. Encouraging voluntary exit could cost the organization untold amounts of money to conduct job searches and train newcomers to fill the vacancies left by exiting employees. Overall, managers should be aware of what peer-influence exit tactics are and how they could be used by organizational members to limit the effectiveness of the organization.

Second, targets of peer-influence exit tactics may use the results of this study to recognize when they are being encouraged to exit, and to realize what is underlying such tactics. Organizational members who form close relationships with their supervisors, are dissimilar from their colleagues, or who are poor performers, are susceptible to receiving peer-influence exit 
tactics. Targets of peer-influence exit tactics may wish to evaluate their performance and relationships with supervisors and colleagues and decide if they can change their behaviors. These targeted organizational members can reevaluate their work performance by asking advice from their colleagues about what they could do to become more productive members of the workforce, or they may observe their colleagues' work performance to find more effective methods for performing their work. Obtaining information from veteran members of the organization about areas of improvement could be a way that organizational members avoid becoming targets of peer-influence exit tactics.

Based upon the data collected in this dissertation, it appears that the use of peer-influence exit tactics may provide some potential benefits for both organizational members and organizations. One benefit is that sources of peer-influence exit tactics could gain better organizational standing by encouraging someone else to exit, especially if the source has worked hard and established a reputation of good performance and citizenship in the organization. The use of affirmation tactics, which are more constructive and helpful in nature, appear to be tactics that competitive organizational members use to accomplish their goals of climbing the organizational ladder. Perhaps by playing nice with their coworkers, they can achieve the organizational status they desire.

Targets of peer-influence exit tactics may benefit by becoming confident about their decisions to voluntarily exit, which could result in greater happiness and satisfaction for them elsewhere. The degree of similarity perceived between sources and targets of peer-influence exit tactics, predicts the use of affirmation tactics. As such, targets who have congruent values and appearance with their peer coworkers might have the chance to exit with greater levels of confidence about their future. 
The use of peer-influence exit tactics could also benefit organizations by ridding them of organizational members who are poor workers or detriments to the climate, thus creating openings for newcomers who could exert greater positive influence on both the organization's functioning and climate. The opportunity to replace poor performing employees with better performers could lead organizations to be more competitive in their industry and to create an environment more conducive to camaraderie between colleagues.

Although there are certainly some benefits for organizational members and organizations from the use of peer-influence exit tactics, there are also many detriments of their use. One repercussion is that the sources of peer-influence exit tactics may create a reputation in their organizations as being hostile and difficult to work with, thus creating reluctance among organizational members to associate with them. Organizational members who are extremely competitive, but are low in agreeableness and self-esteem, seemingly do what they can to encourage their coworkers to leave so they can advance in the organization.

Targets of peer-influence exit tactics may become miserable after being targeted by their peer coworkers, which could result in decreased performance and a disruptive organizational climate. Organizational members who are poor performers and disliked by their peer coworkers tend to be susceptible to unprofessional and depersonalization tactics, which are two destructive peer-influence exit tactics. Thus, targets who fail to adhere to the work standards of their organization and who have had difficulty being liked by their peer coworkers seemingly subject themselves to hostile types of peer-influence exit tactics.

Organizations may see disadvantages in their employees' use of peer-influence exit tactics because strong performers or valued organizational citizens could be the ones being encouraged to exit. Subsequently, organizations stand to lose money from the resulting 
decreased production. Organizations also are disadvantaged because they have to expend precious organizational resources to recruit and train newcomers to replace members who voluntarily exit. Thus, the ability of organizations to properly function can be severely hindered by organizational members who use peer-influence exit tactics. 


\section{References}

Adams, J. S. (1965). Inequity in social exchange. In L. Berkowitz (Ed.), Advances in Experimental Social Psychology (Vol. 2, pp. 267-299). New York: Academic Press.

Amazon.com (2014). Amazon mechanical turk. Retrieved from https://www.mturk.com/mturk/welcome

Allen, M. W. (1996). The relationship between communication, affect, job alternatives, and voluntary turnover intentions. Southern Communication Journal, 61, 198-209. doi:10.1080/10417949609373015

Allen, T. D., \& Finklestein, L. M. (2003). Beyond mentoring: Alternative sources and functions of developmental support. The Career Development Quarterly, 51, 346-355. doi: 10.1002/j.2161-0045.2003.tb00615.x

Andersson, L. E., \& Pearson, C. M. (1999). Tit for Tat?: The spiraling effect of incivility in the workplace. Academy of Management Review, 24, 452-471. doi:10.2307/259136

Apker, J., Propp, K. M., \& Zabava Ford, W. S. (2009). Investigating the effect of nurseteam communication on nurse turnover: Relationships among communication processes, identification, and intent to leave. Health Communication, 24, 106-114. doi:10.1080/10410230802676508

Appelbaum, S. H., Iaconi, G. D., \& Matousek, A. (2007). Positive and negative deviant workplace behaviors: Causes, impacts, and solutions. Corporate Governance, 7, 586-598. doi:10.1108/14720700710827176

Aquino, K., Lewis, M. U., Bradfield, M. (1999). Justice constructs, negative affectivity, and employee deviance: A proposed model and empirical test. Journal of Organizational 
Behavior, 20, 1073-1091. doi:10.1002/(sici)1099-1379(199912)20:7<1073::aidjob943>3.0.co;2-7

Aquino, K., Tripp, T. M., \& Bies, R. J. (2006). Getting even or moving on?: Power, procedural justice, and types of offense as predictors of revenge, forgiveness, reconciliation, and avoidance in organizations. Journal of Applied Psychology, 91, 653-668. doi:10.1037/0021-9010.91.3.653

Ashton, M. C., Lee, K., \& Son, C. (2000). Honesty as a sixth factor of personality: Correlations with Machiavellianism, primary psychopathy, and social adroitness. European Journal of Personality, 14, 359-369. doi:10.1002/1099-0984(200007/08)14:4<359::AIDPER382>3.0.CO;2-Y

Avery, C. M., \& Jablin, F. M. (1988). Retirement preparation programs and organizational communication. Communication Education, 37, 68-80. doi:10.1080/03634528809378704

Avtgis, T. A., \& Chory, R. M. (2010). The darkside of organizational life: Aggressive expression in the workplace. In T. A. Avtgis \& A. S. Rancer (Eds.), Arguments, aggression, and conflict: New directions in theory and research (pp. 285-304). New York: Routledge.

Avtgis, T. A., \& Rancer, A. S. (2008). The relationship between trait verbal aggressiveness and teacher burnout syndrome in K-12 teachers. Communication Research Reports, 25, 8689. doi:10.1080/08824090701831875

Barge, J. K., \& Schlueter, D. W. (2004). Memorable messages and newcomer socialization. Western Journal of Communication, 68, 233-256. doi:10.1080/10570310409374800 Barker, J. R. (1993). Tightening the iron cage: Concertive control in self-managing teams. 
Administrative Science Quarterly, 38, 408-437. doi:10.2307/2393374

Barker, J. R. (1999) The discipline of teamwork: Participation and concertive control. Thousand Oaks, CA: Sage.

Barker, J. R. (2008). Control and authority in organizations. In W. Donsbach (Ed.), The International encyclopedia of communication. Retrieved from http://communicationencyclopedia.com

Barker, J. R., \& Cheney, G. (1994). The concept and the practices of discipline in contemporary organizational life. Communication Monographs, 61, 19-43. doi: $10.1080 / 03637759409376321$

Barker, J. R., \& Tompkins, P. K. (1994). Identification in the self-managing organization: Characteristics of target and tenure. Human Communication Research, 21, 223-240. doi: 10.1111/j.1468-2958.1994.tb00346.x

Baron, R. A. (2004). Workplace aggression and violence: Insights from basic research. In R. W. Griffen \& A. M. O'Leary-Kelly (Eds.), The darkside of organizational behavior. San Francisco: Jossey-Bass.

Barrick, M. R., \& Mount, M. K. (1991). The big five personality dimensions and job performance: A meta-analysis. Personnel Psychology, 44, 1-26. doi:10.1111/j.17446570.1991.tb00688.x

Beatty, M. J., Valencic, K. M., Rudd, J. E., \& Dobos, J. A. (1999). A “dark side” of communication avoidance: indirect interpersonal aggressiveness. Communication Research Reports, 16, 103-109. doi:10.1080/08824099909388707

Becker, J. A. H., \& O’Hair, H. D. (2007). Machiavellians' motives in organizational citizenship behavior. Journal of Applied Communication Research, 35, 246-267. 
doi:10.1080/00909880701434323

Beckstead, J. W. (2012). Isolating and examining sources of suppression and multicollinearity in multiple regression. Multivariate Behavioral Research, 47, 224-246. doi:10.1080/00273171.2012.658331

Benet-Martinez, V., \& John, O. P. (1998). Los Cinco Grandes across cultures and ethnic groups: Multitrait multimethod analyses of the Big Five in Spanish and English. Journal of Personality and Social Psychology, 75, 729-750. doi:10.1037//0022-3514.75.3.729

Bennett, R. J., \& Robinson, S. L. (2000). Development of a measure of workplace deviance. Journal of Applied Psychology, 85, 349-360. doi:10.1037/0021-9010.85.3.349

Bezuijen, X. H., van Dam, K., van den Berg, P. T., \& Thierry, H. (2010). How leaders stimulate employee learning: A leader-member exchange approach. Journal of Occupational Psychology, 83, 673-693. doi: 10.1348/096317909x468099

Berger, C. R. (1997). Planning strategic interaction: Attaining goals through communicative action. Mahwah, NJ: Erlbaum.

Bogler, R. \& Somech, A. (2004). Influence of teacher empowerment on teachers' organizational commitment, professional commitment and organizational citizenship behaviors in schools. Teaching and Teacher Education, 20, 277-289. doi:10.1016j.tate.2004.02.003

Bowling, N. A., Eschleman, K. J., Wang, Q., Kirkendall, C., \& Alarcon, G. (2010). A metaanalysis of the predictors and consequences of organization-based self-esteem. Journal of Occupational and Organizational Psychology, 83, 601-626.

doi:10.1348/096317909X454382

Bridge, K., \& Baxter, L. A. (1992). Blended relationships: Friends as work associates. Western Journal of Communication, 56, 200-225. doi:10.1080/10570319209374414 
Buhrmester, M., Kwang, T., \& Gosling, S. D. (2011). Amazon's Mechanical Turk: A new source of inexpensive, yet high-quality data? Perspectives on Psychological Science, 6, 3-5. doi:10.1177/174569161039380

Bullis, C. (1993). Organizational socialization research: Enabling, constraining, and shifting perspectives. Communication Monographs, 60, 10-17. doi:10.1080/03637759309376289

Bureau of Labor Statistics. (2012, September 27). Annual average unemployment rate, Civilian labor force 16 years and over. Retrieved from http://www.bls.gov/cps/prev_yrs.htm Bureau of Labor Statistics. (2013, September 10). Job openings and labor turnover survey news release. Retrieved from http://www.bls.gov/news.release/jolts.htm

Bureau of Labor Statistics (2012, October). Labor force characteristics by race and ethnicity, 2012. Retrieved from www.bls.gov/cps/cpsrace2012.pdf

Burleson, B. R., \& MacGeorge, E. L. (2002). Supportive communication. In M. L. Knapp \& J. A. Daly (Eds.), Handbook of Interpersonal Communication ( $3^{\text {rd }}$ ed.) (pp. 374-424). Thousand Oaks, CA: Sage.

Butler, K. S., \& Constantine, M. G. (2005). Collective self-esteem and burnout in professional school counselors. Professional School Counseling, 9, 55-62.

Buttner, E. H., Lowe, K. B., \& Billings-Harris, L. (2010). The impact of diversity promise fulfillment on professionals of color outcomes in the USA. Journal of Business Ethics, 91, 501-518. doi:10.1007/s10551-009-0096-y

Brown, S. P., Cron, W. L., \& Slocum, J. W. (1998). Effects of trait competitiveness and perceived intraorganizational competition on salesperson goal setting and performance. Journal of Marketing, 62, 88-98. doi:10.2307/1252289 
Brown, P., \& Levinson, S. C. (1987). Politeness: Some universals in language usage. Cambridge, UK: Cambridge University Press.

Bryant, S. E. (2005). The impact of peer mentoring on organizational knowledge creation and sharing: An empirical study in a software firm. Group \& Organizational Management, 30, 319-338. doi:10.1177/1059601103258439

Cahill, D. J., \& Sias, P. M. (1997). The perceived social costs and importance of seeking emotional support in the workplace: Gender differences and similarities. Communication Research Reports, 14, 231-240. doi:10.1080/08824099709388665

Chiaburu, D. S., \& Harrison, D. A. (2008). Do peers make the place?: Conceptual synthesis and meta-analysis of coworker effects on perceptions, attitudes, OCBs, and performance. Journal of Applied Psychology, 93, 1082-1103. doi:10.1037/0021-9010.93.5.1082

Cialdini, R. B., Schaller, M., Houlihan, D., Arps, K., Fultz, J., \& Beaman, A. L. (1987). Empathy-based helping: Is it selflessly or selfishly motivated. Journal of Personality and Social Psychology, 52, 749-758. doi:10.1037//0022-3514.52.4.749

Clampitt, P. G., \& Williams, M. L. (2005). Conceptualizing and measuring how employees and organizations manage uncertainty. Communication Research Reports, 22, 315-324. doi:10.1080/00036810500317649

Chory, R. M., \& Hubbell, A. P. (2008). Organizational justice and managerial trust as predictors of antisocial employee responses. Communication Quarterly, 56, 357-375. doi:10.1080/01463370802448121

Chory, R. M., \& Westerman, C. Y. K. (2009). Feedback and fairness: The relationship between negative performance feedback and organizational justice. Western Journal of Communication, 73, 157-181. doi:10.1080/10570310902856055 
Christie R., \& Geis, F. C. (1970). Studies in Machiavellianism. New York: Academic Press.

Cohen, J. (1988). Statistical power analysis for the behavioral sciences $\left(2^{\text {nd }}\right.$ ed.). Hillsdale, NJ: Lawrence Erlbaum.

Cohen-Charash, Y., Mueller, J. S. (2007). Does perceived unfairness exacerbate or mitigate interpersonal counterproductive work behaviors related to envy? Journal of Applied Psychology, 92, 666-680. doi:10.1037/003-900093.3666

Colbert, A. E., Mount, M. K., Harter, J. K., Witt, L. A., \& Barrick, M. R. (2004). Interactive effects of personality and perceptions of the work situation on workplace deviance. Journal of Applied Psychology, 89, 599-609. doi:10.1037/0021-9010.89.4.599

Colquitt, J. A. (2001). On the dimensionality of organizational justice: A construct validation of a measure. Journal of Applied Psychology, 86, 386-400. doi:10.1037/0021-9010.86.3.386

Colquitt, J. A., Conlon, D. E., Wesson, M. J., Porter, C. L. H., \& Ng, K. Y. (2001). Justice at the millennium: A meta-analytic review of 25 years of organizational justice research. Journal of Applied Psychology, 86, 425-445. doi:10.1037/0021-9010.86.3.425

Comer, D. R. (1991). Organizational newcomers' acquisition of information from peers. Management Communication Quarterly, 5, 64-89. doi:10.1177/0893318991005001004

Cooper-Thomas, H., \& Anderson, N. (2002). Newcomer adjustment: The relationship between organizational socialization tactics, information acquisition and attitudes. Journal of Occupational and Organizational Psychology, 75, 423-437. doi:10.1348/096317902321119583

Cortina, L. M., Magley, V. J., Williams, J. H., Langhout, R. D. (2001). Incivility in the workplace: Incidence and impact. Journal of Occupational Health and Psychology, 6, 6480. doi:10.1037/1076-8998.6.1.64 
Cotton, J. L., \& Tuttle, J. M. (1986). Employee turnover: A meta-analysis and review with implications for research. Academy of Management Review, 11, 55-70. doi: $10.2307 / 258331$

Cox, S. A. (1999). Group communication and employee turnover: How coworkers encourage peers to voluntarily exit. Southern Communication Journal, 64, 181-192. doi:10.1080/10417949909373133

Cox, S. A., \& Kramer, M. W. (1995). Communication during employee dismissals: social exchange principles and group influences on employee exit. Management Communication Quarterly, 9, 156-190. doi:10.1177/0893318995009002002

Crocker, J., \& Luhtanen, R. (1990). Collective self-esteem and ingroup bias. Journal of Personality and Social Psychology, 58, 60-67. doi:10.1037/0022-3514.58.1.60

Cropanzano, R., Li, A., \& Benson, L. (2011). Peer justice and teamwork process. Group \& Organization Management, 36, 567-596. doi:10.1177/105960111141561

Cude, R. J., \& Jablin, F. M. (1992). Retiring from work: The paradoxical impact of organizational commitment. Journal of Managerial Issues, 4, 31-45.

Dahling, J. J., Whitaker, B. G., \& Levy, P. E. (2009). The development and validation of a new Machiavellianism scale. Journal of Management, 35, 219-257. doi:10.1177/0149206308318618

Davis, C. W., \& Myers, K. K. (2012). Communication and member disengagement in planned organizational exit. Western Journal of Communication, 76, 194-216. doi:10.1080/10570314.2011.651250

DeConinck, J. B., \& Bachmann, D. P. (2011). Organizational commitment and turnover intentions of marketing managers. Journal of Applied Business Research, 10, 87-95. 
DeVellis, D. F. (2003). Scale development: Theory and Applications ( $2^{\text {nd }}$ ed.). Thousand Oaks, CA: Sage

Dillard, J. P. (1990). A goal-driven model of interpersonal influence. In J. P. Dillard (Ed.), Seeking compliance: The production of interpersonal influence messages (pp.41-56). Scottsdale, AZ: Gorsuch Scarisbrick.

Dillard, J. P. (2008). Goals-plans-actions theory of message production. In L. A. Baxter \& D. O. Braithwaite (Eds.), Engaging theories in interpersonal communication: Multiple perspectives (pp. 65-76). Los Angeles, CA: Sage.

Dillard, J. P. (1987). Close relationships at work: Perceptions of the motives and performance of relational participants. Journal of Social and Personal Relationships, 4, 179-193. doi: $10.1177 / 0265407587042005$

Dillard, J. P., \& Broetzmann, S. M. (1989). Romantic relationships at work: Perceived changes in job-related behaviors as a function of participants' motive, partners' motive, and gender. Journal of Applied Social Psychology, 19, 179-193. doi:10.1111/j.15591816.1989.tb00047.x

Dillard, J. P., Hale, J. L., \& Segrin, C. S. (1994). Close relationships in task environments: Perceptions of relational types, illicitness, and power. Management Communication Quarterly, 7, 227-255. doi:10.1177/0893318994007003001

Dillard, J. P., Segrin, C., \& Harden, J. E. (1989). Primary and secondary goals in the production of interpersonal influence messages. Communication Monographs, 56, 19-38. doi:10.1080/03637758909390247

Donnelly, J. H., \& Ivancevich, J. M. (1975). Role clarity and the salesman. Journal of Marketing, 39, 71-74. doi:10.2307/1250806 
Ducharme, L. J., \& Martin, J. K. (2000). Unrewarding work, coworker support, and job satisfaction: A test of the buffering hypothesis. Work and Occupations, 27, 223-243. doi:10.1177/0730888400027002005.

Duffy, M. K., Shaw, J. D., Scott, K. L., \& Tepper, B. J. (2006). The moderating roles of selfesteem and neuroticism in the relationship between group and individual undermining behavior. Journal of Applied Psychology, 91, 1066-1077. doi:10.1037/00219010.91.5.1066

Duck, S., Foley, M. K., \& Kirkpatrick, D. C. (2006). Uncovering the complex roles behind the “difficult” coworker. In J. M. H. Fritz \& B. L. Omdahl (Eds.), Problematic relationships in the workplace (pp. 3-20). New York: Peter Lang.

Dunlop, P. D., \& Lee, K. (2004). Workplace deviance, organizational citizenship behavior, and business unit performance: The bad apples do spoil the whole barrel. Journal of Organizational Behavior, 25, 67-80. doi:10.100/job.243

Ebaugh, H. R. F. (1988). Becoming an ex: The process of role exit. Chicago: University of Chicago Press.

Eisenberger, R., Armeli, S., Rexwinkel, B., Lynch, P., \& Rhoades, L. (2001). Reciprocation of perceived organizational support. Journal of Applied Psychology, 86, 42-51. doi:10.1037/0021-9010.86.1.42

Ellis, B. H. (1992). The effects of uncertainty and source credibility on attitudes about organizational change. Management Communication Quarterly, 6, 34-57. doi:10.1177/0893318992006001002

Elmore, C. (2009). Turning points and turnover among female journalists: Communicating resistance and repression. Women's Studies in Communication, 32, 232-254. 
doi:10.1080/07491409.2009.10162388

Fang, X., \& Mowen, J. C. (2009). Examining the trait and functional motive antecedents of four gambling activities: Slot machines, skilled card games, sports betting, and promotional games. Journal of Consumer Marketing, 26, 121-131. doi:10.1108/07363760910940483

Fairbank, J. F., \& Williams, S. D. (2001). Motivating creativity and enhancing innovation through employee suggestion system technology. Creativity and Innovation Management, 10, 68-74. doi:10.1111/1467-8691.00204

Farrell, D., \& Rusbult, C. E. (1981). Exchange variables as predictors of job satisfaction, job commitment, turnover: The impact of rewards, costs, alternatives, and investments. Organizational Behavior and Human Performance, 27, 78-95. doi:10.1016/00305073(81)90016-7

Farrell, S. K., \& Finkelstein, L. M. (2011). The impact of motive attributions on coworker justice perceptions of rewarded organizational citizenship behavior. Journal of Business Psychology, 26, 57-69. doi:10.1007/s10869-010-9174-5

Fay, M. J., Kline, S. L. (2012). The influence of informal communication on organizational identification and commitment in the context of high-intensity telecommuting. Southern Communication Journal, 77, 61-76. doi:10.1080/1041794x.2011.582921

Feeley, T. H. (2000). Testing a communication network model of employee turnover based on centrality. Journal of Applied Communication Research, 28, 262-277. doi:10.1080/00909880009365574

Feeley, T. H., \& Barnett, G. A. (1997). Predicting employee turnover from communication networks. Human Communication Research, 23, 370-387. doi:10.1111/j.14682958.1997.tb00401.x 
Feeley, T. H., Hwang, J., \& Barnett, G. A. (2008). Predicting employee turnover from friendship networks. Journal of Applied Communication Research, 36, 56-73. doi:10.1080/00909880701799790

Feeley, T. H., Moon, S., Kozey, R. S., \& Slowe, A. S. (2010). An erosion model of employee turnover based on network centrality. Journal of Applied Communication Research, 38, 167-188. doi:10.1080/00909881003639544

Fletcher, T. D., Major, D. A., \& Davis, D. D. (2008). The interactive relationship of competitive climate and trait competitiveness with workplace attitudes, stress, and performance. Journal of Organizational Behavior, 29, 899-922. doi:10.1002/job.503

Fossati, A., Borroni, S., Marchione, D., \& Maffei, C. (2011). The big five inventory (BFI): Reliability and validity of its Italian translation in three independent nonclinical samples. European Journal of Psychological Assessment, 27, 50-58. doi:10.1027/1015$5759 / \mathrm{a} 000043$

Fritz, J. H. (1997). Men's and women's organizational peer relationships: A comparison. The Journal of Business Communication, 34, 27-46. doi:10.1177/002194369703400102

Fritz, J. M. H. (1997). Responses to unpleasant work relationships. Communication Research Reports, 14, 302-311. doi:10.1080/08824099709388673

Fritz, J. M. H. (2002). How do I dislike thee? Let me count the ways. Management Communication Quarterly, 15, 410-438. doi:10.1177/0893318902153004

Fritz, J. M. H. (2006). Typology of troublesome others at work: A follow-up investigation. In J. M. H. Fritz \& B. L. Omdahl (Eds.), Problematic relationships in the workplace (pp. 2146). New York: Peter Lang.

Fritz, J. M. H. (2012). Protecting and promoting workplace relationships: Professional civility. In 
B. L. Omdahl \& J. M. H Fritz (Eds.), Problematic relationships in the workplace (Vol. 2) (pp. 257-266). New York: Peter Lang.

Fritz, J. M. H., \& Omdahl, B. L. (2006). Problematic relationships in the workplace. New York: Peter Lang.

Fritz, J. M. H., \& Omdahl, B. L. (2006). Reduced job satisfaction, diminished commitment, and workplace cynicism as outcomes of negative work relationships. In J. M. H. Fritz \& B. L. Omdahl (Eds.), Problematic relationships in the workplace (pp. 131-151). New York: Peter Lang.

Futrell, C. M., \& Parasuraman, A. (1984). The relationship of satisfaction and performance to salesforce turnover. Journal of Marketing, 48, 33-40. doi:10.2307/1251508

Gailliard, B. M., Myers, K. K., \& Seibold, D. R. (2010). Organizational assimilation: A multidimensional reconceptualization and measure. Management Communication Quarterly, 24, 552-578. doi:10.1177/0893318910374933

Gallagher, E. B., \& Sias, P. M. (2009). The new employee as a source of uncertainty: Veteran employee information seeking about new hires. Western Journal of Communication, 73, 23-46. doi:10.1080/10570310802636326

Gardner, W. L., Reithel, B. J., Cogliser, C. C., Walumbwa, F. O., \& Foley, R. T. (2012). Matching personality and organizational culture: Effects of recruitment strategy and the five-factor model on subjective personal-organization fit. Management Communication Quarterly, 26, 585-622. doi:10.1177/0893318912450663

George, J. M. (1992). The role of personality in organizational life: Issues and evidence. Journal of Management, 18, 185-213. doi:10.1177/014920639201800201

Giang, V. (2013, July 25). A new report ranks America's biggest companies based on how 
quickly employees jump ship. Retrieved October 20, 2013 from

http://www.businessinsider.com/companies-ranked-by-turnover-rates-2013-7

Gillen, H. G., \& Chory, R. M. (2013). Positive and negative effects of workplace romance: A comparison of participants' and observers' perceptions. Unpublished manuscript, Department of Communication Studies, West Virginia University, Morgantown, WV.

Glaser, S. R., Zamanou, S., \& Hacker, K. (1987). Measuring and interpreting organizational culture. Management Communication Quarterly, 1, 173-198. doi:10.1177/ 0893318987001002003

Gordon, J. \& Hartman, R. L. (2009). Affinity-seeking strategies and open communication in peer workplace relationships. Atlantic Journal of Communication, 17, 115-125. doi:10.1080/15456870902873184.

Gordon, M. E. (2011). The dialectics of the exit interview: A fresh look at conversations about organizational disengagement. Management Communication Quarterly, 25, 59-86. doi: $10.1177 / 0893318910376914$

Graen, G. B., \& Uhl-Bien, M. (1995). Relationship-based approach to leadership: Development of leader-member exchange theory. Leadership Quarterly, 6, 219-247. doi:10.1016/1048-9843(95)90036-5

Granose, C. S., \& Portwood, J. D. (1987). Matching individual career plans and organizational career management. Academy of Management Journal, 30, 699-720. doi:10.2307/256156

Greenberg, L., \& Barling, J. (1999). Predicting employee aggression against coworkers, subordinates and supervisors: The roles of person behaviors and perceived workplace 
factors. Journal of Organizational Behavior, 20, 897-913. doi:10.1002/(sici)10991379(199911)20:6<897::aid-job975>3.0.co;2-z

Griffeth, R. W. \& Hom, P. W. (2001). Retaining valued employees. Sage: Thousand Oaks, CA.

Griffeth, R. W., Hom, P. W., \& Gaertner, S. (2000). A meta-analysis of antecedents and correlates of employee turnover: Update, moderator tests, and research implications for the next millennium. Journal of Management, 26, 463-488.

doi:10.1177/014920630002600305

Grojean, M. W., Resick, C. J., Dickson, M. W., \& Smith, D. B. (2004). Leaders, values, and organizational climate: Examining leadership strategies for establishing an organizational climate regarding ethics. Journal of Business Ethics, 55, 223-241. doi:10.1007/s10551004-1275-5

Gunter, B., \& Furnham, A. (1996). Biographical and climate predictors of job satisfaction and pride in organizations. The Journal of Psychology, 13, 193-208. doi: 10.1080/00223980.1996.9915001

Hamel, S. A. (2009). Exit, voice, and sensemaking following psychological contract violations. Journal of Business Communication, 46, 234-261. doi: $10.1177 / 0021943608328079$

Harris, K. J., \& Kacmar, K. M. (2006). Too much of a good thing: The curvilinear effect of leader-member exchange on stress. The Journal of Social Psychology, 146, 65-84. doi:10.3200/SOCP.146.1.65-84

Hart, Z. P. (2012). Message content and sources during organizational socialization. Journal of Business Communication, 49, 191-209. doi:10.1177/0021943612446731

Hart, Z. P., Miller, V. D., \& Johnson, J. R. (2003). Socialization, resocialization, and 
communication relationships in the context of an organizational change. Communication Studies, 54, 483-495. doi:10.1080/10510970309363305

Harvey, M. G., Heames, J. T., Richey, R. G., \& Leonard, N. (2006). Bullying: From the playground to the boardroom. Journal of Leadership and Organizational Studies, 12, 111. doi:10.1177/107179190601200401

Henningsen, M. L. M., Valde, K. S., \& Denbow, J. (2013). Academic misconduct: A GoalsPlans-Action approach to peer confrontation and whistle-blowing. Communication Education, 62, 148-168. doi:10.1080/03634523.2012.752509

Hess, J. A. (2000). Maintaining nonvoluntary relationships with disliked partners: An investigation into the use of distancing behaviors. Human Communication Research, 26, 458-488. doi:10.1111/j.1468-2958.2000.tb00765.x

Hess, J. (2006). Distancing from problematic coworkers. In J. M. H. Fritz \& B. L. Omdahl (Eds.) Problematic relationships in the workplace (pp. 205-232). New York: Peter Lang.

Hess, J., Omdahl, B. L., \& Fritz, J. M. H. (2006). Turning points in relationships with disliked co-workers. In J. M. H. Fritz \& B. L. Omdahl (Eds.) Problematic relationships in the workplace (pp. 89-106). New York: Peter Lang.

Holmes, D. S. (1978). Projection as a defense mechanism. Psychological Bulletin, 85, 677-688. doi:10.1037/0033-2909.85.4.677

Holmstrom, A. J., Russell, J. C., \& Clare, D. D. (2013). Esteem support messages received during the job search: A test of the CETESM. Communication Monographs, 80, 220-242. doi:10.1080/03637751.2013.775699

Horan, S. M., \& Chory, R. M. (2009). When work and love mix: Perceptions of peers in workplace romances. Western Journal of Communication, 73, 349-369. 
doi:10.1080/10570310903279042

Horan, S. M., \& Chory, R. M. (2011). Understanding work/life blending: Credibility implications for those who date at work. Communication Studies, 62, 563-580. doi:10.1080/10510974.2011.582663

Horan, S. M., \& Chory, R. M. (2013). Relational implications of gay and lesbian workplace romances: Understanding trust, deception, and credibility. Journal of Business Communication, 50, 170-189. doi:10.1177/0021943612474993

Hu, L., \& Bentler, P. M. (1999). Cutoff criteria for fit indexes in covariance structure analysis: Conventional criteria values versus new alternatives. Structural Equation Modeling, 6, 155. doi:10.1080/10705519909540118

Hui, C., \& Law, K. S. (1999). A structural equation model of the effects of negative affectivity, leader-member exchange, and perceived job mobility on in-role and extra-role performance: A Chinese case. Organizational Behavior and Human Decision Processes, 77, 3-21. doi:10.1006/obhd.1998.2812

Iaffaldano, M. T., \& Muchinsky, P. M. (1985). Job satisfaction and job performance: A metaanalysis. Psychological Bulletin, 97, 251-273. doi:10.1037//0033-2909.97.2.251

Infante, D. A., \& Gorden, W. I. (1987). Superior and subordinate communication profiles: Implications for independent-mindedness and upward effectiveness. Central States Speech Journal, 38, 73-80. doi:10.1080/10510978709368232

Infante, D. A., \& Gorden, W. I. (1991). How employees' see the boss: Test of an argumentative and affirming model of supervisors' communicative behavior. Western Journal of Communication, 55, 294-304. doi:10.1080/10570319109374386

Ibarra, H., \& Andrews, S. B. (1993). Power, social influence, and sense making: Effects of 
network centrality and proximity on employee perceptions. Administrative Science Quarterly, 38, 277-303. doi:10.2307/2393414

Ipeirotis, P. (2010). Demographics of mechanical turk. Retrieved from https://archive.nyu.edu/handle/2451/29585

Jablin, F. M. (1978). Message-response and "openness" in superior- subordinate communication. In B. D. Ruben (Ed.), Communication Yearbook 2 (pp. 400-415). Transaction Books: New Brunswick, NJ.

Jablin, F. M. (1979). Superior-subordinate communication: The state of the art. Psychological Bulletin, 6, 1201-1222. doi:10.1037/0033-2909.86.6.1201

Jablin, F. M. (1980). Organizational communication theory and research: An overview of communication climate and network research. In D. Nimmo (Ed.), Communication Yearbook 4 (pp. 327-347). New Brunswick, NJ: Transaction Books.

Jablin, F. M. (1982). Organizational communication: An assimilation approach. In M. E. Roloff \& C. R. Berger (Eds.), Social cognition and communication (pp. 255-286). Beverly Hills, CA: Sage.

Jablin, F. M. (1984). Assimilating new members into organizations. In R. N. Bostrom (Ed.), Communication yearbook 8 (pp. 594-626). Beverly Hills, CA: Sage.

Jablin, F. M. (1985). An exploratory study of vocational organizational communication socialization. The Southern Speech Communication Journal, 50, 261-282. doi: $10.1080 / 10417948509372635$

Jablin, F. M. (1987). Organizational entry, assimilation, and exit. In F. M. Jablin, L. L. Putnam, K. H. Roberts, \& L. W. Porter (Eds.), Handbook of organizational communication: An interdisciplinary perspective (pp. 679-740). Newbury Park, CA: Sage. 
Jablin, F. M. (2001). Organizational entry, assimilation, and disengagement/exit. In F.M. Jablin, \& L.L. Putnam (Eds.), The new handbook of organizational communication: Advances in theory, research, and methods (pp. 732-818). Thousand Oaks, CA: SAGE.

Jablin, F. M., \& Krone, K. J. (1987). Organizational assimilation. In C.R. Berger \& S.H. Chaffee (Eds.), Handbook of communication science (pp.711-746). Newbury Park, CA: Sage.

Jelinek, R., \& Ahearne, M. (2010). Be careful what you look for: The effect of trait competitiveness and long hours on salesperson deviance and whether meaningfulness of work matters. Journal of Marketing Theory and Practice, 18, 303-321. doi:10.2753/MP1069-6679180401

John, O. P., Donahue, E. M., \& Kentle, R. L. (1991). The big five inventory--versions 4a and 54. Berkeley, CA: University of California, Berkeley, Institute of Personality and Social Research. Accessed via http://www.ocf.berkeley.edu/ johnlab/bfi.htm

John, O. P., Naumann, L. P., \& Soto, C. J. (2008). Paradigm shift to the integrative big-five trait taxonomy: History, measurement, and conceptual Issues. In O. P. John, R. W. Robins, \& L. A. Pervin (Eds.), Handbook of personality: Theory and research (pp. 114-158). New York: Guilford Press.

John, O. P., \& Srivastava, S. (1999). The big five trait taxonomy: History, measurement, and theoretical perspectives. In L. A. Pervin \& O. P. John (Eds.), Handbook of personality: Theory and research (2 ${ }^{\text {nd }}$ ed.). (pp. 102-138). New York: Guilford Press.

Johnson, J. R., Bernhagen, M. J., Miller, V., \& Allen, M. (1996). The role of communication in managing reductions in work force. Journal of Applied Communication, 24, 139-164. doi:10.1080/00909889609365448 
Johnson, P. R., \& Indvik, J. (2000). Rebels, criticizers, backstabbers, and busybodies: Anger and aggression at work. Public Personnel Management, 29, 165-174.

Jones, G. R. (1986). Socialization tactics, self-efficacy, and newcomers' adjustments to organizations. Academy of Management Journal, 29, 262-279. doi:10.2307/256188

Judge, T. A., \& Bono, J. E. (2001). Relationships of core self-evaluations traits--self-esteem, generalized self-efficacy, locus of control, and emotional stability—with job satisfaction and job performance: A meta-analysis. Journal of Applied Psychology, 86, 80-92. doi:10.1037/0021-9010.86.1.80

Judge, T. A., \& Cable, D. M. (1997). Applicant personality, organizational culture, and organizational attraction. Personnel Psychology, 50, 359-394. doi:10.1111/j.17446570.1997.tb00912.x

Kahn, R. L., Wolfe, D. M., Quinn, R. P., \& Snoek, J. D. (1964). Organizational stress: Studies in role conflict and ambiguity. New York: Wiley.

Kamdar, D., \& Van Dyne, L. (2007). The joint effects of personality and workplace social exchange relationships in predicting task performance and citizenship performance. Journal of Applied Psychology, 92, 1286-1298. doi:10.1037/0021-9010.92.5.1286

Karatepe, O. M., Uludag, O., Menevis, I., Hadzimehmedagic, L., \& Baddar, L. (2006). The effects of selected individual characteristics on frontline employee performance and job satisfaction. Tourism Management, 27, 547-560. doi:10.1016/j.tourman.2005.02.009

Kassing, J. W. (1998). Development and validation of the organizational dissent scale.

Management Communication Quarterly, 12, 183-229. doi:10.1177/0893318998122002

Kassing, J. W., \& Avtgis, T. A. (1999). Examining the relationship between organizational dissent and aggressive communication. Management Communication Quarterly, 13, 100- 
115. doi:10.1177/0893318999131004

Kassing, J. W., \& McDowell, Z. J. (2008). Disagreeing about what's fair: Exploring the relationship between perceptions of justice and employee dissent. Communication Research Reports, 25, 34-43. doi:10.1080/08824090701831784

Kassing, J. W., Piemonte, N. M., Coman, C. C., \& Mitchell, C. A. (2012). Dissent expression as an indicator of work engagement and intention to leave. Journal of Business Communication, 49, 237-253. doi:10.1177/0021943612446751

Kassing, J., \& Waldron, V. R. (2014). Incivility, destructive workplace behavior, and bullying. In L. L. Putnam \& D. K. Mumby (Eds.), The SAGE handbook of organizational communication: Advances in theory, research, and methods ( $3^{\text {rd }}$ ed.). (pp. 643-664). Thousand Oaks, CA: Sage.

Keyton, J. (2011). Communication and organizational culture: A key to understanding work experiences. Thousand Oaks, CA: Sage.

Keyton, J. (2014). Organizational culture. In L. L. Putnam \& D. K. Mumby (Eds.), The SAGE handbook of organizational communication: Advances in theory, research, and methods ( $3^{\text {rd }}$ ed). (pp. 549-568). Thousand Oaks, CA: Sage.

Kinney, T. A. (2012). Workplace bullying as interpersonal violence?: A reconceptualization in progress. In B. L. Omdahl \& J. M. H Fritz (Eds.), Problematic relationships in the workplace (Vol. 2) (pp. 68-84). New York: Peter Lang.

Kram, K. F., \& Isabella, L. A. (1985). Mentoring alternatives: The role of peer relationships in career development. Academy of Management Journal, 28, 110-132. doi: $10.2307 / 256064$

Kramer, M. W. (1989). Communication during intraorganizational job transfers. Management 
Communication Quarterly, 3, 213-248. doi:10.1177/0893318989003002004

Kramer, M. W. (1993). Communication after job transfers: Social exchange processes in learning new roles. Human Communication Research, 20, 147-174. doi:10.1111/j.14682958.1993.tb00319.x

Kramer, M. W. (1994). Uncertainty reduction during job transitions: An exploratory study of the communication experiences of newcomers and transferees. Management Communication Quarterly, 7, 384-412. doi:10.1177/0893318994007004002

Kramer, M. W. (1996). A longitudinal study of peer communication during job transfers: The impact of frequency, quality, and network multiplexity on adjustment. Human Communication Research, 23, 59-86. doi:10.1111/j.1468-2958.1996.tb00387.x

Kramer, M. W. (2004). Managing uncertainty in organizational communication. Mahwah, NJ: Lawrence Erlbaum.

Kramer, M.W. (2009). Managing uncertainty in work interactions. In T.D. Afifi \& W. Afifi (Eds.), Uncertainty, information management, and disclosure decisions: Theories and applications. (pp. 164-181). London: Routledge.

Kramer, M. W. (2010). Organizational socialization: Joining and leaving organizations. Malden, MA: Polity Press.

Kramer, M. W. (2011). A study of voluntary organizational membership: The assimilation process in a community choir. Western Journal of Communication, 75, 52-74. doi:10.1080/10570314.2010.536962

Kramer, M. W., Callister, R. R., \& Turban, D. B. (1995). Information-receiving and informationgiving during job transitions. Western Journal of Communication, 59, 151-170. doi:10.1080/10570319509374513 
Kramer, M. W., Meisenbach, R. J., \& Hansen, G. J. (2013). Communication, uncertainty, and volunteer membership. Journal of Applied Communication Research, 41, 18-39. doi:10.1080/00909882.2012.750002

Kramer, M. W., \& Miller, V. D. (2014). Socialization and assimilation: Theories, Processes, and outcomes. In L. L. Putnam \& D. K. Mumby (Eds.), The SAGE handbook of Organizational communication: Advances in theory, research, and methods ( $\left.3^{\text {rd }} \mathrm{ed}.\right)$. (pp. 525-547). Thousand Oaks, CA: Sage.

Kramer, M. W. \& Noland, T. L. (1999). Communication during job promotions: A case of ongoing assimilation. Journal of Applied Communication Research, 27, 335-355. doi: $10.1080 / 00909889909365544$

Larson, G. S., \& Tompkins, P. K. (2005). Ambivalence and resistance: A study of management in a concertive control system. Communication Monographs, 72, 1-21. doi:10.1080/036377502000342508

LeBel, E. P. (2010). Attitude accessibility as a moderator of implicit and explicit self-esteem correspondence. Self and Identity, 9, 195-208. doi:10.1080/15298860902979166

Lee, T. W., Mitchell, T. R., Wise, L., \& Fireman, S. (1996). An unfolding model of voluntary employee turnover. Academy of Management Journal, 39, 5-36. doi:10.2307/256629

Levine, T. R. (2005). Confirmatory factor analysis and scale validation in communication research. Communication Research Reports, 22, 335-338. doi:10.1080/00036810500317730

Locke, E. A. (2004). Linking goals to monetary incentives. Academy of Management, 18, 130133. doi:10.5465/ame.2004.15268732

Louis, M. R., Posner, B. Z., \& Powell, G. N. (1983). The availability and helpfulness of 
socialization practices. Personnel Psychology, 36, 857-866. doi:10.1111/j.17446570.1983.tb00515.x

Luhtanen, R., \& Crocker, J. (1992). A collective self-esteem scale: Self-evaluation of one's social identity. Personality and Social Psychology Bulletin, 18, 302-318. doi:10.1177 /0146167292183006

Lutgen-Sandvik, P. (2003). The communicative cycle of employee emotional abuse. Management Communication Quarterly, 16, 471-501. doi:10.1177/0893318903251627

Lutgen-Sandvik, P., Namie, G., \& Namie, R. (2009). Workplace bullying: Causes, consequences, and corrections. In P. Lutgen-Sandvik \& B. D. Sypher (Eds.), Destructive organizational communication: Processes, consequences, \& constructive ways of organizing (pp. 2752). New York: Routledge.

Lutgen-Sandvik, P., \& Sypher, B. D. (2009). Destructive organizational communication: Processes, consequences, and constructive ways of organizing. New York: Routledge.

Lutgen-Sandvik, P., Riforgiate, S., \& Fletcher, C. (2011). Work as a source of positive emotional experiences and the discourses informing positive assessment. Western Journal of Communication, 75, 2-27. doi:10.1080/10570314.2010.536936

Lutgen-Sandvik, P., Tracy, S. J., \& Alberts, J. K. (2007). Burned by bullying in the American workplace: Prevalence, perception, degree, and impact. Journal of Management Studies, 44, 837-862. doi:10.1111/j.1467-6486.2807.00715.x

Macy, B. A., \& Mirvis, P. H. (1983). Assessing rates and costs of individual work behaviors. In S. E. Seashore, E. E. Lawler, P. H. Mirvis, \& C. Cammann (Eds.), Assessing organizational change, (pp. 139-177). New York: Wiley. 
Madlock, P. E., \& Booth-Butterfield, M. (2012). The influence of relational maintenance strategies among coworkers. Journal of Business Communication, 49, 21-47. doi:10.1177/0021943611425237

Malachowski, C. C., Chory, R. M., \& Claus, C. J. (2012). Mixing pleasure with work: Employee perceptions of and responses to workplace romance. Western Journal of Communication, 76, 358-379. doi:10.1080/10570314.2012.656215

Malone, P. \& Hayes, J. (2012). Backstabbing in organizations: Employees’ perceptions of incidents, motives, and communicative responses. Communication Studies, 63, 194-219. doi:10.1080/10510974.2011.635552

Marshall, G. W., Michaels, C. E., \& Mulki, J. P. (2007). Workplace isolation: Exploring the construct and its measurement. Psychology \& Marketing, 24, 195-223. doi:10.1008/mar.20158

Martin, J., \& Schmidt, C. (2010). How to keep your top talent. Harvard Business Review, 88, 5461.

Martin, T. N. (1979). A contextual model of employee turnover intentions. Academy of Management Journal, 22, 313-324. doi:10.2307/255592

McEvoy, G. M., \& Cascio, W. F. (1985). Strategies for reducing employee turnover: A meta-analysis. Journal of Applied Psychology, 70, 342-353. doi:10.1037//00219010.70 .2 .342

McEvoy, G. M., \& Cascio, W. F. (1987). Do good or poor performers leave?: A metaanalysis of the relationship between performance and turnover. Academy of Management Journal, 30, 744-762. doi:10.2307/256158 
McCrae, R. R., \& Costa, P. T. (1999). A five-factor theory of personality. In L. A. Pervin \& O. P. John (Eds.), Handbook of personality: Theory and research ( $2^{\text {nd }}$ ed). (pp. 139-153). New York: Guilford Press.

McCroskey, J. C., \& McCain, T. A. (1974). The measurement of interpersonal attraction. Speech Monographs, 41, 261-266. doi:10.1080/03637757409375845

Meyer, J. P., Stanley, D. J., Herscovitch, L., \& Topolnytsky, L. (2002). Affective, continuance, and normative commitment to the organization: A meta-analysis of antecedents, correlates, and consequences. Journal of Vocational Behavior, 61, 20-52. doi:10.1006/jve.2001.1842

Mignerey, J. T., Rubin, R. B., \& Gorden, W. I. (1995). Organizational entry: An investigation of newcomer communication behavior and uncertainty. Communication Research, 22, 5485. doi:10.1177/009365095022001003

Miller, B. K. (2012). Dominance analysis of two measures of organizational justice. Journal of Managerial Psychology, 27, 264-281. doi:10.1108/026839412112058147

Miller, K. (2012). Organizational communication: Approaches and processes (6 ${ }^{\text {th }}$ ed.). Boston, MA: Wadsworth.

Miller, V. D. (1996). An experimental study of newcomers' information seeking behaviors during organizational entry. Communication Studies, 47, 1-24. doi:10.1080/10510979609368460

Miller, V. D., \& Jablin, F. M. (1991). Information seeking during organizational entry: Influences tactics, and a model of the process. Academy of Management Review, 16, 92-120. doi: $10.2307 / 258608$ 
Miller, V. D., Poole, M. S., Seibold, D. R., Myers, K. K., Park, H. S., Monge, P., Fulk, J., et al. (2011). Advancing research in organizational communication through quantitative analysis. Management Communication Quarterly, 25, 4-58. doi:10.1177/0893318910390193

Mishra, K., Boynton, L., \& Mishra, A. (2014). Driving employee engagement: The expanded role of internal communications. International Journal of Business Communication, 51, 183-202. doi:10.1177/232948841525399.

Mitchell, T. R., Holtom, B. C., Lee, T. W., Sablynski, C. J., \& Erez, M. (2001). Why people stay: Using job embeddedness to predict voluntary turnover. Academy of Management Journal, 44, 1102-1121. doi:10.2307/3069391

Mobley, W. H. (1982). Employee turnover: Causes, consequences, and control. AddisonWesley: Reading, MA.

Monge, P. R., \& Eisenberg, E. M. (1987). Emergent communication networks. In F. M. Jablin, L. L. Putnam, K. H. Roberts, \& L. W. Porter (Eds.), Handbook of organizational communication: An interdisciplinary perspective (pp. 304-342). Newbury Park, CA: Sage.

Morman, R. H. (1991). Relationship between organizational justice and organizational citizenship behaviors: Do fairness perceptions influence employee citizenship? Journal of Applied Psychology, 76, 845-855. doi:10.1037/0021-9010.76.6.845

Morrison, E. W. (1993). Newcomer information seeking: Exploring types, modes, sources, and outcomes. Academy of Management Journal, 36, 557-589. doi:10.2307/256592

Morrison, E. W. (1995). Information usefulness and acquisition during organizational encounter. Management Communication Quarterly, 9, 131-155. doi:10.1177/089331895009002001 
Morrison, E. W. (2002). Information seeking within organizations. Human Communication Research, 28, 229-242. doi:10.1111/j.1468-2958.2002.tb00805.x

Morrison, R. L. (2008). Negative relationships in the workplace: Associations with organizational commitment, cohesion, job satisfaction and intention to turnover. Journal of Management \& Organization, 14, 330-344. doi:10.5172/jmo.837.14.4.330

Mowen, J. C. (2004). Exploring the trait of competitiveness and its consumer behavior consequences. Journal of Consumer Psychology, 14, 52-63. doi: 10.1207/s15327663jcp1401\&2_7

Mudrack, P. E. (1989). Job involvement and Machiavellianism: Obsession-compulsion or detachment? Journal of Psychology, 123, 491-496. doi:10.1080/ 00223980.1989.10543003

Mueller, B. H., \& Lee, J. (2002). Leader-member exchange and organizational communication satisfaction in multiple contexts. The Journal of Business Communication, 39, 220-244. doi: $10.1177 / 00219436020390020$

Myers, K. K. (2005). A burning desire: Assimilation into a fire department. Management Communication Quarterly, 18, 344-384. doi:10.1177/0893318904270742

Myers, K. K. (2014). Mixed methods: When more is really more. In L. L. Putnam \& D. K. Mumby (Eds.), The SAGE handbook of organizational communication: Advances in theory, research, and methods ( $3^{\text {rd }}$ ed). (pp. 297-320). Thousand Oaks, CA: Sage.

Myers, K. K., Seibold, D. R., \& Park, H. S. (2011). Interpersonal communication in the workplace. In M. L. Knapp \& J. A. Daly (Eds.), The SAGE handbook of interpersonal communication ( $4^{\text {th }}$ ed.). (pp. 527-562). Los Angeles: Sage. 
Myers, S. A., \& Johnson, A. D. (2003). Verbal aggressiveness and liking in interpersonal relationships. Communication Research Reports, 20, 90-96. doi: $10.1080 / 08824090309388803$

Myers, S. A., \& Johnson, A. D. (2004). Perceived solidarity, self-disclosure, and trust in organizational peer relationships. Communication Research Reports, 21, 75-83. doi:10.1080/08824090409359969

Myers, S. A., Knox, R. L., Pawlowski, D. R., Ropog, B. L. (1999). Perceived communication openness and functional communication skills among organizational peers. Communication Reports, 12, 71-83. doi:10.1080/08934219909367712

Neulip, J. W., Hintz, S. M., \& McCroskey, J. C. (2005). The influence of ethnocentrism in organizational contexts: Perceptions of interviewee and managerial attractiveness, credibility, and effectiveness. Communication Quarterly, 53, 41-56. doi:10.1080/01463370500055954

Odden, C. M., \& Sias, P. M. (1997). Peer communication relationships and psychological climate. Communication Quarterly, 45, 153-166. doi:10.1080/01463379709370058

Ode, S., Robinson, M. D., \& Wilkowski, B. M. (2008). Can one's temper be cooled? A role for agreeableness in moderating neuroticism's influence on anger and aggression. Journal of Research in Personality, 42, 295-311. doi:10.1016/j.jrp.2007.05.007

Omdahl, B. L. \& Fritz, J. M. H. (2006). Stress, burnout, and impaired mental health: Consequences of problematic work relationships. In J. M. H. Fritz \& B. L. Omdahl (Eds.), Problematic relationships in the workplace (pp. 109-130). New York: Peter Lang O’Reilly, C. A., Chatman, J., \& Caldwell, D. F. (1991). People and organizational culture: A 
profile comparison approach to assessing person-organization fit. Academy of Management Journal, 34, 487-516. doi:10.2307/256404

Organ, D. W. (1988). Organizational citizenship behavior: The good soldier syndrome. Lexington, MA: Lexington Books.

Organ, D. W. (1994). Personality and organizational citizenship behavior. Journal of Management, 20, 465-478. doi:10.1177/014920639402000208

Papa, M. J., Auwal, M. A., Singhal, A. (1997). Organizing for social change within concertive control systems: Member identification, empowerment, and the masking of discipline. Communication Monographs, 64, 219-249. doi:10.1080/03637759709376418

Patterson, M. G., West, M. A., Wallace, A. M. (2005). Validating the organizational climate measure: Links to managerial practices, productivity, and innovation. Journal of Organizational Behavior, 26, 379-408. doi:10.1002/job.312

Phillips, J. M. (1998). Effects of realistic job previews on multiple organizational outcomes: A meta-analysis. Academy of Management Journal, 41, 673-690. doi:10.2307/256964

Pierce, C. A., Byrne, D., \& Acquinis, H. (1996). Attraction in organizations: A model of workplace romance. Journal of Organizational Behavior, 17, 5-33. doi: 10.1002/(sici)1099-1379(199601)17:1<5::aid-job734>3.0.co;2-e

Pierce, J. L., \& Gardner, D. G. (2004). Self-esteem within the work and organizational context: A review of the organization-based self-esteem literature. Journal of Management, 30, 591-622. doi:10.1016/j.jm.2003.10.001

Pierce, J. L., \& Gardner, D. G., Cummings, L. L., \& Dunham, R. B. (1989). Organization-based self-esteem: Construct definition, measurement, and validation. Academy of Management Journal, 32, 622-648. doi:10.2307/256437 
Ploeger, N. A., \& Bisel, R. S. (2013). The role of identification in giving sense to unethical organizational behavior. Defending the organization. Management Communication Quarterly, 27, 155-183. doi:10.1177/0893318912469770

Ployhart, R. E., Weekley, J. A., \& Baughman, K. (2006). The structure and function of human capital emergence: A multilevel examination of the attraction-selection-attrition model. Academy of Management Journal, 49, 661-677. doi:10.5465/amj.2006.22083023

Quinn, R. E. (1977). Coping with cupid: The formation, impact, and management of romantic relationships in organizations. Administrative Science Quarterly, 22, 30-45. doi:10.2307/2391744

Raabe, B., \& Beehr, T. A. (2003). Formal mentoring versus supervisor and coworker relationships: Differences in perception and impact. Journal of Organizational Behavior, 24, 271-293. doi:10.1002/job.193

Rancer, A. S., Kosberg, R. L., \& Silvestri, V. N. (1992). The relationship between self-esteem and aggressive communication predispositions. Communication Research Reports, 9, 2332. doi: $10.1080 / 08824099209359894$

Ray, E. B. (1987). Supportive relationships and occupational stress in the workplace. In T. L. Albrecht \& M. B. Adelman (Eds.), Communicating social support (pp. 172-191). Beverly Hills, CA: Sage.

Redding, W. C. \& Tompkins, P. K. (1988). Organizational communication: Past and present tenses. In G. M. Goldhaber \& G. A. Barnett (Eds.), Handbook of organizational communication (pp. 5-33). Norwood, NJ: Ablex.

Reinking, K., \& Bell, R. A. (1991). Relationships among loneliness, communication 
competence, and career success in a state bureaucracy: A field study of the 'lonely at the top' maxim. Communication Quarterly, 39, 358-373. doi:10.1080/01463379109369812

Richardson, B. K., Alexander, A., \& Castleberry, T. (2008). Examining teacher turnover in low-performing, multi-cultural schools: Relationships among emotional labor, communication symmetry, and intent to leave. Communication Research Reports, 25, 1022. doi:10.1080/08824090701831743

Rizzo, J. R., House, R. J., \& Lirtzman, S. I. (1970). Role conflict and ambiguity in complex organizations. Administrative Science Quarterly, 15, 150-163. doi:10.2307/2391486

Robbins, R. W., Hendin, H. M., \&Trzesniewski, K. H. (2001). Measuring global self-esteem: A construct validation of a single-item measure and the Rosenberg Self-esteem Scale. Personality and Social Psychology Bulletin, 27, 151-161. doi:10.1177/0146167201272002

Rosenberg, M. (1965). Society and the adolescent self-image. Princeton, NJ: Princeton University Press.

Ryckman, R. M., Hammer, M., Kaczor, L. M., \& Gold, J. A. (1990). Construction of a hypercompetitive attitude scale. Journal of Personality Assessment, 55, 630-639. doi:10.1207/s15327752jpa5503\&4_19

Salin, D. (2003). Ways of explaining workplace bullying: A review of enabling, motivating and precipitating structures and processes in the work environment. Human Relations, 56, 1213-1232. doi:10.1177/00187267035610003

Scandura, T. A. (1998). Dysfunctional mentoring relationships and outcomes. Journal of Management, 24, 449-467. doi:10.1177/014920639802400307

Scott, C. R., Connaughton, S. L., Diaz-Saenz, H. R., Maguire, K., Ramirez, R., Richardson, B., 
Shaw, S. P., \& Morgan, D. (1999). The impacts of communication and multiple identifications on intent to leave: A multiplemethodological exploration. Management Communication Quarterly, 12, 400-435. doi:10.1177/0893318999123002

Scott, S., \& Myers, K. K. (2005). The socialization of emotion: Learning emotion management at the fire station. Journal of Applied Communication Research, 33, 67-92. doi:10.1080/0090988042000318521

Schrodt, P. (2002). The relationship between organizational identification and organizational culture: Employee perceptions of culture and identification in a retail sales organization. Communication Studies, 53, 189-202. doi:10.1080/10510970209388584

Seibert, S. E., \& Kraimer, M. L. (2001). The five-factor model of personality and career success. Journal of Vocational Behavior, 58, 1-21. doi:10.1006/jvbe.2000.1757

Shumate, M., \& Contractor, N. S. (2014). Emergence of multidimensional social networks. In L. L. Putnam \& D. K. Mumby (Eds.), The SAGE handbook of organizational communication: Advances in theory, research, and methods ( $3^{\text {rd }}$ ed.). (pp. 449-474). Thousand Oaks, CA: Sage.

Sias, P. M. (1996). Constructing perceptions of differential treatment: An analysis of coworker discourse. Communications Monographs, 63, 171-187. doi:10.1080/03637759609376385

Sias, P. M. (2005). Workplace relationship quality and employee information experiences. Communication Studies, 56, 375-395. doi:10.1080/10510970500319450

Sias, P. M. (2009a) Organizing relationships: Traditional and emerging perspectives on workplace relationships. Thousand Oaks, CA: Sage.

Sias, P. M. (2009b). Social ostracism, cliques, and outcasts. In P. Lutgen-Sandvik \& B. D. 
Sypher (Eds.), Destructive organizational communication: Processes, consequences, \& constructive ways of organizing (pp. 155-163). New York: Routledge.

Sias, P. M. (2012). Exclusive or exclusory: Workplace relationships, ostracism, and isolation. In B. L. Omdahl \& J. M. H Fritz (Eds.), Problematic relationships in the workplace (Vol. 2) (pp. 105-121). New York: Peter Lang.

Sias, P. M., \& Cahill, D. J. (1998). From coworkers to friends: The development of peer friendships in the workplace. Western Journal of Communication, 62, 273-299. doi:10.1080/10570319809374611

Sias, P. M., Gallagher, E. B., Kopaneva, I., \& Pedersen, H. (2012). Maintaining workplace friendships: Perceived politeness and predictors of maintenance tactic choice. Communication Research, 39, 239-268. doi:10.1177/0093650210396869

Sias, P. M., Heath, R. G., Perry, T., Silva, D., \& Fix, B. (2004). Narratives of workplace friendship deterioration. Journal of Social and Personal Relationships, 21, 321-340. doi:10.1177/0265407504042835

Sias, P. M., \& Jablin, F. M. (1995). Differential superior-subordinate relations, perceptions of fairness, and coworker communication. Human Communication Research, 22, 5-38. doi:10.1111/j.1468-2958.1995.ttb00360.x

Sias, P. M., Kramer, M. W., \& Jenkins, E. (1997). A comparison of the communication behaviors of temporary employees and new hires. Communication Research, 24, 731754. doi:10.1177/0093650297024006006

Sias, P. M., Krone, K. J., \& Jablin, F. M. (2002). An ecological systems perspective on workplace relationships. In In M. L. Knapp \& J. A. Daly (Eds.), Handbook of interpersonal communication ( ${ }^{\text {rd }}$ ed.) (pp. 615-642). Thousand Oaks, CA: Sage. 
Sias, P. M., Pedersen, H., Gallagher, E. B., \& Kopaneva, I. (2012). Workplace friendship in the electronically connected organization. Human Communication Research, 38, 253-279. doi:10.1111/j.1468-2958.2012.01428.x

Sias, P. M., \& Perry, T. (2004). Disengaging from workplace relationships: A research note. Human Communication Research, 30, 589-602. doi:10.1093/hcr/30.4.589

Sias, P. M., Smith, G., \& Avdeyeva, T. (2003). Sex and sex-composition differences and similarities in peer workplace friendship development. Communication Studies, 54, 322340. doi:10.1080/10510970309363289

Sikorska-Simmons, E. S. (2005). Predictors of organizational commitment among staff in assisted living. The Gerontologist, 45, 196-205. doi:10.1093/geront/45.2.196

Skarlicki, D. P., \& Folger, R. (1997). Retaliation in the workplace: The roles of distributive, procedural, and interactional justice. Journal of Applied Psychology, 82, 434-443. doi: $10.1037 / 0021-9010.82 .3 .434$

Sluss, D. M., \& Ashforth, B. E. (2007). Relational identity and identification: Defining ourselves through work relationships. Academy of Management Review, 32, 9-32. doi: 10.5465/amr.2007.23463672

Smith, F. L. M., \& Dougherty, D. S. (2012). Revealing a master narrative: Discourses of retirement throughout the working life cycle. Management Communication Quarterly, 26, 453-478. doi:10.1177/0893318912438687

Somech, A. \& Drach-Zahavy, A. (2000). Understanding extra-role behavior in schools: the relationship between job satisfaction, sense of efficacy, and teachers' extra-role behavior. Teaching and Teacher Education, 16, 649-659. doi:10.1016/S0742-051X(00)00012-3

Sollitto, M., Chory, R. M., \& Weber, K. (2014, May). Peer-influenced organizational exit: An 
examination of its relationship with workplace jealousy and envy. Paper presented at the annual meeting of the International Communication Association, Seattle, WA.

Sollitto, M., Johnson, Z. D., \& Myers, S. A. (2013). Students' perceptions of college classroom connectedness, assimilation, and peer relationships. Communication Education, 62, 318331. doi:10.1080/03634523.2013.788726

Sollitto, M., \& Martin, M. M. (2013, November). The relationship between aggressive communication traits and peer-influenced exit tactics. Paper presented at the annual meeting of the National Communication Association, Washington, D.C.

Sollitto, M., Weber, K., \& Chory, R. M. (2013, June). Communication organizational exit: The development and validation of the Peer-Influenced Exit Measure. Paper presented at the annual meeting of the International Communication Association, London, England.

Soto, C. J., John, O. P., Gosling, S. D., \& Potter, J. (2011). Age differences in personality traits from 10 to 65: Big five domains and facets in a large cross-sectional sample. Journal of Personality and Social Psychology, 100, 330-348. doi:10.1037/a0021717

Stafford, L., \& Canary, D. J. (1991). Maintenance strategies and romantic relationship type, gender and relational characteristics. Journal of Social and Personal Relationships, 8, 217-242. doi:10.1177/0265407591082004

Staw, B. M. (1984). Organizational behavior: A review and reformulation of the field's outcome variables. Annual Review of Psychology, 35, 627-666

Stohl, C. A. (1995). Organizational communication: Connectedness in action. Thousand Oaks, CA: SAGE.

Strauss, A. L., \& Corbin, J. (1998). Basics of qualitative research: Techniques and procedures 
for developing grounded theory ( $2^{\text {nd }}$ ed.). Newbury Park, CA: Sage.

Susskind, A. M. (2007). Downsizing survivors' communication networks and reactions: A longitudinal examination of information flow and turnover intentions. Communication Research, 34, 156-184. doi:10.1177/0093650206298068

Susskind, A. M., Miller, V. D., \& Johnson, J. D. (1998). Downsizing and structural holes: Their impact on layoff survivors' perceptions of organizational chaos and openness to change. Communication Research, 25, 30-65. doi:10.1177/009365098025001002

Tan, C. L., \& Kramer, M. W. (2012). Communication and voluntary downward career changes. Journal of Applied Communication Research, 40, 87-106. doi:10.1080/00909882.2011.634429

Teboul, J. C. B. (1995). Determinants of new hire information-seeking during organization encounter. Western Journal of Communication, 59, 305-325. doi:10.1080/10570319509374524

Tepper, B. J. (2000). Consequences of abusive supervision. Academy of Management Journal, 43, 178-190. doi:10.2307/1556375

Tidwell, M., \& Sias, P. (2005). Personality and information seeking: Understanding how traits influence information-seeking behaviors. Journal of Business Communication, 42, 51-77. doi:10.1177/0021943604272028

Tompkins, P. K., \& Cheney, G. (1985). Communication and unobtrusive control in contemporary organizations. In R. D. McPhee \& P. K. Tompkins (Eds.), Organizational communication: Traditional themes and new directions (pp. 178-210). Beverly Hills, CA: Sage. 
Tompkins, P. K., Montoya, Y. J., \& Candrian, C. B. (2009). Watch your neighbor watching you: Applying concertive control in changing organizational environments. In D. W. Stacks \& M. B. Salwen (Eds.), An integrated approach to communication theory and research $\left(2^{\text {nd }}\right.$ ed.). New York: Routledge.

Tracy, S. J., Myers, K. K., \& Scott, C. W. (2006). Cracking jokes and crafting selves: Sensemaking and identity management among human service workers. Communication Monographs, 73, 283-308. doi:10.1080/03637750600889500

Tremblay, P. F., \& Ewart, L. A. (2004). The Buss and Perry Aggression Questionnaire and its relations to values, the big five, provoking hypothetical situations, alcohol consumption patterns, and alcohol expectancies. Personality and Individual Differences, 38, 337-346. doi:10.1016/j.paid.2004.04.012

United States Census Bureau (2014). State and county quickfacts. Retrieved from http://quickfacts.census.gov/qfd/states/00000.html

van Dick, R., van Knippenberg, D., Kerschreiter, R., Hertel, G., \& Wieseke, J. (2008). Interactive effects of work group and organizational identification on job satisfaction and extra-role behavior. Journal of Vocational Behavior, 72, 388-399. doi: 10.1016/j.jvb.2007.11.009

Vardi, Y., \& Wiener, Y. (1996). Misbehaviors in organizations: A motivational framework. Organization Science, 7, 151-165. doi:10.1287/orsc.7.2.151

Wadman, R., Durkin, K., \& Conti-Ramsden, G. (2008). Self-esteem, shyness, and sociability in adolescents with specific language impairment (SLI). Journal of Speech, Language, and Hearing Research, 51, 938-952. doi:10.1044/1092-4388(2008/069)

Walter, H. L., Anderson, C. M., \& Martin, M. M. (2005). How subordinates' Machiavellianism 
and motives relate to satisfaction with superiors. Communication Quarterly, 53, 57-70. doi:10.1080/01463370500056051

Walster, E., Berscheid, E., \& Walster, G. W. (1973). New directions in equity research. Journal of Personality and Social Psychology, 25, 151-176. doi:10.1037\%2Fh0033967

Walther, J. B., Van Der Heide, B., Kim, S., Westerman, D., \& Tong, S. T. (2008). The role of friends' appearance and behavior on evaluations of individuals on Facebook: Are we known by the company we keep? Human Communication Research, 34, 28-49. doi:10.1111/j.1468-2958.2007.00312.x

Wanberg, C. R., Glomb, T. M., Song, Z., \& Sorenson, S. (2005). Job-search persistence during unemployment: A 10-wave longitudinal study. Journal of Applied Psychology, 90, 411430. doi:10.1037/0021-9010.90.3.411

Wang, G., \& Netemeyer, R. G. (2002). The effects of job autonomy, customer demandingness, and trait competitiveness on salesperson learning, self-efficacy, and performance. Journal of the Academy of Marketing Science, 30, 217-228. doi:10.1177/00970302030003003

Westerman, C. Y. K. (2013). How people restore equity at work and play: Forgiveness, derogation, and communication. Communication Studies, 64, 296-314. doi:10.1080/10510974.2012.755641

Wiesenfeld, B. M., Raghuram, S., \& Garud, R. (2001). Organizational identification among virtual workers: The role of need for affiliation and perceived work-based social support. Journal of Management, 27, 213-229. doi:10.1016/S0149-2063(00)00096-9

Williams, E. A., \& Connaughton, S. L. (2012). Expressions of identifications: The nature of talk and identity tensions among organizational members in a struggling organization. Communication Studies, 63, 457-481. doi:10.1080/10510974.2011.630439 
Williams, K. D., \& Karau, S. J. (1991). Social loafing and social compensation: The effects of expectations of co-worker performance. Journal of Personality and Social Psychology, 61, 570-581. doi:10.1037//0022-3514.61.4.570

Witt, L. A., Burke, L. A., Barrick, M. R., \& Mount, M. K. (2002). The interactive effects of conscientiousness and agreeableness on job performance. Journal of Applied Psychology, 87, 164-169. doi:10.1037/0021-9010.87.1.164

Youssef, C. M., \& Luthans, F. (2007). Positive organizational behavior in the workplace: The impact of hope, optimism, and resilience. Journal of Management, 33, 774-800. doi:10.1177/0149206307305562

Yurtsever, G. (2003). Measuring the moral entrepreneurial personality. Social Behavior and Personality, 31, 1-12. doi:10.2224/sbp.2003.31.1.1

Zorn, T. E., \& Gregory, K. W. (2005). Learning the ropes together: Assimilation and friendship development among first-year male medical students. Health Communication, 17, 211-231. doi:10.1207/s15327027hc1703.1

Zummuto, R. F., Gifford, B., \& Goodman, E. A. (2000). Managerial ideologies, organization culture, and the outcomes of innovation: A competing values perspective. In N. M. Ashkanasy, C. P. M. Wilderon, \& M. F. Peterson (Eds.), Handbook of organizational culture and climate (pp. 261-278). Thousand Oaks, CA: Sage. 


\section{Appendix A}

\section{Cox's (1999) Strategies Used to Encourage Voluntary Exit}

\section{Message-Based Strategies}

Disparage Peer-Criticize performance and competencies of coworker.

Encourage Peer to Seek Other Employment- Advise coworker to find an occupation more comfortable or congruent with personality and skill set.

Disparage Organization- Employees berate company, other employees, and jobs as representing a bad place to work.

Commend/Praise Other Jobs- Employees speak favorably of other careers and occupations while accentuating the advantages of working elsewhere to their coworkers.

Encourage Self-Evaluation- Employees politely advise coworkers to think about their situation in the workplace.

Inform Peer of Job or Career Alternative- Employees provide messages about job openings or refer them to their coworkers.

Warn Peers of Potential Negative Consequences of Remaining- Employees phrase foreshadowing of future events as an outcome of their coworkers' behavior or talk about possible layoffs in the future.

Review Beliefs about Work and Life- Employees talk to coworkers about their personal views on life and the incongruence between work experiences and their goals.

Tell or Encourage Peers to Leave Immediately- Employees persuade their coworkers to leave without thinking about the future.

Commend the Advantages of Voluntarily Exiting- Employees encourage their coworkers to leave without risking being fired and to maintain good employment record.

Commend Their Peer's Positive Qualities- Employees mention that their coworkers have skills that can be a great use to other organizations.

Issue Exit Ultimatum- Employees persuade their coworkers to change behavior or risk being fired or choose between resigning and being fired. 


\section{Behavior-Based Strategies}

Communication Avoidance with Peer- Employees stop or decrease interaction or exclude coworkers from social activities.

Communication Engagement or Increase with Workgroup Members or SupervisorsEmployees impact other employees' opinions of targeted coworker by spreading gossip or complaining about them.

Increase Communication with Peers- Employees escalate frequency of interaction with coworkers in an effort to lend support toward their exit.

Decrease the Amount of Help or Support Offered to Peers- Employees refuse to assist coworkers.

Act Unfriendly, Hostile, or Rude- Employees berate coworkers or engage in antagonistic communication.

Sabotage or Harm Peers- Employees direct attention toward getting employee fired by engaging in malicious acts to defame employee or restrict flow of information.

Provide Peers with Job Transition Advice- Employees perform helpful acts to prepare coworkers to transition into another organization or occupation. 


\section{Appendix B}

Sollitto, Weber, and Chory's (2013) Peer-Influence Exit Tactics

\section{Antisocial Tactics}

I prevent(ed) my peer's ideas from being heard.

I cease(ed) or decrease(d) helping or supporting my peer.

I attempt(ed) to exclude my peer from social activities.

I intentionally withhold (withheld) important information from my peer.

I impede(d) access to needed resources of my peer.

I avoid(ed) or decrease(d) communication with my peer.

I act(ed) hostile or unfriendly to my peer.

\section{Prosocial Tactics}

I encourage(d) my peer to consider, seek, or find a new job.

I commend(ed) or praise(d) other jobs, organizations, or career alternatives.

I inform(ed) my peer of job or career alternatives.

I directly tell(told) my peer he/she should exit the organization.

I commend(ed) the advantages of choosing to leave the organization.

I commend(ed) the positive qualities that my peer may offer another organization.

I provide(d) my peer assistance for transitioning into another job. 


\section{Appendix C}

\section{Open-Ended Items}

1. Describe [Peer name].

2. Explain why you want(ed) [Peer name] to leave the organization.

3. Once you realized you wanted [Peer name] to leave the organization, describe how you (have) behaved toward and/or communicated with [Peer name].

4. Do/Did you do or say anything to [Peer name] to try to get [Peer name] to leave the organization? Describe what you do/did to encourage [Peer name] to leave the organization.

5. Why do/did you do or say those things to encourage [Peer name] to leave the organization?

6. If [Peer name] left your organization voluntarily, why? Please list reasons.

7. Explain the effect your behavior and/or communication (has) had on [Peer name]'s decision to leave the organization.

8. Describe the thought process behind encouraging [Peer name] to leave. 


\section{Appendix D}

\section{Job Satisfaction Scale}

1. Generally speaking, I am very satisfied with this job.

2. I frequently think of quitting this job.*

3. I am generally satisfied with the kind of work I do in this job.

Note: Items marked with an asterisk (*) are reverse coded. 


\section{Appendix E}

Study 1 Questionnaire

Think of your past work experiences, jobs, organizations you've worked for. From among all those experiences, think of a peer coworker (someone at your same job level, not a superior or subordinate) you want(ed) to leave the organization, quit, transfer, etc. In other words, think of a peer you work(ed) with whom you wish(ed) would leave your organization. Please write the first name of this peer coworker here - Please answer the following questions.

1. Describe [Peer name].

2. Explain why you want(ed) [Peer name] to leave the organization.

3. Once you realized you wanted [Peer name] to leave the organization, describe how you (have) behaved toward and/or communicated with [Peer name].

4. Do/Did you do or say anything to [Peer name] to try to get [Peer name] to leave the organization? Describe what you do/did to encourage [Peer name] to leave the organization.

5. Why do/did you do or say those things to encourage [Peer name] to leave the organization?

6. Does [Peer name] still work at your organization? Please indicate yes or no.

Yes No

If no, did [Peer name] leave voluntarily (e.g., quit, found another job, retired, resigned) or involuntarily (e.g., she/he got fired, his/her job was eliminated, she/he got downsized)? Please indicate voluntarily or involuntarily.

Voluntarily Involuntarily

If voluntarily, why? Please list reasons.

Explain the effect your behavior and/or communication has/had on [Peer name]'s decision to leave the organization.

7. How long ago did these behaviors occur? 
Please answer the following questions about yourself.

1. Your sex: Male Female

2. Your age:

3. Your Ethnic Background: Caucasian/White Native American

African American/Black

Hispanic/Latino Asian American/Asian

Other:

\section{Your current occupation:}

5. Your job title:

\section{Your job field (Circle ONE):}

- Managerial \& Professional (e.g., doctors, lawyers, educators, business executives, scientists, etc.)

- Technical, Sales, \& Administrative Support (e.g., health technicians, salespeople, secretaries, etc.)

- Service Occupations (e.g., child care, police, food service, cleaning, building, hairdressers, etc.)

- Precision Production, Craft, \& Repair (e.g., mechanics, construction, etc.)

- Operators, Fabricators, \& Laborers (e.g., machine operators, truck drivers, farming, assemblers, etc.)

7. On average, how many hours per week do you work at your current organization?

\section{How long have you worked at this organization?}

9. At what type of organization do you work (e.g. hospital, school, etc.)?

10. Instructions: Respond to the following items regarding your feelings about your current organization using the response format below.

\begin{tabular}{ccccc} 
Strongly Disagree & Disagree & $\begin{array}{c}\text { Neither Disagree } \\
\text { nor Agree }\end{array}$ & Agree & $\begin{array}{c}\text { Strongly } \\
\text { Agree }\end{array}$ \\
\hline 1 & 2 & 3 & 4 & 5 \\
\hline
\end{tabular}

Generally speaking, I am very satisfied with this job. I frequently think of quitting this job. I am generally satisfied with the kind of work I do in this job.

11. Approximately how much do you earn per year at this job? (Choose one)

$\begin{array}{lllll}\text { Under } \$ 20,000 & \$ 20,000-30,000 & \$ 30,001-40,000 & \$ 40,001-50,000 & \$ 50,001-60,000 \\ \$ 60,001-70,000 & \$ 70,001-80,000 & \$ 80,001-90,000 & \$ 90,001-100,000 & \text { Over } \$ 100,000\end{array}$




\section{Appendix F}

\section{Study 2 Scenarios}

\section{Scenario 1}

High Performer-High Teamwork-Male

Imagine you have a coworker named Tom who is at the same job level you are - he is not your superior or subordinate. Tom always fulfills his responsibilities, performs essential tasks, pays attention to his job obligations, and is generally a good worker. The people you and Tom work with are concerned about each other, resolve disagreements cooperatively, are honest and considerate, and function as a team. Please respond to the following items regarding your feelings and behavior toward Tom.

\section{Low Performer-Low Teamwork-Male}

\section{Scenario 2}

Imagine you have a coworker named Tom who is at the same job level you are - he is not your superior or subordinate. Tom rarely fulfills his responsibilities, fails to perform essential tasks, neglects his job obligations, and is generally a poor worker. The people you and Tom work with are unconcerned about each other, do not cooperate to resolve disagreements, are dishonest and inconsiderate, and do not function as a team. Please respond to the following items regarding your feelings and behavior toward Tom.

\section{High Performer-Low Teamwork-Male}

\section{Scenario 3}

Imagine you have a coworker named Tom who is at the same job level you are - he is not your superior or subordinate. Tom always fulfills his responsibilities, performs essential tasks, pays attention to his job obligations, and is generally a good worker. The people you and Tom work with are unconcerned about each other, do not cooperate to resolve disagreements, are dishonest and inconsiderate, and do not function as a team. Please respond to the following items regarding your feelings and behavior toward Tom.

\section{Low Performer-High Teamwork-Male}

\section{Scenario 4}

Imagine you have a coworker named Tom who is at the same job level you are - he is not your superior or subordinate. Tom rarely fulfills his responsibilities, fails to perform essential tasks, neglects his job obligations, and is generally a poor worker. The people you and Tom work with are concerned about each other, resolve disagreements cooperatively, are honest and considerate, and function as a team. Please respond to the following items regarding your feelings and behavior toward Tom. 
Scenario 5

High Performer-High Teamwork-Female

Imagine you have a coworker named Mary who is at the same job level you are - she is not your superior or subordinate. Mary always fulfills her responsibilities, performs essential tasks, pays attention to her job obligations, and is generally a good worker. The people you and Mary work with are concerned about each other, resolve disagreements cooperatively, are honest and considerate, and function as a team. Please respond to the following items regarding your feelings and behavior toward Mary.

\section{Scenario 6}

\section{Low Performer-Low Teamwork-Female}

Imagine you have a coworker named Mary who is at the same job level you are - she is not your superior or subordinate. Mary rarely fulfills her responsibilities, fails to perform essential tasks, neglects her job obligations, and is generally a poor worker. The people you and Mary work with are unconcerned about each other, do not cooperate to resolve disagreements, are dishonest and inconsiderate, and do not function as a team. Please respond to the following items regarding your feelings and behavior toward Mary.

\section{Scenario 7}

High Performer-Low Teamwork-Female

Imagine you have a coworker named Mary who is at the same job level you are - she is not your superior or subordinate. Mary always fulfills her responsibilities, performs essential tasks, pays attention to her job obligations, and is generally a good worker. The people you and Mary work with are unconcerned about each other, do not cooperate to resolve disagreements, are dishonest and inconsiderate, and do not function as a team. Please respond to the following items regarding your feelings and behavior toward Mary.

\section{Scenario 8}

\section{Low Performer-High Teamwork-Female}

Imagine you have a coworker named Mary who is at the same job level you are - she is not your superior or subordinate. Mary rarely fulfills her responsibilities, fails to perform essential tasks, neglects her job obligations, and is generally a poor worker. The people you and Mary work with are concerned about each other, resolve disagreements cooperatively, are honest and considerate, and function as a team. Please respond to the following items regarding your feelings and behavior toward Mary. 


\section{Appendix G}

Desire to See a Peer Exit Scale Items

\section{If [Peer name] were my colleague, I would...}

1. want [Peer name] to quit.

2. be happy if [Peer name] quit his/her job.

3. desire for [Peer name] to find a job at another organization.

4. wish [Peer name] would leave.

5. hope [Peer name] would leave the organization. 


\section{Appendix $\mathbf{H}$}

Competitiveness Scale Items

\section{I am someone who...}

1. enjoys competition more than others.

2. feels that it is important to outperform others.

3. enjoys testing my abilities against others.

4. feels that winning is extremely important. 


\section{Appendix I}

\section{Agreeableness Scale Items}

\section{I am someone who...}

1. tends to find fault with others*

2. is helpful and unselfish with others

3. starts quarrels with others*

4. has a forgiving nature

5. is generally trusting

6. can be cold and aloof*

7. is considerate and kind to almost anyone

8. is sometimes rude to others*

9. likes to cooperate with others

Note: Items marked with an asterisk $(*)$ are reverse coded. 


\section{Appendix J}

\section{Rosenberg Self-Esteem Scale Items}

\section{I am someone who...}

1. wishes I could have more respect for myself.*

2. feels that I have a number of good qualities.

3. feels I do not have much to be proud of.*

4. at times thinks I am no good at all.*

5. all in all, is inclined to feel that I am a failure.*

6. takes a positive attitude toward myself.

7. feels that I'm a person of worth, at least on an equal plane with others.

8. on the whole, is satisfied with myself.

9. certainly feels useless at times.*

10. is able to do things as well as most other people.

Note: Items marked with an asterisk (*) are reverse coded. 


\section{Appendix K}

Study 2 Questionnaire

Imagine you have a coworker named Tom who is at the same job level you are - he is not your superior or subordinate. Tom always fulfills his responsibilities, performs essential tasks, pays attention to his job obligations, and is generally a good worker. The people you and Tom work with are concerned about each other, resolve disagreements cooperatively, are honest and considerate, and function as a team. Please respond to the following items regarding your feelings and behavior toward Tom.

Please respond to the following items regarding how you would feel about or act toward [Tom or Mary] if (s)he were your colleague. Use the response format below.

Strongly

Disagree
Disagree

2

Neither Disagree nor Agree
Agree Strongly Agree

If [Tom or Mary] were my colleague, I would...

1. want [Tom or Mary] to quit.

2. be happy if [Tom or Mary] quit his/her job.

3. desire for [Tom or Mary] to find a job at another organization.

4. wish [Tom or Mary] would leave.

5. hope [Tom or Mary] would leave the organization.

Please respond to the following items using the response format below.

\begin{tabular}{ccccc}
$\begin{array}{c}\text { Strongly } \\
\text { Disagree }\end{array}$ & Disagree & $\begin{array}{c}\text { Neither Disagree } \\
\text { nor Agree }\end{array}$ & Agree & $\begin{array}{c}\text { Strongly } \\
\text { Agree }\end{array}$ \\
\hline 1 & 2 & 3 & 4 & 5 \\
\hline
\end{tabular}

1. [Tom or Mary] is a good worker.

2. The organization in which [Tom or Mary] works is one in which people are

friendly and cooperative with one another. 
Please respond to the following items regarding how you would behave toward [Tom or Mary] if (s)he were your colleague. Use the response format below.

\begin{tabular}{ccccc} 
Very Rarely & Rarely & Occasionally & Frequently & Very Frequently \\
\hline 1 & 2 & 3 & 4 & 5 \\
\hline
\end{tabular}

With [Tom] I would...

1. Disparage or negatively criticize him/her.

2. Encourage him/her to consider, seek, or find a new job.

3. Disparage or negatively criticize his/her job, company, or management.

4. Commend or praise other jobs, organizations, or career alternatives.

5. Encourage him to self-evaluate his/her current job situation.

6. Inform him/her of job or career alternatives.

7. Inform him/her of potentially negative consequences he might experience.

8. Encourage him to review his/her personal beliefs about work.

9. Directly tell him he/she should exit the organization.

10. Commend the advantages of choosing to leave the organization.

11. Commend the positive qualities that he/she may offer another organization.

12. Inform him/her that he/she should leave or risk being fired.

13. Prevent his/her ideas from being heard.

14. Cease or decrease helping or supporting him/her.

15. Attempt to exclude him/her from social activities.

16. Intentionally withhold important information from him/her.

17. Impede access to needed resources.

18. Avoid or decrease communication with him/her.

19. Provide him/her assistance for transitioning into another job.

20. Act hostile or unfriendly to him/her.

21. Ignore him/her as much as possible.

22. Avoid discussing work with him/her.

23. Keep his/her role in work project as isolated as possible.

24. Disregard him/her when he/she needs my help.

25. Neglect him/her has much as possible.

26. Exclude him/her from group activities. 
27. Keep to myself instead of engaging in conversations with him/her.

28. Stop talking to him/her.

29. Stay away from him/her as much as possible.

30. Keep conversations to a minimum with him/her.

31. Reduce the number of conversations I have with him/her.

32. Refrain from answering his/her questions.

33. Belittle him/her when we speak with one another.

34. Be unfriendly with him/her.

35. Communicate with him/her in a rude fashion.

36. Act angry in conversations with him/her.

37. Have him take on more responsibility than he/she can handle.

38. Treat him/her poorly.

39. Provide information to him/her about other job openings.

40. Tell him/her about other organizations that are hiring.

41. Help him get a job at another organization.

42. Recommend that he/she attend an interview at another organization.

43. Tell him/her not to worry because other jobs will be available.

44. Inform him/her of the benefit packages offered by other organizations.

45. Confront him/her about leaving the organization.

46. Warn him/her that he/she could be fired.

47. Convince him/her to resign from his/her current position.

48. Directly speak him/her about his/her behavior.

49. Tell him/her that his/her behavior is unwelcomed in this organization.

50. Tell him/her to quit his/her job.

51. Compliment his/her ability.

52. Offer advice about how to improve his/her performance in another organization.

53. Suggest that another organization would better utilize his/her skill set.

54. Say that the organization was failing to use his/her talents like they should.

55. Tell him that he deserved to work for another organization.

56. Detail the problems of the current organization to convince him to leave.

57. Communicate in a friendly manner him/her about his/her decision to leave. 
58. Maintain professionalism when speaking with him/her.

59. Be polite in my discussions with him/her.

60. Treat him/her in a professional way.

61. Be civil with him/her.

62. Avoid showing negative emotions to him/her.

63. Discuss his/her behavior with other coworkers.

64. Speak about his behavior with his/her immediate supervisor.

65. Spread rumors about him/her to everyone in the organization.

66. I speak about his/her wrongdoing with everyone.

67. Inform manager about him/her.

68. Report his/her behavior to Human Resources.

Instructions: Please indicate the extent to which each item applies to you using the scale below.

Strongly

Disagree

1
Disagree

2

Neither Disagree nor Agree
Agree

$$
3
$$

Strongly

Agree

\section{I am someone who...}

1. tends to find fault with others.

2. is helpful and unselfish with others.

3. starts quarrels with others.

4. has a forgiving nature.

5. is generally trusting.

6. can be cold and aloof.

7. is considerate and kind to almost anyone.

8. is sometimes rude to others.

9. likes to cooperate with others.

10. enjoys competition more than others.

11. feels that it is important to outperform others. 
12. enjoys testing my abilities against others.

13. feels that winning is extremely important.

14. wishes I could have more respect for myself.

15. feels that I have a number of good qualities.

16. feels I do not have much to be proud of.

17. at times thinks I am no good at all.

18. all in all, is inclined to feel that I am a failure.

19. takes a positive attitude toward myself.

20. feels that I'm a person of worth, at least on an equal plane with others.

21. on the whole, is satisfied with myself.

22. certainly feels useless at times.

23. is able to do things as well as most other people.

Please answer the following questions about yourself.

1. Your sex: Male Female

2. Your age:

3. Your Ethnic Background: Caucasian/White African American/Black Hispanic/Latino Native American Asian American/Asian Other:

\section{Your current occupation:}

5. Your job title: 


\section{Your job field (Circle ONE):}

- Managerial \& Professional (e.g., doctors, lawyers, educators, business executives, scientists, etc.)

- Technical, Sales, \& Administrative Support (e.g., health technicians, salespeople, secretaries, etc.)

- Service Occupations (e.g., child care, police, food service, cleaning, building, hairdressers, etc.)

- Precision Production, Craft, \& Repair (e.g., mechanics, construction, etc.)

- Operators, Fabricators, \& Laborers (e.g., machine operators, truck drivers, farming, assemblers, etc.)

7. On average, how many hours per week do you work at your current organization?

10. Instructions: Respond to the following items regarding your feelings about your current organization using the response format below.

\begin{tabular}{|c|c|c|c|}
\hline $\begin{array}{l}\text { Strongly } \\
\text { Disagree }\end{array}$ & Disagree & $\begin{array}{c}\text { Neither } \\
\text { Disagree nor }\end{array}$ & Agree \\
\hline
\end{tabular}

\begin{tabular}{ccccc}
\multicolumn{5}{c}{ Agree } \\
\hline 1 & 2 & 3 & 4 & 5 \\
\hline
\end{tabular}

Generally speaking, I am very satisfied with this job.

I frequently think of quitting this job.

I am generally satisfied with the kind of work I do in this job.

11. What is your native language?

12. In what country do you reside?

13. In what country are you a citizen?

14. Approximately how much do you earn per year at this job? (Choose one)

Under $\$ 20,000 \quad \$ 20,000-30,000 \$ \$ 30,001-40,000 \quad \$ 40,001-50,000 \quad \$ 50,001-60,000$

$\$ 60,001-70,000 \quad \$ 70,001-80,000 \$ \$ 80,001-90,000 \quad \$ 90,001-100,000$ Over $\$ 100,000$ 


\section{Appendix L}

\section{Coworker Similarity Scale Items}

1. [Target name] and I share similar values and interests.

2. [Target name] and I share similar values/attitudes.

3. [Target name] and I have a lot in common.

4. [Target name] is a lot like me. 


\section{Appendix M}

Work Performance (In-Role Behaviors Scale) Items

1. [Target name] adequately completes assigned duties.

2. [Target name] fulfills responsibilities specified in the job description.

3. [Target name] performs tasks that are expected of him/her.

4. [Target name] meets formal performance requirements of the job.

5. [Target name] engages in activities that directly affect his/her job performance evaluation.

6. [Target name] neglects aspects of the job he/she is obligated to perform.*

7. [Target name] fails to perform essential duties.*

Note: Items marked with an asterisk (*) are reverse coded. 


\section{Appendix N}

\section{Liking/Social Attraction Scale Items}

1. I think [Target name] could be a friend of mine.

2. I would like to have a friendly chat with [Target name].

3. It would be difficult to meet and talk with [Target name].*

4. [Target name] just wouldn't fit into my circle of friends.*

5. [Target name] and I could never establish a personal friendship with each other.*

Note: Items marked with an asterisk (*) are reverse coded. 


\section{Appendix 0}

Organizational Influence Scale Items

1. [Target name] usually knows how satisfied his/her supervisor is with what (s)he does.

2. [Target name] has enough confidence in his/her supervisor that (s)he would defend and justify the supervisor's decisions if (s)he were not present to do so.

3. [Target name] has an effective working relationship with his/her supervisor.

4. [Target name]'s supervisor understands [Target name]'s job problems and needs.

5. [Target name]'s supervisor recognizes [Target name]'s potential.

6. [Target name]'s supervisor would "bail out" [Target name] at the supervisor's expense, regardless of the supervisor's formal authority.

7. [Target name]'s supervisor would use his/her power to help solve problems in [Target name]'s work regardless of the supervisor's formal authority. 


\section{Appendix P}

Organizational Justice Scale Items

\section{To what extent are/were you fairly rewarded ...}

1. considering the responsibilities that you have/had?

2. in view of the amount of experience that you have/had?

3. for the amount of effort that you put forth?

4. for the work that you have/had done well?

5. for the stresses and strains of your job?

\section{To what extent does/did your employer ...}

6. develop procedures designed to collect accurate information necessary for making decisions?

7. provide opportunities to appeal or challenge decisions?

8. have all sides affected by decisions represented?

9. generate standards so that decisions can/could be made with consistency?

10. hear the concerns of all those affected by decisions?

11. provide useful feedback regarding decisions and their implementation?

12. allow for requests for clarification or additional information about decisions?

\section{In general, representatives of the organization in which you and [Target Name] work(ed)...}

13. consider(ed) your viewpoint

14. are/were able to suppress personal biases

15. provide(d) you with timely feedback about decisions and their implications

16. treat(ed) you with kindness and consideration

17. show(ed) concern for your rights as an employee

18. take/took steps to deal with you in a truthful manner 


\section{Appendix Q}

Organizational Culture (Teamwork) Scale Items

1. People I work(ed) with are/were direct and honest with each other.

2. People I work(ed) with accept(ed) criticism without becoming defensive.

3. People I work(ed) with resolve(d) disagreements cooperatively.

4. People I work(ed) with function(ed) as a team.

5. People I work(ed) with are/were cooperative and considerate.

6. People I work(ed) with constructively confront(ed) problems.

7. People I work(ed) with are/were good listeners.

8. People I work(ed) with are/were concerned about each other. 


\title{
Appendix R
}

\author{
Organizational Climate Scale Items
}

\section{Autonomy}

1. Management lets people make their own decisions much of the time.

2. Management trusts people to make work-related decisions without getting permission first.

3. People at the top of this organization tightly control the work of those below them.*

4. Management keep too tight a rein on the way things are done in the organization.*

5. In this organization it's important to check things first with the boss before making a decision.*

\section{Welfare}

6. This organization pays little attention to the interest of employees.*

7. This organization tries to look after its employees.

8. This organization cares about its employees.

9. This organization tries to be fair in its actions towards employees.

\section{Formalization}

10. It is considered extremely important in this organization to follow rules.

11. People in this organization can ignore formal procedures and rules if it helps get the job done.*

12. Everything has to be done by the book in this organization.

13. It is not necessary to follow procedures to the letter in this organization.*

14. Nobody gets too upset if people break the rules in this organization.*

\section{Effort}

15. People in this organization always want to perform to the best of their ability. 
16. People are enthusiastic about their work.

17. People in this organization get by with doing as little as possible.*

18. People are prepared to make a special effort to do a good job.

19. People in this organization don't put more effort into their work than they have to.*

\section{Pressure to Produce}

20. People in this organization are expected to do too much in a day.

21. In general, peoples' workloads in this organization are not particularly demanding.*

22. Management requires people to work extremely hard.

23. People here/there are under pressure to meet targets.

24. The pace of work here/there is pretty relaxed.*

Note: Items marked with an asterisk $(*)$ are reverse coded. 


\section{Appendix S}

\section{Supervisor Complicity Scale Items}

1. My supervisor and I talk(ed) about organizational members whom my supervisor and I think should leave.

2. My supervisor informs/informed me about organizational members whom my supervisor and I think should leave.

3. My supervisor is/was aware of certain organizational members whom I think/thought should leave.

4. My supervisor asks/asked me to encourage certain organizational members to leave.

5. My supervisor instructs/instructed me to encourage certain organizational members to leave. 


\section{Appendix T}

\section{Coworker Regard Items}

1. Overall, I am considered good by my coworkers.

2. Most of my coworkers consider me, on the average, to be more ineffective than other coworkers.*

3. In general, my coworkers respect me.

4. In general, my coworkers think that I am unworthy.*

Note: Items marked with an asterisk (*) are reverse coded. 


\section{Appendix U}

Study 3 Questionnaire

Think of your past work experiences, jobs, organizations you've worked for. From among all those experiences, think of a peer coworker (someone at your same job level, not a superior or subordinate) you want(ed) to leave the organization, quit, transfer, etc. In other words, think of a peer you work(ed) with whom you wish(ed) would leave your organization. Please write the first name of this peer coworker here . Please answer the following questions.

Read each statement about your coworker [Target name]. For the following items use the response format below and place the appropriate number in the blank beside the item.

\begin{tabular}{ccccc}
$\begin{array}{c}\text { Strongly } \\
\text { Disagree }\end{array}$ & Disagree & $\begin{array}{c}\text { Neither Disagree } \\
\text { nor Agree }\end{array}$ & Agree & $\begin{array}{c}\text { Strongly } \\
\text { Agree }\end{array}$ \\
\hline 1 & 2 & 3 & 4 & 5 \\
\hline
\end{tabular}

1. I think [Target name] could be a friend of mine.

2. I would like to have a friendly chat with [Target name].

3. It would be difficult to meet and talk with [Target name].

4. [Target name] just wouldn't fit into my circle of friends.

5. [Target name] and I could never establish a personal friendship with each other.

6. [Target name] adequately completes assigned duties.

7. [Target name] fulfills responsibilities specified in the job description.

8. [Target name] performs tasks that are expected of him/her.

9. [Target name] meets formal performance requirements of the job.

10. [Target name] engages in activities that directly affect his/her job performance evaluation.

11. [Target name] neglects aspects of the job he/she is obligated to perform.

12. [Target name] fails to perform essential duties.

13. [Target name] and I share similar values and interests. 
14. [Target name] and I share similar values/attitudes.

15. [Target name] and I have a lot in common.

16. [Target name] is a lot like me.

17. [Target name] usually knows how satisfied his/her supervisor is with what (s)he does.

18. [Target name] has enough confidence in his/her supervisor that (s)he would defend and justify the supervisor's decisions if (s)he were not present to do so.

19. [Target name] has an effective working relationship with his/her supervisor.

20. [Target name]'s supervisor understands [Target name]'s job problems and needs.

21. [Target name]'s supervisor recognizes [Target name]'s potential.

22. [Target name]'s supervisor would "bail out" [Target name] at the supervisor's expense, regardless of the supervisor's formal authority.

23. [Target name]'s supervisor would use his/her power to help solve problems in [Target name]'s work regardless of the supervisor's formal authority.

Please respond to the following items regarding how you behave(d) toward [Target name]. Use the response format below.

1. Commend or praise other jobs, organizations, or career alternatives

2. Inform [target name] of job or career alternatives

3. Encourage [target name] to review his/her personal beliefs about work

4. Commend the advantages of choosing to leave the organization

5. Commend the positive qualities that he/she may offer another organization

6. Provide [target name] assistance for transitioning into another job

7. Provide information to [target name] about other job openings

8. Tell [target name] about other organizations that are hiring

9. Help [target name] get a job at another organization. 
10. Recommend that he/she attend an interview at another organization

11. Tell [target name] not to worry because other jobs will be available

12. Inform [target name] of the benefit packages offered by other organizations

13. Suggest that another organization would better utilize [target name] skill set

14. Say that the organization was failing to use [target name] talents like they should

15. Tell [target name] that he/she deserved to work for another organization

16. Prevent [target name] ideas from being heard

17. Intentionally withhold important information from [target name]

18. Impede access to needed resources

19. Act hostile or unfriendly with [target name]

20. Neglect [target name] as much as possible

21. Belittle [target name] when we speak with one another

22. Be unfriendly with [target name]

23. Communicate with [target name] in a rude fashion

24. Act angry in conversations with [target name]

25. Have him take on more responsibility than he/she can handle

26. Treat [target name] poorly

27. Convince [target name] to resign from [target name] current position

28. Tell [target name] to quit [target name] job

29. Spread rumors about [target name] to everyone in the organization

30. Speak about [target name] wrong doing with everyone

31. Avoid discussing work with [target name]

32. Keep [target name] role in work project as isolated as possible 
33. Keep to myself instead of engaging in conversations with [target name]

34. Stop talking to [target name]

35. Stay away from [target name] as much as possible

36. Keep conversations to a minimum with [target name]

37. Reduce the number of conversations I have with [target name]

38. Maintain professionalism when speaking with [target name]

39. Be polite in my discussions with [target name]

40. Treat [target name] in a professional way

41. Be civil with [target name]

42. Avoid showing negative emotions to [target name]

\section{Please answer the following questions about [Target name].}

Does [Target name] still work at your organization? Please indicate yes or no. Yes No

If no, did [Target name] leave voluntarily (e.g., quit, found another job, retired, resigned) or involuntarily (e.g., she/he got fired, his/her job was eliminated, she/he got downsized)? Please indicate voluntarily or involuntarily.

Voluntarily Involuntarily

If voluntarily, why? Please list reasons.

Explain the effect your behavior and/or communication has/had on [Peer name]'s decision to leave the organization. 
Please answer the following questions about the organization in which you and [Target name] work(ed).

Do you still work at the organization in which you and [Target name] work(ed)? Please indicate yes or no.

Yes No

Your occupation at the organization in which you and [Target name] worked:

Your job field at the organization in which you and [Target name] worked (Circle ONE):

- Managerial \& Professional (e.g., doctors, lawyers, educators, business executives, scientists, etc.)

- $\quad$ Technical, Sales, \& Administrative Support (e.g., health technicians, salespeople, secretaries, etc.)

- $\quad$ Service Occupations (e.g., child care, police, food service, cleaning, building, hairdressers, etc.)

- $\quad$ Precision Production, Craft, \& Repair (e.g., mechanics, construction, etc.)

- $\quad$ Operators, Fabricators, \& Laborers (e.g., machine operators, truck drivers, farming, assemblers, etc.)

Approximately how much did you earn per year at job at the organization in which you and [Target name] worked? (Choose one)

Under $\$ 20,000 \quad \$ 20,000-30,000 \quad \$ 30,001-40,000 \quad \$ 40,001-50,000 \quad \$ 50,001-60,000$

$\$ 60,001-70,000 \$ 70,001-80,000 \$ \$ 80,001-90,000 \quad \$ 90,001-100,000$ Over- $\$ 100,000$

How long ago did you want [Target name] to leave the organization at which you worked? 


\section{Please indicate the extent to which each item applies to you using the scale below.}

Strongly

Disagree

1
Disagree

2

Neither Disagree nor Agree
Agree

3

Strongly

Agree

\section{I am someone who...}

1. tends to find fault with others.

2. is helpful and unselfish with others.

3. starts quarrels with others.

4. has a forgiving nature.

5. is generally trusting.

6. can be cold and aloof.

7. is considerate and kind to almost anyone.

8. is sometimes rude to others.

9. likes to cooperate with others.

10. enjoys competition more than others.

11. feels that it is important to outperform others.

12. enjoys testing my abilities against others.

13. feels that winning is extremely important.

14. wishes I could have more respect for myself.

15. feels that I have a number of good qualities.

16. feels I do not have much to be proud of.

17. at times thinks I am no good at all.

18. all in all, is inclined to feel that I am a failure.

19. takes a positive attitude toward myself. 
20. feels that I'm a person of worth, at least on an equal plane with others.

21. on the whole, is satisfied with myself.

22. certainly feels useless at times.

23. is able to do things as well as most other people.

\section{Please indicate the extent to which each item applies to you using the scale below.}

\begin{tabular}{ccccc}
$\begin{array}{c}\text { Strongly } \\
\text { Disagree }\end{array}$ & Disagree & $\begin{array}{c}\text { Neither Disagree } \\
\text { nor Agree }\end{array}$ & Agree & $\begin{array}{c}\text { Strongly } \\
\text { Agree }\end{array}$ \\
\hline 1 & 2 & 3 & 4 & 5 \\
\hline
\end{tabular}

1. Overall, I am considered good by my coworkers.

2. Most of my coworkers consider me, on the average, to be more ineffective than other coworkers.

3. In general, my coworkers respect me.

4. In general, my coworkers think that I am unworthy.

\section{Please respond to the following items about the organization in which you and [Target} Name] work(ed) using the response format below.

To a small extent

To a large extent

\begin{tabular}{lllll}
1 & 2 & 3 & 4 & 5 \\
\hline
\end{tabular}

To what extent are/were you fairly rewarded ...

1. considering the responsibilities that you have/had?

2. in view of the amount of experience that you have/had?

3. for the amount of effort that you put forth?

4. the work that you have/had done well?

5. for the stresses and strains of your job?

To what extent does/did your employer ...

6. develop procedures designed to collect accurate information necessary for making decisions? 
7. provide opportunities to appeal or challenge decisions?

8. have all sides affected by decisions represented?

9. generate standards so that decisions can/could be made with consistency?

10. hear the concerns of all those affected by decisions?

11. provide useful feedback regarding decisions and their implementation?

12. allow for requests for clarification or additional information about decisions?

In general, representatives of the organization in which you and [Target Name] work(ed) . .

13. consider(ed) your viewpoint

14. are/were able to suppress personal biases

15. provide(d) you with timely feedback about decisions and their implications

16. treat(ed) you with kindness and consideration

17. show(ed) concern for your rights as an employee

18. take/took steps to deal with you in a truthful manner

Please indicate the extent to which each item applies to the organization in which you and [Target Name] work(ed) using the response format below.

Strongly

Disagree

Disagree

2

Neither Disagree nor Agree
Agree

3

Strongly

Agree

1. People I work(ed) with are/were direct and honest with each other.

2. People I work(ed) with accept(ed) criticism without becoming defensive.

3. People I work(ed) with resolve(d) disagreements cooperatively.

4. People I work(ed) with function(ed) as a team.

5. People I work(ed) with are/were cooperative and considerate. 
6. People I work(ed) with constructively confront(ed) problems.

7. People I work(ed) with are/were good listeners.

8. People I work(ed) with are/were concerned about each other.

9. Management lets people make their own decisions much of the time.

10. Management trusts people to make work-related decisions without getting permission first.

11. People at the top of this organization tightly control the work of those below them.

12. Management keep too tight a rein on the way things are done in the organization.

13. In this organization it's important to check things first with the boss before making a decision.

14. This organization pays little attention to the interest of employees.

15. This organization tries to look after its employees.

16. This organization cares about its employees.

17. This organization tries to be fair in its actions towards employees.

18. It is considered extremely important in this organization to follow rules.

19. People in this organization can ignore formal procedures and rules if it helps get the job done.

20. Everything has to be done by the book in this organization.

21. It is not necessary to follow procedures to the letter in this organization.

22. Nobody gets too upset if people break the rules in this organization.

23. People in this organization always want to perform to the best of their ability.

24. People are enthusiastic about their work.

25. People in this organization get by with doing as little as possible.

26. People are prepared to make a special effort to do a good job. 
27. People in this organization don't put more effort into their work than they have to.

28. People in this organization are expected to do too much in a day.

29. In general, peoples' workloads in this organization are not particularly demanding.

30. Management requires people to work extremely hard.

31. People here/there are under pressure to meet targets.

32. The pace of work here/there is pretty relaxed.

Instructions: Respond to the following items regarding your feelings about your current organization using the response format below.

Strongly

Disagree
Disagree

\section{Disagree}
Neither
Disagree nor
Agree

Agree

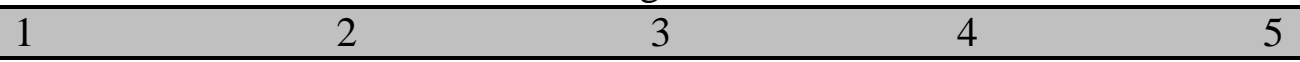

Strongly

Agree

1. Generally speaking, I am very satisfied with this job.

2. I frequently think of quitting this job.

3. I am generally satisfied with the kind of work I do in this job

\section{Please indicate the extent to which each item applies to the relationship between you and your supervisor at the organization in which you and [Target Name] work(ed). Use the response format below.}

\begin{tabular}{ccccc}
$\begin{array}{c}\text { Strongly } \\
\text { Disagree }\end{array}$ & Disagree & $\begin{array}{c}\text { Neither Disagree } \\
\text { nor Agree }\end{array}$ & Agree & $\begin{array}{c}\text { Strongly } \\
\text { Agree }\end{array}$ \\
\hline 1 & 2 & 3 & 4 & 5 \\
\hline
\end{tabular}

1. My supervisor and I talk(ed) about organizational members whom my supervisor and I think/thought should leave.

2. My supervisor informs/informed me about organizational members whom my supervisor and I think/thought should leave.

3. My supervisor is/was aware of certain organizational members whom I think/thought should leave. 
4. My supervisor asks/asked me to encourage certain organizational members to leave.

5. My supervisor instructs/instructed me to encourage certain organizational members to leave.

Please answer the following questions about yourself.

1. Your sex: Male Female

2. Your age:

3. Your Ethnic Background: Caucasian/White

African American/Black

Hispanic/Latino

Native American

Asian American/Asian

Other:

\section{Your current occupation:}

5. Your job title:

6. Your job field (Circle ONE):

- Managerial \& Professional (e.g., doctors, lawyers, educators, business executives, scientists, etc.)

- Technical, Sales, \& Administrative Support (e.g., health technicians, salespeople, secretaries, etc.)

- Service Occupations (e.g., child care, police, food service, cleaning, building, hairdressers, etc.)

- Precision Production, Craft, \& Repair (e.g., mechanics, construction, etc.)

- Operators, Fabricators, \& Laborers (e.g., machine operators, truck drivers, farming, assemblers, etc.)

7. On average, how many hours per week do you work at your current organization?

\section{How many years have you worked at this organization?}

9. At what type of organization do you work (e.g. hospital, school, etc.)?

10. What is your native language?

11. In what country do you reside?

12. In what country are you a citizen?

13. Approximately how much do you earn per year at this job? (Choose one)

Under $\$ 20,000 \quad \$ 20,000-30,000 \$ \$ 30,001-40,000 \quad \$ 40,001-50,000 \quad \$ 50,001-60,000$

$\$ 60,001-70,000 \quad \$ 70,001-80,000 \quad \$ 80,001-90,000 \quad \$ 90,001-100,000$ Over $\$ 100,000$ 


\section{Appendix V}

Hypotheses and Research Questions and the Studies in which they are Examined

\begin{tabular}{|c|c|c|c|}
\hline Hypotheses/Research Questions & S1 & S2 & S3 \\
\hline $\begin{array}{l}\text { RQ1: What types of messages and/or behaviors do organizational members use to } \\
\text { encourage a peer coworker to voluntarily leave the organization? }\end{array}$ & $\mathrm{x}$ & & \\
\hline $\begin{array}{l}\text { RQ2: What motives do organizational members have for influencing a peer coworker } \\
\text { to voluntarily leave the organization? }\end{array}$ & $\mathrm{x}$ & & \\
\hline $\begin{array}{l}\text { RQ3: What is the relationship between organizational members' motives for } \\
\text { influencing a peer coworker to voluntarily leave the organization and the use of peer- } \\
\text { influence exit tactics? }\end{array}$ & $\mathrm{x}$ & & \\
\hline $\begin{array}{l}\text { H1: The source's competitiveness will be related to the use of peer-influence exit } \\
\text { tactics. }\end{array}$ & & $\mathrm{x}$ & $\mathrm{X}$ \\
\hline $\begin{array}{l}\text { H2: The source's agreeableness will be related to the use of peer-influence exit } \\
\text { tactics. }\end{array}$ & & $\mathrm{X}$ & $\mathrm{x}$ \\
\hline $\begin{array}{l}\text { RQ4: What is the relationship between the source's self-esteem and the use of peer- } \\
\text { influence exit tactics? }\end{array}$ & & $\mathrm{x}$ & $\mathrm{x}$ \\
\hline $\begin{array}{l}\text { RQ5: What is the relationship between the source's personality traits (i.e., } \\
\text { competitiveness, agreeableness, and self-esteem) and the source's motives for } \\
\text { influencing a peer coworker to leave the organization? }\end{array}$ & & $\mathrm{x}$ & $\mathrm{x}$ \\
\hline $\begin{array}{l}\text { H3: The source's perceived similarity with the target of peer-influence exit tactics } \\
\text { will be related to the use of peer-influence exit tactics. }\end{array}$ & & $\mathrm{x}$ & $\mathrm{x}$ \\
\hline $\begin{array}{l}\text { RQ6: What is the relationship between the source's perception of the work } \\
\text { performance of the peer-influence exit target and the use of peer-influence exit } \\
\text { tactics? }\end{array}$ & & $\mathrm{x}$ & $\mathrm{x}$ \\
\hline $\begin{array}{l}\text { H4: The source's liking of the peer-influence exit target will be related to the use of } \\
\text { peer-influence exit tactics }\end{array}$ & & & $\mathrm{x}$ \\
\hline $\begin{array}{l}\text { H5: The source's perceptions of the target's organizational influence will be related } \\
\text { to the use of peer-influence exit tactics. }\end{array}$ & & & \\
\hline $\begin{array}{l}\text { RQ7: What is the relationship between the source's perceptions of the target's } \\
\text { similarity, work performance, liking, and organizational influence, and the source's } \\
\text { motives for influencing a peer coworker to voluntarily leave the organization? }\end{array}$ & & $\mathrm{x}$ & $\mathrm{x}$ \\
\hline $\begin{array}{l}\text { RQ8: What is the relationship between the source's perceptions of organizational } \\
\text { teamwork and the use of peer-influence exit tactics? }\end{array}$ & & $\mathrm{x}$ & $\mathrm{x}$ \\
\hline $\begin{array}{l}\text { RQ9: What is the relationship between the source's perceptions of organizational } \\
\text { climate and the use of peer-influence exit tactics? }\end{array}$ & & & $\mathrm{X}$ \\
\hline $\begin{array}{l}\text { H6: The source's perceptions of organizational justice will be related to the use of } \\
\text { peer-influence exit tactics. }\end{array}$ & & & $\mathrm{x}$ \\
\hline $\begin{array}{l}\text { RQ10: What is the relationship between the source's job satisfaction and the use of } \\
\text { peer-influence exit tactics? }\end{array}$ & & & $\mathrm{x}$ \\
\hline $\begin{array}{l}\text { RQ11: What is the relationship between the source's perceptions of coworker regard } \\
\text { and the use of peer-influence exit tactics? }\end{array}$ & & & $\mathrm{x}$ \\
\hline $\begin{array}{l}\text { H7: The source's perceptions of supervisor complicity will be related to the use of } \\
\text { peer-influence exit tactics. }\end{array}$ & & & $\mathrm{x}$ \\
\hline $\begin{array}{l}\text { RQ12: What is the relationship between the source's perceptions of his/her } \\
\text { organization's characteristics (i.e., organizational culture, climate, justice, job }\end{array}$ & & & $\mathrm{X}$ \\
\hline
\end{tabular}


satisfaction, coworker regard, and supervisor complicity) and the source's motives for influencing a peer coworker to voluntarily leave the organization?

RQ13: To what extent do sources consciously plan their use of peer-influence exit tactics?

RQ14: How effective are peer-influence exit tactics in encouraging peer coworkers to voluntarily leave the organization? 